\title{
Cuatro décadas de Sociología en la Universidad de Sonora
}

José Raúl Rodríguez Jiménez, Juan Pablo Durand Villalobos y Juan Manuel Gálvez Andrade (COORDINADORES)

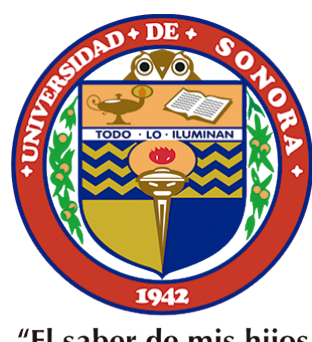

\section{Qartuppi}


Esta obra fue posible con la aportación del Programa de Fortalecimiento de la Calidad Educativa P/PFCE-2018-26MSU0015Z-14-49.

\section{Cuatro décadas de Sociología en la Universidad de Sonora}

1era. edición, marzo 2019

ISBN 978-607-518-312-1

ISBN 978-607-98270-8-3

DOI 10.29410/QTP.19.04

D.R. @ 2019. Universidad de Sonora

Blvd. Luis Encinas y Rosales s/n Col. Centro

Hermosillo, Sonora 83000 México

http://www.unison.mx

D.R. @ 2019. Qartuppi, S. de R.L. de C.V.

Villa Turca 17, Col. Villas del Mediterráneo

Hermosillo, Sonora 83220 México

http://www.qartuppi.com

Diseño y Edición: Qartuppi, S. de R.L. de C.V.

Diseño de portada: León Felipe Irigoyen Morales 


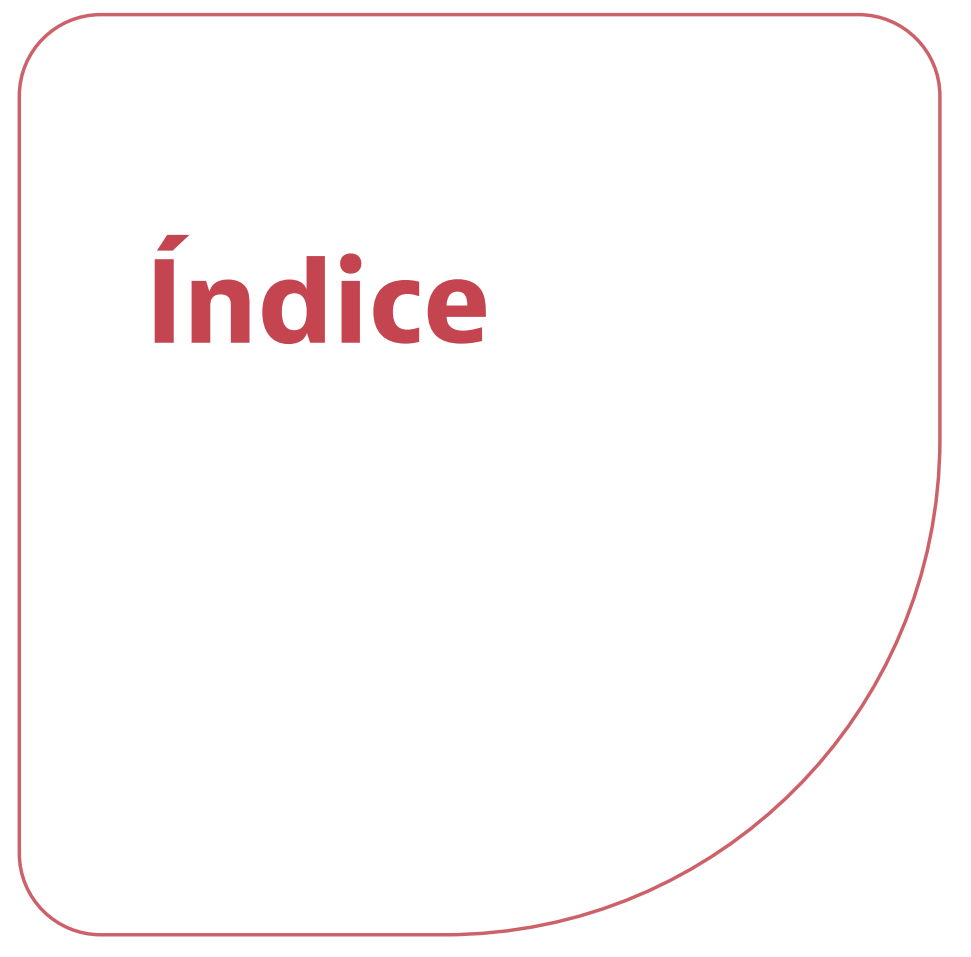

$5 \quad$ Introducción

Cuatro décadas de sociología en la Universidad de Sonora. Obsequios de aniversario José Raúl Rodríguez Jiménez, Juan Pablo Durand Villalobos

y Juan Manuel Gálvez Andrade

13 Capítulo I

Interés nacional y conexiones internacionales en la institucionalización

de la sociología en México

Edgar Miguel Góngora Jaramillo

32 Capítulo II

Las revistas antecesoras y las primeras revistas especializadas de la sociología y las ciencias sociales en México (1920-1955). ¿Un legado para una época presentista? Margarita Olvera Serrano 
55 Capítulo III

Hacia una "sociología de la sociología" en la Universidad de Guadalajara:

notas desde el itinerario institucional

Adrián Acosta Silva

70 Capítulo IV

Cuarenta años de la sociología en la Universidad de Sonora. Trazos generales

José Raúl Rodríguez Jiménez, Juan Pablo Durand Villalobos

y Juan Manuel Gálvez Andrade

92 Capítulo V

Hacia una sociología de las TIC en la educación.

Trayectoria de una elaboración conceptual

Miguel Ángel Casillas Alvarado y Alberto Ramírez Martinell

108 Capítulo VI

Teóricamente difícil de explicar. La sociología de la educación superior en México

Wietse de Vries

129 Capítulo VII

Una aproximación sociológica y ética a la identidad de los ciudadanos

de Cuenca-Ecuador en su relación con los procesos de creación y aplicación del derecho Juan Morales Ordóñez

147 Capítulo VIII

Oportunidades educativas, ocupacionales y movilidad social en México.

El peso de la familia y el lugar de nacimiento

María Rocío Grediaga Kuri

182 Capítulo IX

La investigación científica en el desarrollo humano y social.

A propósito de la visión de Óscar Varsavsky

Hebe Vessuri 


\section{Introducción}

Cuatro décadas de sociología en la Universidad de Sonora. Obsequios de aniversario

Jose Raúl Rodríguez Jiménez, Juan Pablo Duran Villalobos y Juan Manuel Gálvez Andrade 
En el calendario institucional de la Universidad de Sonora (UNISON), el año 2018 tiene especial significación: la licenciatura en Sociología arribó a su cuadragésimo aniversario. Estos eventos suelen ser festejados con actos protocolarios que cuentan las proezas de algunos personajes, develación de placas conmemorativas, reunión de exalumnos y hasta las conocidas mañanitas mexicanas. Nosotros también queremos festejar este aniversario, pero lo queremos hacer desde el propio campo de la disciplina, preguntando por los actores, prácticas, productos e imágenes de quienes han hecho posible la sociología en la UNISON. Más aún, a la distancia de 40 años, nos cuestionamos sobre la pertinencia de la carrera misma en la universidad. Este tipo de interrogantes no son ajenas a nuestra disciplina. Desde su propia creación y hasta la actualidad, la sociología realiza periódicamente escrupulosos exámenes sobre sus cuerpos teóricos, recursos metodológicos y capacidades analíticas para acercarse al conocimiento de los procesos sociales. Más allá de los debates y conflictos entre los principales representantes de las escuelas de sociología, estos ejercicios muestran una ciencia que trata de actualizar permanentemente sus saberes frente a los siempre nuevos y complejos escenarios sociales.

En México, los análisis sobre el estado de conocimiento en el campo de la sociología también se producen regularmente desde la década de 1980. Se tocan, entre otros puntos, la institucionalización de la disciplina, sus precursores, las agendas de investigación, los obstáculos enfrentados y algunos logros disciplinarios (Andrade, 2015; Moya y Olvera, 2013). Los trabajos tratan sobre todo los casos de establecimientos ubicados en la Ciudad de México -la Universidad Nacional Autónoma de México (UNAM), El Colegio de México y la Universidad Autónoma Metropolitana (UAM) - dejando fuera de foco otras regiones. En la actualidad, la licenciatura en Sociología se imparte en 33 establecimientos, ubicados en 25 estados de la república, incluida la Ciudad de México (Asociación Nacional de Universidades e Instituciones de Educación Superior [ANUIES], 2017). 
Quizá la escasa atención que despierta la sociología realizada en las entidades de la república se deba a lo reducido de la matrícula estudiantil en el nivel licenciatura. De los 9,819 de estudiantes que tiene esta carrera en todo el país, 42\% se ubica en 29 licenciaturas repartidas en 24 entidades, se trata de escuelas con una matrícula modesta, 100 estudiantes en promedio por cada una de ellas. El resto de la población estudiantil (58\%) se reparte en proporciones prácticamente iguales entre las sedes de la UNAM y la UAM (2,864 y 2,827 estudiantes, respectivamente) (ANUIES, 2017). En el terreno de la investigación, la sociología también tiende a la concentración, aunque no tan contundentemente como en el caso de la matrícula. De los 1,334 miembros en el Sistema Nacional de Investigadores (SNI) registrados en el campo de la sociología, Área V1, 63\% de ellos se ubican en seis entidades: Ciudad de México, 430; Jalisco, 125; Estado de México, 94; Nuevo León, 68; Puebla y Baja California, 65 cada uno de ellos. El 37\% restante de los investigadores se distribuye en 26 entidades (Consejo Nacional de Ciencia y Tecnología [CONACYT], 2017).

Pese a la escasa atención que ha recibido la disciplina en las entidades que integran el país, la sociología existe en esas regiones, sobre todo en su versión de enseñanza en el nivel licenciatura, aunque por ahora no se tengan aproximaciones suficientemente claras de sus inicios y desarrollo. Poco se sabe de las instituciones que la albergan, los académicos que la practican, los conocimientos que se privilegian en la enseñanza o las relaciones que entabla la disciplina con los entornos locales, por señalar algunas de las ausencias.

Nuestro aniversario/festejo quiere contribuir al reconocimiento de la sociología en los estados, concretamente en Sonora. Pero pasar del deseo, combinado con la emoción de arribar a la cuarta década de existencia, al estudio de la sociología en la UNISON, significó enfrentar desafíos, sobre todo por la insuficiencia de información en el tema². Se conocen algunos datos aislados de la creación y desarrollo de la sociología en la UNISON, pero otros tuvieron que ser reconstruidos y, en algunos temas más, el acercamiento es claramente aproximado. Sobre los antecedentes de la sociología en la entidad, se tiene registro de algunos eventos ligados con la disciplina. En 1960, la UNISON creó el Instituto de Investigaciones Sociales y Económicas que durante un par de años

$1 \quad$ El Área V del SNI agrupa una docena de campos de conocimiento de las ciencias sociales, entre ellos, sociología. Esta es el área que agrupa preferentemente al grueso de la comunidad de la sociología, sin embargo, puede ser que otros practicantes de esta disciplina se adscriban en otras áreas debido a la orientación de sus investigaciones, por ejemplo, en el Área IV, correspondiente a Humanidades y Ciencias de la Conducta.

$2 \quad$ El proyecto sobre la situación de las ciencias sociales en México (Puga y Conteras, 2015) reconoce una situación similar. La información sobre esta área de conocimiento es tan limitada que se tuvo que iniciar con un inventario de instituciones y entidades académicas de ciencias sociales en México. 
realizó estudios relacionados con el desarrollo de la entidad (en 1962, el Instituto fue incorporado a la rectoría universitaria) (Bobadilla, 2002). En abril de 1962, el gobierno estatal, encabezado por Luis Encinas Johnson³, organizó el Primer Congreso Industrial de Sonora que trató temas relacionados con la industrialización del estado y sus efectos sociales. En noviembre de ese mismo año, el gobierno de Sonora y la UNISON auspiciaron el Décimo Tercer Congreso Nacional de Sociología, teniendo como tema general la Sociología del Desarrollo Nacional y Regional (Uribe, 1961). El congreso se realizó en la ciudad de Hermosillo y contó con algunos de los más importantes personajes de la sociología de este tiempo, entre ellos, Morris Ginsberg y Talcott Parsons, además de Lucio Mendieta y Núñez, que fue el impulsor de los congresos nacionales de sociología4 (Villegas, 1963).

No es posible trazar una línea directa entre estos eventos y la creación de la licenciatura en Sociología en la UNISON en 1978. Se sabe que la UNAM, el principal asiento institucional de la sociología en el país durante este período, continuó colaborando con la UNISON en varios proyectos -especialmente en la creación de la Escuela de Altos Estudios en 1964- aunque no en temas sociales. Se conoce también que algunas escuelas universitarias -Preparatoria (incluida en la UNISON en este tiempo), Derecho y, más adelante, Economía y Agricultura y Ganadería- consideraban la sociología como materia en sus planes de estudio.

Pero, el interés institucional por la sociología, al menos por los temas de las ciencias sociales, se vio empeñado en la segunda mitad de la década de 1960. En 1967, la UNISON participó directamente en un amplio y profundo movimiento social ligado a la elección del candidato a la gubernatura del estado. Tal participación concluyó con la represión policiaca en mayo de este año. Sin embargo, las protestas estudiantiles y, más adelante, las confrontaciones con los sindicatos universitarios se extendieron por más de un decenio. En este escenario, en la UNISON se generaron varios proyectos académicos -creación de nuevas licenciaturas, actualización de planes de estudio, fomento a la investigación, reordenación integral universitaria- que no fueron concretados,

3 Antes de ocupar la gubernatura (1961-1967), Luis Encinas Johnson fue rector de la UNISON (19561961) e hizo esfuerzos por fortalecer la docencia en la institución, sobre todo con la incorporación de profesores externos provenientes de la Ciudad de México, así como el impulso a la investigación en las escuelas de Agricultura y Ganadería y; Ciencias Químicas. En su período se creó el Instituto de Investigaciones Sociales Económicas y Sociales (1960). En 1954 publica el libro Progreso y Problemas de México, que recibió comentarios favorables de Enrique Flores Magón, Vito Alessio Robles y Lucio Mendieta y Núñez (Aldaco, 2002).

4 Aprovechando la presencia de Lucio Mendieta y Núñez en la ciudad de Hermosillo, la Escuela de Derecho y Ciencias Sociales de la UNISON lo invitó a dictar un par de conferencias durante los festejos de aniversario de esa escuela. 
sobre todo porque la agenda institucional fue dominada por asuntos de índole política; paros estudiantiles, grupos de choque, huelgas laborales y manejo de relaciones con el gobierno del estado fueron algunos de los asuntos que captaron la atención del gobierno universitario.

Justamente, en este escenario institucional es donde ocurrió la creación de la licenciatura en Sociología. Una prolongada inestabilidad institucional en la UNISON, junto a una crisis del gobierno estatal que llevó a la destitución del gobernador en 1975, hacen aún más interesante la creación de esta licenciatura. Pese a que la documentación es escasa, pudieron reconstruirse las líneas generales de la fundación de la carrera, así como la trayectoria que ha tenido en sus cuatro décadas de existencia. En la actualidad, Sociología en una carrera de pequeñas dimensiones, con alrededor de una centena de estudiantes y una veintena de profesores. Sus indicadores muestran un desempeño modesto, sobre todo en la enseñanza de la disciplina, así como en la investigación.

El resultado del trabajo, una primera aproximación a la fundación y desarrollo de la sociología en la institución nos permite festejar el 40 aniversario de la licenciatura. Pero no quisimos hacerlo solos -no encontramos ningún sentido organizar una reunión en la que se encuentran antiguos conocidos para rememorar añejas anécdotas-, por lo que decidimos hacer un festejo más amplio y fresco, invitando a colegas de distintas comunidades sociológicas. Los invitados aceptaron acompañarnos y amablemente trajeron obsequios especiales para la ocasión. Cada uno de ellos nos regaló un trabajo inédito sobre la disciplina; algunos recuperando y reinterpretando el pasado de la sociología; otros observando la emergencia de nuevos horizontes; y otros más, repensando a la luz de la actualidad los grandes temas originales de nuestra ciencia (poder, política, movilidad social). Más allá de las temáticas y de la manera de encarar los asuntos, en todos los escritos está presente la intención de analizar críticamente las contribuciones de nuestra disciplina.

\section{El orden de los capítulos}

Para el lector formado en la disciplina, los temas tratados en este libro le serán familiares, aunque novedosos en el tratamiento y resultados, por lo que no tendrán mayor problema para establecer las conexiones entre ellos. Pero para lectores en proceso de formación sociológica o para los interesados en la disciplina, que para nosotros son igualmente importantes, pensamos en una cierta orientación didáctica que inicia con los capítulos que muestran la reinterpretación de los orígenes y trayectoria de la sociología en México; sigue con los apartados sobre nuevos horizontes disciplinarios; y concluye con un par de capítulos sobre movilidad social, y ciencia y política, respectivamente. A continuación, hacemos un breve recuento de lo que encontrará el lector en cada uno de los apartados. 
El libro abre con el capítulo Interés nacional y conexiones internacionales en la institucionalización de la sociología en México, que trata la institucionalización y legitimación de la sociología en México. Su autor, Edgar Miguel Góngora Jaramillo, sostiene que desde su nacimiento la sociología académica mexicana cuenta con fuertes raíces nacionales, pero a la vez con ligas e intercambios internacionales, por lo que su desarrollo se hace con arreglo a los centros y periferias disciplinarias.

En el siguiente capítulo, Las revistas antecesoras y las primeras revistas especializadas de la sociología y las ciencias sociales en México (1920-1955). ¿Un legado para una época presentista?, Margarita Olvera Serrano toma un paquete de publicaciones mexicanas de la primera mitad del siglo XX y encuentra que, además de dar a conocer resultados de investigación, temas y autores de aquel momento, estas revistas perfilan los contornos temáticos de las futuras ciencias sociales y son piezas imprescindibles para la institucionalización de la sociología en México.

Los dos apartados siguientes tienen temas comunes, el origen y trayectoria de la sociología en universidades públicas estatales. Adrián Acosta Silva, en su contribución Hacia una "sociología de la sociología" en la Universidad de Guadalajara: notas desde el itinerario social, toma el caso de la sociología en la Universidad de Guadalajara y sostiene que la creación y evolución de la sociología en esa universidad es parte de un complejo de configuraciones (estructuras, significaciones y actores) que perfilan los rasgos básicos del itinerario institucional de la disciplina. El capítulo siguiente, Cuarenta años de la sociología en la Universidad de Sonora. Trazos generales, firmado por los anfitriones del festejo -José Raúl Rodríguez, Juan Pablo Durand y Juan Manuel Gálvezreconstruye la fundación y trayectoria de la licenciatura en Sociología en la UNISON, concede especial atención a las relaciones entre institución, actores y disciplina para explicar la situación de esta licenciatura.

El libro avanza con tres capítulos que ilustran nuevos horizontes de la sociología. Miguel Ángel Casillas Alvarado y Alberto Ramírez Martinelli proponen en su escrito, Hacia una sociología de las TIC en la educación. Trayectoria de una elaboración conceptual, una perspectiva para comprender la incorporación de las TIC en la educación. La orientación recupera la teoría de Bourdieu y se nutre de las experiencias de investigación desarrolladas desde hace años por ellos mismos en la Universidad Veracruzana. Otro horizonte de la sociología se muestra en el apartado elaborado por Wietse de Vries, Teóricamente difícil de explicar. La sociología de la educación superior en México. De Vries analiza la emergencia de un campo de conocimiento relativamente nuevo, la educación superior en México. Observa los trabajos desarrollados y los impulsores del campo, su rápido desarrollo, las relaciones con los temas internacionales y los olvidos temáticos 
del campo. Además, formula fuertes desafíos analíticos para esta área. Una perspectiva más de la sociología se encuentra en Una aproximación sociológica y ética a la identidad de los ciudadanos de Cuenca-Ecuador en su relación con los procesos de creación y aplicación del derecho, firmado por Juan Morales Ordóñez. El autor enlaza sociológicamente dos problemas de trascendencia teórica y práctica en nuestro subcontinente: de un lado, la identidad de los latinoamericanos y, de otro, la perspectiva jurídica. Sostiene que, para América Latina y concretamente para Ecuador, el sistema jurídico debe incorporar la diversidad cultural como punto central.

El libro cierra con un par de capítulos que retornan a temas originales de la sociología, lo hacen desde problemas completamente actuales para mostrar la fortaleza y vitalidad de la sociología. En Oportunidades educativas, ocupacionales y movilidad social en México. El peso de la familia y el lugar de nacimiento, María Rocío Grediaga Kuri encara dos problemas: desigualdad y movilidad social. Con sólidos referentes teóricos y el apoyo de información empírica escrupulosamente analizada, la autora muestra que para el caso mexicano existen algunos avances en movilidad social, pero a su lado persiste la reproducción de las desigualdades. En el otro capítulo, La investigación científica en el desarrollo humano y social. A propósito de la visión de Óscar Varsavsky, Hebe Vessuri recupera la problemática formulada por Varsavsky en torno a la ciencia y la política en sociedades altamente desiguales. Lejos del reconocimiento fácil al pensador tratado, Vessuri discute la actualidad de sus formulaciones y va más allá para cuestionar el sentido de la ciencia, la sociología incluida en las sociedades. Incluso, en la parte final del capítulo critica la concepción política de cuatro gobiernos latinoamericanos -Argentina, Venezuela, Brasil y México- para superar la desigualdad.

Resta en esta presentación agradecer a nuestros invitados por sus obsequios. Estamos verdaderamente complacidos con sus trabajos, porque muestran las posibilidades de conocimiento de nuestra disciplina, y creemos que los lectores también lo estarán. Además, la participación de los colegas en este trabajo muestra que tenemos un alto aprecio por la comunidad, en el sentido sociológico del término. 


\section{Referencias}

Aldaco, G. (2002). Nuestros rectores. México: Universidad de Sonora.

Andrade, A. (Coord.). (2015). La sociología en México: temas, campos científicos y tradición disciplinaria. México: UNAM. Recuperado de http://www.librosoa.unam.mx/bitstream/ handle/123456789/382/La_soc\%20_en_Mex\%20Rev_i\%20e.pdf?sequence=1\&isAllowed=y

Asociación Nacional de Universidades e Instituciones de Educación Superior (ANUIES). (2017). Anuarios Estadísticos de la Educación Superior, Licenciatura. Recuperado de http://www. anuies.mx/informacion-y-servicios/informacion-estadistica-de-educacion-superior/ anuario-estadistico-de-educacion-superior

Bobadilla, B. (2002). Una aproximación sociológica a los investigadores de la Universidad de Sonora. Tesis de licenciatura. Universidad de Sonora, México.

Consejo Nacional de Ciencia y Tecnología (CONACYT). (2017). Sistema Nacional de Investigadores. Padrón de Beneficiarios. Recuperado de https://www.conacyt.gob.mx/index.php/elconacyt/sistema-nacional-de-investigadores

Moya L., \& Olvera, M. (2013). La historiografía de la sociología en México; balances y una propuesta de interpretación desde la historia conceptual. Sociológica, 28(80), 7-40. Recuperado de http://www.scielo.org.mx/pdf/soc/v28n80/v28n80a1.pdf

Puga, C., \& Contreras, O. (Coord.). (2015). Informe sobre las ciencias sociales en México. México: COMECSO-Foro Consultivo y Científico A.C.

Uribe, O. (1961). Preparativos para el XIII Congreso Nacional de Sociología. Revista Mexicana de Sociología, 23(3), 1015-1017.

Villegas, O. (1963). Decimotercer Congreso Nacional de Sociología. Revista Mexicana de Sociología, 25(2), 819-868. 


\section{Capítulo I}

Interés nacional y conexiones internacionales en la institucionalización de la sociología en México

Edgar Miguel Góngora Jaramillo *

* Sociólogo por la Universidad Autónoma Metropolitana. UNAM, Becario del Programa de Becas Posdoctorales de la UNAM, Instituto de Investigaciones sobre la Universidad y la Educación, asesorado por el Dr. Armando Alcántara Santuario. Este trabajo es la reelaboración de un capítulo de la tesis doctoral del autor, titulada "Condiciones de formación y capitalización de redes académicas en Sociología en México", defendida en 2014 en el Centro de Investigación y de Estudios Avanzados del Instituto Politécnico Nacional, bajo la dirección de la Dra. Sylvie Didou Aupetit. Contacto: mgongorajaramillo@yahoo.com.mx 


\section{Introducción}

En nuestra época participamos de intensos debates respecto a la organización de las formas de producción del conocimiento científico. Palabras como disciplina, interdisciplina o transdisciplina orientan numerosas discusiones en torno a campos de conocimiento, áreas, temas y enfoques. Un punto de vista que adopto en este texto es que la discusión sobre la organización del conocimiento debe incluir elementos sobre la configuración de las disciplinas científicas. Ello está sustentado en la noción de que el conocimiento disciplinario fortalece las capacidades de producción, reproducción, transferencia y aplicación de saberes y que eso facilita la adopción de perspectivas de trabajo científico basadas en la comunicación, la colaboración y la concurrencia entre diferentes disciplinas.

En el campo de las ciencias sociales, la sociología tiene la función -a nivel mundial- de ser la forma organizada de pensamiento-investigación-intervención para el abordaje de las relaciones sociales y de las interacciones entre estructuras sociales y la acción de sujetos-actores-agentes. La sociología es una ciencia disciplinaria que tiene su propia historia. Estar al tanto de ella es importante para contar con mejores condiciones comprensivas respecto a su peso científico y social contemporáneo. Landesman (2006) asume con razón que el abordaje de la institucionalización de las disciplinas científicas requiere poner atención a los "entrecruzamientos de contextos sociopolíticos disciplinarios e historias de establecimientos, de líderes académicos, de grupos, de generaciones y de trayectorias de individuos" (p. 20). Esos aspectos dan cuenta de las múltiples relaciones, negociaciones y conflictos que delinean la historia de una disciplina.

Para el caso de la sociología, conviene enlazar los aspectos aludidos por Landesman con tres cuestiones clave. La primera es que la sociología es una disciplina con fuertes tradiciones nacionales en la configuración de su estatuto científico (Wagner, 2006). La segunda es que, casi desde su nacimiento, tendió a consolidarse a través de intensos intercambios internacionales, fundados en 
la circulación de ideas, metodologías y personas, que facilitaron puntos de conexión y de debate entre las tradiciones nacionales disciplinarias, que dieron lugar a la legitimación de corrientes sociológicas y a la conformación de centros disciplinarios enclavados en algunos países. La tercera es resultado de la interacción de los dos primeros aspectos: la sociología ha construido su historia con arreglo a la existencia de centros y periferias disciplinarias (Beigel, 2010; 2013) pues, como en toda disciplina, cuando se le observa desde un mirador geopolítico, existe una división internacional del trabajo que tiene efectos en las formas en que los actores disciplinarios realizan sus actividades, consolidan sus instituciones y dan forma a sus soportes académicos y comunicativos.

Al considerar las tres cuestiones clave, este capítulo ofrece una revisión socio histórica de la institucionalización de la sociología académica en México, con la atención puesta en las lógicas internas que propiciaron la instauración y consolidación de la disciplina en el país, así como las conexiones internacionales realizadas por los actores centrales para orientar y legitimar la formación de sociólogos, la investigación e intervención sociológica y la comunicación de resultados.

El desarrollo de la argumentación implica trabajar en dos líneas concurrentes, que son los contenidos de este capítulo. La primera es una revisión panorámica de las características nacionales, desde su origen, de la sociología como disciplina científica, tanto en lo que respecta a los centros disciplinarios como en lo que atañe a las periferias disciplinarias. En la segunda, avanzaremos en la identificación de los rasgos distintivos de la institucionalización de la sociología académica en México, atendiendo el carácter nacional de esta ciencia y sus conexiones internacionales correspondientes. Finalmente, en las conclusiones presento algunas reflexiones sobre los temas tratados en el desarrollo de la argumentación.

\section{Centros y periferias en la institucionalización de la sociología}

La sociología tiene un origen preciso. En Francia, durante las primeras décadas del siglo XIX, Augusto Comte escribió un conjunto de trabajos que fueron publicados bajo la denominación de Curso de filosofía positiva. De esa obra, surgió el término "sociología" para denotar la creación de un nuevo sistema de pensamiento social independiente de la historia, la filosofía, el derecho y la política. La sociología como disciplina buscó, en sus orígenes, constituirse como la ciencia que permitiera establecer el orden y el progreso en las sociedades modernas, pero sobro todo, buscó -a diferencia de la antropología social-comprender y explicar a la sociedad de la que formaba parte, en un período histórico señaladamente propenso a la construcción de las naciones y las nacionalidades. De allí que la sociología fuera rápidamente asumida con apellidos: sociología francesa, alemana, inglesa, italiana, estadounidense. 
Desde el siglo XIX, la expansión del pensamiento sociológico fue relativamente rápida: entre la última década de ese siglo y la primera mitad del siglo XX, fueron fundados centros de investigación y docencia sociológicas en países como los indicados; surgieron revistas especializadas y fueron organizados congresos que constituyeron las primeras conexiones internacionales entre pares.

Las tradiciones nacionales en sociología, surgidas en aquellos países y que conformaron los centros disciplinarios, tuvieron una expresión clave en la temprana tendencia a articular internacionalmente actividades académicas y políticas en función de las luchas por la legitimidad en el campo académico y por la intención expresa de internacionalizar corrientes de pensamiento que tuvieran influencia en el desarrollo de la disciplina, tanto en sus aspectos propiamente académicos como en la transferencia de conocimientos a actores no académicos (Wagner, 2006, p. 41). La expansión de la sociología como disciplina científica y académica fue entonces resultado del interés, por parte de sus practicantes, de articular comunidades de expertos disciplinarios en todo el mundo.

El antecedente más antiguo para organizar a la sociología en redes internacionales es el Instituto Internacional de Sociología, con sede en Francia, fundado bajo los auspicios de René Worms en 1893. El primer congreso mundial de sociología fue realizado en el marco de ese Instituto. Otro antecedente importante lo constituyó la agrupación internacional de sociólogos en torno a la Asociación Internacional de Sociología (AIS), fundada en 1949 y a la que se integró el Instituto Internacional de Sociología en 1971. Como resultado de esas iniciales formas de concurrencia disciplinaria, se publican desde 1898 los Annales de I'Institut International de Sociologie, sustentados en la compilación de las actas y trabajos presentados en sus congresos mundiales, además de la Revue Internationale de Sociologie, cuyo primer número data también de 1893². Esos espacios de comunicación disciplinaria fueron organizados y coordinados desde los centros disciplinarios, pero su influencia fue decisiva en la circulación de ideas y conocimientos en las regiones periféricas.

Los enfoques nacionales de la sociología y su tendencia a la internacionalización son aspectos fundamentales para entender el surgimiento, la institucionalización y la consolidación de la sociología. Todo ello contribuyó a fincar, en los países centrales, dinámicas de trabajo sociológico colaborativo ancladas en la diversidad, el conflicto y la negociación. En los espacios académicos asentados en países como Francia, Alemania, Inglaterra y Estados Unidos, las redes de trabajo formales e informales tendieron a reproducir tanto las lógicas disciplinarias nacionales como a fomentar una supranacionalidad de enfoques teóricos y metodológicos (Wagner, 2006). Tendieron, asimismo, a organizar y difundir posturas teóricas acordes a la función social e intelectual 1 Véase http://www.iisoc.org/ 
atribuida por los actores a su disciplina. Esos aspectos tuvieron repercusiones no sólo en los polos disciplinarios ubicados en países centrales: constituyeron criterios ordenadores para la institucionalización de la sociología académica y la formación de redes en regiones periféricas, como América Latina.

En los países periféricos, la sociología fue un "discurso importado" (Castañeda, 1992, p. 15), pese a ser adaptado a las particularidades nacionales de la región. La legitimidad de enfoques, teorías y perspectivas metodológicas fue, en consecuencia, históricamente supeditada a las formulaciones elaboradas en los centros disciplinarios, como lo indica Altbach (2004) en términos generales y las investigaciones coordinadas por Beigel $(2010 ; 2013)$ en relación a la sociología en países de América Latina. La consolidación de espacios sociológicos en la región latinoamericana implicó la circulación y adaptación de saberes legitimados en otros contextos regionales, que tuvieron la función de servir como fuentes de legitimación local (nacional).

No obstante, desde la década de 1930, en países sudamericanos como Chile, Argentina y Brasil (además de México en América del Norte), la apertura de centros especializados para la docencia y la investigación sociológica, la fundación de editoriales y revistas especializadas, el diseño de programas de investigación específicos, contribuyeron a la configuración de "centros periféricos" de la sociología (Beigel, 2010). Esos permitieron articular los conocimientos e ideas construidos en los países centrales con las especificidades nacionales y regionales identificadas por los sociólogos locales. El resultado de ello fue el establecimiento de circuitos latinoamericanos en la sociología académica: si bien mantuvieron lazos de dependencia académica con los centros disciplinarios, fraguaron relaciones de colaboración y esquemas de circulación de conocimientos entre individuos y grupos de la región. Estudios como el de Morales (2014) muestran las relaciones establecidas entre sociólogos de México y Argentina en las décadas de 1940 y 1950, cuya correa de transmisión fue la presencia, en esos países, de sociólogos españoles exiliados como consecuencia de la guerra civil en aquel país, así como los entrecruzamientos entre sociólogos latinoamericanos y estadounidenses a través del papel de "puente intelectual" de Gino Germani (Morales, 2013) y otros sociólogos provenientes de países centrales que se asentaron y trabajaron en la región latinoamericana.

Las conexiones tempranas entre sociólogos asentados en diferentes países de América Latina, los viajes académicos de los fundadores a los centros disciplinarios, así como el establecimiento de circuitos sociológicos regionales desde la década de 1940, sentaron las bases para que la sociología, en varios países de la región, se institucionalizara y tuviera continuidad con los herederos. La sociología en la región latinoamericana, desde sus inicios, tuvo en la configuración de 
redes internacionales uno de sus principales mecanismos para la institucionalización: contribuyó a fundar espacios académicos, a darles rumbo y a formar cuadros de relevo que, a través del tiempo, fueron consolidando líneas de investigación, creando asociaciones y estableciendo soportes de comunicación de resultados de investigación.

En América Latina, desde mediados del siglo XX, diversas fundaciones internacionales constituyeron soportes institucionales y financieros que posibilitaron la apertura de centros de investigación en sociología (Beigel, 2010), de manera similar a lo ocurrido durante décadas en la sociología estadounidense (Picó, 2001). Además de las fundaciones internacionales en países de América del Sur, fue crucial la participación de la iglesia católica, destacadamente de la Compañía de Jesús, en la institucionalización de la sociología (Navarro, 2013). Las fundaciones y la iglesia católica funcionaron en reiteradas ocasiones como estructuras que facilitaron la conexión internacional de los sociólogos latinoamericanos.

En síntesis, los mecanismos de coordinación de actividades académicas entre los sociólogos latinoamericanos, vistos desde una perspectiva histórica, evidencian el interés de los líderes académicos de la región por establecer conexiones tanto con los centros disciplinarios como con pares regionales. Las instituciones y espacios académicos disciplinarios, fundados desde la década de 1930 en varios países de América Latina, operaron a través de la circulación internacional de conocimientos y de su adaptación a las realidades locales. La movilidad de sociólogos latinoamericanos a países centrales, ya fuera para hacer estudios de doctorado o para conocer directamente los debates centrales en la disciplina (Morales, 2013), la residencia de sociólogos de otras regiones - destacadamente españoles- en América Latina (Morales, 2009), así como la creación de revistas y asociaciones regionales, fomentaron los intercambios y las conexiones académicas entre los actores regionales de la disciplina.

\section{La sociología en México: conexiones y circulación centro-periferia}

Existe abundante literatura sobre los procesos históricos de institucionalización de la sociología en México. De esa literatura, es factible extraer argumentos que demuestren la relevancia de la configuración de redes nacionales e internacionales en las diferentes etapas de institucionalización de la disciplina en el país. De acuerdo con Moya (2013), la literatura socio histórica respecto a la sociología en México aborda, fundamentalmente, los procesos de institucionalización disciplinar y de profesionalización de la sociología, la historia de la disciplina a partir de la identificación de comunidades sociológicas, así como estudios sobre las ideas sociológicas, sus autores y sus espacios de socialización. 
El principal énfasis identificado en la literatura socio histórica sobre la sociología académica en México está puesto, precisamente, en sus procesos de institucionalización. Durante las décadas de 1970, 1980, e inicios de la de 1990, los sociólogos que estudiaron la institucionalización se interesaron en aspectos como la creación de escuelas y revistas académicas, así como en la identificación de los principales líderes disciplinarios fundacionales. En este ámbito, figuran trabajos como los de Arguedas y Loyo (1979), González (1970), Andrade (1998), Castañeda (1992; 2004) y Olvera (2004). Otros trabajos colectivos más recientes, como el coordinado por Camero y Andrade (2008), revisan las trayectorias y los principales aportes disciplinarios de los precursores de la sociología desarrollada en México.

Por su parte, Reyna (1979), Andrade (1989) y Murguía (1994) analizaron el desarrollo de la investigación sociológica en los periodos denominados de institucionalización y de sociología institucionalizada, es decir, desde la fundación del Instituto de Investigaciones Sociales de la Universidad Nacional Autónoma de México (UNAM) hasta la consolidación de la disciplina en la década de 1970. Trabajos como el de Andrade (1990) y el de Osorio (1995) resultan útiles para ubicar los procesos de la "latinoamericanización" en las orientaciones de la sociología mexicana desde inicios de la década de 1960, pero con antecedentes relevantes desde la de 1930. Por su parte, Villamil (2005) ofrece una reconstrucción histórica tanto de la investigación sociológica como de su enseñanza desde 1930 hasta 1990.

La literatura indicada muestra tangencialmente la relevancia de las conexiones y del trabajo colaborativo en la institucionalización de la sociología en México: si se leen con atención, ilustran el establecimiento de lazos de colaboración y las estrategias de grupos e individuos para crear espacios académicos y soportes de comunicación disciplinaria que estuvieron relativamente conectados, a través de la circulación de conocimientos y la movilidad de personas, con los polos disciplinarios ubicados en los países centrales y con los pares regionales. A partir de la revisión de los textos indicados, en lo que sigue presento una reconstrucción de la institucionalización de la sociología en el país, haciendo énfasis en los procesos colaborativos y en las conexiones internacionales identificables durante diferentes etapas de institucionalización.

Gabino Barreda, fundador y primer director de la Escuela Nacional Preparatoria (ENP) en 1867, incorporó la sociología al plan de estudios de dicha institución en la cátedra de Lógica, inspirado en los cursos de Comte a los que asistió en 1847 (González, 1970, p. 3). De acuerdo con Castañeda (1992, p. 17), la razón para que Barreda no abriera directamente una cátedra de sociología pudo deberse a la oposición de la iglesia católica, que consideraba al positivismo -y por ende a la sociología- como un peligro para el orden establecido. Este periodo de la sociología 
"enmascarada" (González, 1970) permitió organizar un incipiente discurso sociológico y establecer en el ámbito educativo mexicano fundamentos para, posteriormente, incorporar la sociología en los planes de estudio de las carreras de Derecho (gracias a la influencia de Carlos Pereyra) y de Economía. Pero fue hasta el plan de estudios de la ENP de 1895, organizado por Justo Sierra, cuando se abre una cátedra de Sociología, independiente de la de Lógica (Castañeda, 1992, p. 21), debido en buena medida a la consolidación de los grupos políticos hegemónicos del Porfiriato, conocidos como "los científicos".

Durante esa primera etapa, las polémicas sobre el estatuto científico de la sociología contribuyeron de manera notable a la posterior construcción de un discurso más disciplinario (aunque fragmentario). En esos debates, las figuras de Porfirio Parra y Justo Sierra fueron relevantes, tanto para el desarrollo de las orientaciones disciplinares de la sociología como para los intentos de institucionalización de espacios propiamente sociológicos, como la Sociedad de Estudios Sociales, en 1905, esfuerzo que fue interrumpido al iniciarse la revolución de 1910. La génesis de la sociología mexicana puede entenderse como un proceso de adaptación de saberes derivados del positivismo a las circunstancias nacionales. Los actores, en la etapa de la "prehistoria de la institucionalización" (Castañeda, 1992, p. 15), hicieron uso de saberes obtenidos en Francia para construir un discurso legítimo, que contribuyó al posicionamiento de una nueva disciplina de las ciencias sociales en aquel momento. Después de la agitada etapa de la lucha revolucionaria, otros actores orientaron sus acciones a dotar a la nueva disciplina de elementos propiamente académicos y fueron ellos quienes a partir de 1930 fundaron las instituciones propiamente sociológicas del país (Murguía, 1994, p. 209).

A partir de esa década, la sociología mexicana inicia su fase de institucionalización, a través de la apertura de espacios académicos disciplinarios (para realizar actividades tanto de investigación como de docencia), de la fundación de soportes comunicativos (revistas y casas editoriales) y de la emergencia de liderazgos académicos que marcaron el rumbo de iniciativas disciplinarias, mediante la circulación y adaptación de conocimientos sociológicos construidos en otros contextos disciplinarios.

El proceso de desarrollo de la sociología mexicana tiene su primer momento de institucionalización formal al fundarse, en la UNAM, el Instituto de Investigaciones Sociales (IIS) en 1930. Los primeros nueve años del IIS pueden definirse como los de una organización académica embrionaria en un espacio específico para la investigación sociológica. Durante esos nueve años, los fundadores del IIS: Alfonso Caso, Narciso Bassols, Vicente Lombardo Toledano, Luis Chico Goerne y Miguel Otón de Mendizábal, además de diseñar colegiadamente las bases, 
el reglamento y los programas del Instituto, ejercieron de manera rotativa la dirección, teniendo Othón de Mendizábal el encargo de la Secretaría, por lo que fue él quien realmente coordinó las actividades (Arguedas y Loyo, 1979, p. 7).

Destaca que en el proceso de institucionalización de la sociología en México, a diferencia de lo ocurrido en países de Europa y en Estados Unidos, donde la creación de centros de investigación obedeció a la necesidad de especializar la formación como resultado de la profesionalización en la disciplina, la sociología mexicana se orientó en primera instancia a la creación de un espacio destinado a la investigación, el IIS, y a la difusión de la literatura disciplinaria con la fundación de la Revista Mexicana de Sociología (RMS), veinte y once años, respectivamente, antes de la creación del primer espacio docente para la formación de sociólogos profesionales: la Escuela Nacional de Ciencias Políticas y Sociales, abierta hasta 1951 (Olvera, 2004, p. 11; Arguedas y Loyo, 1979, p. 8).

La razón para que ello ocurriera obedeció a la cualidad que los sociólogos mexicanos le atribuían a su disciplina como campo idóneo para la resolución de los grandes problemas nacionales; constituiría ello un rasgo central de la institucionalización de la sociología en el país: las motivaciones que dieron lugar a la institucionalización se adscribieron al interés político e intelectual de sus actores por generar un espacio de organización disciplinar que les permitiera influir en el derrotero de la vida nacional, por medio de la producción de conocimientos, más que por propiciar la creación de una disciplina profesional en el sentido de formar a los cuadros de relevo necesarios para el desarrollo disciplinar. Tal situación evidencia que la sociología en México tuvo en su origen una función social de tipo nacional, como ocurrió con las sociologías francesa y alemana en sus propios procesos de institucionalización (Wagner, 2006).

La articulación de las funciones docentes, de investigación y de transferencia de conocimientos de la sociología mexicana, es decir, los aspectos que le confieren su estatuto académico, fue promovida por líderes académicos, quienes en justicia pueden ser definidos como los fundadores de la disciplina en el país. Esos líderes actuaron como puentes y conectores entre los intereses disciplinarios locales y las tendencias desarrolladas en los polos sociológicos enclavados en los países centrales. No fueron correas de transmisión o intermediarios, sino mediadores (Latour, 2008, p. 63) que transformaron los contenidos que fluían por las redes académicas en las que participaban a nivel internacional, para adecuarlos -transformados- a las necesidades concretas identificadas en México.

La larga gestión, de veintiséis años, de Lucio Mendieta y Núñez como director del IIS (de 1939 a 1965) constituye, según diferentes autores (Olvera, 2004, p. 7; Castañeda, 1992, p. 26; Murguía, 1994, p. 211) la etapa en la que la sociología en México propiamente se institucionaliza, pues se 
reorganiza el trabajo de investigación al interior del IIS desde una perspectiva más académica y se perfila una mayor profesionalización de sus practicantes. Mendieta y Núñez no se limitó a reorganizar el IIS, sino que lo constituyó en la simiente de la sociología mexicana tanto en orientaciones de investigación como en la enseñanza y en la difusión de productos disciplinares (originales y traducciones de obras de Europa, Estados Unidos y América Latina).

La preocupación por dotar a la sociología mexicana de un estatuto disciplinar autónomo se manifiesta tanto en la creación de la Revista Mexicana de Sociología (RMS), en 1939, como en la fundación de la Escuela Nacional de Ciencias Políticas y Sociales (ENCPS) en 1951. En el primer caso, Mendieta y Núñez impulsó un proyecto de difusión de la sociología con una doble intención: 1) abrir un espacio para la comunicación de los resultados de la reflexión o de la investigación sociológica producida en México (Villamil, 2005, p. 79), y 2) difundir en México la producción y tendencias de la sociología en otros países.

La producción editorial, durante la década de 1940, fue mínima, debido en buena medida a presiones presupuestales que impedían publicar trabajos de los miembros del IIS, por lo que el verdadero impulso, tanto a la producción de libros como a la difusión de la RMS, se produce en los años cincuenta (Arguedas y Loyo, 1979, p. 13). Desde inicios de esa década, Mendieta y Núñez promovió la publicación de los Cuadernos de Sociología, la creación de la Biblioteca de Ensayos Sociológicos, la edición de libros de sociólogos mexicanos y latinoamericanos, así como las traducciones de obras sociológicas propuestas por integrantes de los principales polos disciplinarios y la realización de dieciséis congresos nacionales de sociología entre 1950 y 1965 (Benítez, 2008, p. 23).

Ese cúmulo de acciones fue fundamental tanto para la consolidación de la sociología en México como para la circulación de ideas y conocimientos. Implicó el uso de los soportes de comunicación en una doble dinámica: por un lado, permitió a los sociólogos mexicanos conocer los principales debates, enfoques y perspectivas metodológicas formuladas por sus pares en los países centrales y en América Latina; por el otro, funcionaron como espacios que dieron visibilidad a los sociólogos mexicanos y permitieron, en consecuencia, insertarlos en circuitos internacionales de producción de conocimientos sociológicos. La proyección internacional de la RMS revela con claridad esta doble dinámica:

Los tratadistas norteamericanos acogieron la Revista Mexicana de Sociología (RMS) con entusiasmo: Pitirim Sorokin en Harvard, Robert Redfield, William Ogbum en Chicago, experto este último en cambio social; Eric S. Thompson también de Harvard. La RMS se envía (desde esa época) a muchos ámbitos, fuera y dentro del país. De 
inmediato se la conoce en toda América Latina y los expertos de nuestra región son muy bien acogidos y poco a poco es considerada como la mejor revista de temas sociológicos editada en español. (Benítez, 2008, p. 23)

Por otra parte, la sociología mexicana fue también consolidándose con base en una intensa interacción de los fundadores, como Lucio Mendieta y José Medina Echavarría, con sociólogos adscritos a espacios académicos fuera del país. Al mismo tiempo que se fraguaban las condiciones para institucionalizar la disciplina en México, se establecían conexiones internacionales que, en ocasiones, propiciaban la configuración de redes académicas. Muestra de ello fue la estrecha colaboración que mantuvieron los sociólogos españoles exiliados Francisco Ayala (en Argentina) y José Medina Echavarría (en México). Sus trabajos colaborativos permitieron configurar redes disciplinarias entre ambos países avocadas a publicar y traducir artículos y libros, así como a sustentar intercambios de profesores de un país a otro para realizar actividades de docencia e investigación, entre otras (Morales, 2014).

Si bien, el proceso de institucionalización de la sociología mexicana se concentró en buena medida en la UNAM a través del IIS, la ENCPS y la RMS, en ese periodo fueron abiertas otras tres instituciones relevantes para la disciplina: el Colegio de México (COLMEX) en 1940, el Fondo de Cultura Económica (FCE) en 1934 y la Facultad Latinoamericana de Ciencias Sociales (FLACSO), sede México, en 1957. En los tres casos, las redes nacionales e internacionales de los fundadores fueron determinantes tanto para el establecimiento de las instituciones como para la definición de sus orientaciones. El COLMEX abrió un Centro de Estudios Sociales en 1943: aunque sólo funcionó durante dos años, definió pautas importantes en las orientaciones de la sociología mexicana. Fue hasta 1971 cuando El COLMEX fundó el Centro de Estudios Sociológicos y en 1973 cuando inició su programa de doctorado en Sociología (Castañeda, 1992, p. 39; Reyna, 1979, p. 45). Por su parte, el FCE fue relevante en estos años debido a la traducción al español y publicación de autores clásicos de la sociología como Durkheim, Weber, Pareto, Simmel, Comte y Marx. Finalmente, la FLACSO surgió con la intención de volverse una institución regional -latinoamericana- para la enseñanza de las ciencias sociales de alto nivel (Arguedas y Loyo, 1979, p. 25; Beigel, 2009).

En las tres instituciones referidas, la influencia del sociólogo español exiliado José Medina Echavarría fue fundamental. Echavarría es relevante no sólo por haber coordinado la traducción al español de la obra clásica de Max Weber, Economía y sociedad, sino por su labor como investigador y formador de nuevos sociólogos tanto en EI COLMEX como en la UNAM; desempeñó un destacado papel como divulgador del pensamiento sociológico europeo a través del FCE (Villamil, 
2005, p. 78) y funcionó como un puente entre la sociología mexicana y la latinoamericana, destacadamente con la argentina, brasileña y chilena, por medio de sus actividades en la FLACSO (Faletto, 2002; Moya, 2013).

A través de los soportes institucionales para organizar la investigación y la docencia sociológica, de la creación de revistas especializadas y casas editoriales, así como de la organización y participación de los sociólogos en eventos académicos internacionales, la sociología académica practicada en México estuvo en condiciones de intensificar sus relaciones con grupos e individuos de otros contextos nacionales. En ello, el papel desempeñado por Pablo González Casanova fue crucial.

En efecto, al iniciarse la década de 1960, la situación disciplinaria de la sociología académica mexicana mostraba evidencias de consolidación. No obstante, el trabajo sociológico de investigación (los instrumentales teóricos y metodológicos) y, sobre todo, las orientaciones normativas respecto a los focos de atención de los problemas atendidos por los sociólogos, no contaban con una visión claramente definida. El arribo de Pablo González Casanova a la dirección del IIS, en 1965, contribuyó destacadamente al surgimiento de una nueva etapa de circulación de conocimientos sociológicos y al establecimiento de redes entre quienes trabajaban en México y sus pares disciplinarios en América Latina, en Estados Unidos y en países europeos como Francia, Alemania e Inglaterra.

La conexión de Pablo González Casanova con la Universidad de las Naciones Unidas, sus funciones directivas tanto en espacios sociológicos (la ENCPS y el IIS) como en la rectoría de la UNAM y su capacidad de convocatoria fueron relevantes para introducir nuevos enfoques y perspectivas disciplinarias en la práctica sociológica realizada en México. Pablo González Casanova operó, de acuerdo con Andrade (1989; 1990), como un articulador entre la sociología practicada en las instituciones mexicanas y las realizadas en otros espacios nacionales. En ese sentido, lideró los intereses de conexión y de intercambio de los sociólogos con inclinaciones a la internacionalización: estimuló la movilidad para hacer estudios doctorales en países centrales de la sociología, atrajo a investigadores europeos, estadounidenses y latinoamericanos a México, tanto para realizar actividades académicas de corta duración como permanentes, incentivó la publicación de estudios sociológicos y fomentó la participación de sociólogos mexicanos en eventos internacionales.

El liderazgo académico de González Casanova contribuyó a reorientar la definición de los problemas de investigación y la enseñanza a través de la profesionalización y la incorporación de abordajes teóricos, metodológicos y epistemológicos novedosos: promovió así una reorganización de las líneas de investigación del IIS desde que asumió su dirección (Arguedas y Loyo, 1979, p. 23). 
La preocupación de González Casanova por contribuir al mejoramiento disciplinar de la sociología, considerando perspectivas novedosas sobre los problemas sociales del país, se expresa con claridad en un ensayo publicado en 1968, que da cuenta de los resultados obtenidos de una encuesta nacional aplicada para conocer la percepción que se tenía en México respecto a los problemas que las ciencias sociales deberían atender como prioridad (González, 1968). En el ámbito de la reorganización de la investigación en el IIS, la gestión de González Casanova se caracterizó por delinear tres líneas fundamentales: a) la investigación básica sobre los temas centrales que venía tratando la sociología mexicana, b) la mayor profesionalización de la investigación aplicada y c) el desarrollo de estudios monográficos sobre las clases sociales, el Estado y la ideología (Arguedas y Loyo, 1979, p. 28). La influencia de González Casanova en la sociología mexicana no se expresa únicamente en su trabajo al frente de la ENCPS y del IIS. Su libro La democracia en México, publicado en 1965, constituye, de acuerdo con Reyna (1979) "un punto de inflexión de la práctica sociológica" (p. 53), no sólo por sus aportaciones hechas al conocimiento de la realidad socio política de México sino porque se convierte en punto de partida de numerosas investigaciones. En efecto, en el ámbito de la sociología mexicana, ese estudio de González Casanova es hasta la actualidad uno de los referentes en toda institución de enseñanza de sociología. La democracia en México es relevante porque muestra cómo una obra elaborada por un líder académico, al convertirse en un texto fundante en una disciplina, se convierte en contexto, es decir, en referente de significación en una comunidad de conocimiento (Castañeda, 2004).

Además de los liderazgos académicos, la institucionalización de la sociología en México estuvo fuertemente condicionada por las transformaciones en las realidades del país y del mundo. Desde los inicios de la década de 1960 y hasta la de 1980, la multiplicidad de cambios económicos, políticos, sociales y culturales hicieron visible la necesidad de que la sociología mexicana modificara sus orientaciones temáticas, sus campos de aplicación y sus ejes de interpretación (Andrade, 1998). Llegó entonces el tiempo de la sociología enfocada en el marxismo, de la investigación aplicada y de los análisis anclados en los temas del desarrollo, la dependencia y el imperialismo. Esos constituyeron vertientes centrales en la "latinoamericanización" de la sociología mexicana, sobre todo en las décadas de 1970 y 1980 (Osorio, 1995, pp. 95-115). Como resultado del movimiento estudiantil de 1968, el estudio sistemático de los movimientos sociales y otras formas de resistencia, así como la investigación vinculada a los temas del poder (retomando a Foucault), del sistema político mexicano, de la dominación y del Estado (Villamil, 2005, p. 84) caracterizaron la sociología académica mexicana en esa época. 
Los ejes, problemas y orientaciones de la disciplina se multiplicaron, dando lugar a un pluralismo en el trabajo de investigación y abriendo nuevas perspectivas tendientes a construir explicaciones de lo social con criterios teóricos y metodológicos más sólidos, dando lugar a una auténtica comunidad disciplinaria en la sociología mexicana (Girola y Olvera, 1994). También, en esas décadas, existieron fenómenos de polarización y de fragmentación de la sociología mexicana que trascendieron los liderazgos académicos de personajes como González Casanova o Raúl Benítez Zenteno (director del IIS en la década de 1970), pero que, al mismo tiempo, encontraron en ellos bases organizativas para una labor sociológica cotidiana plasmada en prácticas institucionalizadas en los espacios de investigación, enseñanza y difusión.

En las décadas de 1960, 1970 y 1980, la sociología académica mexicana expandió sus orientaciones pero, también, multiplicó sus espacios: fueron fundados centros de investigación especializados en sociología; se abrieron carreras de sociología en una buena cantidad de universidades (lo que se explica también por el crecimiento exponencial de la educación superior en la década de 1970); se especializó la formación de sociólogos de alto nivel, a través de los posgrados en sociología surgidos en la UNAM y en la Universidad Iberoamericana a partir de 1967 (Arguedas y Loyo, 1979, p. 28; Villamil, 2005, p. 67) así como en El COLMEX, en 1973. Instituciones como la Universidad Autónoma Metropolitana (UAM), el Instituto de Investigaciones Sociales José María Luis Mora y la FLACSO contribuyeron asimismo al desarrollo de la disciplina en México.

La formación doctoral fuera de México de un número considerable de sociólogos que retornaron al país, la consolidación de espacios disciplinarios en instituciones de educación superior, la creación y perduración de soportes para la comunicación especializada, propiciaron el posicionamiento de líneas de investigación, la formación de grupos académicos y la visibilidad internacional de algunos líderes. Esos aspectos incidieron en las características de la sociología académica en México y permitieron que sus actores continuaran estableciendo dinámicas de trabajo colaborativo con individuos y grupos tanto de países centrales como periféricos, tal como hicieron antes los fundadores.

Como resultado de esa larga historia de institucionalización y de consolidación de la sociología en México, actualmente la disciplina está desplegada en el territorio nacional, aunque sigue concentrada en la Ciudad de México. En 2015, existían en el país treinta y siete programas de licenciatura en Sociología en instituciones de educación superior públicas y cinco en particulares, siete programas de maestría en instituciones públicas y cuatro en particulares, además de ocho de doctorado en instituciones públicas y uno en particulares (Puga y Contreras, 2015). La sociología mexicana cuenta con un cuerpo de especialistas consolidado y un número significativo de jóvenes investigadores que aseguren el relevo generacional. De acuerdo al Atlas de la ciencia mexicana 
(Consejo Nacional de Ciencia y Tecnología [CONACYT], 2010), la sociología es la disciplina de las ciencias sociales con el mayor número de investigadores con doctorado en México y concentra la mayoría de grupos de investigación.

\section{Conclusiones}

La sociología en México ha transitado por diferentes etapas durante las casi nueve décadas transcurridas desde los primeros esfuerzos disciplinarios de los fundadores al crear el IIS de la Universidad Nacional Autónoma de México. El conjunto de aspectos que delinearon sus particularidades como una disciplina científica distinguible de otras, forma parte de una historia que a todo sociólogo conviene tener presente, pues de ese modo nuestra disciplina podrá re-definir su lugar en los procesos contemporáneos y futuros de organización del conocimiento científico y de su uso social.

La sociología mexicana se institucionalizó y consolidó a través de un complejo proceso de orientaciones, intereses y preocupaciones intelectuales de sus actores, quienes fundamentaron la necesidad de establecer en el país una disciplina autónoma que diera cuenta de los problemas sociales de mayor relevancia. En ese sentido, los sociólogos mexicanos buscaron contar con espacios adecuados para el desarrollo de la disciplina en los ámbitos de investigación, enseñanza y difusión, al tiempo que generaron debates en torno a qué tradiciones sociológicas internacionales eran las más adecuadas para el contexto mexicano. Esto tuvo como consecuencia que, por un lado, la sociología fuera adquiriendo autonomía disciplinar pero que, por el otro, no fuera posible consolidar un discurso sociológico totalmente innovador.

La dependencia académica de los sociólogos latinoamericanos con respecto a las formulaciones elaboradas en los polos disciplinarios centrales es una constante histórica. México no fue ni es la excepción. No obstante, los sociólogos que trabajan en México han puesto en operación estrategias de visibilidad y de posicionamiento que les ha permitido integrarse o configurar redes académicas tanto nacionales como internacionales, en algunas ocasiones en forma subordinada a la hegemonía de los polos disciplinarios, pero en otras penetrando sus muros de contención.

Por otra parte, los espacios académicos de comunicación disciplinaria fueron fundamentales tanto para la consolidación de la sociología en México como para la circulación de ideas y conocimientos. Esa circulación implicó el uso de los soportes en una doble dinámica: por un lado, permitió a los sociólogos mexicanos conocer los principales debates, enfoques y perspectivas metodológicas formuladas por sus pares en los países centrales y en América Latina; por el otro, funcionaron como espacios que dieron visibilidad a los sociólogos mexicanos y permitieron, en consecuencia, insertarlos en circuitos internacionales de producción de conocimientos sociológicos. 
El surgimiento y permanencia de la Revista Mexicana de Sociología ilustra uno de los principales soportes de comunicación disciplinaria y constituye, hasta la actualidad, un modelo de difusión del pensamiento y la investigación sociológica tanto en México como en América Latina.

Con base en los diferentes aspectos tratados en este texto, es factible definir a la sociología académica practicada en México como consolidada en sus atributos disciplinarios, periférica en cuanto a su posición en los debates internacionales dentro de la disciplina, reproductiva en cuanto a que existen espacios dedicados a la formación profesional de nuevos sociólogos y estrategias de política e individuales para cursar estudios de posgrado, productiva en cuanto a la construcción de saberes disciplinarios.

La interdisciplina y la transdisciplina, así como lo que se denomina estudios de frontera, son formas interesantes de organizar la producción de conocimientos científicos y, en su caso, de transferirlos como uso social y ambiental de la ciencia. El trasfondo de esas formas de organización de los saberes científicos es precisamente que la ciencia contribuya al bien común, aunque siempre esté presente la tensión respecto a ese uso y la apropiación / uso particular / económico / dominante del conocimiento científico. La identificación de los aspectos concernientes al surgimiento e institucionalización de la sociología en México, es un recordatorio de que nuestra disciplina fue pensada para contribuir a comprender nuestra sociedad y para intervenir desde el conocimiento codificado en la solución de los grandes problemas nacionales.

Me parece que esa perspectiva de la función social de la sociología debería nutrir los debates actuales respecto a la disciplina, porque de esa forma el trabajo sociológico tendría una especificidad que aportar a los enlaces disciplinarios orientados al estudio e intervención de temas concretos. En ese sentido, conviene tener clara una enseñanza del surgimiento de la sociología en México: debe servir para entender e intervenir en la sociedad. Las conexiones internacionales de los sociólogos que trabajan en el país tendrían, en consecuencia, que estar signadas por una expresa intención de fomentar la colaboración internacional para reforzar las capacidades nacionales de investigación, enseñanza, difusión, circulación, transferencia, aplicación e intervención de los saberes sociológicos, donde la internacionalización disciplinaria sea una estrategia de fortalecimiento endógeno que contribuya al uso social y ambiental de la sociología. Nuestros antepasados disciplinarios nos enseñaron eso, debemos aprender de ellos para seguir trabajando en el buen funcionamiento de la sociología mexicana. Pero, sobre todo, con estudios enfocados a la función social, y no sólo académica, de la disciplina; así, estaremos en mejores condiciones para promover que la sociología practicada en México configure redes nacionales e internacionales para atender los grandes problemas nacionales, lo cual fue la aspiración de los fundadores de la disciplina en el país. 


\section{Referencias}

Altbach, P. (2004). Centros y periferias en la profesión académica: los retos particulares que enfrentan los países en desarrollo. En El ocaso del gurú. La profesión académica en el tercer mundo (pp. 15-41). México: UAM.

Andrade, A. (1989). La institucionalización de la investigación en ciencias sociales. Revista Mexicana de Ciencias Políticas y Sociales, XXXV(136-137), 61-98.

Andrade, A. (1990). Trayectoria de las ciencias sociales en América Latina. Revista Mexicana de Ciencias Políticas y Sociales, XXXVI(141), 89-105.

Andrade, A. (1998). La sociología en México: temas, campos científicos y tradición disciplinaria. México: UNAM.

Arguedas, L., \& Loyo, A. (1979). La institucionalización de la sociología en México. En L. Arguedas et al., Sociología y ciencia política en México (pp. 5-40). México: UNAM.

Beigel, F. (2009). La FLACSO chilena y la regionalización de las ciencias sociales en América Latina (1957-1973). Revista Mexicana de Sociología, 71(2), 319-349.

Beigel, F. (Coord.). (2010). Autonomía y dependencia académica. Universidad e investigación científica en un circuito periférico: Chile y Argentina (1950-1980). Argentina: Editorial Biblos.

Beigel, F. (Ed.). (2013). The Politics of Academic Autonomy in Latin America. England: Ashgate.

Benítez, R. (2008). Lucio Mendieta y Núñez: sociólogo y fundador de instituciones. En V. Camero y A. Andrade (Coord.), Precursores de la sociología moderna en México (pp. 13-34). México: UNAM/Siglo XXI editores.

Camero, V., \& Andrade, A. (Coord.). (2008). Precursores de la sociología moderna en México. México: UNAM/Siglo XXI editores.

Castañeda, F. (1992). Desarrollo histórico de la formación de sociólogos en las universidades. En G. Villaseñor (Comp.), Las profesiones en México. Sociología (pp. 15-41). México: UAM, Xochimilco.

Castañeda, F. (2004). La crisis de la sociología académica en México. México: Porrúa/UNAM.

Consejo Nacional de Ciencia y Tecnología (CONACYT). (2010). Atlas de la ciencia mexicana. México: CONACYT. Recuperado de http://atlasdelacienciamexicana.org/atlas_version_impresa_2010/ Faletto, E. (2002). La ciencia social y el cientista social en el pensamiento de José Medina Echavarría. Argumentos. Estudios Críticos de la Sociedad, (43), 5-15. 
Girola, L., \& Olvera, M. (1994). Comunidad disciplinaria. Etapa de desarrollo y cambios en la sociología mexicana de los años setenta y ochenta. En J. Leal, A. Andrade, A. Murguía, \& A. Coría (Coord.), La sociología contemporánea en México. Perspectivas disciplinarias y nuevos desafíos (pp. 175-194). México: UNAM.

González, M. (1970). Sociología e historia en México (Barreda, Sierra, Parra, Molina Enríquez, Gamio, Caso). México: El Colegio de México.

González, P. (1968). Las ciencias sociales. En P. González, \& P. Bonfil, Las ciencias sociales y la antropología (dos ensayos) (pp. 1-44). México: Ediciones Productividad.

Landesmann, M. (Coord.). (2006). Instituciones educativas. Instituyendo disciplinas e identidades. México: Juan Pablos.

Latour, B. (2008). Reensamblar lo social. Una introducción a la teoría del actor-red. Argentina: Manantial.

Morales, J. (2009). Hacer la América: una estrategia alternativa al proceso de inserción académica en la sociología española. Nómadas, (24).

Morales, J. (2013). Entrecruzamientos en el Instituto de Sociología de la Universidad de Buenos Aires (1955-1965) y sus derivaciones: movilidad académica y Latin American Studies. Ponencia.

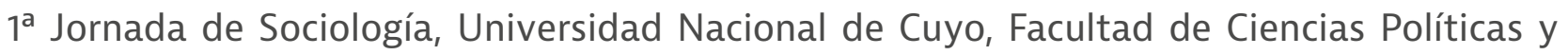
Sociales, Argentina.

Morales, J. (2014). Un corredor de ideas entre México y Argentina. El intercambio científico e intelectual entre los sociólogos del exilio español. Iberoamericana, 14(53), 29-48.

Moya, L. (2013). José Medina Echeverría y la sociología como ciencia social (1939-1980). México: El Colegio de México.

Murguía, A. (1994). Conocimiento científico y realidad en la sociología mexicana. Acta Sociológica, (12), 207-224.

Navarro, G. (2013). Catholic International Cooperation: Social Research in the Society of Jesus. En F. Beigel (Ed.), The Politics of Academic Autonomy in Latin America (pp. 119.134). England: Ashgate Publishing Limited.

Olvera, M. (2004). Lucio Mendieta y Núñez y la institucionalización de la sociología en México 19391965. México: Porrúa/UAM-Azcapotzalco.

Osorio, J. (1995). Las dos caras del espejo. Ruptura y continuidad en la sociología latinoamericana. México: Triana.

Picó, J. (2001). El protagonismo de las fundaciones americanas en la institucionalización de la sociología (1945-1960). Papers, Revista de Sociología, (63-64), 11-32. 
Puga, C., \& Contreras, O. (Coord.). (2015). Informe sobre las ciencias sociales en México. México: COMECSO/FCCyT.

Reyna, J. (1979). La investigación sociológica en México. En L. Arguedas et al., Sociología y ciencia política en México (pp. 41-62). México: UNAM.

Villamil, R. (2005). Docencia e investigación sociológica en México hasta 1990. En T. Pacheco (Coord.), Universidad, sociedad y modernidad en el contexto de las ciencias sociales (pp. 57115). México: Fontamara.

Wagner, P. (2006). Variedades de interpretaciones de la modernidad: sobre las tradiciones nacionales en sociología y otras ciencias sociales. En C.H. Christophe, J. Schriewer, \& P. Wagner (Comp.), Formas de conocimiento académico y búsqueda de identidades culturales (pp. 22-45). México: Ediciones Redes intelectuales trasnacionales. 


\section{Capítulo II}

Las revistas antecesoras y las primeras revistas especializadas de la sociología y las ciencias sociales en México (1920-1955). ¿Un legado para una época presentista?

Margarita Olvera Serrano *

* Profesora investigadora, Departamento de Sociología, Universidad Autónoma Metropolitana, Azcapotzalco. Integrante del Sistema Nacional de Investigadores. Contacto: habril@prodigy.net.mx 


\section{Introducción}

Una cuestión que plantea la observación del pasado de nuestras ciencias, es el sentido contemporáneo que tiene el reconstruir acontecimientos, procesos y experiencias pasadas ${ }^{1}$ que, frecuentemente, son poco conocidos o considerados como carentes de relevancia, a pesar de que buena parte de las instituciones, prácticas y condiciones de posibilidad del trabajo de nuestras comunidades disciplinarias, son producto precisamente de las consecuencias de las iniciativas y proyectos de quienes nos antecedieron. Esto es comprensible en contextos societales como el nuestro, en el que el espacio de experiencia pasada (Koselleck,1993) constantemente ve cuestionada su capacidad de orientación para la formación de las iniciativas del presente y en los cuales, en paralelo, el futuro frecuentemente se percibe con reserva, cautela y/o desconfianza. Si, por otra parte, consideramos la creciente hiperespecialización de los objetos de nuestras disciplinas, el aumento geométrico de la producción de conocimiento, la aceleración creciente de su transmisión-recepción, y la presión que esto implica para sobrevalorar a priori lo nuevo y reciente sobre lo anterior, a nadie debe sorprender la dificultad para reconocer las cadenas intergeneracionales en las que estamos inscritos como observadores y lo que esto implica para asumir nuestra posición de legatarios de formas de comunicabilidad intelectual y acervos intelectuales formados a lo largo de no menos de un siglo.

$1 \quad$ Nos referimos al pasado como un amplio espacio de experiencia del que la observación sociológica e historiográfica selecciona determinados segmentos, con base en preguntas, procedimientos y criterios acotados, para reconducirlos al estatus de historia escrita, comunicable y significativa para el presente contemporáneo. En este sentido, este trabajo se inscribe en una línea de investigación sobre la historia de la sociología y las ciencias sociales que ha estado orientada a contribuir a una escritura relativa a estas cuestiones, que asume la triple temporalidad (pasado-presente-futuro) que atraviesa tanto dicha experiencia, como su reconstrucción por parte de los observadores (Moya y Olvera, 2016). 
La percepción de irrelevancia de estas herencias, cuando no de desconocimiento, olvido e incluso supresión, se suspende -si bien temporalmente-en ocasiones de corte conmemorativo en las que los ciclos recuerdo-olvido fijados por los calendarios definen fechas en las que existen estímulos práctico-institucionales para reconocer la experiencia acumulada e identificar líneas de continuidad/discontinuidad pasado-presente-futuro. Esto abre una invaluable oportunidad de reconocer, valorar y recolocar en contextos contemporáneos los legados de los antecesores de nuestras ciencias, así como de replantear algunos ejes de la fijación de sus horizontes fundacionales. ${ }^{2}$ En estos términos y bajo las coordenadas de un ciclo conmemorativo en el que se celebran los 40 años de la Licenciatura en Sociología de la Universidad de Sonora, carrera que sin duda mantiene una relación de continuidad transgeneracional con los proyectos fundacionales de las ciencias sociales emprendidos en México desde los años veinte del siglo pasado, en este trabajo buscamos analizar los principales aportes de lo que llamaremos revistas pioneras o antecesoras, a la formación de un primer acervo de conocimiento escriturario, como condición para la institucionalización inicial de la sociología y las ciencias sociales en México como disciplinas y como profesiones.

El examen de estas publicaciones se limita a un trazo general que, no obstante, permite identificar y dar visibilidad a la cadena antecesores-contemporáneos-sucesores que articula los itinerarios intelectuales de nuestras disciplinas. Si bien, el periodo considerado en este trabajo es únicamente de 1920 a 1955, debe señalarse que está inscrito en un eje diacrónico que, en términos del universo textual representado por las revistas pioneras y especializadas en conjunto, abarca ya casi un siglo en nuestro país. Esto significa que los eslabones contemporáneos más recientes de esta cadena temporal, por así decirlo, están integrados por las etapas actuales de profesionalización e hiperespecialización a la que aludimos antes y que, desde luego, han condicionado una fisonomía completamente diferente en las revistas especializadas actuales, en comparación con aquellas de las que nos ocuparemos aquí. Muestra de ello es, por ejemplo, la tendencia a la pérdida de relevancia del número como unidad textual de una revista impresa, frente al artículo individual publicado digitalmente.

$2 \quad$ No ha sido esta la única conmemoración institucional relevante de la sociología en México en tiempos recientes. Por ejemplo, hace unos años se celebraron 70 años del Centro de Estudios Sociológico de El Colegio de México; medio siglo de La democracia en México, de Pablo González Casanova y de 7 tesis equivocadas sobre América Latina, de Rodolfo Stavenhagen; 60 años de la Revista Mexicana de Ciencias Políticas y Sociales; 40 años de la Facultad de Sociología de la Universidad Veracruzana. En 2019, se cumplirán 80 años de la Revista Mexicana de Sociología y, en 2021, la Facultad de Ciencias Políticas y Sociales de la UNAM arribará a su septuagésimo aniversario. Algunos trabajos recientes sobre estos puntos pueden consultarse en Olvera (2016; 2018); y Moya y Olvera (2016). 
Se sobrentiende que las publicaciones periódicas son una vía privilegiada para la investigación de la historia de la sociología y las ciencias sociales en nuestro país, abarcables y comparables empíricamente en términos de proyectos, expectativas y experiencia del tiempo, editores, autores, teorías, conceptos, métodos, temas, relación volumen/artículo individual, énfasis normativos, continuidades, rupturas, tipos de escritura y formatos, así como soportes materiales y modalidades de transmisión y recepción de conocimiento, entre muchos otros registros de observación que no podemos abordar aquí, pero que forman parte inescindible del universo de investigación que representan las revistas.

Es importante aclarar que la intención de ocuparse de este tipo de publicaciones periódicas no supone proponer un regreso - por otra parte, imposible- a la vieja idea de la historia como magistra vitae de la que se pueden extraer certezas y criterios claros de orientación para el presente (Koselleck, 1993; 2004). Se trata únicamente de reconocer y reinterpretar selectivamente orígenes y legados acumulados, desde una perspectiva que busca contribuir a una escritura de la historia de las ciencias sociales con un mínimo de significación para el presente, como posible contrapeso a una experiencia del tiempo predominantemente presentista ${ }^{3}$ que implica percepciones que no favorecen el reconocimiento de los nexos que nos vinculan a lo anterior $y$, en consecuencia, comprometen la capacidad de comunidades e instituciones para elaborar proyectos de futuro viables y mantener una oferta de identidad intelectual transgeneracional significativa para sus hipotéticos sucesores. Una condición indispensable, aunque insuficiente, para su posible formación es un conocimiento mayor de los procesos, acontecimientos y experiencias que nos anteceden para revalorar críticamente las tradiciones intelectuales de las que formamos parte, resignificar constructivamente lo que aún nos pueden aportar y deslindarnos de lo que, con argumentos, identifiquemos como poco relevante. Esto implica reconocer la producción de conocimiento como un proceso diacrónico que está atravesado por la tensa dialéctica de las relaciones entre

3 La noción presentismo, acuñada por Hartog (2007), alude a una modalidad de la experiencia humana del tiempo en la que, por una parte, se desdibujan las conexiones con un pasado en el que se percibe escaso potencial orientador y, por otra, la relación con el futuro ya no es de espera optimista, sino de duda, dilación temor, e incluso, de deuda anticipada. En consecuencia, predomina una experiencia de la temporalidad en la que el presente se vuelca sobre sí mismo, dado que pareciera que no pueden obtenerse orientaciones, ni del pasado, ni del futuro, como en la modernidad progresista típica de los siglos XIX y buena parte del XX (Durán, 2017). 
conservación e innovación ${ }^{4}$, esto es, por líneas de continuidad y discontinuidad pasado/presente/ futuro, así como por condicionamientos práctico-políticos fluctuantes que pueden favorecer o dificultar el desarrollo y viabilidad de la sociología y las ciencias sociales.

\section{Las revistas antecesoras y sus expectativas de futuro}

Las revistas pioneras de la sociología y ciencias sociales en el periodo que nos interesa, sociológica e historiográficamente, son universos textuales que deben examinarse como parte de una historia centenaria ${ }^{5}$ que, en consecuencia, atraviesa un denso tejido intergeneracional. Publicaciones como Ethnos (1920), Revista de Ciencias Sociales (1922), Revista Mexicana de Economía (1928), y El Trimestre Económico (1934) fueron pioneras en la formación de acervos de conocimiento fijados textualmente que dieron lugar a formas de sociabilidad intelectual (recepción, transmisión, transferencias internacionales de conocimiento, nuevas prácticas de lectura y escritura, etc.) que favorecieron la posterior institucionalización de las ciencias sociales en México como disciplinas autónomas y como profesiones, así como la fundación de las primeras revistas especializadas de las ciencias sociales en México, como la Revista Mexicana de Sociología (1939), Revista de Investigación Económica (1942), Jornadas (1943) y Ciencias Políticas y Sociales (1955). Con excepción de esta última, todas ellas lograron convertirse en publicaciones acumuladoras que han hecho y siguen haciendo aportes significativos en México y América Latina, como lo muestra el análisis diacrónico de sus contenidos y el hecho de que sus trayectorias se mantienen en marcha en la actualidad. Han sido también, sin duda, referentes y modelos para las más importantes revistas fundadas en los años ochenta en nuestro país, ya en plena etapa de profesionalización y especialización, como Estudios Sociológicos (1983), Sociológica (1986) y Acta Sociológica, en su segunda época (1987), entre las más relevantes.

Los propósitos a los que trataron de responder las revistas pioneras, fueron muy heterogéneos, por lo que no es posible imputar relaciones de identidad unívocas entre ellas; sin embargo,

$4 \quad$ En este sentido, este trabajo está en deuda, aunque no exclusivamente, con los aportes de la fenomenología sociológica de Schütz (1972); con las contribuciones de la historia conceptual en la vertiente desarrollada por Koselleck (1993; 2004; 2012); así como con las reflexiones de Rüsen (2014) sobre la escritura de la historia, las funciones prácticas del saber histórico y la formación de sentido histórico.

5 Sin considerar la herencia de legados fundamentales, como la Revista Positiva, que corresponden al periodo que hemos tipificado de precursores individuales. Dejamos de lado también muchas revistas que fueron relevantes en el periodo considerado en este trabajo, como Revista de Investigación Económica, El Economista, Criminalia y Problemas Agrícolas e Industriales de México. 
estuvieron atravesadas por un interés común, que en muchos sentidos fue también un punto de partida para las fases fundacionales de las revistas especializadas a las que hicimos referencia en el párrafo anterior: generar condiciones para producir un conocimiento científico de las estructuras, procesos, grupos y problemas político-prácticos de la sociedad mexicana que pudiese ser un insumo para la elaboración de proyectos dirigidos a promover mejoras societales; en estos términos, puede afirmarse que estas publicaciones estuvieron movidas por una expectativa de futuro producto del horizonte posrevolucionario. Se trató de poner al servicio de la nación un conocimiento científico, para que las demandas sociales acumuladas pudieran ser solucionadas con la celeridad que demandaban los tiempos que se estaban viviendo. El régimen político surgido del movimiento armado de 1910, a partir de una experiencia del tiempo, que bien puede adjetivarse de futurista, convirtió a la revolución en un concepto de movimiento (Koselleck, 2004; 2012) en una categoría política de acción, en indicador y factor de cambios que abrió un horizonte de futuro que favoreció la apertura de espacios intelectuales e institucionales para la sociología y las ciencias sociales. En este proceso, la aportación de estas primeras revistas fue fundamental, en particular, para el surgimiento de la economía y la sociología como disciplinas y profesiones comprometidas con la nación.

La antropología, la etnografía, la economía, la criminología y la sociología, en el México posrevolucionario, emprendieron la tarea de diferenciarse de la jurisprudencia y de replantear sus propósitos cognitivos a la luz de la agenda del programa social de la Revolución de 1910, con todas las limitantes de la época -que no fueron pocas-. Estas fueron las ciencias de las que procedieron los liderazgos, las protocomunidades de practicantes, así como los primeros esbozos y proyectos de descripción empírica de la realidad social del México de los años veinte y treinta. Un proyecto fundamental en este contexto fue, precisamente, la instauración de publicaciones periódicas como medio editorial/escriturario que permitió que los resultados de estas indagaciones estuviesen a disposición de un público lector/receptor potencial que abarcó un amplio espectro: practicantes incipientes de las ciencias sociales, estudiantes, abogados, profesionistas de diverso signo, funcionarios universitarios, funcionarios del gobierno y algunos segmentos del público en general. Asimismo, estas publicaciones dieron lugar a la difusión, registro y acumulación de información sobre la existencia y contenidos de las literaturas especializadas en estas ciencias, procedentes de países donde su cultivo tenía ya una larga historia, como Francia, Bélgica, Italia, Alemania y otros países europeos y, desde luego, Estados Unidos. Reseñas, notas y listas bibliográficas, traducciones y clasificaciones temáticas fueron parte fundamental de los formatos y mapas cognitivos que estas primeras generaciones de cultivadores de las ciencias sociales en México obtuvieron 
de estas revistas y que utilizaron para trazar coordenadas mínimas útiles para orientar proyectos e iniciativas (independientemente de sus resultados efectivos) dirigidos, tanto a crear un clima favorable en la sociedad para la germinación de lugares institucionales para estas ciencias, como a tratar de producir un conocimiento tipificado como experto y útil para el país. Una de las dificultades más serias para ello, a juicio de estos practicantes, fue la carencia de acceso a las bibliografías producidas en los países en los que estas ciencias contaban ya con una amplia trayectoria; por otra parte, la inexistencia de investigación propia sobre los problemas locales.

Lo anterior significa que, a diferencia de Europa y Estados Unidos, donde las revistas especializadas surgieron como una respuesta frente al exceso y la lentitud en la difusión de libros científicos en México, al menos parcialmente, se fundan como una solución a su escasez, bajo el reconocimiento de que la existencia de investigación científica de los problemas de la nación, exigía de un saber sobre perspectivas, métodos, orientaciones y técnicas desarrolladas en cada campo de las ciencias sociales a nivel internacional, a fin de adaptarlos a los requerimientos locales. De ahí la importancia que tuvo en las revistas antecesoras la difusión de información relativa a listas bibliográficas y reseñas.

Nuestras revistas pioneras se orientaron no sólo a argumentar la necesidad de un conocimiento científico de lo social y dar a conocer algunas descripciones incipientes de estructuras y procesos económicos, jurídicos y sociales locales, sino también a divulgar libros e informar a potenciales públicos lectores de forma rápida. Se consideró que frente a la aceleración de los tiempos que significó la Revolución de 1910, la correspondencia privada y los folletos ya no eran formas eficientes de sociabilidad intelectual. En estos términos, la urgencia práctico-política del horizonte de los años veinte y treinta fue un potente estímulo externo para la aparición de las primeras revistas de lo que hoy conocemos como disciplinas sociales. No se trató de revistas especializadas en sentido estricto, como lo sería las fundadas en los años treinta, por ejemplo; sin embargo, cumplieron un papel crucial en la formación de las expectativas y proyectos que cristalizarían en la década siguiente en la creación de escuelas formadoras de economistas, institutos de investigación social, así como de las primeras publicaciones especializadas con las que contaron las ciencias sociales en México. Este es el sentido en que las publicaciones que examinamos aquí pueden considerarse plenamente como revistas pioneras que generaron condiciones de posibilidad para la existencia de sus sucesoras, las revistas especializadas. En las páginas que siguen, abordamos de forma sucinta las orientaciones y aportes de estas publicaciones desde el reconocimiento retroactivo de nuestro estatus de legatarios de espacios de experiencia que nos preceden en el tiempo, independientemente de que el presentismo y la aceleración temporal como modalidades domi- 
nantes de la experiencia del tiempo en nuestra época, dificulten la visibilidad de este entramado antecesores-contemporáneos-sucesores.

\section{Ethnos. Revista Mensual de Antropología sobre México y Centroamérica (1920)}

Una de las antecesoras de las revistas especializadas de las ciencias sociales en México más antigua es, indudablemente Ethnos, fundada por Manuel Gamio con la colaboración del lingüista y filólogo Pablo González Casanova e Ignacio del Castillo como secretarios de redacción. Sus propósitos pueden entenderse dentro de un entramado que, en muchos sentidos, forma parte de la historia efectual de la Revolución Mexicana; se buscó, sobre todo, el estudio de los fenómenos que entrañaba el desarrollo humano, bajo los principios y métodos "preconizados por las ciencias sociales: Historia, Sociología, Antropología, Psicología" (Ethnos, 1920, p. 2). En ese horizonte de época, esto significó tratar de identificar qué "proporciones" de los grupos sociales que conformaban el país en ese entonces, eran conocidos científicamente y cuáles no. Desde luego, la cuestión partió de una convicción previa, puesto que desde este primer número se concluyó que era abrumadora la cantidad de los que no se conocían sus características y aspectos más esenciales; se buscó llamar la atención sobre el hecho de que los mexicanos ignorados tenían "derecho a ser estudiados para ser conocidos y conscientemente impulsados en su evolución social" (Ethnos, 1920, p. 2) como condición para su integración a la vida nacional. Este componente normativo fue el punto de partida que justificó a Ethnos como proyecto editorial.

Los temas abordados en los primeros meses de esta publicación fueron, entre otros, el estado civil en México, el problema indígena, la marihuana, los descubrimientos arqueológicos en Teotihuacán, la incorporación de los Yaquis a la vida nacional, el derecho mexicano antes de la conquista. Los campos cognitivos desde los cuales fueron examinadas estas cuestiones fueron la antropología, la etnografía, el derecho, la historia y una protosociología de corte descriptivo. La tarea fue avanzar en la producción de un saber científico que pudiese ser un insumo cognitivo para la orientación de la acción gubernamental, la elaboración de iniciativas, de proyectos dirigidos a contribuir al progreso de la nación, a la fusión racial, a la elevación del indígena ${ }^{6}$, y con ello, de la patria (Gamio, 1916). El argumento de fondo procedía del positivismo mexicano del siglo XIX y su núcleo fue la convicción de que los gobernantes necesitaban con urgencia conocer las características de los grupos sociales que trataban de dirigir, que no existía un conocimiento observacional riguroso al respecto y que la antropología y las ciencias sociales podrían cumplir esta tarea. La

6 Esta dimensión normativa quedó fijada con mayor fuerza en 1923, cuando Ethnos agrega a su nombre la leyenda "Revista dedicada al estudio y mejoría de la población indígena de México", en 1923. 
población debía ser investigada "integralmente" en sus dimensiones cuantitativa, cualitativa, estadística, geográfico-ambiental y territorial. No sobra señalar que Manuel Gamio lustros después, en 1938, dirigió el Instituto de Investigaciones Sociales en la fase inicial de directores rotativos, ni que su discípulo desde los diecisiete años, cercanísimo colaborador y principal líder fundador de la sociología en México en su etapa de institucionalización temprana, Lucio Mendieta y Núñez, colaboró en Ethnos como autor y, además, fue su director en 1925. En sus escritos, Mendieta muestra el peso de la influencia de Gamio, de la antropología, la etnografía, así como la convicción de que el conocimiento científico de los indígenas mexicanos era imprescindible para encontrar formas eficientes de lograr su desarrollo e inserción en el progreso nacional (Mendieta, 1925, p. 46). Este nexo intelectual, personal organizativo e institucional, sin duda, tuvo entre sus consecuencias más relevantes, la fundación de la Revista Mexicana de Sociología bajo el modelo de comunicabilidad aportado por Ethnos.

\section{Revista de Ciencias Sociales (1922)}

Dos años después de la fundación de Ethnos nació otra importante publicación antecesora, específicamente en el espacio institucional del derecho: la Revista de Ciencias Sociales (RCS), auspiciada por las autoridades de la Escuela Nacional de Jurisprudencia (ENJ) de la Universidad Nacional. El primer número se publicó en 1922, bajo la iniciativa y dirección de Daniel Cosío Villegas y un consejo de redacción formado por profesores y alumnos. Al igual que ocurrió con Ethnos, la RCS buscó promover estudios sociales de la realidad social mexicana: medio geográfico, raza, población, división del trabajo y educación. Se intentó conocer objetivamente la especificidad nacional, en un contexto en el que había un gran desconocimiento de las estructuras y procesos que definían los condicionamientos y problemas que enfrentaba un país embarcado en un proceso acelerado de transformaciones de diverso signo.

Esta publicación trató de llamar la atención sobre la necesidad de generar "con tenacidad patriótica" (Caso, 1922, p. 1) un saber sobre lo propio, alejado de la abstracción generalizante y, paralelamente, contribuir al reconocimiento de que uno de los problemas fundamentales que enfrentaba este tipo de investigaciones, era asegurar el acceder al conocimiento acumulado por las ciencias sociales en Europa y Estados Unidos. Estos líderes fundadores sabían bien que las ciencias que buscaban instaurar a nivel local no comenzaban de cero y desplegaron grandes esfuerzos para crear condiciones favorables para la recepción de estos legados. En este sentido debe entenderse, por ejemplo, la colaboración de Daniel Cosío Villegas en el primer número, orientada a proveer a los abogados que presumiblemente habrían de salir del mundo de los expedientes jurídicos y 
estudiar la sociedad mexicana, de una bibliografía especializada en la que figuraban obras de Giddings, Rousseau, Durkheim, Spencer, Tarde, Ward, Bouglé, entre otros autores relevantes de la época (Cosío, 1922). Durante su primer año, en la RCS se publicaron pequeños escritos sobre el sistema constitucional, la psicología del movimiento obrero, el subsuelo, las reformas al código civil, todos ellos abordados, sin duda, en un registro juridicista. Sin embargo, se pueden identificar ya desde entonces ramificaciones discursivas que, menos de una década después, conducirían a la formación - desde la matriz del derecho- de la economía y la sociología como ciencias formalmente independientes con un cobijo institucional propio.

La vida de la RCS estuvo cruzada por avatares financieros y prácticos constantes, por lo que la publicación de cada número representó grandes dificultades; su último número salió a la luz en 1933. Pese a su corta trayectoria, su contribución al desprendimiento de la economía y de la sociología del tronco de la jurisprudencia fue fundamental para el inicio de su proceso de instauración como campos de conocimiento independientes, precisamente en la década de los años treinta del siglo XX (Toledano, 1929; Rivera, 1927; 1930). La RCS promovió constantemente la idea de que era necesario extender con celeridad el campo de las investigaciones relativas a las condiciones sociales, económicas, criminológicas y jurídicas del país, a fin de obtener un conocimiento racional coherente, dirigido sistemáticamente a su mejora (Bach, 1929). En este sentido, puede afirmarse que una de sus principales aportaciones a las revistas especializadas que surgieron pocos lustros después, fue la difusión de la convicción de que el conocimiento tenía que ser especializado, no generalizante, si pretendía tener utilidad para el país. Otro más, fue el estímulo a la formación de una cultura abierta a la esfera pública, centrada en la escritura, junto con la formación de un líder y fundador de instituciones y publicaciones, como Daniel Cosío Villegas, cuyos cursos de sociología mexicana de los años veinte en la ENJ, por ejemplo, se fraguaron, en buena medida, en paralelo a su impulso a esta publicación.

\section{Revista Mexicana de Economía (1928)}

La Revista Mexicana de Economía (RME), al igual que las anteriores, surge con la intención de formar un ambiente intelectual y político en el que fuese posible el reconocimiento de la necesidad de investigar científicamente los problemas económicos y sociales concernientes a un ámbito que se definió normativamente como nacional. Esta publicación nació como órgano informativo del Instituto Mexicano de Investigaciones Económicas (IMIE), creado por sugerencia 
de Alfons Goldschmidt en 1928.7 Formaron parte de esta institución, Jesús Silva Herzog, Antonio Espinosa de los Monteros, Eduardo Villaseñor, Manuel Gómez Morín y muchos otros importantes promotores de la ciencia económica en México. La RMS se funda en 1928, bajo la dirección de Jesús Silva Herzog, como un medio de sociabilidad intelectual orientado a formar un saber económico experto, informado empíricamente y deslindado de la improvisación y la falta de cálculo. Silva estaba convencido de que la mayor parte de los problemas que México había tenido a lo largo de su historia, incluida la revolución de 1910, se debían a un desconocimiento de la realidad económica, a la ausencia de un saber científico sobre las condiciones reales del pueblo. A diferencia de las revistas mencionadas antes, la RME contó con un formato más profesional, colaboraciones que abordaban en profundidad temas como el ejido, la reforma agraria, la industria, la lucha mundial por el petróleo, banca, moneda, o bien, el problema de la colonización de zonas nuevas y el indio. Se buscó realizar investigación de "primera mano", a fin de avanzar en la construcción de una economía científica moderna útil para el progreso del país y la formación de una nación homogénea. ${ }^{8}$ Daniel Cosío Villegas aportó, como había hecho en la RCS, la identificación de acervos de conocimiento textuales, bibliografías, reseñas y traducciones que facilitaron, posteriormente, la creación de la carrera de economía, así como la formación de publicaciones de mayor alcance, como El Trimestre Económico (1934).

El propósito central de esta publicación, de corta vida pero gran influencia programática, fue la publicación de estudios sobre los problemas económicos de México que exigían la más urgente resolución, y paralelamente, propagar la lectura de obras económicas, para despertar interés por esta clase de estudios (Silva Herzog, 1928). La construcción del futuro de México requería de un conocimiento integral de las relaciones económicas, de un conocimiento concreto y local acumulable, pero referido obligadamente a las contribuciones de la ciencia económica a nivel internacional. En este sentido, la influencia de Alfons Goldschmidt permite comprender la relevancia

7 Intelectual alemán, socialista, judío, profesor de la Universidad de Leipzig. José Vasconcelos lo conoce en Argentina y lo invita a México. Fue profesor de Jesús Silva Herzog a principios de la década de 1920 y, junto con Fritz Bach, una importante influencia en la institucionalización de la economía como profesión universitaria en México e introductor del estudio de la economía política marxista en la Universidad Nacional en los años veinte (López de la Parra, 2009).

8 Los economistas de la época, al igual que los antropólogos, etnógrafos y abogados-sociólogos, estaban convencidos de que la integración de los indígenas a la nación era una condición indispensable para el progreso de México (Villaseñor, 1928). La importancia de esta temática en la RME puede constatarse en el hecho de que, de 27 trabajos publicados en su único año de vida, nueve se dedicaron al problema de los indios y su relación con la cuestión agraria. 
de las tradiciones disciplinarias de Europa y Estados Unidos en la instauración de formas de sociabilidad intelectual de corte escriturario, como las representarían las revistas especializadas, como condición para la institucionalización de las ciencias sociales en México.

En el primer número de la RME, Jesús Silva Herzog, afirmó que los errores que se había cometido en el país desde 1821 tenían su origen en el desconocimiento de la realidad económica, es decir, en la falta de un conocimiento científico sobre las condiciones reales del pueblo. Destacó la importancia de que la economía se convirtiera en un campo capaz de producir un saber racional que contribuyera a la solución de los principales problemas de la nación: una producción agrícola insuficiente y magra, por una parte, y el problema de la elevación del indio, por otra. Lo efímero de esta publicación se debe, en buena medida, a que sus fundadores estaban llamados a ser hombres de acción, constructores de instituciones y formadores de varias generaciones de profesionistas. No obstante, su gran aportación fue lograr el reconocimiento de la importancia de un conocimiento especializado y situado de lo propio, así como de la recepción y transmisión internacional de saberes para el desarrollo de las ciencias sociales a nivel local, como disciplinas y como profesiones universitarias. No obstante, debe señalarse que la apertura de la RME a los saberes de la ciencia económica a nivel mundial, en realidad se limitaron a aquellos acervos de conocimiento que fueron compatibles con la convicción de que la ciencia económica debía ser una ciencia de estado al servicio de la nación, más que una disciplina autónoma en sentido estricto.

Una de las consecuencias prácticas más relevantes de la RME fue la apertura de la Licenciatura de Economía, dentro de la sección correspondiente en la Escuela Nacional de Jurisprudencia, en 1929. Muchos de los miembros del comité editorial de la revista fueron también responsables de la elaboración del proyecto para esta nueva carrera y de los planes y programas de estudio que la articularían en su primera etapa. Estos planes, al igual que en el caso de la sociología y las ciencias sociales en la Escuela Nacional de Ciencias Políticas y Sociales (1951) se inspiraron inicialmente en los de las universidades europeas, con algunas adaptaciones locales debidas precisamente al grupo que estuvo detrás de la RME. La discusión sobre la necesidad de economistas profesionales comenzó abiertamente en algunos artículos y notas publicados en sus páginas. La economía (así como la sociología) se proyectó como ciencia de estado permeada por tareas práctico-políticas comprensibles únicamente en el horizonte de la historia efectual de la revolución mexicana y el nuevo régimen.

Debe señalarse que entre el grupo que dio pleno apoyo a la RME se encontraban, con frecuencia, profesionistas e intelectuales que tuvieron una doble adscripción: ocupaban puestos en la administración pública y, paralelamente, eran docentes de la Universidad Nacional, típicamente 
de la ENJ, como Ramón Beteta, Luis Chico Goerne, Luis Sánchez Pontón, Miguel Othón de Mendizábal, Antonio Espinosa de los Monteros, entre muchos otros. Esta doble posición, muestra el incipiente grado de especialización del saber económico en esos años; por otro lado, permite ver también las relaciones entre conocimiento y poder público que respaldaron las etapas de institucionalización inicial de la economía en México.

De los principales logros de la RME destaca el esbozo de un primer proyecto de ciencia económica en México que incluyó la necesidad de contar con literaturas especializadas, por lo que se consideró urgente la ruptura con el conocimiento lego e improvisado para dar lugar a saberes expertos. El saber especializado era imprescindible para explicar la complejidad de los procesos económicos en marcha en México y en el mundo; a juicio de los editores de la RME, este saber tendría la función de desentrañar estos procesos, con todas las consecuencias prácticas que ello implicaba para el proyecto de modernización de las estructuras económicas que se había puesto en marcha desde los años veinte en México. La aportación principal de la RME fue, en este sentido, de corte programático, tanto en el ámbito de la economía como campo de conocimiento especializado, como en el relativo a sus vínculos con el poder público que fueron su condición de posibilidad y justificación práctico-política.

\section{El Trimestre Económico (1934)}

Por su parte, El Trimestre Económico, aun siendo revista tiene rasgos que muestran que surge, en realidad, con un estatus paralelo de revista orientada a la especialización; sus promotores fueron Daniel Cosío Villegas, Antonio Espinosa de los Monteros, Miguel Palacios Macedo y Manuel Gómez Morín, principalmente.

La estructura de la revista estaba conformada por una sección de notas editoriales seguida del cuerpo de las colaboraciones, de un apartado de crítica de libros y, finalmente, de una sección llamada "Libros recientes de economía", que consistía en una larga lista de trabajos especializados publicados (en su abrumadora mayoría) en lenguas extranjeras: inglés, francés, alemán, italiano y ruso. En este primer número, la lista comprendió casi ochenta libros, clasificados en materias que indican qué se consideraba significativo y digno de darse a conocer a nivel local en materia económica: teoría, historia y geografía, agricultura y minería, industrias de la transformación, transportes, comercio y crisis, trabajo y organización capitalista, trabajo y organización obrera, moneda y banca, finanzas y aranceles, problemas sociales, pensiones y seguros, estadísticas y, finalmente, socialismo. Si tomamos en cuenta que cualquier criterio de clasificación se desprende de determinada representación del conocimiento y de los problemas político-prácticos que se consideran 
relevantes en un horizonte espacio-temporal específico, podemos afirmar que en la elaboración de la lista de libros operó, tanto la experiencia y la decisión individuales, como los condicionamientos societales propios de los procesos de modernización económica que experimentaba el país en ese tiempo. Rubros como trabajo y organización obrera o problemas sociales y socialismo dan cuenta de ello.

Una característica de El Trimestre Económico, desde sus inicios, fue la apertura a acervos de conocimiento especializado, teórico y metodológico, originado en otros países. En el primer número aparecen en la lista de colaboradores Frank Tannembaum, Clarence H. Herring, Abbot P. Usher, de las Universidades de Washington y Cambridge, con lo cual podemos ver las expectativas que abrigaron sus fundadores respecto de las posibilidades que tenía la ciencia económica en México de abrevar de los patrimonios de conocimiento más reconocidos de la época. Otro aspecto que es evidencia de la claridad que los promotores de esta revista tenían sobre las coordenadas metanacionales de la economía, es el tipo de temas de los que se ocuparon. Por ejemplo, también en el primer número, apareció la nota "Los caminos internacionales de México" (El Trimestre Económico, 1934), en este escrito se reflexiona sobre la carencia de una opinión pública local en materia internacional y sobre la dirección incongruente, cuando no francamente caprichosa, de la política internacional del país. Más allá del contenido específico al respecto, vemos aquí un trazo discursivo que se proponía llamar la atención sobre el hecho de que la economía mexicana estaba ubicada en un contexto inter-nacional en el que los derroteros del país estaban condicionados por la vecindad con uno de los países más fuertes del mundo y con el que nuestro país mantenía densas interdependencias. La conciencia espacial, fronteriza y territorial a la que se hace alusión, iba más allá de la defensa de lo propio que encontrábamos en las páginas de la RME. En El Trimestre Económico se advierte una mira de mayor alcance: se llama a desarrollar cuanto esfuerzo fuese necesario para integrar la economía mexicana a la inevitable trama de la economía mundial.

En sus primeros números, las temáticas analizadas fueron los planes sexenales de gobierno, el nuevo código agrario, el comercio exterior en México, la controversia monetaria en la economía, las teorías de la deflación, la habitación de los obreros en Inglaterra, la producción del arroz en México. Se difundió una gran cantidad de información sobre la literatura especializada de la economía como ciencia en Estados Unidos y Europa. De hecho, dos de sus secciones se dedicaron a ello: "Crítica de libros" y "Libros recientes de economía". Esta revista formaba parte del esfuerzo de gran aliento emprendido, sobre todo por Daniel Cosío Villegas -quien hacia finales de la década de los años treinta contaba con estancias de estudios en las Universidades de Harvard y Cornellpara que México tuviera acceso a libros básicos para la formación de los estudiantes de economía 
que, en general, llevaban adelante sus cursos con notas escritas por sus profesores. ${ }^{9}$ La principal contribución de esta revista en sus primeros años fue la creación de acervos de conocimiento textuales: la difusión de una literatura especializada de alcance internacional dirigida selectivamente a producir un conocimiento científico de lo propio; el fomento de una cultura económica con capacidad de orientación de los proyectos de empresas, bancos, industriales y gobierno, así como la articulación de procesos de transmisión internacional de conocimiento que fortalecerían a la economía como disciplina y como profesión en los años siguientes.

Una contribución de El Trimestre Económico, que merece una mención aparte, fue la apertura a las obras clásicas y contemporáneas más importantes de la época a través de la traducción de notas, ensayos, reseñas, publicación de listas de libros recientes en inglés, alemán, francés, ruso e italiano (y más tarde, de la traducción de obras capitales de teoría económica a través del Fondo de Cultura Económica). El proyecto editorial que comenzó a forjar Daniel Cosío Villegas desde finales de los años veinte, cuando dirigió la Sección de Economía de la ENJ que cobijó inicialmente la Licenciatura en Economía, comenzó a cristalizar en resultados que tendrían un gran alcance en el tiempo, principalmente con esta revista, pero también con la fundación del Fondo de Cultura Económica, pocos meses después de la aparición de su primer número.

\section{Revista Mexicana de Sociología (1939)}

El caso de la Revista Mexicana de Sociología (RMS) tiene un horizonte temporal distinto a las publicaciones anteriores. El primer tramo de su historia es mucho más conocido que el de las publicaciones descritas antes y solo lo referiremos de forma sucinta. Se funda nueve años después de la apertura del Instituto de Investigaciones Sociales (IIS) de la Universidad Nacional (1930), cuando Lucio Mendieta y Núñez asume su dirección. Es pertinente recordar que el director inmediatamente anterior a Mendieta había sido Manuel Gamio, del que fue discípulo y colaborador, como se mencionó en el apartado dedicado a la revista Ethnos. Esta influencia tuvo un peso fundamental en el hecho de que uno de los primeros objetivos de Mendieta fue promover la investigación social y antropológica sobre los problemas de la nación y hacer públicos sus resultados, a fin de que las políticas de gobierno contaran con insumos cognitivos útiles para resolverlos. En los hechos, esto se tradujo en un vuelco hacia el estudio de la heterogeneidad étnica de la población en el IIS que, en realidad, había comenzado desde los años veinte. Si los economistas pensaron en elevar

$9 \quad$ Para ello se fundó el Fondo de Cultura Económica, también en 1934, en cuya Junta figuraron Gonzalo Robles, Manuel Gómez Morín, Eduardo Villaseñor, Emigdio Martínez Adame, Adolfo Prieto y el propio Daniel Cosío Villegas. 
al indio, disolviéndolo, los abogados-sociólogos que echaron a andar la RMS hicieron una tarea equivalente en un campo difuso en el que la antropología, la etnografía y la criminología fueron fundamentales para plantear el objetivo de estudiar y describir a los indígenas de México e integrarlos a una imaginada nación homogénea.

El IIS y la RMS son inseparables del liderazgo de Lucio Mendieta durante el periodo que abarca de 1939 a 1965; este dilatado liderazgo, por cierto, ha sido el más largo en la historia de la sociología en México. Cuando Mendieta llega a la dirección del IIS se encuentra con sólo dos investigadores, una secretaría, nula investigación, pero con la herencia programática dejada por Manuel Gamio en los seis meses que fue director de este espacio formal de investigación en 1938. A Mendieta se deben los primeros ejercicios de investigación empírica en el IIS, los primeros intentos de formación de una comunidad de practicantes de la sociología en México y la formación de una literatura propia, precisamente alrededor de la RMS fundada por él.

La RMS formó parte del plan de reorganización del IIS que llevó a cabo Mendieta y Núñez. Se buscó la formación de nuevos cuerpos de conocimiento, estimular la investigación sociológica en el país, dar a conocer estudios sociológicos "modernos" de Europa y América Latina, promover intercambios con las distintas instituciones de cultura dedicadas al cultivo de las ciencias sociales. Hubo aquí una clara orientación hacia la investigación, a diferencia de la RME y El Trimestre Económico, que centraron sus esfuerzos, sobre todo, en la formación de economistas profesionales. La sociología en México habría de esperar dos décadas más para contar con su primer programa universitario de formación de sociólogos, en 1951, es decir, veinte años después que el caso de la economía.

En el primer número de la RMS, Mendieta (1939) enuncia claramente que los propósitos de la revista eran dar a conocer trabajos de investigación que tendieran a "encontrar las fórmulas de acción adecuadas para resolver los problemas sociales más importantes del país" (p. 3). Mendieta abogó por un deslinde del empirismo político y su sustitución por un conocimiento experto, fundado en la ciencia; las publicaciones universitarias especializadas serían la herramienta para romper con la cultura oral que implicaba el conocimiento lego (Mendieta, 1939). En este sentido, la RMS se dirigió a promover formas de comunicabilidad intelectual centradas en la escritura de textos propios y en la publicación. Esto, sin embargo, no tuvo equivalencia en las formas de organización: a diferencia de la RME y de El Trimestre Económico, la RMS fue dirigida unipersonalmente y no hay reconocimiento alguno al trabajo editorial de sus colaboradores cercanos en sus páginas, como tampoco hubo consejo de redacción o alguna entidad de este tipo. 
Mendieta asumió que tanto el IIS como la RMS, y la Universidad Nacional misma, debía ponerse al servicio de la vida pública a través de la generación de prácticas útiles para la sociedad. Bajo esta orientación normativa, compartida por funcionarios universitarios, principalmente ligados de origen a la Escuela Nacional de Jurisprudencia, muchos de ellos ubicados en las estructuras del poder público, fue posible la existencia de la RMS.

En el primer número se anunció la Exposición Etnográfica de la Universidad Nacional que se planeaba presentar hacia finales de 1939, como "una contribución a la obra indigenista del presidente Cárdenas". En este texto, se delineó lo que sería la tendencia temática de la revista durante toda la década de los años cuarenta: el estudio de los indígenas. Se afirmó que, a pesar de innumerables trabajos de investigación de intelectuales mexicanos y extranjeros sobre las razas indígenas, la "esencia" del indio estaba pendiente de investigación. Los trabajos de descripción emprendidos por el IIS durante los años cuarenta y publicados en la RMS encuentran aquí su origen programático. Para tratar de colmar este vacío, se publicaron trabajos descriptivos sobre la demografía, las características tipológicas, la criminalidad, la religión, las costumbres y la educación de las poblaciones indígenas de México.

El primer número incluyó también reseñas bibliográficas de materiales sobre salubridad y demografía, derecho constitucional en México, el concepto marxista del derecho, así como una nota sobre Maurice Halbwachs. Puede verse una variedad de campos de conocimiento que son indicador de la amalgama de saberes que convivieron en la RMS con los enfoques antropológico, etnográfico y criminológico de los que se desprendería posteriormente la sociología como una disciplina autónoma. Los números que completaron el primer año de esta publicación incluyeron los trabajos presentados en el Congreso Internacional de Americanistas, celebrado en México, monografías sobre distintos aspectos de la vida de los Huastecos, notas sobre el servicio social en la Facultad de Medicina, entre otros materiales. Las temáticas, escalas de observación, consideraciones normativas, formatos y propósitos de la RMS en esta primera etapa, muestran claramente la huella de la influencia de Manuel Gamio y de Ethnos. Nociones como pueblo, raza y nación permearon los contenidos de la RMS en su primera década como conceptos simultáneamente normativos y colectivos que justificaron un conocimiento sociológico, difuso, impreciso, pero al que se debe el reconocimiento público de la pertinencia científica y práctico-política del cultivo de la sociología, no sólo en México, sino también en América Latina. Como en el caso de El Trimestre Económico, la RMS fue un medio de institucionalización, pero con el tiempo se convirtió en una institución en sí misma, puesto que su vida abarca ya 80 años de publicación ininterrumpida y un patrimonio de conocimiento escriturario que es, potencialmente, un amplio campo de investigación empírica para la historia de la sociología y las ciencias sociales en nuestro país y en América Latina. 


\section{Ciencias Políticas y Sociales (1955)}

Ciencias Políticas y Sociales (actualmente Revista Mexicana de Ciencias Políticas y Sociales de la UNAM) se funda en 1955, cuando egresan los primeros licenciados en Ciencias Sociales, Ciencias Diplomáticas, Ciencias Políticas y Periodismo de la Escuela Nacional de Ciencias Políticas y Sociales (ENCPyS), cuyas puertas habían sido abiertas en 1951. Al igual que otras revistas universitarias, como la Revista de Investigación Económica (1942) de la Escuela Nacional de Economía, Ciencias Políticas y Sociales fue pensada fundamentalmente como un instrumento útil para la formación profesional. Sus principales objetivos fueron ser un medio de socialización intelectual específicamente orientado a profesores y estudiantes; promover la elaboración de textos propios entre ellos; contribuir a la formación de una cultura de corte escriturario que pudiese sustituir, paulatinamente, el registro oral alrededor del cual giraba la habilitación de los futuros científicos sociales de México en los años cincuenta.

Los orígenes de Ciencias Políticas y Sociales están asociados a la publicación de una revista estudiantil que, bajo el mismo nombre, editaron Óscar Uribe Villegas ${ }^{10}$ y Gustavo Leyva Ochoa en 1953, con la finalidad de que la comunidad estudiantil contara con un medio de difusión escrita de sus experiencias y aprendizajes. El formato de esta publicación partió de la organización de las carreras de la propia ENCPyS, como lo muestran sus secciones: Sociología, Política, Diplomacia, Periodismo, junto con espacios destinados a la difusión de información general sobre literaturas especializadas relativas a estas disciplinas. El primer número incluyó colaboraciones del primer director de la ENCPyS, Ernesto Enríquez Coyro, de Lucio Mendieta y Núñez, Ramón Santoyo, Wigberto Jiménez (director del Museo Nacional) y de Horacio Labastida. Esta revista estudiantil fue impulsada por Raúl Carrancá y Trujillo, director de la escuela quien, tras conocer la anuencia de la UNESCO al respecto, redefinió esta publicación de origen estudiantil para darle el estatus de órgano informativo de aquella.

El aval recibido por la UNESCO fue fundamental para dar certeza institucional a la revista Ciencias Políticas y Sociales en su etapa fundacional. El contexto práctico en el que fue posible que prosperara esta iniciativa editorial fueron los proyectos que, desde finales de los años cuarenta, emprendió este organismo internacional para promover las ciencias sociales a niveles locales. Sólo

10 Poco después, Óscar Uribe Villegas, como estudiante de la carrera de Ciencias Sociales, fue reclutado como profesor de estadística; posteriormente, fue cercanísimo colaborador de los dos líderes más importantes que han tenido las ciencias sociales en México: Lucio Mendieta y Núñez y Pablo González Casanova, así como integrante del Instituto de Investigaciones Sociales. Junto con ellos, forma parte del trío de autores más prolíficos de la RMS a lo largo de toda su historia. 
en este horizonte se puede comprender adecuadamente el impulso que recibieron las instituciones que, ya desde los años treinta, se orientaron al cultivo de éstas en México, como el IIS y la RMS. Tanto la fundación de la ENCPyS, como de su propia revista, forman parte de un amplio y complejo entramado intergeneracional en el que se entrecruzan nuestras propias herencias intelectuales locales, como las provenientes de los centros para los cuales la producción regular de saberes científicos sobre sus propias sociedades y la formación de profesionales de las ciencias sociales eran en esa época realidades presentes y no, como para nosotros, expectativas de futuro orientadoras de proyectos, más que realidades factuales.

Ciencias Políticas y Sociales significó la apertura de un espacio editorial estable en el que se publicarían colaboraciones que mostrarían a la comunidad practicante de las ciencias sociales en México, a funcionarios, a la propia comunidad universitaria y a la opinión pública, el tipo de saberes que producían los profesores y los egresados de la ENCPyS, la primera institución del país encargada de formar licenciados en las diversas disciplinas sociales. En este primer tramo, la revista estuvo orientada a la promoción del trabajo de sus egresados como un saber experto, superior al conocimiento lego y, en consecuencia, indispensable para la identificación y análisis de los principales problemas de México. A diferencia de la RMS, esta publicación contó desde el principio con un Consejo Técnico que incluyó tanto a profesores, como a algunos alumnos y representantes de éstos ante el Consejo Universitario, entre ellos, el primer titulado de la ENCPyS, Moisés González Ochoa Campos. El Comité Editorial, a su vez, estuvo formado por el director de la escuela Raúl Carrancá y Trujillo y por el profesor José Carrillo. En realidad, el responsable de la mayor parte del trabajo implicado en la publicación quedó en manos del abogado Enrique González Pedrero.

La aparición de Ciencias Políticas y Sociales, como publicación académica especializada, representó un esfuerzo de institucionalización de la enseñanza de las ciencias sociales enorme. Las colaboraciones trataron de mostrar que la promesa que forjó los lazos entre saber y poder que presidió la institucionalización de las ciencias sociales como profesiones universitarias, estaba en camino de su cabal realización. Este efecto de sentido, en general, puede decirse que se cumplió, aunque la realidad de sus contenidos estaba aún lejos de un saber empírico sobre la realidad nacional del que tanto se hablaba. Lo que indudablemente estuvo presente desde el inicio, fue un programa para el futuro desarrollo de las ciencias sociales en México que dio aliento a la consolidación institucional de la ENCPyS durante la década de los años sesenta del siglo pasado; esta consolidación fue la base experiencial profesional y disciplinar interna que dio sustento a la multiplicación de programas universitarios dirigidos a la formación de científicos sociales en los años setenta del siglo XX. 


\section{Nota final}

La justificación político-práctica de la existencia de las revistas antecesoras fue la aceleración del progreso de la patria, la integración de una nacionalidad homogénea capaz de dar dirección y sentido a la acción colectiva, la civilización de los indios y, en general, generar un conocimiento útil para el cumplimiento del programa social de la Constitución de 1917. En este sentido, puede afirmarse que su existencia, forma parte de la historia de los efectos de la Revolución de 1910. Estos esfuerzos editoriales formaron parte de una cadena de aprendizaje y experiencia histórico-social que sabemos se remonta, al menos, al último tercio del siglo XIX y principios del XX. Los logros de antecesores de la etapa pre-institucional de estas ciencias abrieron horizontes cognitivos en los que germinó la idea de que, sin un conocimiento cabal de los problemas sociales, económicos y políticos del país, éste no podría resolver su atraso ni plantearse como una nación moderna viable. En este sentido, las revistas pioneras examinadas fueron, a su vez, legatarias de experiencias previas que recondujeron hacia horizontes de expectativas que abonaron el terreno en el que surgieron las primeras revistas especializadas de la sociología y las ciencias sociales en México como sus sucesoras directas.

Estas revistas antecesoras aportaron la base normativa sin la cual no habría sido posible ni la aparición de las revistas especializadas, ni la institucionalización de las ciencias sociales en México en los términos en los que tuvieron lugar. En este sentido trataron, en primer lugar, de Ilamar la atención en la esfera pública del carácter imprescindible de un saber científico sobre los problemas del país, así como sobre la realidad de su inexistencia a nivel local y la consecuente necesidad de abrir espacios para producirlo. En términos temáticos, buscaron sumar al indígena como cifra positiva a los valores económico-sociales que estaban por detrás del proyecto de modernización posrevolucionario, para lo cual era necesario promover estudios empíricos que pudieran ofrecer un conocimiento detallado del conjunto de sus condiciones de vida y de las tradiciones culturales que, al menos parcialmente, las orientaban y les daban sentido. Pero el problema de la integración cultural era advertido como crucial para poder integrar una nacionalidad homogénea. Se planteaba entonces una tarea paradójica: por una parte, incorporarlos a una presunta cultura nacional y, por otra, lograrlo sin que perdieran sus legados, concepciones y aspectos válidos de su existencia -sin aclarar cuáles eran éstos-. Y, para ello, se consideraba imperiosa la investigación científica.

A nivel normativo, la defensa de la necesidad de un pacto social, el reconocimiento de nuevos actores, la defensa de lo propio, el saber científico como orientador de la acción y la devaluación del empirismo, la improvisación y la falta de planeación, fueron las señas de identidad de estas publicaciones pioneras. Desde un punto de vista disciplinar, aportaron un diagnóstico 
societal y un esbozo de lo que podían y debían ser las ciencias sociales en México, así como sus propósitos prácticos. Remontar el atraso implicado en tal diagnóstico, suponía romper con un pasado de improvisación para dar fundamento técnico al programa social emanado de la Revolución. La comprensión del tiempo histórico en el universo de los contenidos de estas publicaciones era moderna, en el sentido de que a nivel metadiscursivo sus textos estaban atravesados por la idea de que el pasado estaba devaluado, el presente urgía a la acción y el futuro aparecía promisorio, siempre y cuando se le construyera con base en el conocimiento científico de los hechos de la propia realidad. En este sentido, puede afirmarse -sociológica e historiográficamente hablandoque estas publicaciones son claramente antecesoras de las revistas especializadas que lograron permanencia y conformaron legados intelectuales de largo alcance y que contribuyeron decisivamente a la institucionalización de la economía en México. Esto puede constatarse en los casos de publicaciones especializadas en México que son, simultáneamente, acervos de conocimiento escriturario especializado acumulado e instituciones de conocimiento, como El Trimestre Económico, Revista Mexicana de Sociología y la actual Revista Mexicana de Ciencias Políticas y Sociales. Todas, en mayor o menor medida, incorporan en sus modelos de comunicabilidad, formatos, temas, escrituras y conceptos, elementos que sin duda proceden del espacio de experiencia de las revistas antecesoras.

Aunque no fue analizado aquí el perfil de las publicaciones especializadas contemporáneas de la sociología y las ciencias sociales en México, el trazo hecho en este trabajo plantea coordenadas que son necesarias para su investigación como parte de esta cadena intergeneracional de acumulación de universos escriturarios, independientemente de que las radicales transformaciones que ha experimentado en los últimos veinte años su fisonomía, formato, tipos de escritura, soportes materiales, transmisión digital, etc., parecieran otorgarles un estatus desvinculado del espacio de experiencia anterior. No es posible comprender sociológicamente las modalidades contemporáneas de las revistas especializadas examinándolas sincrónicamente, es decir, en una lógica presentista; deben investigarse reconociendo plenamente su estatus de herederas de legados previos, sin los cuales les sería imposible innovar. Un saber de este tipo, podría favorecer una autocomprensión mayor de nuestras instituciones y prácticas, así del papel central que en la actualidad tiene la publicación de artículos individuales en revistas especializadas, por encima de la correspondiente a libros, capítulos de libros y otro tipo de escritos. Esta tendencia, a la vez, es indicador de un tipo de desarrollo disciplinar que aún no entendemos en todas sus dimensiones, pero que, desde una perspectiva diacrónica, debe observarse como parte del eslabón más reciente de nuestra cadena antecesores-contemporáneos-sucesores. 


\section{Referencias}

Bach, F. (1929). Los problemas de México. Revista de Ciencias Sociales, VIII(1), 65-68.

Caso, A. (1922). Los estudios sociales. Revista de Ciencias Sociales, 1(1), 1-2.

Cosío, D. (1922). Bibliografía sociológica. Revista de Ciencias Sociales, 1(1), 24-30.

Durán, N. (2017). Francois Hartog, la historia y el presentismo del presente. En Epistemología histórica e historiografía (pp. 257-290). México: UAM-A.

El Trimestre Económico. (1934). Notas Editoriales. Los caminos internacionales de México. El Trimestre Económico, 1(1), 3-13.

Ethnos (1920). Introducción. Ethnos, 1(1), 1-2.

Gamio, M. (1916). Forjando Patria. México: Porrúa.

Hartog, F. (2007). Regímenes de historicidad. México: Universidad Iberoamericana.

Koselleck, R. (1993). Futuro pasado. Barcelona: Paidós.

Koselleck, R. (2004). historia/Historia. Madrid: Trotta.

Koselleck, R. (2012). Historia de conceptos. Madrid: Trotta.

López de la Parra, M. (2009). El pensamiento económico y político de Alfons Goldschmidt. México: UNAM.

Mendieta, L. (1925). Importancia científica y práctica de los estudios etnológicos y etnográficos. Ethnos, 1(3-4), 43-46.

Mendieta, L. (1939). El Instituto de Investigaciones Sociales de la Universidad Nacional. Revista Mexicana de Sociología, 1(1), 3-18.

Moya, L., \& Olvera, M. (2016). Cien años de Estudios Sociológicos. Itinerarios intelectuales y acervos de conocimiento. 1983-2014. Estudios Sociológicos XXXIV(número conmemorativo), 7-63.

Olvera, M. (2016). La etapa inicial de la Revista Mexicana de Ciencias Políticas y Sociales a 60 años de distancia. Prácticas conmemorativas, legados, olvidos y nuevos pasados-presentes. Revista Mexicana de Ciencias Políticas y Sociales, LXI(226), 427-456.

Olvera, M. (2018). Los entramados de la experiencia nacional e internacional. Lucio Mendieta y Núñez, el IIS y los Congresos Nacionales de Sociología. En H.J. Suárez (Coord.), El Instituto de Investigaciones Sociales en el espejo: Conmemoración del 85 aniversario (pp. 59-106). México: IIS/UNAM.

Rivera, J. (1927). Las nuevas orientaciones de la Facultad de Derecho y Ciencias Sociales. Revista de Ciencias Sociales, IV(5), 47-49.

Rivera, J. (1930). Plan de reforma de la Facultad de Derecho y Ciencias Sociales. Revista de Ciencias Sociales, I(4), 111-148. 
54 - Capítulo II

Rüsen, J. (2014). Tiempo en ruptura. México: UAM-A.

Silva Herzog, J. (1928). Nuestros puntos de vista. Revista Mexicana de Economía, (1), 1-4.

Toledano, L. (1929). La Facultad como centro de investigación científica. Revista de Ciencias Sociales, VIII(1), 65-68.

Schutz, A. (1972). La fenomenología del mundo social. Buenos Aires: Paidós.

Villaseñor, E. (1928). Las zonas nuevas y el indio. Revista Mexicana de Economía, (1), 37-51. 


\section{Capítulo III}

Hacia una "sociología de la sociología" en la Universidad de Guadalajara: notas desde el itinerario institucional

Adrián Acosta Silva*

* Profesor investigador, Instituto de Investigaciones en Políticas Públicas y Gobierno, Centro Universitario de Ciencias Económico-Administrativas (CUCEA), Universidad de Guadalajara. Integrante del Sistema Nacional de Investigadores. Contacto: aacosta@cucea.udg.mx 


\section{Introducción}

Nunca es fácil reconstruir la trayectoria de una profesión, una disciplina o una carrera universitaria. La escasa disponibilidad de fuentes confiables y datos básicos, la ausencia de informes institucionales, de relatos y memorias de fundadores o protagonistas de los hechos, constituyen siempre obstáculos importantes para la explicación de un proceso de suyo complejo, multidimensional, contradictorio y errático. Estas notas intentan aportar algunos datos, hipótesis y conjeturas en torno a un caso específico -el desarrollo de la sociología en una universidad pública mexicanamirado desde la perspectiva del "itinerario institucional" de esa disciplina a través de cuarenta años de su desarrollo (1977-2017), que se combina con una perspectiva típicamente sociológica, es decir, desde la observación y el análisis de cómo las ideas y los intereses, los contextos y las coyunturas institucionales, los actores y sus prácticas, configuran parte de la trayectoria de una disciplina académica en una universidad pública estatal. Esta doble perspectiva confluye en el propósito de desarrollar un esfuerzo de análisis de las dimensiones sociológicas del itinerario institucional, que pretende contribuir a la construcción de una suerte de "sociología de la sociología" en la Universidad de Guadalajara (UdeG) durante los primeros cuarenta años de su existencia institucional.

El capítulo parte del postulado básico de que toda explicación sociológica es siempre una explicación causal de los fenómenos sociales y esa explicación ayuda a comprender de mejor manera los dilemas y las tensiones de la trayectoria posterior de los fenómenos, donde la "complejidad causal" constituye siempre una característica central de sus procesos (Elster, 2010). La distinción entre hechos (o sucesos) y acontecimientos es fundamental para desarrollar esta perspectiva explicativa basada en la identificación de los mecanismos causales de la acción. Desde esta perspectiva, la fundación de la carrera de Sociología, que anticipa la institucionalización de la disciplina en la UdeG, es un hecho empíricamente demostrable, pero las causas que lo producen o produjeron, no son del todo claras. Tampoco es obvio que el proceso de hechura de la trayectoria institucional de la carrera a lo largo de cuatro décadas tenga algún sentido progresivo o evolucionista, producto de una intencionalidad manifiesta y de decisiones racionales, es decir, calculadas, de consecuencias deliberadas y efectos más o menos previstos. 
Los fenómenos sociales son, por supuesto, más que una trayectoria o secuencia de relaciones entre hechos y acontecimientos, pero la identificación de esas relaciones a lo largo de un período determinado en un espacio institucional específico permite elaborar un marco general de análisis para estudios más precisos y profundos. En este sentido, la idea central que anima estas notas es que la sociología en la UdeG forma parte de una serie de configuraciones que han determinado los rasgos básicos de su itinerario institucional, es decir, de su origen, sus patrones de legitimación académica y consolidación organizacional, sus crisis y dilemas académicos, intelectuales y aún políticos. Esas configuraciones (estructuras, significaciones, actores) se originan parcialmente en las causas de su creación, pero también en las tensiones y ambigüedades de los intereses y prácticas académicas que se han desarrollado a lo largo de la existencia del programa, protagonizados por sus estudiantes, egresados, profesores y los funcionarios universitarios directa o indirectamente relacionados con la gestión de los cambios y adaptaciones de la carrera a través de su trayectoria institucional.

Conviene decir que las notas que siguen son justamente eso: una colección de apuntes, anotaciones al margen, intuiciones, impresiones al vuelo, que se acompañan a veces de registros documentales, de algunos datos, del análisis de los relatos y discursos que se han construido a lo largo del desarrollo de la disciplina en la UdeG. Como egresado de esa carrera, como académico y como funcionario universitario, he acompañado como espectador $y$, a veces, como protagonista, el proceso de institucionalización de la sociología en la universidad. Ello explica cierta tendencia a una crónica personal del itinerario institucional de la disciplina, una crónica que explicita el carácter relativamente parcial, impreciso, subjetivo, de las propias notas que, sin embargo, he tratado de equilibrar con una mirada donde el escepticismo metodológico y las pretensiones de objetividad intentan ofrecer algo más que un relato impresionista de la sociología universitaria.

Para ello, el capítulo se divide en cuatro secciones. En la primera, se relatan algunos de los hechos y posibles causas que dieron origen a la carrera de Sociología en la UdeG hacia finales de la década de los setenta del siglo pasado. En la segunda, se ofrecen apuntes de la construcción del contexto institucional y los actores relevantes del proceso de legitimación y consolidación de la carrera sociológica en la universidad. En la tercera parte, se examina brevemente la trayectoria de la disciplina a través de las prácticas académicas e institucionales de investigación que irán configurando el modelo o patrón de legitimidad del estatus profesional y científico de la sociología universitaria en Guadalajara. Finalmente, se incluye una sección de consideraciones generales sobre el tema, pensadas más como apuntes para indagaciones futuras que como conclusiones sobre la experiencia de la formación de sociólogos y el desarrollo de la sociología en la UdeG. 


\section{Los orígenes: en el principio fue el interés}

En septiembre de 1977, inició sus cursos la primera generación de estudiantes de sociología de la UdeG. Según los registros disponibles, se inscribieron en el primer año un total de 118 estudiantes, un dato que hay que tomar con reservas (UdeG, 1983, p. 155). Fue un acontecimiento importante para ellos, por supuesto, pero también para la Facultad de Filosofía y Letras de la UdeG, que para ese entonces era el espacio institucional que albergaba, junto con las carreras de Filosofía, Letras e Historia, a la naciente carrera de Sociología. El nuevo programa reflejaba la intención de introducir y desarrollar una nueva disciplina de las ciencias sociales en el campus universitario, al igual que lo habían comenzado a hacer, a lo largo de la década de los setenta, otras universidades públicas del país. Una mezcla confusa de creencias e ideas, de intereses institucionales y académicos, de ilusiones y expectativas, alimentaba el optimismo sobre el futuro de la sociología, digamos, nacional, "mexicanizada", aclimatada en los diversos contextos universitarios locales.

Los orígenes de la iniciativa para crear esa carrera en la UdeG son también confusos. Había claramente el interés de algunos profesores de Derecho, de Filosofía y de Historia por impulsar esa iniciativa desde los primeros años de la década de 1970, cuando en universidades como la Universidad Nacional Autónoma de México (UNAM) la sociología gozaba de un importante prestigio nacional e internacional a través de la formación de profesionistas e investigadores, de la publicación de revistas y libros, de una fuerte presencia en medios y posiciones públicas en la vida política, cultural e intelectual (UNAM, 2010). Había también el interés de algunos funcionarios universitarios -el Rector en funciones (1975-1983), el arquitecto Jorge Enrique Zambrano Villa, y el Director de la Facultad, el Prof. Diego Huízar Martínez- por acoger una carrera que se comenzaba a llamar la atención en las universidades públicas, y de la cual en Jalisco y en la región occidental del país (Aguascalientes, Nayarit, Colima) no existían antecedentes. Pero, es también el interés de los entonces dirigentes de la Federación de Estudiantes de Guadalajara (FEG) de los períodos 1977-

$1 \quad$ Es preciso aclarar que, según la organización curricular de la Facultad de Filosofía y Letras de esos años, los alumnos de las cuatro carreras (Letras, Filosofía, Historia y, por supuesto, Sociología) se incorporaban a un tronco común de materias durante el primer año. También se incluía por esos mismos años la "licenciatura en estudios anglosajones y franceses", un programa que fue cancelado hacia 1980. Eso significa que, en términos estrictos, la primera generación de sociólogos de la UdeG comenzó sus cursos en septiembre de 1978. De cualquier forma, es muy alto el número de los inscritos en la primera generación (118), un número que se fue reduciendo en 1979 a 70 (segunda generación), y en 1980 a sólo 24 (tercera generación). Se estima que, en promedio, durante esos primeros años de la carrera (1981-1984) la tasa de egreso fue de sólo el 4\%, y, de ese porcentaje, solo una cuarta parte alcanzaban la titulación (García y de la Torre, 2009). 
1979 y 1979-1981 (Raúl Padilla López y Horacio García Pérez, respectivamente), egresados ambos de la carrera de Historia de la propia Facultad de Filosofía y Letras, el factor que, probablemente, definió la decisión política de fundar la carrera de Sociología en la UdeG.

Los antecedentes institucionales también juegan un papel importante en la causalidad de la decisión. De un lado, entre los antecedentes remotos, está la fundación de la Escuela de Economía en 1935 (que en 1955 se convirtió en Facultad), el efímero Instituto de Ciencias Sociales (1935) y la creación de la Facultad de Filosofía y Letras desde el año de 1957 (que desapareció en 1994, como producto de la reforma universitaria de ese año), espacios en los cuales se habían desarroIlado disciplinas humanísticas como Filosofía y Letras, pero también la carrera de Historia. Por otro lado, la fundación, a principios de 1976, del Instituto de Estudios Sociales (IES), cuyo primer director fue el Dr. Manuel Rodríguez Lapuente, un abogado e intelectual local pero que construyó una carrera académica en las ciencias sociales de cierto reconocimiento nacional (UdeG, 1983). Este último antecedente parece ser especialmente relevante en la constitución y legitimación académica de la idea de una carrera de Sociología en la UdeG, pues desde el IES se comenzaron a desarrollar algunos estudios de Educación, de Historia Social y de Sociología Política.

Entre 1976 y 1977 fue cristalizando la iniciativa institucional de esta idea. Era la época de la mayor expansión de la matrícula universitaria conocida en México -la "masificación"-, lo que implicaba el crecimiento y la relativa diversificación de la oferta de programas de licenciatura en prácticamente todas las áreas del conocimiento en muchas de las universidades públicas federales y estatales del país, y la sociología era una de ellas. Para no pocos académicos, intelectuales, funcionarios universitarios y políticos nacionales y locales, la sociología era una disciplina indispensable para el conocimiento de los comportamientos sociales, pero también para determinar el tipo de desarrollo que era necesario o deseable para Jalisco y para el país. La creencia de que el conocimiento científico-sociológico era una herramienta fundamental para solucionar los problemas sociales se constituyó desde el principio como una exigencia práctica que implicaba la formación de profesionistas especializados en tales tareas. Como ocurrió con otras experiencias académicas, intelectuales e institucionales de las ciencias sociales, la distinción entre la sociología como profesión, como ciencia y como producto (reflejo) de determinaciones sociales y políticas más amplias, se constituyó como una zona de articulaciones de tensiones y pretensiones más o menos desmesuradas desde el origen mismo del programa (Escalante, 1999).

El propio texto original de dictamen del Consejo General Universitario respecto de la creación de la carrera corresponde a esta creencia fundacional. Ahí se señala que: 
se prevé la formación de un Profesionista Sociólogo definido como aquel que estudia las obras del hombre a través de sus instituciones, así como la conducta del mismo y también, las fuerzas que le han dado impulso determinando su cambio y continuidad; investiga las formas de conciencia social o ideológica, los conflictos de clases que las producen y las contradicciones históricas que dan lugar a su proceso de desarrollo. (Universidad de Guadalajara, 1977, p. 3)

El lenguaje del dictamen es importante. El fraseo, la sintaxis, el ordenamiento lógico es sin duda cuestionable, pues suele ser producto de la intervención de los asesores jurídicos de ocasión. No obstante, conviene retener el núcleo conceptual y argumentativo del texto: "Profesionista Sociólogo", "Instituciones", "Cambio", "Conciencia", "Conflictos de clases", "Proceso de desarrollo". Detrás de esas palabras resuenan los ecos de las teorías sociológicas clásicas y contemporáneas de los años setenta: el marxismo, la sociología comprensiva, las teorías de la modernización. Menos, pero suenan también las aproximaciones estructuralistas y funcionalistas, el positivismo clásico, las obsesiones metodológicas, las reglas del método sociológico.

Con todo, el arranque formal del programa adquiría desde su diseño un perfil académico claramente orientado hacia el ejercicio profesional, no orientado hacia la investigación. Era inevitable dadas las circunstancias (los hechos) políticas, intelectuales e institucionales que rodeaban el acontecimiento. Se trataba de un ordenamiento basado en la enseñanza de las teorías sociológicas de la época, pero donde el predominio del paradigma marxista era, en los años setenta, el dispositivo teórico y conceptual central en la formación de los sociólogos en prácticamente todo el país. Además, los primeros profesores de la nueva carrera no eran sociólogos, sino filósofos, economistas, historiadores, abogados. También, la mayor parte eran profesores de tiempo parcial y muy pocos eran profesores o investigadores de tiempo completo, a tono con la época del perfil del profesorado universitario mexicano de la época de la primera masificación de la universidad. Ello explica que la lógica de la formación profesional descansaba no tanto en los programas de los cursos como en los perfiles de los profesores y sus propias experiencias y prácticas académicas y docentes.

Las primeras generaciones de sociólogos comenzaron así su proceso formativo. Era lo que había, tanto en términos de antecedentes, como de experiencia y recursos, planes de estudio, de perfiles formativos de profesores, y de las diversas creencias, expectativas y deseos de los nuevos estudiantes universitarios, que no eran (ni son) un conglomerado homogéneo. El clima de la época -el espíritu- también jugaba su papel: el autoritarismo político, la persistencia de la desigualdad 
social, la crisis económica, la crisis de las ideologías y los mapas de la representación política ordenadas en los ejes de las izquierdas y las derechas, entre socialismo y capitalismo, alimentaban las ilusiones y voluntades de generaciones de universitarios que aspiraban a transformar al mundo más que a interpretarlo, como señalaba en sus conocidas Tesis sobre Feuerbach el viejo Karl Marx.

\section{La organización y sus actores}

Las estructuras y prácticas académicas de las primeras generaciones de sociólogos determinaron significativamente la orientación y organización futura de la carrera. Pero la organización misma del programa -el plan de estudios, las normas, los valores, las rutinas, los recursos y los actores involucrados- conforma en sí misma un espacio analítico crucial para comprender mejor el comportamiento y la lógica del programa en sus distintas etapas. En este sentido, hay por lo menos tres dimensiones a considerar. La primera es el comportamiento de los estudiantes y egresados del programa. La segunda es el tipo de profesorado de la carrera. La tercera, los cambios y adaptaciones del programa en relación a las transformaciones del contexto general de la UdeG, sobre todo las derivadas de la reforma universitaria de 1989-1994 (Acosta, 2002).

Los inicios fueron por supuesto difíciles. Los cursos y actividades escolares cotidianas transcurrían según los calendarios y ritmos marcados en el programa. Sabemos que entre 1977 y 2017 egresaron de la carrera un total de 70 generaciones de estudiantes. Las cuatro primeras fueron anuales y, desde 1985 hasta 2017, 66 fueron semestrales. Sabemos también, como ya dijimos en la sección anterior, que en la primera generación fueron admitidos 118 estudiantes y, 41 años después, en agosto de 2018, fueron admitidos 80 (Universidad de Guadalajara, 2018). Sabemos que en los últimos diez años (2009-2018) ingresaron, en promedio, 176 nuevos estudiantes cada año al programa, lo que indica un flujo relativamente estable de solicitudes de admisión durante cada ciclo escolar; pero también sabemos que en el mismo período egresaron solamente en promedio 12 estudiantes del programa por año escolar (tabla 1). Desconocemos, sin embargo, cuál es la cifra total de los ingresos y egresados de la carrera a lo largo de estas cuatro décadas, así como los datos de abandonos, deserción o cambios de carrera de los estudiantes. Según algunos estudios (García y Bustos, 2009), entre 1980 y 1988 egresaron 501 estudiantes de la carrera de Sociología (en promedio, 55 por año), pero no sabemos qué porcentaje representan en relación con los que ingresaron. Tampoco disponemos de datos consistentes para el período posterior (1988-2009).

Los datos de los estudiantes que ingresan, egresan y se titulan son importantes como parte de cualquier ejercicio analítico básico sobre la trayectoria institucional de los procesos formativos de la sociología universitaria. Pero también importan los procesos de transición laboral de sus 
egresados, determinados siempre por una combinación compleja de creencias, deseos y oportunidades (Hedström, 2006). Sobre este último punto tampoco hay estudios que permitan identificar las trayectorias escolares y los patrones o tipos de inserción laboral de los estudiantes y egresados universitarios, que incluyen a los cientos de sociólogos egresados de la UdeG durante 40 años (Acosta y Planas, 2014; Valdivia, 2014). Estos déficits de información y conocimiento limitan de manera importante la explicación causal del proceso en su conjunto.

Tabla 1. Número de estudiantes de primer semestre y egresados de Sociología en la UdeG por ciclo escolar, 2009-2018

\begin{tabular}{ccc} 
Ciclo escolar & $\begin{array}{c}\text { Número de alumnos inscritos } \\
\text { en primer semestre* }\end{array}$ & $\begin{array}{c}\text { Número de alumnos egresados } \\
\text { por ciclo escolar }\end{array}$ \\
\hline $2009-2010$ & 154 & 14 \\
\hline $2010-2011$ & 169 & 16 \\
\hline $2011-2012$ & 185 & 27 \\
\hline $2012-2013$ & 146 & 10 \\
\hline $2013-2014$ & 144 & 4 \\
\hline $2014-2015$ & 191 & 9 \\
\hline $2015-2016$ & 195 & 14 \\
\hline $2016-2017$ & 226 & 13 \\
\hline $2017-2018$ & 202 & s.d. \\
\hline $2018-2019$ & $154^{\star *}$ & \\
\hline
\end{tabular}

Notas: *Estadística anualizada, que incluye estudiantes inscritos en los calendarios A y B por ciclo escolar. **Para este ciclo, aparecen reportados 74 estudiantes inscritos en el ciclo 2018 A, a los que se suman 80 nuevos estudiantes en el ciclo 2018 B. Fuente: Elaboración propia, a partir de informes anuales de matrícula de inicio de curso 911, Coordinación General Escolar, UdeG, 2009-2018. http://www.escolar.udg.mx/estadisticas/ alumnos/informe-de-matricula-inicio-de-curso-911

A pesar de esta limitación sobre las trayectorias de los estudiantes, es posible identificar otros puntos importantes de las relaciones entre la organización de la carrera de Sociología y de sus principales actores. Se pueden mencionar por lo menos dos dimensiones: el perfil de su profesorado y los cambios/adaptaciones de la carrera a las transformaciones universitarias más amplias. El primero tiene que ver con las transformaciones en el proceso de conformación de los 
docentes que se han integrado en distintos momentos a la carrera de Sociología; el segundo, con los efectos de la reforma universitaria de 1993-1994 en la lógica institucional de la carrera.

Como fue apuntado anteriormente, los primeros profesores de la carrera de Sociología no eran sociólogos. Ese rasgo no es inusual en las carreras universitarias de nueva aparición institucional. Abogados, historiadores, economistas, antropólogos, que ya impartían clases en otras carreras de la Facultad de Filosofía y Letras, o en otras Facultades de la propia Universidad (Derecho, Economía), fueron invitados para desarrollar los contenidos de los cursos e impartir sus clases a las primeras generaciones de estudiantes (específicamente, a las cuatro únicas generaciones de ciclo anual, 1977-1981). Salvo uno o dos casos, la mayor parte de los profesores eran de tiempo parcial o por horas y no desarrollaban investigación. Tampoco abundaban los profesores con posgrado. La mayoría solo disponían del título de la licenciatura de origen, y algún profesor tenía una maestría obtenida en el extranjero (en la Universidad de Lovaina, en Bélgica) y otro más un doctorado, cursado en una universidad pública mexicana (la Universidad Autónoma de Puebla). No eran los tiempos de las exigencias del posgrado para impartir clases en licenciatura.

Pero, a partir de 1982-1985, se inició un lento proceso de diversificación y expansión de la planta docente. Varios de los primeros egresados de la carrera se convirtieron en profesores de la misma. Por vez primera, se veían sociólogos formando sociólogos. Aunque no formaban parte de los objetivos explícitos del dictamen de creación, la formación de profesores de sociología se convirtió en una típica función no declarada pero manifiesta (para emplear la clásica tesis de Robert K. Merton) de la carrera de Sociología en la UdeG. La incorporación de los jóvenes profesores fue un factor que amplió el capital académico de la carrera, pues se iniciaba también el interés por la investigación, las publicaciones y la obtención de posgrados por parte de las nuevas generaciones de profesores de Sociología. La influencia del reconocimiento de los académicos como parte del Sistema Nacional de Investigadores (SNI), creado en 1984, también jugó un papel importante en la configuración de la diferenciación, del prestigio y la reputación académica (además de un mejoramiento importante de los ingresos pecuniarios) de los investigadores y profesores universitarios. Todo esto tuvo efectos profundos en los modelos académicos y en los patrones de legitimación del ejercicio sociológico en la universidad (Álvarez, 2002). Entre 1977 y 2004, la figura del profesorado centrado exclusivamente en la docencia, cedió el paso lentamente a la figura del profesor-investigador; el prestigio ganado en las prácticas de enseñanza fue desplazado por el prestigio de los posgrados y de las publicaciones del profesorado. Los tiempos estaban cambiando.

Varios de los nuevos sociólogos alimentaron también la impartición de clases de sociología en las escuelas, facultades y preparatorias de la propia universidad. Algunos más, fueron 
contratados como profesores de ciencias sociales en otras instituciones de educación superior públicas y privadas de Jalisco. En varios casos, optaron por cursar estudios de maestría y doctorado en universidades e instituciones nacionales o internacionales. En otros, se incorporaron como asistentes o investigadores de tiempo completo en el Instituto de Estudios Sociales de la propia UdeG, desarrollando estudios en el campo de la sociología de la educación, la sociología urbana o la sociología política, o de la teoría sociológica. También, varios de los egresados se incorporaron al sector gubernamental como funcionarios medios y altos de la administración pública municipal, estatal y federal.

Ese cambio en el perfil del profesorado se acompañó también por la emergencia de nuevas teorías, enfoques y metodologías sociológicas. Durante los años ochenta y noventa, enfoques relativamente emergentes se incorporaron en la formación de los sociólogos universitarios. La centralidad de los enfoques marxistas cedió el paso a los enfoques neo-institucionalistas (o neo-weberianos), a las teorías de la estructuración social (Giddens), a las relaciones micro-macro (Alexander), a las teorías de los capitales (Bourdieu). También aparecieron nuevas especialidades y subdisciplinas de la sociología, articuladas al estudio de temas y problemas específicos: el sindicalismo, el Estado, los movimientos sociales, los partidos políticos, las universidades, los jóvenes, las mujeres, las urbes, la desigualdad, la pobreza. También influyó el hecho de que nuevas carreras y programas se crearon en la UdeG, por ejemplo, la licenciatura en Estudios Políticos y de Gobierno, a principios de los años noventa o la de Antropología en 2002, áreas que eran tratadas como parte de la formación de las primeras generaciones de sociólogos. Estos enfoques, objetos y subdisciplinas ayudan a explicar las reformas a los planes de estudio de la carrera en 1983 y, posteriormente, en 2004 y 2007.

Pero, al lado de estas transformaciones en el perfil del profesorado y de los paradigmas y modelos de la formación sociológica, ocurrió un fenómeno particularmente significativo de la UdeG: la incorporación de los egresados tanto como profesores, como investigadores y como funcionarios universitarios. Una suerte de nueva elite dirigente - de carácter académico, burocrático y político- se configuró en torno a algunos de los egresados de las primeras generaciones de sociólogos. Fraguados en las lides de la política estudiantil durante sus años de juventud (militando en la Federación de Estudiantes de Guadalajara [FEG] o en su opositora), esos sociólogos conquistaron posiciones académicas como profesores para luego transitar hacia posiciones como funcionarios universitarios e incluso, como políticos profesionales. No todos, ni la mayoría de los egresados, por supuesto, pero sí algunos de los egresados desarrollaron un patrón de comportamiento y movilidad política e institucional que marcó de alguna manera el comportamiento, las 
creencias, las expectativas y los deseos, de otras generaciones de sociólogos.²

\section{La reforma de 1993 y los cambios de la carrera}

Pero la lenta metamorfosis institucional de la carrera no se entiende sin referir los cambios en el contexto general de la universidad. Entre 1989 y 1994 se desarrolla un proceso de reforma que culminará en la configuración de la Red Universitaria en Jalisco de la UdeG. Esa reforma tendrá varias implicaciones en la estructura, la organización y en la lógica académica universitaria. Específicamente, la sustitución de las antiguas escuelas y facultades por divisiones y departamentos académicos, articulados en una red de centros temáticos y regionales universitarios distribuidos en el estado de Jalisco, significará una reorganización académica y administrativa importante, que incorporará específicamente las tareas de investigación y docencia como el núcleo básico de las actividades departamentales, en el que la figura de profesor-investigador de tiempo completo será parte de la "base pesada" del funcionamiento académico habitual.

Eso explica la fundación del Departamento de Sociología del Centro Universitario de Ciencias Sociales y Humanidades en julio de 1994. Este espacio albergará a la carrera de Sociología, pero también impulsará nuevos programas de maestría y doctorado en el campo de las ciencias sociales. Las actividades de investigación se concentrarán en el Centro de Investigaciones de ese departamento, que sustituyó al antiguo Instituto de Estudios Sociales (1976-1993), al igual que el nuevo departamento sustituyó parcialmente las actividades de la desaparecida Facultad de Filosofía y Letras (1957-1993). Con la reforma universitaria, la formación de sociólogos experimentaría una nueva etapa, que se reflejaría sin embargo de manera tardía, con las reformas a su plan de estudios en 2004 y 2007. Esas reformas se acompañarían con un errático comportamiento del

2 Son particularmente ilustrativos de dicha afirmación casos como los de José Trinidad Padilla López, Marco Antonio Cortés, Misael Gradilla o Héctor Raúl Solís. Los primeros tres casos pertenecen a la primera generación de sociólogos de la UdeG (1977-1982), y los dos primeros alcanzaron puestos como rectores generales (2001-2007 y 2008-2013, respectivamente), el tercero fue vicerrector ejecutivo (1995-2001) y, el último, rector de centro universitario (2013-actual). Además, en el caso del primero, fue diputado federal y local por parte del PRI, después de haber sido rector de la UdeG. Desde luego, esta expresión de movilidad ascendente no se desprende naturalmente (y exclusivamente) de su formación como sociólogos, sino que se determina por factores como su pertenencia a las redes de poder universitario (el padillismo), y por sus relaciones con los partidos políticos dominantes en Jalisco durante un largo ciclo. Pero son casos que parecen explicar cómo en la UdeG, la sociología ha sido una profesión más que académica, también burocrática y política. Al respecto, cfr. Acosta (2006). 
ingreso, el tránsito y el egreso de los estudiantes universitarios. También se acompañaría a lo largo de los siguientes años por una expansión de su planta docente y de investigación, conformada por un porcentaje importante de profesores-investigadores de tiempo completo, la mayoría con posgrados obtenidos en instituciones locales, nacionales y extranjeras.

\section{Estudiar la sociología: la agenda, la coyuntura y los problemas}

Parte de la reconstrucción histórica de la sociología en la UdeG pasa también por el análisis de las tendencias, las agendas y los proyectos de investigación predominantes en el desarrollo de la disciplina, más allá del comportamiento de los estudiantes y de los egresados, del perfil del profesorado o de las características y perfiles de la carrera y de los planes de estudio. Aquí también se puede identificar un déficit de información y conocimiento. No obstante, existen algunos referentes que pueden orientar un estudio futuro sobre la investigación sociológica en la UdeG, un estudio más de carácter cualitativo que cuantitativo.

Una primera consideración respecto de las prácticas de investigación tiene que ver con la constitución del Departamento de Sociología y la determinación de que la investigación sociológica fuera una de las tareas sustantivas de este nuevo espacio universitario. Sin agenda ni políticas institucionales claras, el desarrollo de la investigación obedecía fundamentalmente a las iniciativas y proyectos individuales que emprendían algunos de los profesores-investigadores de tiempo completo con posgrado que se integraron a la nueva estructura departamental a través del Centro de Investigaciones del propio Departamento, creado en el año de 1997. Bajo los efectos del establecimiento del SNI y las políticas de estímulos académicos impulsadas por el gobierno federal y por la propia UdeG desde finales de los años noventa, la investigación se convirtió en una práctica deliberada, organizada y recompensada con apoyos académicos y estímulos salariales.

En esas condiciones, el desarrollo de la investigación sociológica universitaria se asentó en tres conjuntos de procesos: a) la relación entre la docencia y la investigación; b) el tipo de proyectos y publicaciones surgidas de los estudios sociológicos; y c) los temas, objetos, y problemas de investigación realizados por el Departamento. La revisión de estos procesos permitiría dar cuenta de la intensidad, la naturaleza y diversidad teórica y metodológica de los estudios sociológicos realizados durante los últimos cuarenta años en la UdeG.

a. Relaciones docencia-investigación: el papel de las tesis de grado. Un primer balance al respecto se puede encontrar en el examen de los procesos de elaboración, los temas y los tipos de tesis de grado que los egresados presentan o han presentado como parte de su titulación. En el análisis de las orientaciones, las metodologías y los procesos de construcción 
de esos trabajos académicos se pueden rastrear los vínculos entre la lógica de la investigación de la disciplina, el cultivo de ciertas subdisciplinas, y el perfil de las interacciones entre profesores y estudiantes -es decir, entre docencia e investigación- a lo largo de la carrera.

b. Publicaciones. Un segundo referente del análisis se encuentra en el tipo, calidad y cantidad de publicaciones que estudiantes, profesores e investigadores de sociología han producido a lo largo de los cuarenta años de la carrera. Sabemos que las exigencias de la carrera académica universitaria implican hoy y desde hace tiempo -las exigencias del capitalismo académico- una preocupación constante por la productividad académica: publicación de libros, artículos, reseñas, ensayos. También la formalización de proyectos y líneas de investigación de individuos, grupos de investigación y cuerpos académicos. También sabemos que existen espacios editoriales propios donde los investigadores y profesores universitarios suelen publicar sus productos y resultados - por ejemplo, la revista Espiral, o la Editorial Universitaria- que registran el tipo de investigaciones o estudios sociológicos que se realizan en la UdeG, aunque muchos de esos resultados también se suelen publicar, cada vez más, en revistas nacionales o internacionales.

c. Objetos de investigación sociológica. Un tercer punto a considerar en el análisis de la investigación sociológica tiene que ver con los objetos y problemas de investigación predominantes a lo largo de los cuarenta años del programa. Es posible afirmar que de un muy bajo nivel de investigación en torno a problemas sociales de la región o del país, fue posible advertir un incremento del número y variedad de estudios disciplinarios o interdisciplinarios en prácticamente todos los campos de la sociología: educación, política, medio ambiente, movimientos sociales, cohesión social, violencia, género, políticas públicas, medio ambiente, urbanización, pobreza y desigualdad, cultura política, ciudadanía, y el Estado. También es posible advertir el lento predominio de la lógica de las líneas y proyectos de investigación impulsados por dos o más investigadores sobre la tradición de la tendencia al desarrollo de proyectos estrictamente individuales.

Los puntos enunciados constituyen apenas parte de una primera aproximación descriptiva en torno a las diversas dimensiones de la organización y las prácticas de la investigación sociológica en la UdeG. Con ellas, se podría también avanzar en el análisis de los déficits y los logros académicos, las aportaciones cognitivas y los impactos institucionales de la sociología universitaria. Ello permitiría una mayor y mejor comprensión sobre los factores que determinan el tipo de investigaciones que se realizan y la lógica institucional de su desarrollo. Además, permitiría 
apreciar con mayor precisión las tensiones que ocurren, han ocurrido y seguramente ocurrirán entre los procesos formativos e investigativos de la sociología en la UdeG.

\section{Consideraciones finales}

Este ensayo partió de la afirmación casi obvia de que la construcción de una "sociología de la sociología" en la UdeG es una empresa intelectual vasta, compleja y arriesgada. Vista desde la perspectiva del itinerario institucional, implica identificar las distintas dimensiones, causalidades y factores que ayudan a explicar el origen y el desarrollo del ejercicio sociológico en la universidad. Vista desde la perspectiva del análisis sociológico, se trata de valorar las relaciones entre los individuos y las estructuras o, para decirlo en un lenguaje sociológico clásico, entre los individuos y las instituciones. Tomar a la sociología como objeto de investigación implica considerar el análisis del comportamiento de los individuos - profesores e investigadores, estudiantes y egresados- en el contexto institucional más amplio a lo largo de un espacio y un tiempo determinado, bajo el supuesto de que siempre existe una relación compleja entre la lógica de la acción colectiva, las formulación y hechura de las decisiones individuales y el peso de las restricciones institucionales. El análisis del itinerario institucional y el análisis sociológico de la sociología en la universidad pueden ayudar a comprender mejor el comportamiento de la disciplina. Quizá eso contribuya también a desarrollar una perspectiva comparada en relación a los casos de otras universidades públicas - la UNAM, la UAM, la Universidad de Sonora-, que permita apreciar similitudes y diferencias básicas o complejas. Bien visto, el desarrollo de una sociología de la sociología tiene que ver con la construcción de una identidad disciplinaria, con un estatuto científico y profesional propio en el campo de las ciencias sociales, y con los cambiantes y a veces extraños patrones de legitimación institucional, académica, intelectual y política de la sociología. Indagar en la configuración de esos patrones y procesos, explorar sus rasgos, describir la complejidad causal que los explica, forman parte del diseño de un programa de investigación que permita elaborar un balance riguroso del oficio sociológico durante más de cuarenta años de existencia en la universidad. 


\section{Referencias}

Acosta, A. (2002). Ensamblajes conflictivos. Políticas públicas y reformas universitarias en México. El caso de la Universidad de Guadalajara. México: Universidad de Guadalajara.

Acosta, A. (2006). El vino y los odres. Gobernabilidad y cambio institucional en la Universidad de Guadalajara. En Poder, gobernabilidad y cambio institucional en las universidades públicas en México, 1990-2000. Tomo 2. México: CUCEA-Universidad de Guadalajara.

Acosta, A., \& Planas, J. (Coords.). (2014). La arquitectura del poliedro. Itinerarios universitarios, equidad y movilidad ocupacional en México. Guadalajara, México: Editorial Universitaria.

Álvarez, G. (2002). Las tensiones del cambio: modelos académicos de ciencias sociales y legitimación científica en México. Un estudio comparativo de tres casos. México: ANUIES.

Elster, J. (2010). La explicación del comportamiento social. Más tuercas y tornillos para las ciencias sociales. Barcelona: Gedisa.

Escalante, F. (1999). Una idea de las ciencias sociales. México: Paidós

García, R., \& Bustos, G. (2009). Las modalidades y opciones de titulación y el comportamiento recepcional de los egresados de la Licenciatura en Sociología de la UdeG. Revista Sincronía, $14(50)$.

García, R., \& de la Torre, J. (2009). Egreso y titulación de la Licenciatura en Sociología de la UdeG, 1981-1994. Guadalajara: Editorial Umbral Digital.

Hedström, P. (2006). Explaining social change: an analytical approach. Papers. Revista de Sociología, 80, 73-95.

Universidad de Guadalajara (1983). Piensa y Trabaja. Universidad de Guadalajara 1976-1983. Guadalajara: Departamento de Planeación y Desarrollo-Universidad de Guadalajara.

Universidad de Guadalajara (1977). Dictamen de creación de la Licenciatura en Sociología. H. Consejo General Universitario, UdeG, Guadalajara, México.

Universidad de Guadalajara (2018). El Resultado de los dictámenes de admisión realizados por los Centros Universitarios correspondiente al ciclo 2018 B, tanto de la zona metropolitana de Guadalajara como regionales. La Gaceta, (suplemento especial). Recuperado de https:// issuu.com/udeg.mx/docs/dictamen_2018a

Universidad Nacional Autónoma de México (UNAM). (2010). Sociología. En La UNAM por México, Tomo 2 (pp. 1232-1259). México: UNAM.

Valdivia, B. (2014). Trayectorias discontinuas y estrategias de adaptación. El caso del CUCSH de la Universidad de Guadalajara. Tesis de Maestría, CUCEA-Universidad de Guadalajara. Guadalajara, México. 


\section{Capítulo IV}

Cuarenta años de la sociología

en la Universidad de Sonora.

Trazos generales

José Raúl Rodríguez Jiménez, *

Juan Pablo Durand Villalobos **

y Juan Manuel Gálvez Andrade ***

* Profesor Investigador, Departamento de Sociología y Administración Pública, Universidad de Sonora. Integrante del Sistema Nacional de Investigadores. Contacto: rraul@sociales.uson.mx

** Profesor Investigador, Departamento de Psicología y Ciencias de la Comunicación, Universidad de Sonora. Integrante del Sistema Nacional de Investigadores. Contacto: pablo.durand@unison.mx

*** Profesor Investigador, Departamento de Sociología y Administración Pública, Universidad de Sonora. Coordinador del Programa de Sociología. Contacto: mgalvez@sociales.uson.mx 


\section{Introducción}

La licenciatura en Sociología en la Universidad de Sonora (UNISON) arriba a su cuarta década de existencia en condiciones relativamente adversas. En 2017, contaba con 102 estudiantes, junto con la licenciatura en Historia (112 estudiantes), es la de menor población estudiantil en el área de las ciencias sociales de la UNISON. En general, los indicadores estudiantiles muestran un modesto desempeño: la tasa de deserción es de 22\% (2016); la eficiencia terminal 5.3\% (2017); la proporción de estudiantes aprobados en todas las materias 66\% (2017); y el tiempo promedio en cursar los estudios es de 11 semestres (UNISON, 2018). Pese a estos indicadores, los estudiantes tienen valoraciones positivas para la escuela y sus profesores; las opiniones sobre conocimiento de las materias impartidas por los maestros, claridad en la exposición y vinculación entre conocimientos teóricos y prácticos, así como el índice de satisfacción de los estudios son favorables, incluso en algunos casos superan los porcentajes promedio de la División de Ciencias Sociales de la UNISON (UNISON, 2018).

En 2017, la planta académica estaba compuesta por 21 profesores, la mayoría de ellos varones (18) y muy escasa presencia de mujeres (3). Se trata de profesores que están arribando a la última etapa de su vida laboral, puesto que la edad promedio era de 56 años y la antigüedad laboral de 26 años. En cuanto a la escolaridad, exceptuando un profesor, todos los maestros cuentan con posgrado (9 doctores y 11 maestros). Pese a ello y a la amplia experiencia laboral, los académicos no cuentan con producción destacada. Su actividad principal es la docencia. Los proyectos de investigación y publicaciones son desarrollados consistentemente solo por tres maestros, que son quienes mayormente participan en el sistema institucional de becas al desempeño. Cinco académicos tienen reconocimiento del Programa para el Desarrollo Profesional Docente (PRODEP) y dos en el Sistema Nacional de Investigadores (SNI) (tabla 1). Además, en los dos últimos años, algunos profesores colaboraron esporádicamente en proyectos de desarrollo social. 
Tabla 1. Licenciatura en Sociología, Universidad de Sonora. Datos generales, 1990-2017

\begin{tabular}{|c|c|c|c|c|}
\hline Indicadores & 1990 & 2000 & 2010 & 2017 \\
\hline \multicolumn{5}{|l|}{ Estudiantes } \\
\hline Matrícula & 83 & 119 & 113 & 102 \\
\hline Índice de reprobación & & & 19.9 & 10.6 \\
\hline Tasa de retención (primero al segundo año) & & & 74.1 & 95.4 \\
\hline Eficiencia terminal por cohorte & & & $17 \%$ * & $13 \%$ ** \\
\hline Índice de satisfacción & & & 5.2 & 5.1 \\
\hline \multicolumn{5}{|l|}{ Académicos } \\
\hline Planta de profesores & 14 & 25 & 25 & 21 \\
\hline \multicolumn{5}{|l|}{ Escolaridad profesores } \\
\hline Pasantía & 6 & 5 & & \\
\hline Licenciatura & 5 & 12 & 1 & 1 \\
\hline Maestría & 3 & & 19 & 11 \\
\hline Doctorado & & & 4 & 9 \\
\hline Profesores de tiempo completo & 8 & 12 & 14 & 13 \\
\hline Perfil PRODEP & & 1 & 3 & 5 \\
\hline SNI & & & 2 & 2 \\
\hline
\end{tabular}

Notas: *Corresponde a la cohorte 2010-2015. ${ }^{\star *}$ Corresponde a la cohorte 2012-2017.

Fuente: Elaboración propia con información de Sistema de Información Estadística. Dirección de Planeación; Archivo del Departamento de Sociología y Administración Pública, Universidad de Sonora.

Estos indicadores, aunados a otros relacionados con la actualización del plan de estudios (aprobado en 2004), los índices de deserción estudiantil y titulación fueron algunos de los aspectos connsiderados por la Asociación para la Acreditación y Certificación de las Ciencias Sociales (ACCECISO) suspendiera temporalmente la acreditación de la licenciatura en Sociología.

La descripción anterior muestra un panorama poco alentador de la licenciatura en Sociología de la UNISON. Por su importancia institucional y disciplinaria, conviene preguntarse ¿cómo se llegó a esta situación?, ¿cuáles fueron los factores que intervinieron? Las respuestas a estas interrogantes se encuentran en la propia creación e institucionalización de la sociología en la

$1 \quad$ Un nuevo plan de estudios fue aprobado en agosto de 2018 y se iniciaron los trabajos para recuperar la acreditación de la licenciatura. 
universidad, pero también en los arreglos logrados por los actores, sobre todo por los profesores, que marcaron el desarrollo ulterior de la licenciatura.

En México y en América Latina, el análisis sobre la disciplina, que bien pudiera ser nombrado "sociología de la sociología", es constante desde la década de 1980. Algunos de esos análisis tratan sobre los precursores de la sociología, otros trabajan la institucionalización de la disciplina a través de la creación de facultades y centros de investigación, otros más, los cambios organizacionales y las temáticas de estudio (Andrade, 2015; Moya y Olvera, 2013; Camero, 2015; Álvarez, 2004; Ansaldi, 2015; Girola y Zabludovsky, 1990). En nuestro país, el grueso de la literatura centra su atención en las universidades federales mexicanas y en los principales centros públicos de investigación en ciencias sociales. Por el contrario, el origen y desarrollo de la sociología académica en el interior de la república mexicana son temas prácticamente desconocidos, pese a que la sociología en el nivel licenciatura se imparte en 33 establecimientos ubicados en 24 estados, además de las instituciones con asiento en la Ciudad de México (ANUIES, 2017).

Este capítulo trata de contribuir al conocimiento de la creación y desarrollo de la sociología en México, mediante el análisis de la institucionalización y evolución de la licenciatura en Sociología en la UNISON. EI material que sustenta el escrito proviene de documentos institucionales, sobre todo del Archivo Histórico de la UNISON y el archivo del Departamento de Sociología y Administración Pública. Además, para la reconstrucción de la fundación y operación de la licenciatura en sus primeros años, fue necesario entrevistar a funcionarios universitarios de los años setenta, así como algunos de los profesores pioneros y estudiantes de las generaciones iniciales de la licenciatura.

El capítulo se ordena en cinco apartados. Los dos primeros exponen la fundación y evolución inicial de la disciplina en la UNISON. El siguiente, muestra los cambios universitarios en la década de 1990 y los efectos en la licenciatura. El cuarto apartado describe la situación de la licenciatura de 2000 a 2017. En la parte final del capítulo aparecen algunas pistas para explicar lo sucedido con la sociología en la UNISON y sus desafíos inmediatos.

\section{La Universidad de Sonora y la fundación de la sociología en Sonora. Una cuna inestable}

Desde su fundación en 1942 y hasta finales de la década de 1960, la UNISON fue la institución escolar y cultural más importante en Sonora, por lo que gozaba de gran reconocimiento y respaldo en la sociedad local. Sin embargo, para fines de la década de 1960 e inicios de la siguiente, ocurren varios procesos que la afectan profundamente. De un lado, una serie de conflictos internos y, de otro lado, relaciones tensas con el gobierno estatal y la sociedad local, generan una institución inestable. Frente a esta situación, los funcionarios universitarios desplegaron diversas estrategias para 
recuperar la estabilidad política mediante el control de los órganos de gobierno universitario o la confrontación (en ocasiones en forma de violencia física) con los grupos disidentes (Durand, 2006).

En paralelo a la acción propiamente política, entre 1973 y 1978 se advierten los trazos de un proyecto de modernización institucional. En 1974, la UNISON presentó ante el titular de la Secretaría de Educación Pública (SEP) y funcionarios de la Asociación Nacional de Universidades e Instituciones de Educación Superior (ANUIES), un programa para la Reestructuración Integral de la Educación Profesional y Técnica de la Universidad de Sonora (UNISON, 1975). El documento consideraba cambios en todas las áreas universitarias - docencia, investigación, administración, finanzas, extensión- y sería operado por la Comisión de Planeación y Desarrollo (CPD), que fungiría como oficina asesora de la rectoría. ${ }^{2}$ Entre sus iniciativas figuraban: mecanismos para incrementar el presupuesto universitario; desincorporación de las escuelas secundaria y preparatoria; creación de un centro cultural y unidad deportiva; apertura de sedes institucionales en el norte y sur del estado; reorganización universitaria por departamentos académicos; creación de las licenciaturas de Ciencias del Mar, Arquitectura, Medicina (incluido un hospital universitario), Lingüística, Administración Pública y Sociología (Consejo Universitario, 1976; 1977; 1978). En buena medida, estas propuestas trataban de modernizar la institución y de responder a las transformaciones de la sociedad sonorense, en especial al declive de un modelo económico sustentado en la agricultura, el ascenso de las actividades industriales y la emergencia de las ciudades como centros de concentración poblacional (Castro, 2013; Lara, Velázquez y Rodríguez, 2007).

De las iniciativas propuestas, solo unas cuantas fueron concretadas, aunque con resultados lejanos a los proyectados. La atención de la institución se volcó hacia la resolución de los constantes conflictos políticos que rebasaban su capacidad de respuesta: paros estudiantiles, expulsión de estudiantes, huelgas laborales y sindicalización, por mencionar los más frecuentes, consumían las energías de los funcionarios y de los órganos de gobierno.

De entre las propuestas académicas aprobadas, destaca la departamentalización. El proyecto propone la reordenación universitaria en seis departamentos que organizan la enseñanza e investigación en grandes campos de conocimiento y que absorberán paulatinamente a las escuelas existentes (Molina, Carrión, Larios, León y Hernández, 1979). Uno de esos departamentos

2 Ilse Brunner, primera directora de la CPD de la UNISON fue contratada en 1974 para llevar a cabo el proyecto de restructuración universitaria, especialmente para desarrollar la propuesta de departamentalización universitaria (I. Brunner, comunicación personal, 10 de junio de 2018). No es claro si este proyecto fue iniciativa de la propia UNISON o si fue una recomendación de alguna oficina del gobierno federal. 
es Ciencias Sociales, que agrupa la licenciatura en Derecho, ya existente, y las carreras de Administración Pública y Sociología, ambas de nueva creación. En el mes de noviembre de 1978, la UNISON inició un nuevo ciclo escolar ya con la departamentalización y que incluyó las tres licenciaturas mencionadas (Lingüística, Administración Pública y Sociología). ${ }^{3}$

No existe registro oficial de algún acto de inauguración de la licenciatura en Sociología, tampoco se tiene conocimiento de la presencia de figuras destacadas en esta área para los inicios de la carrera. En cierta manera, es razonable que así sucediera. El clima político no era propicio para tales actos; cualquier concentración con presencia estudiantil podía devenir en protestas violentas. Dos casos ilustran esta situación. En junio de 1978, se llevó a cabo un plebiscito entre los estudiantes universitarios para determinar la continuación de Castellanos Idiáquez al frente de rectoría y aunque el resultado (rotundo desconocimiento del rector) no tuvo consecuencias legales, entre los estudiantes el rector era repudiado. En septiembre de ese mismo año, la UNISON aplicó, por primera ocasión en la década de 1970, un examen de admisión para alumnos de nuevo ingreso, lo que generó protestas estudiantiles que fueron reprimidas (Moreno, 2015). Junto a las adversidades políticas, la institución y la entidad tuvieron poco conocimiento de la sociología por lo que sus imágenes de la profesión recién inaugurada son confusas. Pero, si esta última apreciación es correcta, ¿por qué la UNISON generó una licenciatura de este tipo?

La información disponible permite suponer dos causas en la creación de la licenciatura. De un lado, además de las transformaciones sociales y económicas del Estado anotada antes, la entidad vivió una profunda crisis política. En octubre de 1975, la ocupación de tierras por campesinos en el sur del estado concluyó con la muerte de siete jornaleros agrícolas a manos de las fuerzas policiales, lo que motivó que el Congreso del Estado destituyera al entonces gobernador sonorense, Carlos A. Biebrich (1973-1975), y en su lugar nombró a Alejandro Carillo Marcor (1975-1979). El nuevo gobernador enfrentó un estado convulsionado por el movimiento campesino, expropiación de tierras y presión de propietarios agrícolas (Jiménez, 1976), además de la politización de la UNISON. En este escenario, el gobernador trató de generar nuevos acuerdos y alianzas entre los diversos actores. Para el caso de la UNISON, Carrillo Marcor sugirió en noviembre de 1975 la renuncia del rector Castellanos Idiáquez como una manera de desactivar el movimiento estudiantil y la apertura

3 No existe información oficial de la fecha de arranque del año escolar de 1978 en la UNISON. De acuerdo con inserciones pagadas en la prensa local (El imparcial, 10 y 17 de noviembre de 1978), las Escuelas de Derecho y Ciencias Químicas iniciaron cursos el 21 de noviembre de ese año. En Caborca, sede de la UNISON en el norte del Estado, el semestre inició el 27 de noviembre (El imparcial, 20 de noviembre de 1978). Con base en esta información podemos suponer que el inicio del semestre, al menos para la sede en Hermosillo, ocurrió el martes 21 de noviembre de 1978. 
de nuevas licenciaturas en ciencias sociales para atender los conflictos sociales en Sonora (Moreno, 2015; M. Von der Borch, comunicación personal, 25 de junio de 2018). Lejos de lograr su cometido, la sugerencia del gobernador favoreció a Castellanos Idiáquez, puesto que permaneció en el cargo por siete años más. ${ }^{4}$ En cuanto a la creación de licenciaturas, su petición tuvo eco, aunque no de manera inmediata; pasaron tres años para que se concretaran.

Otro posible origen de la licenciatura se encuentra en el proyecto mismo de departamentalización. Como se sostiene antes, la departamentalización trató de reordenar las actividades de enseñanza e investigación por campos de conocimiento, para el caso del Departamento de Ciencias Sociales se llegó a la conclusión, por recomendación de los asesores externos, que Sociología y Administración Pública, junto a Derecho, podían ser la base para ofrecer servicios de ciencias sociales a los demás departamentos. Además, la departamentalización pretendió contribuir a la desactivación del movimiento estudiantil restando fuerza a las escuelas, sobre todo aquellas con alta participación política, y transfiriendo las actividades escolares a los Departamentos ${ }^{5}$ (Saúl Hernández, comunicación personal, 27 de junio de 2018; Enrique Carrión, comunicación personal, 27 de abril 2018).

Más allá de la autoría de la idea germinal de creación de la licenciatura en Sociología, fue necesario desarrollar el proyecto. Aunque el estado contaba con algunos antecedentes de la sociología en Sonora, entre los que destacan la creación, en 1960, del Instituto de Investigaciones Económicas y Sociales de la UNISON, que incluía la perspectiva sociológica para desarrollar investigación (Bobadilla, 2002); el Décimo Tercer Congreso Nacional de Sociología, en 1962, con sede en la UNISON, que reunió a importantes personajes de la sociología para tratar los temas del desarroIlo nacional y regional; finalmente, la impartición de cursos de sociología desde la década de 1970 en las escuelas Preparatoria (en ese entonces integrada a la universidad), Economía y Agricultura y Ganadería. ${ }^{6}$ Pese a su importancia, ninguno de estos antecedentes logró desarrollar la disciplina

4 Para sortear el complejo conflicto con el gobernador, el rector Castellanos I. convocó al Consejo Universitario el 24 de noviembre de 1975 e informó que recibió amenazas para su persona y su familia, así como para la comunidad universitaria, además de que no observar apoyos en el exterior de la UNISON, por lo que propone su renuncia (Consejo Universitario, 1975, acta 6). El Consejo no acepta su propuesta de renuncia y el rector continuó en su cargo.

5 La departamentalización suponía que los estudiantes deberían tomar algunos cursos en los departamentos relacionados con su formación y otros más en sus respectivas escuelas, por lo que se desplazarían constantemente entre uno a otro sitio, lo que evitaría el contacto prolongado entre ellos. A su arribo a Sonora, en 1976, Maren Von der Borch (comunicación personal, 25 de junio de 2018) conoció un par de sociólogos en la entidad; una profesora que impartía varios cursos de sociología en la Escuela de Agricultura y Ganadería y realizaba investigación sobre el agua; la otra persona estudió Sociología, pero no la ejercía profesionalmente. 
institucionalmente, por lo que para 1978 se tuvo que recurrir al apoyo externo para desarrollar el proyecto.

Funcionarios universitarios que trabajaron entre 1976 y 1980 aseguran que el proyecto estuvo a cargo de la CPD (E. Carrión, comunicación personal, 27 de junio de 2018; S. Hernández, comunicación personal, 27 de abril 2018). Para el caso de Sociología, desde 1976 se contó con la colaboración de un par de profesores de El Colegio de México quienes hicieron una propuesta general. Según Maren Von der Borch (comunicación personal, 25 de junio de 2018), la elección de esa institución se basó no solo en su solvencia académica, sino que además era un establecimiento con neutralidad en el tratamiento de la disciplina y sin movimientos estudiantiles visibles, con ello, la UNISON trataba de evitar la posible politización de la futura licenciatura. Von der Borch recuperó la propuesta general que hicieron los asesores externos al proyecto, que solo contenía los trazos más generales, y entregó a la CPD la versión final a inicios de 1978.

En la actualidad, ese documento no es conocido en su totalidad, sin embargo, Planteamientos básicos para la licenciatura en Sociología de la Universidad de Sonora (UNISON, s.f.) forma parte de aquel proyecto original. Este documento contiene una caracterización de las sociedades modernas de ese momento y consigna las materias que conforman el plan de estudios. La idea de fondo en la propuesta es el desarrollo y las tensiones sociales que genera, algo que recuerda la sugerencia del gobernador Carillo Marcor en 1975. Sobre la organización de las materias, los ejes de ordenación son teoría sociológica y metodología, además de cursos de apoyo (Rodríguez, 1990). Más allá de la consistencia del proyecto, importa apuntar que el documento fue ignorado durante los años iniciales de la licenciatura, por lo que no operó en la organización efectiva de la licenciatura u operó solo en las materias impartidas en los primeros semestres de la licenciatura.

En apoyo a esta idea, se tiene que, en 1980, el Consejo Universitario, máximo órgano de gobierno en la UNISON, nombró una comisión para analizar la departamentalización. Los informes de esa comisión muestran una situación institucional crítica, puesto que no se logró diferenciar el departamento de las escuelas. Para sociología, se sostiene que estudiantes y profesores carecen de órgano colegiado interno y cuentan con un plan de estudios incompleto, por lo que se desconocen las materias que deberán cursarse en los semestres finales de la carrera (Rodríguez, 1990; Consejo Universitario, 1980). Dada esta situación, la tarea más apremiante fue integrar el plan de estudios, al menos un listado completo de materias. ${ }^{7}$ Pese a la urgencia, los cursos fueron defini-

$7 \quad$ El grupo responsable del diseño de programas operó efectivamente en 1982, estuvo integrado por una decena de profesores de la propia licenciatura y dirigido por el coordinador de la licenciatura, Pablo Romero, que había cursado el doctorado en Sociología en la UNAM. 
dos dos años después y el plan de estudios fue aprobado con carácter retroactivo por el Consejo Universitario el 29 de abril de 1982 (Consejo Universitario, 1983).

\section{Primeros años, inestabilidad y la búsqueda de sentido}

Además de los problemas señalados, la licenciatura enfrentaba otra adversidad. El proyecto de creación no delineó las características de los futuros maestros y tampoco evaluó la existencia de personal capacitado en la localidad, por lo que al inaugurar el programa se recurrió al personal mejor capacitado en la localidad, preferentemente economistas y abogados, y solo dos profesores formados en sociología. Además, quienes fueron contratados entre 1978 y 1982 debían no ser identificados como adversarios de rectoría y estar alejados de la ideología marxista. ${ }^{8}$ Al término del rectorado de Castellanos Idiáquez (1982) y hasta finales del decenio de 1980, la planta académica fue renovada con 14 nuevos profesores (los antiguos maestros irán abandonado paulatinamente la licenciatura). En general, se trató de jóvenes (28 años de edad promedio), con niveles de escolaridad situados en la licenciatura; seis profesores contaban con la pasantía, cinco con licenciatura y tres con maestría. Además, tenían una característica inédita en la licenciatura, puesto que siete de ellos estudiaron Sociología (dos en la UNISON) y el resto cursó estudios en alguna área de conocimiento cercana a la Sociología (Antropología e Historia). Conviene apuntar que, en todos los casos, la obtención del empleo fue por nombramiento o asignación directa. ${ }^{9}$ A lo largo de la década, de esos maestros, ocho obtuvieron plazas de tiempo completo.

Las actividades académicas desarrolladas por los profesores, incluidos los de tiempo completo, se concentraron en la docencia. En cierta forma, fue razonable que así fuera puesto que el grueso de los académicos no estaba capacitado para la investigación. Pero, ¿qué conocimientos se enseñaban? En sus inicios, la docencia tomó conocimientos generales de las ciencias sociales y solo en unos cuantos casos se usaron referentes sociológicos superficiales. Más adelante, a partir

Hubo ciertas excepciones en este patrón. Algunos profesores ingresaron a la licenciatura a través del Departamento de Letras, que administraba un par de materias (redacción y metodología de la investigación) y que se impartían en prácticamente todas las licenciaturas. Este Departamento fue coordinado por la Mtra. Olga Quiroz Martínez entre 1978 y 1982, y permitió la entrada de jóvenes sonorenses que regresaban de sus estudios universitarios en la $\mathrm{Cd}$. de México e identificados con la ideología marxista. En Sociología, al menos tres profesores fueron contratados de esta manera.

9 De acuerdo a la legislación universitaria de ese tiempo, la contratación de profesores debía ocurrir oficialmente por nombramiento del coordinador del Departamento de Ciencias Sociales, pero dada la inestabilidad política de ese puesto, se procedió al nombramiento por el Consejo Directivo, integrado paritariamente por estudiantes y profesores, y presidido por el coordinador del departamento. A partir de 1986, con la aprobación del Estatuto de Personal Académico, el ingreso de profesores fue fijado por concurso de oposición. 
de 1983, el marxismo fue la teoría que sustentó la enseñanza en prácticamente todas las asignaturas, un trabajo de aquel tiempo sostiene que el marxismo estaba considerado en 45 de las 48 asignaturas del plan de estudios (Rodríguez, 1990). La versión más usada de esta perspectiva estaba contenida en textos interpretativos y no en las fuentes originales. ${ }^{10}$ Aunque el marxismo logró dotar de una cierta unidad teórica a la licenciatura, fue incapaz de aportar un sentido de identidad disciplinaria y profesional, puesto que esta teoría también era enseñada, incluso con los mismos textos, en otras licenciaturas de la UNISON.

Otra fuente de problemas en la licenciatura fue una permanente inestabilidad política, expresada de manera clara en la elección anual de representantes estudiantiles y académicos ante el Consejo Directivo, órgano de gobierno en el Departamento, pero también en el nombramiento o destitución de funcionarios departamentales. La legislación universitaria, en la década de 1980, consideraba un coordinador de departamento y jefes de licenciatura, nombrados por el rector y con duración de cuatro años, pero en el Departamento de Ciencias Sociales ese mecanismo solía combinarse con elecciones estudiantiles anuales. La inestabilidad también impidió generar acuerdos. Durante esta década, no existió algún punto de consenso entre los actores, por el contrario, cualquier aspecto generaba conflictos: el nombramiento y desempeño de los funcionarios departamentales, el plan de estudios, el contenido de las materias y, eventualmente, la contratación y desempeño de los profesores fueron temas de análisis, comúnmente en asambleas o foros de estudiantes y profesores, que se dirimían en votaciones.

La situación en el resto de la UNISON no era distinta a la descrita. En la década de 1980, la universidad también registró constantes procesos electorales para elegir rector, paros estudiantiles, huelgas laborales y limitaciones presupuestales agravadas por la crisis financiera del país. En sus momentos más álgidos, la UNISON fue una institución con fuertes problemas de gobernabilidad (Durand, 2006).

En este escenario fue imposible fijar criterios académicos para la regulación de la licenciatura. Más allá de la docencia, no se conoció otras modalidades de trabajo académico; investigación,

10 En varias de las asignaturas se usaron como textos escolares los manuales soviéticos del marxismo. En este escenario de docencia hubo simplificaciones teóricas. Estudiantes de aquel tiempo recuerdan que al preguntarle a uno de sus profesores por algún autor no tratado en el curso - por ejemplo, T. Hobbes, J. Locke, A. Comte o M. Weber- la respuesta era la misma en todos los casos: Burgués. El adjetivo ilustraba bien la carga ideológica en la enseñanza. Pero también conviene observar la situación cultural de la institución y la localidad; en la UNISON y en todo el estado no existían bibliotecas especializadas en ciencias sociales y tampoco librerías con textos sociológicos. Los libros eran propiedad de los profesores que los prestaban para fotocopiar las secciones usadas en el curso. 
publicaciones, vinculación con organizaciones extrauniversitarias fueron desconocidas. Hay razones que explican la situación. Primero, porque la institución misma se orientaba hacia la docencia, pero también por la inexistencia de liderazgos académicos en la licenciatura. Para fines de la década de 1980, no se observa algún profesor o grupo de profesores que desarrolle otras actividades académicas y menos aún que tenga capacidad de convocatoria en el plano disciplinario.

\section{La reforma universitaria, nuevo piso institucional (1991-2000)}

A inicios de la década de 1990, un grupo de profesores universitarios, en conjunción con el gobierno local, impulsó una reforma de amplias dimensiones en la UNISON. La transformación representó un nuevo marco jurídico universitario, con cambios en el gobierno universitario y la organización académica (Durand, 2006). A partir de 1991, la UNISON quedó organizada jerárquicamente en Unidades Regionales (campus), Divisiones y Departamentos; cada una de estas instancias dirigidas por órganos de gobierno personales y colegiados, exceptuando los Departamentos, que son coordinados por un jefe de Departamento.

El cambio en la UNISON coincide en el tiempo con la puesta en marcha de políticas públicas impulsados por el gobierno federal mexicano que proponen un nuevo patrón de legitimación académica para las instituciones de educación superior (Álvarez, 2004). Este patrón pretende elevar las calidades de los establecimientos, para lo cual dispone de un amplio repertorio de programas que incluye evaluaciones, indicadores y la disposición de bolsas de recursos extraordinarios para quienes adopten estos lineamientos.

La reordenación institucional permitió estabilizar políticamente a la universidad; salvo algunos problemas menores, durante los siguientes 15 años no se registraron conflictos institucionales. También permitió el acceso fluido de programas de política pública; regulación en el ingreso de estudiantes, renovación de planes de estudios, acreditación de programas ante agencias oficiales, programa de estímulos para profesores, fomento al posgrado y la investigación, por mencionar unos cuantos programas (Rodríguez y Durand, 2015).

Para la licenciatura en Sociología, esta reforma universitaria tuvo varios efectos. En primer lugar, desaparece el Departamento de Ciencias Sociales y se genera el Departamento de Sociología y Administración Pública. Con ello, se formaliza la separación de la licenciatura en Derecho, que forma su propio Departamento, algo que en los hechos ocurría desde mediados de la década de 1980.

Respecto a los estudiantes, al igual que para toda la universidad, el ingreso fue regulado mediante examen de admisión que valora aptitudes y conocimientos en distintas áreas; se generaron nuevas opciones de titulación (promedio escolar sobresaliente, experiencia profesional, cursos y presentación de tesis); y se exigió el conocimiento del idioma inglés en un nivel intermedio. 
La reorganización del gobierno universitario tuvo un efecto directo en el terreno político de la licenciatura. Con el nuevo marco jurídico desapareció el órgano de gobierno departamental y se constituyó el Consejo Divisional, integrado por representantes de todos los departamentos agrupados en la División, con ello, las antiguas disputas generadas por elecciones internas concluyeron en poco tiempo. Los conflictos por el poder continuaron, sobre todo en el terreno sindical o en la elección de consejeros divisionales, pero no generaron parálisis como antaño.

El cambio más significativo se produce en la planta de profesores. El fomento a la profesionalización de los académicos impulsado por la UNISON, pero también por el gobierno federal, en especial por el Programa de Mejoramiento del Profesorado (PROMEP) -hoy Programa para el Desarrollo Profesional Docente (PRODEP)-, tuvo resultados en el avance de la escolaridad de los profesores. A partir de la segunda mitad de la década de 1980 y el siguiente decenio, los profesores fueron apoyados con becas institucionales y federales para estudios de posgrado, sobre todo de maestría, y para inicios del siglo los apoyos se destinaron para estudios doctorales (Rodríguez, Guzmán y Durand, 2018). Para finales de la década de 1990, los profesores de tiempo completo habían concluido o estaban por concluir la maestría y un par de ellos iniciaban estudios doctorales.

También en el terreno de la planta académica se incrementó la contratación de maestros, con 11 nuevos profesores, la mayor parte de ellos en puestos de asignatura y solo dos obtuvieron plazas de tiempo completo. Las características de estos profesores no difieren substancialmente respecto a los que ingresaron en la década anterior -jóvenes, con credenciales escolares situadas en la licenciatura- salvo que todos estudiaron Sociología, sobre todo en la propia UNISON. Estos profesores, junto a los incorporados en la década de 1980, conformaron una planta académica de alrededor de 25 maestros. Conviene anotar que no todos los profesores impartieron docencia en la licenciatura puesto que el tamaño de la matrícula era de modestas dimensiones -en 1990, la población estudiantil registra la menor cantidad de estudiantes en su historia (83 estudiantes) (UNISON, 2018)- por lo que una buena parte de los maestros son asignados a cursos administrados por el Departamento, pero impartidos en otras licenciaturas.11

Las actividades académicas continuaron centrándose en la docencia. La escasa investigación desarrollada fue esporádica y asociada a los posgrados cursados por los profesores y no tuvo continuidad. Pero, lo que cambió fue el contenido de la enseñanza. Desde finales de la década

11 El Departamento de Sociología y Administración Pública administra algunos cursos que son ofrecidos en otras licenciaturas, sobre todo de la División de Ciencias Sociales, pero también administra un puñado de cursos en otras áreas. Habitualmente, los profesores de menor antigüedad y escolaridad son programados en estos cursos. 
de 1980, se advierten transformaciones en algunos cursos, sobre todo los relacionados con teoría sociológica. Los textos generales van cediendo terreno frente a las obras de los principales autores de la teoría sociológica; por primera ocasión desde la fundación de la licenciatura se leyeron algunos libros de autores clásicos en la disciplina (Marx, Durkheim y Weber). En la década de 1990, esa práctica estaba en los siete cursos de teoría sociológica y se extendía a otras áreas del plan de estudios.

El impulso dado a la lectura de materiales sociológicos generó cierta identidad disciplinaria. Los profesores de aquel tiempo mostraron a sus estudiantes que la sociología contaba con autores, teorías y conceptos propios, lo que perfiló un campo de estudio independiente. En el plano profesional también la sociología ganó terreno, puesto que una buena parte de los egresados de las décadas de 1980 y 1990 obtuvieron empleo como profesores de educación superior o de bachillerato (Navarro, 2002). Junto a estos avances, algunos académicos lograron figurar en el ámbito institucional y estatal. En el primer caso, se tuvo un par de funcionarios de primer nivel en la administración universitaria entre 1990 y 2001; y el Secretario General del Sindicato de Académicos de la UNISON en dos períodos consecutivos (1993-1997). En el escenario estatal, se contó con un diputado local (1997-2000) y un consejero en el Consejo Estatal Electoral en dos períodos consecutivos (1999-2005).12 Además, dos egresados de la licenciatura figuraron en la política estatal: uno como presidente municipal del segundo municipio más importante del estado, Cajeme (1997-2000) y otro más como diputado local (1997-2000).

Vista en perspectiva, quizá esta fue la década de mayor realce de la sociología en la UNISON, al menos la más prometedora; una planta académica joven y en proceso de formación escolar; enseñanza de contenidos propiamente sociológicos; ascenso profesional de egresados y profesores. Con estas características se esperaría que en los años siguientes la sociología tendría su consolidación. Pero eso no sucedió, al menos no en su totalidad.

\section{Nueva década, problemas no resueltos, 2000-2015}

Durante la primera década de este siglo, la UNISON no registró problemas políticos que amenazaran su estabilidad, por el contrario, fue una institución ordenada y cada vez más alineada a los programas de política pública, sobre todo porque representan fondos financieros extraordinarios. Desde el decenio pasado y con mayor relevancia en este, la universidad realizó esfuerzos

12 Entre 1999 y 2005, de los cinco consejeros titulares del Consejo Estatal Electoral de Sonora (hoy Instituto Estatal Electoral), cuatro eran profesores universitarios y tres de ellos eran maestros de tiempo completo en el Departamento de Sociología y Administración Pública. 
para impulsar el cumplimiento de los programas federales. Destacan, la obtención del doctorado, realización de investigación y publicaciones entre los académicos de tiempo completo; certificación de programas de licenciatura, impulso al posgrado con reconocimiento en el Padrón Nacional de Excelencia en la esfera de la oferta educativa; exámenes de ingreso, dominio del idioma inglés, apoyo a la internacionalización entre los estudiantes.

En términos de gobierno universitario, lo más destacado fue el relevo en la rectoría. En 2001, Jorge Ibarra concluyó su segundo periodo rectoral (1997-2001) y es relevado por Pedro Ortega Romero (2001-2009). A diferencia de Ibarra, que tuvo que pactar con diversos grupos universitarios puesto que su carrera profesional fue externa a la UNISON -en 1983 obtiene un puesto de investigador en el Colegio de Sonora y en 1988 fue rector de esa institución-, Ortega inclinó su administración hacia sus grupos de apoyo universitarios, sobre todo del área de Química e Ingeniería. En su administración no hubo participación de profesores de Sociología (tampoco de Administración Pública), más aún, desde ese año y hasta la actualidad, los académicos de sociología no han sido funcionarios universitarios de primer nivel, por lo que esa vía parece que llegó a su fin. En cambio, en el sindicato de académicos, que siguió siendo una pieza central en la política universitaria, los profesores de sociología conservaron posiciones en prácticamente todos los comités ejecutivos, aunque sin acceder a la máxima posición sindical.

En el plano estatal continuaron teniendo presencia política un par de profesores; uno, como se refiere antes, como consejero en el Consejo Estatal Electoral y otro más como diputado federal (2006-2009). Un puñado de egresados fungieron como líderes de movimientos sociales y dirigentes del Partido de la Revolución Democrática (PRD). Pero, para el grueso de los egresados la obtención de empleo profesional, sobre todo en la docencia, resultó más complicada que en las dos décadas precedentes. Quizás estas dificultades influyeron para que la licenciatura tuviera una disminución en su matrícula; entre 2000 y 2017 la población estudiantil pierde 16\%.

Como efecto en el estancamiento de la matrícula, la contratación de profesores disminuyó considerablemente, solo seis maestros entre 2001 y 2010, aunque cuatro de ellos de tiempo completo. ${ }^{13}$ Lo que aumentó notablemente en este decenio fue la escolaridad de la planta académica, exceptuando un profesor, en 2010 todos los académicos contaban ya con el grado de maestría y cinco con doctorado. El aumento en la escolaridad en parte fue efecto, como en otras regiones del país, de los programas de profesionalización de los académicos (Grediaga, Rodríguez y Padilla,

13 En esta década el sindicato de académicos logró pactar con la universidad que profesores de asignatura con cierta antigüedad y carga laboral ocuparan puestos de tiempo completo. Los profesores de la licenciatura se beneficiaron con estos acuerdos. 
2005). En el caso de la UNISON, la obtención del posgrado, sobre todo el doctorado, se tradujo en avances en el escalafón laboral y obtención de un puesto de tiempo completo, además de la posibilidad de participar en una serie de incentivos económicos.

Las actividades de los maestros, incluidos los de jornada completa, continuaron concentradas en la docencia, con un promedio de dos cursos semestrales por profesor. Solo tres académicos diversificaron de manera permanente sus actividades; en estos casos se desarrolló trabajo de investigación consistente en tres áreas (turismo, género, educación superior); establecieron relaciones de colaboración con diversas organizaciones extrauniversitarias; y participan en posgrados de la propia UNISON. Estos profesores capitalizaron los beneficios de los programas de estímulos y dos de ellos ingresaron en el Sistema Nacional de Investigadores (SNI). El resto no logró acoplarse a las nuevas reglas del trabajo académico impulsados por la UNISON y el gobierno federal.

La enseñanza tuvo un par de adelantos significativos. De un lado, como se señaló antes, el plan de estudios se modificó en 2004, estableciendo una relación estrecha entre conocimientos teóricos y prácticos. De otro lado, la enseñanza se benefició de los posgrados realizados por los profesores, sobre todo, se incorporaron temáticas, referentes teóricos y literatura reciente de ese momento. Conviene anotar que la reforma universitaria de 1991, generó las academias, integradas por profesores, preferentemente de tiempo completo, adscritos a un área de conocimiento común y responsable de ordenar la investigación e intervenir en asuntos académicos. En Sociología, se creó una sola academia que agrupó al grueso de la planta académica (en 2005, la Academia de Sociología contaba con 12 integrantes). El logro más importante de la Academia fue el diseño del plan de estudios en 2004, pero una vez concluida la tarea, el trabajo colegiado tendió a disolverse.

En los últimos ocho años, el proceso más significativo en la licenciatura fue el envejecimiento de la planta académica. Para 2017, la edad promedio de los profesores se situaba en 56 años y 26 años de antigüedad laboral. A partir de ese año, los profesores iniciaron gestiones para obtener su jubilación que se ha visto postergada por la agencia de seguridad social estatal. Además del envejecimiento, jubilación y relevo en la planta académica, la licenciatura enfrenta desafíos en la enseñanza, investigación e innovación educativa. De los tres desafíos, la enseñanza es el que recibió mayor atención, sobre todo por la creación de un nuevo plan de estudios. Aun así, la docencia deberá de incorporar conocimientos internacionales que aparecen mayoritariamente en idioma inglés e innovar la enseñanza de la disciplina mediante nuevos recursos. Pero para la investigación y la innovación no se tienen claras respuestas, lo que genera ciertas incertidumbres. 


\section{Pistas de explicación, institución y actor}

La descripción presentada muestra los esfuerzos por edificar la sociología en la UNISON. EI resultado de estos esfuerzos es una licenciatura centrada en la enseñanza, que no logró diversificar sus actividades, sobre todo hacia la investigación, y con una planta académica en declive por envejecimiento. A la luz de cuatro décadas de existencia conviene preguntarse por qué la sociología evolucionó en esta dirección, por qué no llegó a constituir en una potente escuela. Las respuestas a las interrogantes están en la propia organización universitaria, pero también en las prácticas desarrolladas por los actores, sobre todo de la planta académica.

La literatura especializada reconoce la importancia de la institución por su capacidad para estructurar las acciones humanas mediante sistemas de reglas formales e informales (Hodgson, 2011); también reconoce a la organización como un tipo particular de institución que incorpora jerarquías, cadenas de mando, autoridad y responsabilidades (Alpuche y Bernal, 2015). En esta perspectiva, podría pensarse que la institución -el ajuste a las reglas- determina por completo el accionar de sus integrantes. Esta apreciación no es del todo correcta puesto que los actores, que son las piezas imprescindibles en las instituciones y organizaciones, tienen capacidad de agencia. Dentro de los márgenes que otorga la organización -estructura de gobierno, normas, reglas, incentivos, zonas de incertidumbre- y con una racionalidad limitada a la vez que emociones, el actor puede tomar decisiones, desplegar estrategias, generar acuerdos colectivos e influir en el desarrollo de la institución (Alpuche y Bernal, 2015).

Tomando en cuenta estos referentes, podría considerarse que la UNISON generó las condiciones para la creación de la licenciatura en Sociología. Estas condiciones estuvieron signadas por la inestabilidad política, conflictos entre grupos y amplias zonas de incertidumbre institucional. La licenciatura recogió estas condiciones institucionales, incluso las profundizó, en sus primeros diez años. Más adelante, con la reforma y reorganización universitaria de inicios de la década de 1990, junto a la puesta en marcha de los programas federales para la educación superior, el piso institucional adquiere otras características: estabilidad política, impulso a la regulación de las actividades, alineación con los programas de política pública y fijación de indicadores de desempeño universitario asociados a los programas federales: número de miembros en el PRODEP, en el SNI, acreditación de estudios por agencias de evaluación, actualización de planes de estudios, entre otros. Para la licenciatura en Sociología, el cambio en el escenario institucional significó un esfuerzo por tratar de cumplir con las nuevas reglas, aunque sin lograrlo plenamente, sobre todo en lo que se refiere a los indicadores. 
Este es el piso institucional en que se ubican a los actores. Los referentes anotados señalan que los actores se orientan por la organización, sobre todo por sus reglas, gobierno, posibles beneficios o sanciones. Pero, a lo anterior, es necesario agregar más elementos. Clark (1982) sostiene que los establecimientos universitarios tienen una función ordenadora de actividades e individuos, pero con un elemento que tiende a tensar esa organización y que es el conocimiento (base del establecimiento), que toma forma en las disciplinas. Las disciplinas operan como fundamento del campo de conocimiento practicado, pero también como principio cultural de identidad de sus practicantes (Becher, 2001), por lo que pueden ser consideradas como un componte central en la acción de los integrantes de la universidad. Dada su importancia, conviene preguntarse cómo fue la relación de los actores con la disciplina en la licenciatura en Sociología, cómo orientó sus acciones y qué peso ha tenido en el desarrollo de la licenciatura.

Una constante en la relación entre disciplina y actores (sobre todo de los académicos), es la individualidad. Exceptuando algunos eventos aislados -reforma al plan de estudios en 2004 y 2016-, desde su fundación y hasta la actualidad, las conexiones con la sociología han sido marcadamente individuales; la obtención de literatura especializada, la comprensión de autores, teorías, así como las dificultades de la enseñanza o la indagación han sido afrontadas de manera individual. Por el contrario, el trabajo en colectivo, las discusiones y acuerdos disciplinarios han estado ausentes. Este tipo de prácticas tiene refuerzo en los programas de estímulo al desempeño académico, puesto que ningún programa en curso valora y premia relaciones colectivas.

Otra relación constante con la disciplina es la modalidad de enseñanza. Los profesores (y estudiantes) tratan la sociología básicamente con fines de enseñanza y aprendizaje. Los académicos revisan materiales y seleccionan textos que son tratados en clases, con mayor frecuencia expuestos por profesores o estudiantes en sesiones de trabajo. Es razonable que así sea, puesto que la licenciatura tiene como propósito central la formación de sus estudiantes en esta área. Sin embargo, no existe mecanismo institucionalizado para probar la pertinencia de los saberes enseñados, por lo que son los maestros individualmente quienes deciden los saberes.

Finalmente, el vínculo entre sociología e investigación es inexistente. Salvo unos cuantos casos, la planta académica no se relaciona con la disciplina en términos de indagación. La producción de conocimiento nuevo y la publicación de resultados de indagación son prácticamente desconocidos. Sin esta práctica se pierde, además del avance en el conocimiento mismo, la posibilidad de probar la pertinencia de los referentes teóricos enseñados.

De esta manera, la explicación sobre la sociología en la UNISON se encuentra en los vínculos que tejieron los actores con su institución y disciplina. Esas relaciones reportaron algunos 
logros para una y otros; la institución logró crear y desarrollar una opción profesional, por su parte los profesores lograron puestos de trabajo y los egresados una credencial que los habilita para el ejercicio profesional. Pero, esos arreglos no propiciaron otras formas de desarrollo de la sociología. Más aún, este tipo de relaciones tiene una gran distancia respecto a los patrones de legitimación de las ciencias sociales (incluida la sociología) centrados en evaluaciones periódicas de la producción académica, sobre todo de investigación (Álvarez, 2004).

\section{A manera de corolario}

En los últimos 40 años, la sociología ha pervivido en la UNISON, lo ha hecho bajo cierta ordenación y relaciones, pero ¿podrá continuar así en el futuro inmediato? No se cuenta con elementos suficientes para hacer un sólido ejercicio de prospectiva. No obstante, es posible trazar algunas ideas sobre su futuro inmediato. Además de los añejos problemas arrastrados desde hace años, en especial, la relación con la disciplina, existen algunos desafíos que deberán ser enfrentados. El primero es mantener la población estudiantil. Hasta ahora, la licenciatura y la UNISON misma, operan bajo el supuesto que existen jóvenes interesados en formarse profesionalmente en esta disciplina, por lo que basta con la apertura de inscripciones para tener candidatos. Quizá este supuesto esté llegando a su fin. La diversidad de establecimientos y opciones profesionales en la entidad, así como las modalidades de estudio, ya no aseguran un número de candidatos para estudiar Sociología. En el futuro inmediato habrá que hacer esfuerzos por acercarse a un público más amplio y mostrar las bondades de la disciplina y la profesión para tratar de captar estudiantes.

El segundo desafío se localiza en la enseñanza. Desde su origen, la docencia en Sociología se vale de la lectura de materiales especializados y la exposición del profesor en las sesiones del curso. Este recurso es ampliamente criticado -tedio de estudiantes por escuchar al profesor durante horas, materiales que no resultan atractivos, fatiga de profesores por captar la atención de sus alumnos, entre otros-. Los maestros deberán de innovar la enseñanza mediante nuevos recursos y tecnologías para lograr mejores resultados en la enseñanza, quizá el uso de tecnologías de la información, la ampliación de los espacios de enseñanza y flexibilización de los horarios de curso o la relación efectiva entre saberes, problemas y alternativas de solución sean algunas de las alternativas.

Otro reto importante es quebrar el aislamiento de la sociología. En la historia de la licenciatura, los vínculos de colaboración con la sociedad local son excepcionales; la licenciatura ha seguido una ruta que no recupera problemas locales, por ejemplo, los asuntos de gobierno, empresas u organizaciones sociales no han sido foco de atención y menos aún se han generado alternativas de 
solución. En el futuro inmediato esto deberá de cambiar si se quiere elevar la presencia profesional de la sociología en la entidad.

Pero el reto urgente e inmediato de la licenciatura es la renovación de su planta académica. En los próximos cinco años, la planta académica no podrá continuar laborando o lo hará limitadamente puesto que la edad promedio superará los 60 años de edad. Aunque en la licenciatura y la propia universidad muestran preocupación por el tema, no se han tomado medidas concretas para atenderlo. La UNISON cuenta con un nuevo Estatuto de Personal Académico aprobado en 2015, que fija elevados criterios para el ingreso de profesores -doctorado, experiencia en investigación, publicaciones internacionales, patentes, formación de recursos humanos de posgrado- que solo cumplen áreas de larga data en investigación en la UNISON, que no es el caso de Sociología. Pero la licenciatura no tiene un plan de reemplazo del profesorado, menos aún los criterios internos para el ingreso de los futuros profesores. 


\section{Referencias}

Alpuche, E., \& Bernal, J. (2015). La institución y la organización: un análisis centrado en el actor. Intersticios Sociales, (10), 1-29. Recuperado de http://www.scielo.org.mx/pdf/ins/n10/n10a2. pdf

Álvarez, G. (2004). Modelos académicos de ciencias sociales y legitimación científica en México. México: ANUIES.

Andrade, A. (Coord.) (2015). La sociología en México: temas, campos científicos y tradición disciplinaria. México: UNAM. Recuperado de http://www.librosoa.unam.mx/bitstream/ handle/123456789/427/La_soc\%20_en_Mex\%20Rev_i\%20e.pdf?sequence=3\&isAllowed=y

Ansaldi, W. (2015). Entre perplejidades y angustias. Notas para pensar las ciencias sociales latinoamericanas, En W. Acosta, W. Ansaldi, V. Giordano, \& L. Soler (Coords.), América Latina piensa América Latina. Buenos Aires: CLACSO. Recuperado de http://biblioteca.clacso.edu. ar/clacso/gt/20151026052305/piensa.pdf

Asociación Nacional de Universidades e Instituciones de Educación Superior (ANUIES). (2017). Anuarios Estadísticos de la Educación Superior, Licenciatura. Recuperado de http://www. anuies.mx/informacion-y-servicios/informacion-estadistica-de-educacion-superior/ anuario-estadistico-de-educacion-superior

Becher, T. (2001). Tribus y territorios académicos. La indagación intelectual y las culturas. Barcelona: Gedisa.

Bobadilla, B. (2002). Una aproximación sociológica a los investigadores de la Universidad de Sonora. Tesis. Licenciatura en Sociología de la Universidad de Sonora, México.

Camero, V. (Coord.). (2015). Estudios de teoría e historia de la sociología en México. México: UNAM. Recuperado de http://www.librosoa.unam.mx/bitstream/handle/123456789/383/est_ teoria_hist_soc_enmex.pdf?sequence=1\&isAllowed $=y$

Castro, A. (2013). El siglo XX sonorense, cien años de oportunidad demográfica. En COESPO (coord.), 100 años de población y desarrollo. T. III. México: Gobierno del Estado de Sonora. Recuperado de http://www.coespo.sonora.gob.mx/documentos/publicaciones/ CienAnosdePoblacionyDesarrolloTomoll.pdf

Clark, B. (1982). El sistema de educación superior. Una visión comparativa de la organización académica. México: Nueva Imagen/UAM-Azcapotzalco.

Consejo Universitario (1976). Acta 18 del Consejo Universitario de la Universidad de Sonora. Recuperado de http://www.archivohistorico.uson.mx/into/servicios/Actas\%20del\%20 Consejo\%20Universitario.htm 
Consejo Universitario (1977). Acta 25 del Consejo Universitario de la Universidad de Sonora. Recuperado de http://www.archivohistorico.uson.mx/into/servicios/Actas\%20del\%20 Consejo\%20Universitario.htm

Consejo Universitario (1978). Acta 27 del Consejo Universitario de la Universidad de Sonora. Recuperado de http://www.archivohistorico.uson.mx/into/servicios/Actas\%20del\%20 Consejo\%20Universitario.htm

Consejo Universitario (1980). Acta 42 del Consejo Universitario de la Universidad de Sonora. Recuperado de http://www.archivohistorico.uson.mx/into/servicios/Actas\%20del\%20 Consejo\%20Universitario.htm

Consejo Universitario (1983). Acta 80 del Consejo Universitario de la Universidad de Sonora. Recuperado de http://www.archivohistorico.uson.mx/into/servicios/Actas\%20del\%20 Consejo\%20Universitario.htm

Durand, J.P. (2006). Poder, gobernabilidad y cambio institucional en la Universidad de Sonora. México: ANUIES.

Girola, L., \& Zabludovsky, G. (1990). La teoría sociológica en México en la década de los ochenta. Sociológica, 6(15), 1-44. Recuperado de http://www.sociologicamexico.azc.uam.mx/index. php/Sociologica/article/view/881/854

Grediaga, R., Rodríguez, R., \& Padilla, L. (2005). Políticas públicas y cambios en la profesión académica en México en la última década. México: ANUIES.

Hodgson, G. (2011) ¿Qué son las instituciones? CS, (53), 20-53. Recuperado de http://www.scielo. org.co/pdf/recs/n8/n8a02.pdf

Jiménez, R. (1976). Movimiento campesino en Sonora. Cuadernos Políticos, (7), 67-78. Recuperado de http://www.cuadernospoliticos.unam.mx/cuadernos/contenido/CP.7/CP7.7RubenJimenezR. pdf

Lara, B., Velázquez, L., \& Rodríguez, I. (2007). Especialización económica en Sonora. Características y retos al inicio del nuevo milenio. Región y Sociedad, XIX(especial), 27-49.

Molina, G., Carrión, E., Larios, R., León, C., \& Hernández, S. (1979). Modelo de departamentalización de la Universidad de Sonora. Revista de la Educación Superior, 8(30), 1-10. Recuperado de http://publicaciones.anuies.mx/pdfs/revista/Revista30_S3A1ES.pdf

Moreno, A. (2015). Cambio y continuidad institucional en la historia de la Universidad de Sonora, 1938-1982. Tesis. Doctorado en Ciencias Sociales, Universidad de Sonora, México. 
Moya L., \& Olvera, M. (2013). La historiografía de la sociología en México; balances y una propuesta de interpretación desde la historia conceptual. Sociológica, 28(80), 7-40. Recuperado de http://www.scielo.org.mx/pdf/soc/v28n80/v28n80a1.pdf

Navarro, A. (2002). La profesión de sociólogo en Sonora. Tesis de Maestría. El Colegio de Sonora, México.

Rodríguez, R. (1990). Una aproximación del currículo. El caso de la licenciatura en Sociología de la Universidad de Sonora. Tesis. Maestría en Innovación Educativa, Universidad Autónoma de Querétaro, México.

Rodríguez, R., Guzmán, A., \& Durand, P. (2018). Programa de becas para académicos en la Universidad de Sonora, balance general. En R. Jorquera y A. Avendaño (Coords.), Instituciones y actores sociales. Perspectivas de la investigación sociológica en la Universidad de Sonora. Hermosillo: UNISON/Qartuppi.

Rodríguez, R., \& Durand, P. (2015). Quince años después. Nueva visita a la UNISON. En A. Acosta (coord.), Historias paralelas: 15 años después. México: UACJ.

Universidad de Sonora (s.f.). Planteamientos básicos para la Licenciatura en Sociología de la Universidad de Sonora. Documento interno.

Universidad de Sonora (UNISON). (1975). Reestructuración Integral de la Educación Profesional y Técnica de la Universidad de Sonora. Revista de la Educación Superior, (15), 1-9. Recuperado de http://publicaciones.anuies.mx/pdfs/revista/Revista15_S2A2ES.pdf

Universidad de Sonora (UNISON). (2018). Dirección de Planeación. Sistema de Información Estadística. Universidad de Sonora. Recuperado de http://www.planeacion.uson.mx/sie. htm 


\section{Capítulo V}

Hacia una sociología de las TIC en la educación. Trayectoria de una elaboración conceptual*

Miguel Ángel Casillas Alvarado **

Alberto Ramírez Martinell ***

* Este trabajo se inscribe como parte del proyecto Brecha digital entre estudiantes y profesores de la Universidad Veracruzana: capital cultural; trayectorias escolares y desempeño académico; y grado de apropiación tecnológica. Los principales productos de este proyecto se encuentran en www.uv.mx/ blogs/brechadigital/pubicaciones. Una versión preliminar de este documento sirvió de base para la ponencia que presentamos en el congreso de la Asociación Latinoamericana de Sociología (ALAS) en Montevideo en 2017.

** Investigador del Centro de Investigación e Innovación en Educación Superior de la Universidad Veracruzana. Integrante del Sistema Nacional de Investigadores. Contacto: mcasillas@uv.mx

*** Investigador del Centro de Investigación e Innovación en Educación Superior de la Universidad Veracruzana. Integrante del Sistema Nacional de Investigadores. Contacto: albramirez@uv.mx 


\section{Introducción}

En este capítulo exponemos de manera sintética la propuesta sociológica que hemos construido para tratar de comprender la incorporación de las Tecnologías de la Información y la Comunicación (TIC) a la educación. Se trata de un ejercicio en el que se pone en claro no sólo un proceso de construcción de categorías y conceptos pertinentes para el conocimiento sociológico, sino en el que también se ubican los referentes desde los cuales se interpreta este proceso histórico. La elaboración de esta perspectiva no ha sido fácil, pues hemos tenido que construir conceptos para entender nuevas realidades, apoyándonos en nociones sociológicas diseñadas para otra época, pero que funcionaron como los únicos recursos de los cuales pudimos asirnos en esta aventura intelectual. Desde 2012 comenzamos a estudiar la incorporación de las TIC a la educación y nuestra perspectiva ha ido madurando paulatinamente.

La revolución tecnológica que deriva del uso masivo de computadoras, aplicaciones y otros recursos digitales (Castells, 2002; 2001), así como el exponencial crecimiento de Internet, ha dado lugar a una nueva cultura digital (Lévy, 2007; Castells, 2002; 2001). La escuela y la educación no han estado exentas de estas transformaciones (Brunner, 2003), dando lugar a nuevas configuraciones sociales y educativas. En ese contexto, las ciencias sociales tienen el desafío de proponer herramientas analíticas para comprender el proceso de incorporación de las TIC a la educación. Como sucede con frecuencia en la historia del pensamiento sociológico, si logramos comprender cómo ha sido la incorporación de las TIC a la educación, podremos contar con pistas para interpretar sociológicamente lo que está sucediendo en las profesiones, en el campo artístico o en el campo científico, donde se han transformado las bases de la producción, la distribución y el consumo de los bienes culturales. 
Para comprender este proceso hemos recuperado la teoría sociológica de Pierre Bourdieu y formulado una aproximación sociogenética sobre la evolución de las TIC y su llegada al campo educativo, hemos también construido las definiciones y la operacionalización de dos conceptos clave: el capital tecnológico y el habitus digital. Ambos conceptos (Casillas, Ramírez y Ortiz, 2014; Casillas y Ramírez, 2018) los hemos abordado en otros espacios, en los que hemos descrito nuestra visión a modo de herramientas analíticas que nos han permitido pensar en la experiencia escolar enriquecida por TIC de estudiantes y profesores de todos los campos del conocimiento y niveles educativos.

En las sociedades modernas, el grado de apropiación tecnológica resulta crucial para explicar nuevos fenómenos de dominación cultural, de exclusión social, de marginalidades en el seno de la sociedad del conocimiento que prolongan y exaltan las tradicionales formas de exclusión y dominación social. Las ciencias sociales tienen la obligación de ensayar explicaciones sobre la génesis de lo que está sucediendo, de hacer visibles a los nuevos imperios y de denunciar las nuevas desigualdades.

\section{Dimensión histórico-social}

Cualquier aproximación sociológica sobre las TIC exige una reflexión histórico-social. Se trata de una perspectiva en la que se ubique la condición nacional en términos de la evolución global de las TIC, la incorporación de los países a la sociedad del conocimiento y la llegada de las TIC a las instituciones educativas. Es imprescindible saber dónde estamos ubicados en relación con los avances de otras instituciones y naciones. Como hemos estudiado, México, por ejemplo, guarda una condición periférica, donde a diferencia de los países desarrollados, su población tiene una muy desigual distribución y acceso a los recursos informáticos. Mientras que en los países desarrollados prácticamente se ha universalizado el acceso a Internet y la cultura digital ha transformado cientos de servicios, en México sólo 40\% de la población tiene acceso a Internet y la digitalización de servicios es incipiente. Más aún, habríamos de resaltar que al interior de los países latinoamericanos la distribución del acceso a Internet es profundamente desigual; en la Ciudad de México el acceso guarda proporciones similares a las de las ciudades del primer mundo, mientras que en las zonas rurales e indígenas el acceso es completamente marginal (Casillas, Ramírez, Carvajal y Valencia, 2016).

La perspectiva histórica nos obliga a pensar en el tiempo. En efecto, la evolución en el desarrollo de la cultura digital guarda temporalidades diferentes entre las naciones y a su interior. En Estados Unidos, en Japón y en Europa, el uso de las computadoras, Internet y la digitalización 
de servicios lleva años, mientras que en algunas regiones de los países latinoamericanos el acceso a los recursos digitales no solamente es reciente sino incipiente.

En ambas dimensiones, la cobertura o el alcance social de los recursos digitales, por un lado, y en términos de la antigüedad de los procesos, por el otro, evidencian profundas desigualdades entre las naciones desarrolladas y las de América Latina, que a su vez guardan grandes desigualdades a su interior. Destacan dos: las diferencias geográficas que contrastan regiones ampliamente dotadas de recursos tecnológicos desde hace mucho tiempo con aquellas regiones con escasa y reciente dotación tecnológica. Por otro lado, las diferencias entre las clases y los grupos sociales también son dignos de mención, pues el acceso a recursos y bienes tecnológicos está claramente asociado con las diferencias económicas y con el capital cultural que facilita una amplia apropiación de esos recursos tecnológicos.

En esta dimensión de carácter histórico social se debe inscribir la reflexión específica sobre la incorporación de las TIC a la educación y la dotación de recursos tecnológicos a las escuelas. En cada país, las políticas educativas han evolucionado de modo diferente y con resultados muy diversos. Específicamente, para el caso mexicano está documentado cómo estas políticas han sido retóricas, sin diagnósticos ni planes bien formulados, con enormes dosis de improvisación y con gastos mal aplicados (Lizarazo y Andión, 2013; Martínez, 2017).

Según The Global Information Technology Report de 2016, el número de escuelas con acceso a Internet es muy variable entre los países. Arriba de la media se encuentran en los diez primeros lugares: Islandia, Singapur, Noruega, Suecia, Holanda, Gran Bretaña, Estonia, Emiratos Árabes Unidos y Hong Kong. Los países latinoamericanos mejor colocados son Uruguay en el lugar 22, Panamá en el 52 y Costa Rica en el 53. Alrededor de la media, hay países como España (67) y Azerbaijan (68), de América Latina destacan Jamaica (73), Argentina (75), Ecuador (76), Colombia (77) y Guyana (78). En la parte baja de la tabla, los países más atrasados son Guinea (137), Burundi (138) y Chad (139); de América Latina, México ocupa el lugar 90, Perú el 95, Brasil 97, Guatemala 98, El Salvador 99, Bolivia 197, República Dominicana 108, Venezuela 111, Paraguay 125, Nicaragua 129 y Haití 130.

A nivel de la educación superior las cosas son muy diferentes entre subsistemas y modalidades. A falta de mayor información, el caso de las universidades públicas puede ilustrarse en una unidad de análisis más pequeña, al reconstruir el proceso histórico mediante el cual se incorporaron las TIC a la vida cotidiana de la Universidad Veracruzana, para ello, hemos realizado una investigación en la que buscamos construir una memoria institucional en materia de TIC que nos ha permitido identificar que su evolución es un proceso reciente, que sigue en curso, y que no ha sido documentado de manera formal y que de no hacerlo se olvidará (Casillas y Ramírez, 2015a). 
Analíticamente, hemos establecido una periodización, fundamentando que la incorporación de las TIC a las instituciones de educación superior se asocia con: el grado de desarrollo y la evolución de las propias tecnologías; el tipo de políticas nacionales; el grado de confianza en las TIC; y el potencial de los agentes institucionales, el volumen de recursos económicos e institucionales disponibles, y el empuje decisivo de determinados promotores o animadores.

Los periodos de incorporación de las TIC a la universidad que definimos son seis hitos tecnológicos que cambiaron las formas de operar en las Instituciones de Educación Superior (IES), sucediendo algunos de ellos prácticamente en paralelo (tabla 1).

Tabla 1. Periodos de la incorporación de las TIC a la universidad

\begin{tabular}{lc}
\multicolumn{1}{c}{ Hito tecnológico } & Período \\
Grandes computadoras & $1959-1974$ \\
\hline Mini Computadoras & $1975-1985$ \\
\hline Computadora personal & $1985-2000$ \\
\hline Redes de computadoras & $1985-1990$ \\
\hline Universidad en Internet & $1996-2003$ \\
\hline Computación social & $2004-2014$ \\
\hline
\end{tabular}

Con la llegada de las grandes computadoras de postguerra (1959-1974), las IES que pudieron adquirir alguno de estos equipos lo hicieron para mejorar sus procesos financieros y de administración. Unos años más tarde, las Mini Computadoras (1975-1985) vieron con mayor aceptación su ingreso a los departamentos de administración y finanzas de las IES, pero también a las facultades de ingeniería y ciencias, dando pie al nacimiento de las carreras de informática y computación. Con la miniaturización de componentes electrónicos y el abaratamiento de los equipos de cómputo, para 1985 las computadoras personales se volvieron símbolos de modernización institucional por lo que su masificación no se hizo esperar. Los paquetes informáticos diversificaron las características de sus usuarios y con las redes de computadora (1985-1990) laboratorios, oficinas y dependencias de las IES se conectaron entre sí. Una conectividad hacia fuera de la Universidad era inminente y con la popularización de Internet (1996-2003) en las IES el acceso a la información se volvió crucial. El manejo de la información, la presencia digital y la reputación en línea aunados al boom de las redes sociales, permitieron que las IES maduraran en el tema del acceso a la información para dar paso al periodo de la computación social (2004-2014). 
De acuerdo con lo que hemos explorado, podemos exponer como conclusiones parciales sobre la evolución histórica institucional los siguientes rasgos distintivos:

La consolidación de una infraestructura de conectividad que lleva Internet a prácticamente todas las dependencias de las universidades; la incorporación de las TIC al currículum con la creación de materias especializadas en la fase inicial de la formación profesional; la masificación de las computadoras personales y la popularización de los paquetes informáticos de propósito específico que diversificaron las características de los usuarios de sistemas de cómputo.

Según nuestra experiencia, en la evolución histórica que lleva la incorporación de las TIC a las universidades han dominado las ocurrencias y la buena voluntad (en lugar de decisiones informadas, legítimas, transparentes y sujetas a evaluación); ha predominado la improvisación y ha estado ausente la planeación. Hasta ahora, la posibilidad de que las TIC se incorporen a la enseñanza ha sido resultado del azar, cuando debería de ser la base de la experiencia escolar en cada materia. En las instituciones predominan las políticas generales para el desarrollo tecnológico, cuando deberían primar las necesidades de las disciplinas académicas. Hasta ahora, dominan las adquisiciones de equipos basadas en criterios comerciales o en decisiones personales, cuando deberían estar orientadas por criterios académicos, en procesos transparentes y con base en licitaciones públicas.

Finalmente, hemos observado que se trata de una historia que debemos documentar en cada una de las instituciones, pues se están transformando de manera radical los procesos y funciones universitarias (ocurren cambios en los modos de enseñar, de producir y difundir el conocimiento); se están reestructurando los espacios universitarios convencionales (como las aulas, los laboratorios, las bibliotecas), y se está reconfigurando la noción del espacio con la conformación de nuevos ambientes abiertos (wifi) y virtuales.

\section{Dimensión cultural}

La nueva cultura digital comprende el conjunto de referentes, técnicas, prácticas, actitudes, modos de pensamiento, representaciones sociales y valores que se desarrollan en torno a Internet, al ciberespacio y al uso masivo de las computadoras. La revolución tecnológica ha creado un nuevo mundo simbólico que comprende los modos de pensamiento de las personas y los grupos sociales: tanto el conjunto de referentes desde los cuales se mira y se interpretan los usos de las TIC; como la ampliación del dominio técnico; los usos y prácticas; las actitudes, las representaciones sociales y valores. 
La cultura digital ha transformado los antiguos espacios sociales: la información es ampliamente accesible; ha ocurrido un aceleramiento del tiempo histórico y un redimensionamiento del mundo. Han cambiado la comunicación humana, las prácticas e interacciones sociales cotidianas. Se han diversificado las formas de encuentro e interacción. Todas las ramas y procesos económicos han incorporado las computadoras e Internet en sus prácticas laborales. Se ha favorecido la rendición de cuentas y la transparencia. Aparecieron y se expandió el uso de las redes sociales, se alienta el consumo y las ideologías dominantes dan lugar a dinámicas sociales estandarizados de escala global (Lévy, 2007; Casillas y Ramírez, 2015b; Casillas y Ramírez, 2016).

En términos de la educación, la nueva cultura digital está dando lugar a importantes transformaciones: se están desarrollando nuevas formas de lectura, escritura, aprendizaje, producción curaduría y difusión del conocimiento. La figura de maestro, el rol de estudiante, la escuela y sus procesos están siendo transformados con una serie de incorporaciones tecnológicas. Los recursos de aprendizaje se están modificando en todos los niveles educativos. La comunicación entre pares y docentes se da en línea, las tareas y proyectos se entregan en formato electrónico. Hay un creciente libre acceso a bienes culturales que antes eran difíciles de alcanzar y de uso muy exclusivo (Brunner y Tedesco, 2003; Tedesco, s.f.).

En educación básica, desde hace más de 20 años se diseñaron y agregaron a la malla curricular asignaturas de computación para secundarias y bachilleratos públicos y como un distintivo de modernidad se hizo lo propio en escuelas primarias y preescolares cuyo origen de financiamiento es privado. La alfabetización digital en el sistema educativo mexicano consistió en sus inicios en la enseñanza del software de oficina y del sistema operativo de Microsoft. Sin embargo, los contenidos evolucionaron poco, añadieron el manejo de internet y, en algunos casos, se agregó la robótica en escuelas privadas o en educación media superior como una opción moderna y alternativa a la ofimática.

El enfoque de ese primer momento de alfabetización digital en México fue correcto, el problema consistió en que fue prácticamente nula la adaptación a lo que es hoy el mundo digital. El plan de estudios basado en ofimática se diseñó en los albores del año 2000, sin considerar que los dispositivos digitales portátiles, el software especializado, los múltiples sistemas operativos, la web 2.0, las redes sociales, los mensajeros instantáneos y la convivencia en Internet eran actividades comunes de una cultura digital.

Para lograr pasar de enseñar con TIC (presentaciones y repositorios digitales) a enseñar para las TIC se necesita preparar a los profesores de educación básica, para que sean ellos los que puedan enseñar los contenidos clave y su relación con las TIC. Saber crear texto y texto enriquecido para la materia de Español; saber manipular conjunto de datos para el caso de Matemáticas, 
saber usar dispositivos de georeferenciación y mapas en geografía o saber consultar bibliotecas digitales o fuentes de información especializada cuando la empresa es encontrar datos históricos, científicos o artísticos. Las TIC podrán dosificarse en los contenidos de la educación básica en la medida en que el perfil tecnológico del egresado de las escuelas normales lo considere (Ramírez y Casillas, 2017, p. 13).

Para el caso de la educación superior hemos podido constatar que se han transformado la gestión, la administración, la enseñanza, la investigación, la difusión, y las formas de comunicación e intercambio. La enseñanza se modifica con la utilización de programas informáticos, bases de datos de alta especialización, simuladores y el estudio con libros accesibles en formato digital. Los nuevos modos de producción del conocimiento tienen una base tecnológica muy desarrollada en la que el mayor dinamismo del cambio tecnológico está pasando por las disciplinas académicas y el desarrollo del software especializado. En las universidades latinoamericanas la incorporación de las TIC y los cambios asociados con ello han ocurrido de manera improvisada, escasamente regulada, sin conocimiento de cuánto saben nuestros alumnos cuando ingresan y sin precisión sobre cuánto queremos que sepan al egresar. Cada día es más apremiante un diagnóstico nacional sobre el grado de apropiación tecnológica de profesores y estudiantes.

\section{TIC, trabajo académico y profesiones}

A pesar del sentido común y de las políticas institucionales en las que se ve a la integración de las TIC como un proceso homogéneo en todos los campos profesionales; la realidad es que dada la naturaleza del trabajo académico (Clark, 1987) y la heterogeneidad institucional que estructura y delimita el desarrollo de las disciplinas académicas y las profesiones, la incorporación de las TIC sucede de manera diferenciada. Hay campos del conocimiento altamente tecnologizados y otros con diversos grados de consolidación de su perfil tecnológico.

Hemos observado en diversas intervenciones ${ }^{1}$ que hay una enorme y creciente diversificación del equipo y los dispositivos, del software y las aplicaciones, de los modos de usar los recursos tecnológicos y apropiarse del ciberespacio entre las disciplinas y las profesiones académicas. Siguiendo a Becher (2001), hemos comprobado que los cuadrantes propuestos para diferenciar la naturaleza del trabajo académico no sólo son pertinentes para observar la densidad paradigmática, sino resultan ejemplares para observar el modo diferenciado en que se están incorporando las TIC a la educación (Casillas, Ramírez, Luna y Marini, 2017; Ramírez y Casillas, 2015a).

1 Véase reportes de los talleres para la incorporación de las TIC al currículum: https://www.uv.mx/ blogs/brechadigital/reportes_sd/ 


\section{Capital tecnológico}

Una nueva especie de capital cultural (Bourdieu, 1980; 1987; 1997) se configura y valoriza en la universidad: el capital tecnológico, que funciona como capital cultural cuando los estudiantes lo ponen en juego para avanzar en su trayectoria y competir en el campo escolar.

La diferencia en el logro estudiantil puede explicarse por las diferencias en el volumen del capital tecnológico. Pero las diferencias en el desempeño entre los estudiantes no son casuales ni naturales y encubren marcadas discrepancias sociales que se expresan como diferencias escolares.

El uso de las TIC en la educación, valoriza un nuevo tipo de saberes y exige un nuevo tipo de habilidades y destrezas que no han sido plenamente reconocidas: no hay un diagnóstico que permita saber qué disposiciones poseen estudiantes y profesores, por lo que buscamos construir una interpretación de corte sociológico de las diferencias que distinguen a los estudiantes y profesores por su grado de apropiación tecnológica, por su grado de afinidad tecnológica, por su disponibilidad y por el grado de acceso que tienen. Sostenemos que las diferencias en las dotaciones de capital tecnológico están asociadas a las condiciones de vida, al origen social y a la historia personal de los estudiantes, que los hace ser diversos y desiguales en sus dotaciones culturales, aunque en las instituciones se estén tratando como si fueran iguales.

Nuestro propósito es observar cómo ponen en operación este capital tecnológico los profesores y los estudiantes en la escuela. Hemos comprobado en el contexto universitario, cómo este nuevo tipo de saberes y habilidades se distribuye de manera desigual, genera opiniones y actitudes diferenciadas y permite grados de desempeño distintos (Casillas, Ramírez y Ortega, 2016).

El capital tecnológico comprende al conjunto de saberes, savoir-faire (saber hacer) y saber usar que tienen los agentes sociales de las TIC. Su posesión es un atributo que diferencia a los individuos y les permite competir de mejor manera en muy diversos espacios sociales. En el campo escolar se establece una competencia para establecer quiénes obtienen las mejores notas y tienen un mejor desempeño. Se trata de un proceso competitivo, donde los distintos individuos ponen en juego los recursos que utilizan con el propósito de maximizar sus beneficios y obtener las mejores recompensas escolares. Cuando observamos el capital tecnológico en el campo escolar ponemos el acento en el proceso educativo, en el sentido con que los distintos agentes escolares utilizan las TIC en la escuela.

Consideramos que el capital tecnológico, en tanto nueva especie del capital cultural, también se puede medir en términos de sus estados: incorporado, objetivado e institucionalizado.

El capital tecnológico incorporado comprende el tiempo de trabajo invertido durante el que se va construyendo el habitus (conjunto de disposiciones incorporadas / estructuras estruc- 
turantes). Resulta de un proceso de socialización que tiene un contenido (conocimientos, prácticas, instrumentos) y supone las condiciones de su operación (tiempo, dinero, valoración familiar). Comprende el grado de domino sobre las TIC y el savoir-faire (utilización, uso, destrezas) sobre TIC que tienen los agentes sociales y el sentido con que las utilizan, perciben y valoran.

Para medir los conocimientos digitales y el grado de dominio que tienen los agentes sobre las TIC, construimos un índice que mide el grado de apropiación tecnológica que puede poseer una persona. Este índice establece 10 saberes digitales, en tanto síntesis del enorme conjunto de conocimientos digitales que tienen las personas (Casillas et al., 2014; Ramírez y Casillas, 2015). Los saberes digitales y sus definiciones operativas se presentan en la tabla 2.

\section{Tabla 2. Saberes digitales}

Saber digital

Usar dispositivos

Administrar archivos

Usar programas y

sistemas de información

especializados

\section{Definición}

Conocimientos y habilidades necesarias para la operación de sistemas digitales mediante la interacción con elementos gráficos del sistema operativo; físicos; o a través del establecimiento de conexiones con dispositivos periféricos o con redes de datos.

Conocimientos y habilidades necesarias para la manipulación, edición y transferencia de archivos ya sea de manera local, por proximidad o de forma remota.

Conocimientos y habilidades referidas a dos elementos: al software cuyas funciones y fines específicos son relevantes para enriquecer procesos y/o resolver tareas propias de una disciplina; y a las fuentes de información digital especializadas.

Crear y manipular contenido de texto y texto enriquecido Conocimientos y habilidades para la creación, edición, formato y manipulación de los elementos de un texto plano; o la inserción de elementos audiovisuales de un texto enriquecido.

Crear y manipular conConocimientos y habilidades para la creación, agrupación, edición, manipujuntos de datos lación y visualización de datos.

Crear y manipular Conocimientos y habilidades para la identificación; reproducción, medios y multimedia producción, edición e integración de medios en un producto multimedia. 
Saber digital

Comunicarse en entornos digitales

Socializar y colaborar en
entornos digitales

Ejercer y Respetar una Ciudadanía Digital

Literacidad Digital

\section{Definición}

Conocimientos y habilidades para transmitir información a uno o más destinatarios; o recibirla de uno o más remitentes de manera sincrónica o asincrónica.

Conocimientos y habilidades orientadas a la difusión de información, interacción social presencia en web y al trabajo grupal mediado por web.

Conocimientos, valores, actitudes y habilidades referentes a las acciones y usos sociales de la información; ejercicio de la ciudadanía y a las normas relativas a los derechos y deberes de los usuarios de sistemas digitales en el espacio público y específicamente en el contexto escolar.

Conocimientos, habilidades y actitudes dirigidas a la búsqueda efectiva de contenido digital y a su manejo, mediante la consideración de palabras clave y metadatos; adopción de una postura crítica; aplicación de estrategias determinadas para un manejo adecuado de la información.

Fuente: Ramírez y Casillas (2015).

El capital tecnológico objetivado comprende el conjunto de objetos tecnológicos que son apropiados en su materialidad y en su significado simbólico por los agentes sociales. Se valora la propiedad y el acceso a los objetos y los dispositivos tecnológicos, recursos de conectividad, software (comercial, libre o apócrifo), grado de actualización (versión), dominio sobre paquetería y programas.

El capital tecnológico institucionalizado comprende el conjunto de títulos, diplomas y certificados que validan, instituyen y reconocen saberes, conocimientos y habilidades. Referentes que recubren de un valor simbólico al diploma (factor institución, grado de prestigio) y definen un status jerárquico por el tipo de conocimiento consagrado (Casillas et al., 2014).

\section{Habitus digital}

La noción de habitus nos orienta a la reflexión sobre el funcionamiento sistemático del cuerpo socializado -incluida la postura corporal-, hacia el conocimiento incorporado -saber, saber-hacer, conocimiento del juego y de sus leyes-, que es determinante para las estrategias de los agentes, de sus prácticas y de sus formas de conducta (Bourdieu, 1992; Bonnewitz 2003; Chevallier y Chauviré, 2011). 
Siguiendo a Bourdieu:

Por habitus se entiende un sistema de disposiciones durables y transportables. Disposiciones, es decir, inclinaciones a percibir, sentir, hacer y pensar de una cierta manera, interiorizadas e incorporadas, frecuentemente de un modo no consciente, por cada individuo, a partir de sus condiciones objetivas de existencia y de su trayectoria social. (Casillas, 2003, p. 75)

Durables, pues están fuertemente enraizadas; transportables, pues las disposiciones adquiridas en ciertas experiencias sirven para otras; sistema, pues las disposiciones tienden a estar unificadas entre sí (Corcuff, 1995).

El habitus digital comprende el conjunto de capacidades y prácticas que los individuos desarrollan en el marco de la cultura digital. Por un lado, estructura el comportamiento en un entorno virtual, permite su reconocimiento y comprende la capacidad de podérselo apropiar (trabajar, comunicarse, interactuar y navegar en ambientes virtuales). También significa saber buscar, discriminar, proteger, salvaguardar y reconocer derechos de autor, lo que condiciona una nueva moralidad, donde los conceptos de privacidad y de propiedad se están reconfigurando de manera radical.

Por otro lado, el habitus digital comprende las representaciones sociales que los individuos tienen sobre las TIC, sobre su uso y su preeminencia en la vida social contemporánea. Opiniones, creencias y valoraciones conforman sistemas de representación que orientan y definen a los individuos en una configuración histórico-social determinada.

El habitus digital implica conocimientos, habilidades y maneras pertinentes de usar las TIC. Se requiere experiencia, familiaridad con equipos digitales, plataformas y ambientes virtuales, es preciso el acceso a determinadas tecnologías y el dominio de ciertos lenguajes. Comprende un grado de familiaridad con los saberes digitales de carácter informático.

Por último, el habitus digital considera al sentido práctico con que los individuos están utilizando o poniendo en práctica las TIC en los diferentes espacios sociales. Además de la expansión del software de oficina básico, hay una explosión de programas, sitios, bibliotecas digitales, repositorios, páginas web, blogs, que reflejan la intensa división del trabajo que acompaña la incesante especialización en los oficios y profesiones, que se expresan en lo que hemos llamado la dimensión de las disciplinas académicas (Morales y Ramírez, 2015; Morales, Ramírez y Excelente, 2015; Ramírez, Casillas y Contreras, 2014). Al mismo tiempo, los individuos incorporan su posición 
en el sistema cultural digital, como consumidores, productores o administradores de contenido digital.

El habitus digital, en tanto conjunto de disposiciones incorporadas refiere a la dimensión cognitiva de los saberes digitales, esto es, al conjunto de conocimiento teóricos y experienciales que representan un grado de dominio diferente de los saberes digitales de carácter informático (Ramírez y Casillas 2015; Casillas et al., 2014).

El habitus digital, en su sentido práctico comprende saber utilizar, interactuar y utilizar de un modo práctico los dispositivos digitales y la información. Se trata de saberes prácticos, del sentido de uso y de saber usar de un modo eficiente y pertinente las TIC. Se trata se observar lo que están haciendo los estudiantes, conocer el aspecto instrumental, el saber hacer puesto en práctica. Por lo mismo, la dimensión instrumental de los saberes informáticos funciona como guía y orientación de la observación etnográfica en el aula.

El habitus como estructura de la cultura digital, comprende la dimensión actitudinal y de comportamiento en la red, lo que hemos Ilamado como ciudadanía digital y literacidad digital.

\section{Conclusiones}

Los nuevos entramados sociales exigen posturas renovadas que ayuden a explicar la realidad social. Aquí se han formulado las bases para una aproximación sociológica para entender la incorporación de las TIC a la educación.

Amparados en la sociología de Bourdieu e inspirados en Norbert Elias nos hemos propuesto operacionalizar nuevos conceptos para interpretar el cambio cultural que representa el uso común de las TIC en los distintos ámbitos de la vida social. Para el caso de la incorporación de las TIC a la educación y específicamente al caso de la educación superior, nos propusimos explorar esta nueva faceta de la vida escolar para ayudarnos a pensar en el cambio social que está ocurriendo.

Las valoraciones que tienen los jóvenes estudiantes sobre la tecnología digital, sus diferentes formas de aproximarse a sistemas de información, plataformas de comunicación o redes sociales y la cada vez más creciente necesidad de hacer uso de herramientas digitales de alto grado de especialización para resolver problemas disciplinarios, han forzado un cambio en los métodos tradicionales de enseñanza.

Las instituciones de educación superior deben trascender la visión de la incorporación de las TIC para la presentación de contenidos en el aula y para disponer de recursos fuera de ella. Las presentaciones electrónicas y los repositorios digitales, sin duda, son herramientas cada vez más comunes y arraigadas en la dinámica educativa actual, pero no son suficientes para que una nueva 
generación de universitarios disponga de los saberes digitales propios de un profesionista y los emplee para la resolución de problemas propios de su campo disciplinario.

Si bien, las TIC como herramientas docentes ya se han incorporado a las prácticas cotidianas de las instituciones educativas, cuya infraestructura tecnológica lo permite, la definición de un conjunto de saberes digitales con filiación disciplinaria sigue quedando pendiente.

Un perfil de egreso que no cuente con un enfoque de TIC disciplinarias sumado a la inequitativa distribución de los bienes culturales y la desigual capacidad social para podérselos apropiar, así como las diferencias de acceso a infraestructura tecnológica -software, hardware y conectividad- pueden sustentar nuevas y variadas formas de desigualdad social dentro y fuera de la escuela.

Es por eso que las instituciones educativas deben hacer caso a los movimientos sociotecnológicos de impacto global en los que se promueven el acceso abierto y a la libre circulación de la información. La filosofía del software libre, del libre acceso a la Internet y a los bienes culturales, de las licencias abiertas y de la libre circulación de los productos académicos que, si bien, contraviene con la tendencia dominante del uso social de las TIC tendiente al licenciamiento del software privativo, debería ser reconsiderada.

El signo de los tiempos nos plantea reconocer y luchar contra las nuevas formas de las desigualdades sociales y nos abre el imperativo de un acceso libre a los recursos digitales y a favorecer experiencias escolares donde haya una apropiación crítica y productiva de las TIC. 


\section{Referencias}

Becher, T. (2001). Tribus y territorios académicos: La indagación intelectual y las culturas de las disciplinas. Barcelona: Gedisa.

Bonnewitz, P. (2003). La sociología de Pierre Bourdieu. Buenos Aires: Nueva Visión.

Bourdieu, P. (1980). Le sens pratique. Paris: Les Editions de Minuit.

Bourdieu, P. (1987). Los tres estados del capital cultural. Revista sociológica, (5). Recuperado de http://www.sociologicamexico.azc.uam.mx/index.php/Sociologica/article/view/1043/1015

Bourdieu, P. (1992). Réponses: Pour une anthropologie réflexive. Paris: Éditions Du Seuil.

Bourdieu, P. (1997). Capital cultural, escuela y espacio social. México: Siglo XXI.

Brunner, J.J. (2003). Educación e Internet ¿La próxima revolución? México: Fondo de Cultura Económica.

Brunner, J.J., \& Tedesco, J.C. (2003). Las nuevas tecnologías y el futuro de la educación. Buenos Aires: Septiembre Grupo Editor. Recuperado de http://unesdoc.unesco.org/ images/0014/001423/142329so.pdf

Casillas, M.A. (2003). La sociología de Pierre Bourdieu. En A. García, Teoría sociológica contemporánea: un debate inconcluso. México: UAM, Azcapotzalco.

Casillas, M.A., \& Ramírez, A. (Coords.). (2015a). Génesis de las TIC en la Universidad Veracruzana: Ensayo de periodización. México: Productora de Contenidos Culturales Sagahón Repoll.

Casillas, M.A., \& Ramírez, A. (Coords.). (2015b). Háblame de TIC 2: Internet en Educación Superior. Córdoba, Argentina: Editorial Brujas.

Casillas, M.A., \& Ramírez, A. (Coords.). (2016). Háblame de TIC 3: Educación Virtual y Recursos Educativos. Córdoba, Argentina: Brujas.

Casillas, M., \& Ramírez, A. (2018). El habitus digital: una propuesta para su observación. En R. Castro y H.J. Suárez (Coords.), Pierre Bourdieu en la sociología latinoamericana: el uso de campo y habitus en la investigación (pp. 317-342). Cuernavaca: UNAM.

Casillas, M., Ramírez, A., Carvajal, M., \& Valencia, K. (2016). La integración de México a la sociedad de la Información. En E. Téllez (Coord.), Derecho y TIC. Vertientes Actuales (pp. 1-31). México: UNAM.

Casillas, M.A., Ramírez, A., Luna, M., \& Marini, V. (2017). Ensayo de definición del perfil tecnológico del abogado. En E. Téllez, A. Ramírez, \& M.A. Casillas (Coords.), El abogado actual. Frente al derecho informático y su enseñanza (pp. 42-60). Xalapa: Universidad Veracruzana.

Casillas, M.A., Ramírez, A., \& Ortega, J.C.(2016). Afinidad tecnológica de los estudiantes universitarios. Innovación educativa, 16(70), 151-175. 
Casillas, M.A., Ramírez, A., \& Ortiz, V. (2014). El capital tecnológico una nueva especie de capital cultural. Una propuesta para su medición. En A. Ramírez, \& M.A. Casillas, Háblame de TIC: Tecnología digital en la Educación Superior (pp. 23-38). Córdoba, Argentina: Brujas.

Castells, M. (2001). La Era de la Información. Vol. II: El poder de la identidad. México: Siglo XXI Editores.

Castells, M. (2002). La Era de la Información. Vol. I: La Sociedad Red. México: Siglo XXI Editores.

Chevallier, S., \& Chauviré, C. (2011). Diccionario Bourdieu. Buenos Aires: Nueva Visión.

Clark, B. (1987). The Academic Profession. National, Disciplinary, and Institutional Settings. United States of America: University of California.

Corcuff, P. (1995). Les nouvelles sociologies. Paris: Nathan.

Lévy, P. (2007). Cibercultura: La cultura de la sociedad digital. México: Anthropos Editorial, UAMIztapalapa.

Lizarazo, D., \& Andión, M. (Dirs.) (2013). Símbolos digitales: Representaciones de las TIC en la comunidad escolar. México: Universidad Autónoma Metropolitana y Siglo XXI editores.

Martínez, K.P. (2017). La incorporación de las TIC en las políticas públicas para la Educación Superior en México. En R. López, D. Hernández, \& A.J. Bustamante (Coords.), Háblame de TIC 4: Las tecnologías digitales en los contextos educativos. La voz de los estudiantes. Córdoba, Argentina: Editorial Brujas.

Morales, A.T., \& Ramírez, A. (2015). Brecha digital de acceso entre profesores universitarios, de acuerdo a su disciplina. Revista Debate Universitario, 3(6),149-158.

Morales, A.T., Ramírez, A., \& Excelente, C.B. (2015). Apropiación de las TIC en la Educación Superior, una mirada desde la disciplina del profesorado. Revista Research in Computing Science: Avances en Tecnologías de Información, 108, 35-43.

Ramírez, A., \& Casillas, M.A. (2015). Los saberes digitales de los universitarios. En J. Micheli, Educación virtual y universidad, un modelo de evolución (pp. 77-106). México: UAM.

Ramírez, A., \& Casillas, M.A. (Coords.). (2017). Saberes digitales de los docentes de educación básica. Una propuesta para la discusión desde Veracruz. Veracruz: Secretaría de Educación de Veracruz.

Ramírez, A., Casillas, M.A., \& Contreras, C.C. (2014). La incorporación de las TIC a la enseñanza universitaria de los idiomas. Revista Debate Universitario, 5(3), 123-138.

Tedesco, J.C. (s.f.). Tecnologías de la Información y desigualdad educativa en América Latina. Recuperado de http://www.virtualeduca.info/Documentos/veBA09\%20_confTedesco.pdf 


\section{Capítulo VI}

Teóricamente difícil de explicar.

La sociología de la educación superior

en México

Wietse de Vries *

* Profesor-investigador del Instituto de Ciencias de Gobierno y Desarrollo Estratégico, Benemérita Universidad Autónoma de Puebla. Integrante del Sistema Nacional de Investigadores.

Contacto: wietsedevries4@gmail.com 


\section{Introducción}

Este capítulo revisa el avance de un campo específico de la sociología, conocido como sociología de la educación superior. Después de revisar cómo surgió este campo en México al inicio de los años noventa del siglo XX, y cuáles han sido sus aportaciones, analizamos cuáles fueron los factores que influyeron en este desarrollo, y cuál es la situación actual. Terminamos con algunas propuestas para una posible agenda de investigación.

Señalaré que el campo tuvo una primera etapa de rápido desarrollo, lo cual se evidencia en una gran cantidad de publicaciones. En efecto, resulta difícil mencionar todas las aportaciones durante las últimas tres décadas, y este capítulo solamente señala algunas. No pretendo hacer un estado del arte. Sin embargo, en la última década el campo ha conocido un progreso más lento, lo cual se relaciona con el ámbito disciplinario de la sociología, los cambios en el terreno de la educación superior y el cambio generacional en la profesión académica.

\section{Los vaivenes de la sociología}

La sociología es una disciplina reciente y el campo de la sociología de la educación superior aún más. La sociología surgió como disciplina al final del siglo XIX, cuando en 1895 Durkheim ocupó la primera cátedra de Sociología, una distinción que nunca le tocó al otro fundador de la sociología, Max Weber. Fuera de Europa, el campo empezó a consolidarse apenas después de la Segunda Guerra Mundial. En México, arrancó con las publicaciones de Lucio Mendieta y Núñez en la Revista Mexicana de Sociología, publicación que él mismo había fundado en 1939. Ya en los años cincuenta, otros como Pablo González Casanova consolidaron los estudios sociológicos, pero fue hasta los sesenta que la disciplina cobró fuerza (Moya-López y Olvera-Serrano, 2013). 
Eso no impidió que la disciplina pasara pronto por crisis que parecían fatales: Gouldner (1970) predijo la eminente crisis de la sociología occidental. El anuncio resultó prematuro, ya que la sociología pasó durante las décadas siguientes por un impresionante renacimiento, con un auge en la matrícula sin precedente, y con la presencia de nuevos sabios como C. Wright Mills, Ralph Dahrendorf, Ralph Miliband, Pierre Bourdieu, Anthony Giddens, Zygmund Bauman y el mismo Gouldner. Cabe recordar que eran décadas en que los cambios revolucionarios y la crisis del capitalismo parecían estar a la vuelta de la esquina, y Karl Marx seguía siendo una lectura obligatoria en muchas universidades alrededor del mundo.

Actualmente, la sociología parece estar nuevamente en el borde de la crisis (Castañeda, 2004; Szelenyi, 2015). Décadas de políticas neoliberales, inspiradas por el pensamiento racional economicista, aunado a la caída del muro de Berlín, significan que el pensamiento sociológico pareciera en gran parte obsoleto o, por lo menos, pasado de moda. La matrícula ha caída alrededor del mundo, para regresar prácticamente a los niveles de los años cincuenta. En México, en 2016, había alrededor de seis mil estudiantes de licenciatura en Sociología, concentrados en la Universidad Nacional Autónoma de México (UNAM) con 1,756 y la Universidad Autónoma Metropolitana (UAM) con 2,827. En las universidades públicas estatales, la carrera atrae cuanto más a 300 estudiantes, mientras las universidades privadas raras veces ofrecen el programa. En varios estados, la opción no existe. Con ello, la sociología atrae incluso menos estudiantes que la física (7,971 estudiantes), y es claramente marginal comparado con otras ciencias sociales: economía registra 31,055 y psicología 175,756 (Asociación Nacional de Universidades e Instituciones de Educación Superior [ANUIES], 2018). A partir de estos datos, un buen sociólogo llegaría a la conclusión que la problemática social actual en México concierne aspectos psicológicos, económicos, educativos, administrativos y contables, pero escasamente sociales. A la par, los gurús disciplinarios ya no parecen existir o pertenecer a los viejos tiempos.

\section{La sociología de la educación superior}

Es en este contexto que surgió el campo específico de la sociología de la educación superior. Se puede postular, como hacen Gumport y otros (Gumport, 2007), que este campo empieza formalmente con un artículo de Burton Clark (1973). Si bien otros, desde un enfoque sociológico, habían escrito sobre la educación superior, es Clark quien observa que los distintos estudios existentes ya se podrían agrupar dentro de un campo específico, bajo el nombre de sociología de la educación superior. 
Con eso, describe una lenta culminación del encuentro entre la sociología y la universidad. Max Weber, en 1917, ya había analizado, desde un enfoque sociológico, las vicisitudes del profesorado alemán (Weber, 1992 [1917]), y Durkheim había hecho observaciones sobre el fenómeno educativo, aunque principalmente revisaba a la educación primaria (Durkheim, 1975 [1922]). Ninguno de los dos había considerado a la universidad como objeto de estudio. Años más tarde, en los años sesenta, Bourdieu y Passeron analizaron la educación superior como fenómeno social, pero enfatizando su función social como mecanismo de selección, sin meterse en las entrañas del bicho (Bourdieu y Passeron, 1964; 1990).

En otras palabras, los estudios se centraban en la función social de la universidad, sin analizar cómo funcionaba la organización. Con ello, los sociólogos seguían la misma lógica que los economistas, como los de la teoría de capital humano, al señalar que aquellos que lograban acceder a la educación superior heredaban la riqueza de sus antepasados. Lo hacían quizá con ojos marxistas más críticos, pero el capital social de Pierre Bourdieu es muy parecido al capital humano de Gary Becker. Con Clark, empieza un nuevo tipo de análisis, más internalista, de los sistemas e instituciones.

También otros investigadores habían empezado a analizar cómo funcionaba la universidad internamente. Estos estudios dieron lugar a tipificaciones famosas como la "multiversidad" (Kerr, 2001) o la "anarquía organizada" (Cohen, March y Olson, 1972). Sin embargo, destaca que estos estudios fueron realizados por observadores participantes en la política o por expertos en el campo de la teoría organizacional, raras veces por sociólogos. En efecto, en años posteriores, Clark empezó a retomar estas observaciones de otros campos disciplinarios para su análisis sociológico de los distintos sistemas de educación superior (Clark, 1983). Con ello, desde el inicio de la nueva rama del conocimiento, confluyeron distintos enfoques disciplinarios, un fenómeno que permanece hasta hoy.

\section{El surgimiento en México}

En el mismo sentido, podemos postular que, en México, la sociología de la educación superior arrancó "formalmente" cuando salió El sistema de educación superior de Burton Clark, traducido por Rollin Kent, al mercado académico mexicano en 1991 (Clark, 1991). Se trata igualmente de un punto de arranque simbólico: ya varios investigadores habían empezado a analizar cómo funcionaba la universidad o cómo se comportaban varios actores en su interior. Además, ya se publicaba, desde 1989, la revista Universidad Futura. Más que nada, la publicación del libro de Clark es una señal de que en aquella época el conocimiento tardaba en difundirse y que el internet todavía 
no funcionaba: el libro había salido en inglés en 1983 y el artículo de 1973 nunca fue traducido al español (y casi nunca es citado en México).

En México, el campo se desarrolló según una dinámica propia. Para empezar, la sociología no había tenido un desarrollo tan fuerte como en Estados Unidos o Europa, y el pensamiento sociológico mexicano se orientaba más por la tradición europea que por los estudios norteamericanos. Había cierta predilección por lo teórico estilo francés que lo empírico norteamericano, con más énfasis en lo cualitativo que en lo cuantitativo (Álvarez, 2004; Aguilar-Villanueva, 1995). Esto no sólo se presentaba en la sociología, sino en una carrera como economía y otras ciencias sociales en la universidad pública (Kent, Álvarez, González, Ramírez y de Vries, 2002). Así que, cuando Clark escribió en 1973 sobre el establecimiento del campo y observa que ya existe un cuerpo de conocimiento sociológico amplio sobre ciertos temas educativos en los Estados Unidos, describió una situación muy distinta que el contexto mexicano, donde estos mismos temas tardarían décadas en desarrollarse.

Además de ser tardío, el desarrollo ha sido mucho más limitado. Como señaló Brunner (2009), en América Latina este campo agrupó núcleos pequeños en Chile, Argentina, Brasil y México, con un impacto marginal en cuanto a investigadores, estudiantes, proyectos y publicaciones. Casi una década después, en 2018, estos núcleos siguen siendo pequeños, compuestos básicamente por los mismos actores.

En realidad, es difícil hacer un conteo de los investigadores dentro del campo de la sociología de la educación superior en México, porque solamente una pequeña parte de los sociólogos graduados se dedica a este campo específico. Al mismo tiempo, hay egresados de una multitud de otras carreras que estudian fenómenos educativos, en ocasiones desde una perspectiva sociológica, aunque solo parte de estos investigadores -certificados como sociólogos o no- se dedica a estudios sobre la educación superior.

Si bien, Brunner está en lo correcto acerca del número limitado de investigadores que se podrían considerar como sociólogos de la educación superior, cabe señalar que el impacto de estos grupos pequeños ha sido importante. En los hechos, se dio una fuerte colaboración entre estos grupos y colegas alrededor del mundo, lo cual resultó en numerosas publicaciones en revistas y libros internacionales. La cantidad de publicaciones internacionales quizá resulta pequeña en comparación con otras disciplinas, pero destaca dentro del campo de investigaciones educativas en México. 


\section{Iniciativas iniciales}

En el caso mexicano, el desarrollo inicial se marcó por dos grupos organizados alrededor de dos proyectos financiados internacionalmente: uno, con sede en la Universidad Autónoma Metropolitana unidad Azcapotzalco (UAM-A), dedicado al estudio de la profesión académica, con financiamiento de la Fundación Carnegie; y otros, con su punto de partida en el Departamento de Investigaciones Educativas del Centro de Investigación y Estudios Avanzados del Instituto Politécnico Nacional (DIE-CINVESTAV), dedicado al estudio de las políticas públicas de reforma de la educación superior, con financiamiento de la Fundación Ford.

Eso implica que, en México, el campo se desarrolló de manera distinta que en los Estados Unidos. Como señalaba Clark (1973), la sociología de la educación superior en los Estados Unidos inició a partir de una base fuerte de investigaciones sobre cuestiones de inequidad en la educación post-secundaria, así como de estudios acerca del impacto que tiene la educación superior en los estudiantes. Como campos emergentes, señaló a la profesión académica y cuestiones de gobernanza y organización interna. Así, en términos comparativos, se puede decir que en México se inició con los campos emergentes, para acercarse años más tarde a los campos ya establecidos en los Estados Unidos y varios países europeos.

Este desarrollo no fue planeado: fue así por la historia y el contexto de cada país, los intereses de algunos investigadores y la disponibilidad de recursos externos. Distintos factores confluyeron en México: no fue hasta finales de los años ochenta del siglo pasado que el gobierno mexicano empezó a formular políticas hacia la educación superior, y como parte de estas políticas figuraba la regulación del personal académico de las universidades públicas. Así, estos objetos de estudio apenas estaban surgiendo.

Sin embargo, el hecho de que en México se empezó por estudiar los temas emergentes planteó desde el inicio un problema peculiar: en Estados Unidos y Europa se tenía información sobre la suerte de estudiantes, lo cual implicaba que se podrían estudiar los cambios en las políticas y la profesión académica a la luz de los efectos que producían en la formación de estudiantes. En México, en cambio, tanto los sociólogos como los hacedores de políticas partían, y siguen partiendo, de la idea de que cambios en la profesión o la organización seguramente conllevarían mejoras en la formación, pero sin datos empíricos para comprobar o falsificar tal aseveración. Durante décadas, los estudios carecían de información sobre cuantos estudiantes realmente había, y los que estaban dentro eran actores desconocidos (de Garay, 2001).

Lo anterior tuvo otras implicaciones: hacia finales de los ochenta, había en México un sentimiento ampliamente compartido de que la educación superior estaba en crisis y que requería 
reformas. Sin embargo, se trata de un sentimiento sin sustento empírico. En realidad, nadie sabía a ciencia cierta cuántos estudiantes, académicos, administrativos o dinero había. Igualmente, se carecía de estudios sobre cómo funcionaban las universidades en la práctica cotidiana más allá de lo anecdótico y, así, tampoco se sabía qué era exactamente lo que andaba mal.

Frente a este desconocimiento del sistema de educación superior, surgieron varios proyectos interesantes. Empezamos con los dos temas que figuraban en la agenda de temas emergentes de Clark en 1973, para luego revisar los temas que ya daba por bien establecidos en Estados Unidos.

\section{La profesión académica}

La investigación sobre la profesión académica ha avanzado mucho desde inicios de los noventa. Se destaca que, al igual que en el caso de los estudiantes, tampoco existían datos sobre profesores. Sin embargo, un grupo importante de investigadores empezó a aplicar cuestionarios a muestras representativas para luego generar informes. Este esfuerzo llevó a una situación excepcional: los investigadores lograron tener más información sobre los académicos que la propia Secretaría de Educación Pública (SEP) o las universidades. Por la misma razón, también es un campo que logró influir (para bien o para mal) sobre las políticas educativas, como la creación en 1997 del Programa de Mejora del Profesorado (PROMEP).

Los resultados de estas investigaciones indican que en el caso mexicano hay cada vez más personas de tiempo completo con doctorado, mientras que la investigación ocupa cada vez más tiempo. Con ello, las plantas académicas de las universidades públicas se asemejan cada vez más a aquellas en países desarrollados, también porque en estos países se tiende a contratar más personal de tiempo parcial (Gil-Antón, 2003). Eso plantea un fenómeno interesante para estudios comparativos: el desarrollo de la profesión académica en México ha sido notablemente distinto en comparación con lo que sucede en países desarrollados, lo cual implicaría que los efectos también tendrían que ser distintos.

Sin embargo, no queda claro si este crecimiento en el número de doctores con plazas de tiempo completo, acompañado por programas de estímulos a la productividad, han llevado realmente a una mayor productividad en investigación científica o si los estudiantes ahora reciben una mejor formación. Algunos estudios apuntan que el doctorado y el contrato de tiempo completo no garantizan un mejor desempeño académico. Cabe señalar que, aunque haya una gran cantidad de estudios que ponen en duda la efectividad de programas de estímulos, estos esquemas continúan operando sin modificaciones. Aparentemente, la investigación existente no logra convencer a los hacedores de políticas, aunque se trata de estudios bien hechos y escritos. 
Asimismo, no queda claro si en México los académicos han perdido poder frente a los administradores de las instituciones o si simplemente nunca tuvieron el mismo poder que sus colegas en las universidades de investigación en países desarrollados.

Así, la investigación sobre la profesión académica en México ha tenido avances, pero enfrenta actualmente el reto de cómo juzgar y comparar los cambios que se presentaron durante casi tres décadas (Finkelstein, Galaz-Fontes y Scott Metcalfe, 2009). ¿Se inscriben estos cambios dentro de la misma lógica del capitalismo académico que está presente en países desarrollados o se trata de una profesionalización sui generis mexicana? O, más bien, ¿se trató de un fenómeno pasajero que afectó a una parte de los académicos, mismos que ahora están por jubilarse y ser reemplazados por académicos de tiempo parcial? Esta última pregunta refleja los cambios en la agenda de investigación: hace tres décadas el tema era la incorporación al trabajo, ahora un tema central es la jubilación.

\section{Políticas públicas educativas}

El estudio de políticas surgió hacia finales de los ochenta como novedad en casi todo el mundo, como resultado de los cambios en la relación entre el Estado y la educación superior, centrados en la evaluación y nuevas formas del financiamiento público. Estos cambios se manifestaron primeramente en Europa occidental, para luego encontrar eco en otros países del mundo. Quizá el país donde menos se presentó este aspecto fue en Estados Unidos, donde la educación no se regula desde el gobierno federal.

En los años siguientes se desarrollaron estudios comparativos, dentro de la región de América Latina, luego con países europeos, Estados Unidos y Canadá, en ocasiones con una participación de organismos internacionales, como la Organización de las Naciones Unidas para la Educación, la Ciencia y la Cultura (UNESCO), el Banco Mundial y el Banco Interamericano de Desarrollo.

Los resultados muestran que los cambios reales han sido muy desiguales según cada país. Un hallazgo es que una política semejante puede tener resultados muy distintos en diferentes países y que, por lo tanto, resulta complicado comparar políticas (Kent-Serna, 2009). La implementación puede ser diferente y los resultados pueden ser perversos (De Vries y Álvarez-Mendiola, 2005). Además, siempre queda la duda de cuáles cambios se deben a las políticas y cuáles simplemente se producen, aun en ausencia de iniciativas gubernamentales.

Una complicación en el estudio de políticas es que dependen fuertemente del contexto local, y solo se pueden interpretar según este contexto. Otro es que el desarrollo de las investigaciones es sensible a los vaivenes políticos: los intentos de reformar la educación surgieron en los 
ochenta, tuvieron su auge desde 1990 hasta inicios del siglo XXI, pero la reforma dejó de ser tema de discusión en muchas partes desde 2010. Desde ese entonces, la regulación del sistema se volvió un tema administrativo, lo cual llevó a la institucionalización de las políticas. De esta manera, las políticas dejaron de intentar reformar el sistema, e incluso las políticas mismas se vuelven irreformables (De Vries y Álvarez-Mendiola, 2015).

Al igual que los estudios sobre la profesión, el campo de políticas ha avanzado mucho y hay muchos traslapes entre ambos campos. Pero también hay diferencias importantes entre ellos: la investigación sobre la profesión académica indaga sobre cambios en los atributos y comportamiento de un grupo específico, mientras que el estudio de políticas se enfrenta con averiguar qué se busca cambiar, cómo se busca cambiar y cuáles son los resultados finales. Como tal, estudia intentos de cambio y las respuestas de actores, tratando establecer relaciones causales complejas. Este tipo de estudios son más complicados -ciertamente en contextos comparativos- y pueden llevar a situaciones inesperadas: ¿Qué hacer como investigador, cuando un gobierno decide que basta de reformas y que no es necesario formular más políticas? Los expertos plantearán que no formular políticas también constituye una política, pero ciertamente resulta más complicado estudiar la ausencia de políticas.

\section{Inequidad}

El tardío desarrollo en México de estudios sobre la inequidad en la educación terciaria no se debe a una falta de interés de sociólogos. Ya en los años sesenta fue señalado como problema crucial, en particular a partir de 1968, lo cual llevó a políticas universitarias de "puertas abiertas" y colegiaturas muy bajas.

Algunos estudios buscaron una óptica sociológica más amplia, más allá de la "propensión existente en el medio educativo a buscar explicaciones al aprovechamiento diferencial de las oportunidades escolares exclusivamente en la clase social de origen" (Bartolucci-Incico, 1994, p. 1). Sin embargo, a falta de datos confiables nacionales, prácticamente todos los estudios han sido de casos muy específicos y el referente teórico en muchas ocasiones sigue siendo Bourdieu (Bourdieu y Passeron, 1964). Así, hasta la fecha, gran parte se centra en el origen socioeconómico o el capital social de los estudiantes (donde el capital social se suele medir por la escolaridad y el ingreso de los padres).

En comparación con otros países, los estudios sobre estudiantes y egresados han avanzado poco, con excepciones de algunos estudios sociológicos (Casillas, Chaín y Jácome, 2007; de Garay, 2004). Igualmente, hay muy poca información sobre las razones que llevan al abandono de los es- 
tudios o que llevan al éxito en el mercado laboral (de Vries, León, Romero y Hernández, 2011). Sin embargo, lo que resalta de estos estudios es que los caminos por la educación superior raras veces son rectos y que existe una miríada de factores sociales, culturales y económicos (Acosta-Silva y Planas-Coll, 2014).

La relación entre estudios y trabajo permanece igualmente oscura. Aunque muchas universidades han hecho algún tipo de seguimiento de sus egresados, estos estudios se caracterizan por ser elaborados por la presión de demandas externas, como las políticas del gobierno federal o las observaciones de instancias de acreditación. Como resultado, los informes son escuetos, poco analíticos o críticos, y cada universidad maneja su propia metodología. Cabe resaltar finalmente que los datos son guardados con más secrecía que los informes financieros.

Ha habido muy pocos estudios comparativos nacionales e internacionales, salvo un proyecto financiado por la Unión Europea al inicio del siglo XXI (Mora, Carot y Conchada, 2010). Así, las reformas iniciadas desde los setenta en prácticamente todo el mundo carecen de un fundamento empírico sobre los estudiantes de antes y los actuales: siguen siendo en gran medida los actores desconocidos.

En comparación con países desarrollados, México (y América Latina en general) está apenas incursionando en un campo de conocimiento ya bien establecido en otros países. Esto implica una desventaja importante, ya que no existe la posibilidad de juzgar el efecto de políticas educativas o los cambios en la profesión académica a la luz de cambios en el comportamiento de otro actor crucial: el estudiante.

\section{Cómo afecta la universidad a sus estudiantes}

Si bien hay una creciente literatura sobre culturas juveniles (Guzmán-Gómez y Saucedo-Ramos, 2015), la forma en que la universidad afecta a sus estudiantes es aún poco conocido, ciertamente si una lo compara con la información disponible en otros países, y que se refleja en las obras ya clásicas, como las de Pascarella y Terenzini (2005).

En este sentido, el campo de estudios sobre cómo los estudiantes son afectados por las universidades sigue siendo un campo en construcción. Desde apenas hace una década hay estudios sociológicos sistemáticos sobre las trayectorias de estudiantes desde la escuela media superior hasta el mercado laboral (Acosta-Silva y Planas-Coll, 2014; Planas, 2013).

El sentido común dice que se ha diversificado la población estudiantil a partir de la creciente masificación, pero no hay datos que permiten documentarlo más allá de los datos socioeconómicos. Igualmente, podemos especular que distintos estudiantes atienden diferentes establecimientos, lo cual implicaría que dentro de cada institución hay poca diversidad. 
No sabemos qué es lo que los estudiantes aprenden, pero esto quizá no es un tema para la sociología. Es además un tema no resuelto en ningún sistema hasta la fecha. Desde la perspectiva de la sociología, sería más importante investigar cómo cambian las relaciones sociales de personas o de grupos que acceden, comparados con los que no acceden a la educación superior. Esto implica estudios que distinguen por género, por origen social y económico, pero también por distintas culturas juveniles. Significa también distinguir entre disciplinas o áreas de conocimiento, y sobre valores, creencias y mitos que los actores sustentan.

\section{Organización del sistema e instituciones}

El objetivo de muchas políticas fue cambiar el sistema nacional en cada país, y cambiar el funcionamiento interior de cada institución. En este terreno, las políticas han sido muy exitosas.

El análisis del sistema nacional de educación superior en México se confrontó desde el inicio con la pregunta de si realmente se trataba de un sistema, es decir, un conjunto donde las partes guardaban relaciones entre sí. Adicionalmente, desde el inicio de los noventa este conjunto pasó por una rápida diversificación: se crearon numerosos establecimientos, tanto en el sector público como en el privado, y en cada establecimiento se amplió la oferta de programas. A la par, el posgrado pasó por una rápida expansión, tanto en el número de instituciones y programas, como en la matrícula.

A su vez, hubo cambios al interior de cada establecimiento. Las viejas formas de gobierno recibieron muchas críticas, así que cada establecimiento emprendió numerosos reajustes de reglas y estructuras.

Dada la complejidad del sistema -si merece esta calificación- muchos estudios apenas alcanzan a ser descriptivos. Ha habido intentos de tipificar o establecer tipos ideales de instituciones, pero no hay una que satisface las necesidades analíticas. En la práctica, ha habido pocos avances en este terreno desde que Levy (1986) dividió al sector privado entre universidades de élite y otras de absorción de la demanda. Contrario a lo que describió Clark (1998) para Europa, nunca prosperaron universidades emprendedoras en México. Acosta-Silva (2009) ha planteado que las políticas buscan a la research university como tipo ideal, pero solamente se podría concluir que las políticas han sido sumamente ineficaces en este terreno: en casi todas las universidades mexicanas la investigación científica sigue jugando un papel marginal. Ordorika (2013) señala que una función importante de las universidades radicó en ser constructoras de la nación, pero esta función ya parece haber quedado en el pasado. Lo que destaca del sistema mexicano es la enorme 
cantidad de establecimientos, pero el crecimiento ha sido anárquico y desafía cualquier categorización (de Garay, 2013; Mendoza-Rojas, 2015).

Al interior de las instituciones se ha desatado también una ola de reformas y reestructuraciones desde inicios de los noventa. En términos generales, estas reformas, al igual que en otras partes del mundo, han incrementado el poder de los administradores frente a los académicos y la toma de decisiones se ha vuelta más ejecutiva y menos colegiada (Acosta-Silva, 2009; De Vries \& Ibarra-Colado, 2004 López-Zárate, 2014).

Pero, nuevamente, es difícil captar estos cambios nítidamente en categorías sociológicas, 0 comparar los cambios en las universidades mexicanas con los que se presentaron en otros países. En la práctica, los nuevos gerentes universitarios vacilan entre querer ser príncipes u operar como burócratas, y la creciente "burocratización" del trabajo académico no parece acoplarse al tipo ideal descrito por Max Weber desde hace un siglo. Además, dentro del contexto mexicano, cada universidad parece haber establecido su propia forma de gobierno y solamente algunas formas se asemejan a lo descrito en la literatura sociológica. Por el contrario, hay formas muy sui generis como las universidades que operan como pequeñas o medianas empresas familiares, donde la forma de gobierno se acopla al linaje familiar.

\section{Un balance de tres décadas}

Además de estos cuatro campos, la sociología de la educación superior ha incursionado en otros temas. Algunos de ellos son clásicos, como el debate sobre la autonomía, el papel de los sindicatos, estudios de género o el financiamiento; otros más recientes, como la globalización e internacionalización de la educación superior o las formas de evaluación. Todavía otros han recibido poca atención, como la tercera misión de la universidad, la extensión y difusión de la cultura.

Lo que destaca es que la agenda de investigación de este campo particular refleja la influencia de una miríada de factores. Como en otros campos, la agenda depende de intereses personales o de grupos, y de las posibilidades del financiamiento. Pero la sociología de la educación superior se caracteriza además por la confluencia de distintos factores específicos. En primer lugar, hay elementos provenientes de la lógica disciplinaria de la sociología, lo cual se relaciona con los cambios sociales en las sociedades modernas. En segundo lugar, el objeto de estudio -la educación superior- pasó por vertiginosas transformaciones en tres décadas. En tercer lugar, los investigadores son académicos y, como tales, partícipes -rehenes o espectadores- en los cambios que suceden en la educación superior (Gil-Antón, 2000). La investigación en este campo es inescapablemente participativa. 


\section{Cambios sociales y sociológicos}

Desde que surgió la sociología de la educación superior, tanto las sociedades como la sociología han cambiado. Según distintos sociólogos, estamos viviendo en un mundo posmoderno, poscapitalista, más individualista, más globalizado, más educado, con nuevas tecnologías, lo cual modifica las relaciones sociales. Desde que Burton Clark anunció el establecimiento de la sociología de la educación superior en 1973, mucho ha cambiado. En este entonces no existía Internet, no se usaba mucho la computadora, no había Tecnologías de la Información y la Comunicación (TIC). No existía la Unión Europea, estaba en su cima la Guerra Fría (la Unión Soviética y China no parecían tener sistemas de educación superior en 1983). Existía el muro de Berlín y dos Alemanias (una, aparentemente sin sistema de educación superior). Aunque había crecido la matrícula, la educación superior todavía era para una minoría de jóvenes. Aun así, el desempleo era alto entre jóvenes, incluso para los que habían estudiado.

No se trata meramente de señalar que el mundo ha cambiado, sino enfatizar que la sociología, como disciplina, ha tenido grandes dificultades para encontrar los conceptos que ayudan a entender las nuevas relaciones sociales del siglo XXI. En 1973, la sociología todavía andaba en su etapa funcionalista, mientras ahora se debata si lo que se necesita es una sociología del posmodernismo o una sociología posmodernista (Bauman, 1992). Ante la falta de respuestas de sociología, han nacido interpretaciones desde la psicología, la filosofía, la economía, las ciencias políticas y otras. Aun así, sigue siendo complicado definir en qué consiste o consistirá el posmodernismo.

Lo que resalta de la literatura reciente es que el mundo social se mueve rápidamente hacia el posmodernismo, debido al crecimiento acelerado de los medios masivos de comunicación y las nuevas tecnologías, a la par del desarrollo de sociedades multiculturales, con un aumento en la movilidad de la gente. Sin embargo, no queda claro si la sociología actual, tradicional, carece de herramientas para describir, entender o explicar este nuevo mundo posmoderno.

Algunos críticos argumentan que la sociología era adecuada para analizar el capitalismo, la industrialización y el estado-nación, pero que tiene insuficiencias para enfrentarse con un mundo posmoderno, que se caracteriza por ser descentralizado, plural, saturado por los medios y globalizado, o con complejas interacciones glonacales, según algunos, describiendo la interacción entre lo global, nacional y local (Marginson y Rhoades, 2002). Se necesitaría una sociología posmoderna, aunque no queda claro en qué consiste.

Para complicar el panorama, algunos sociólogos, como Bauman (1992), señalan que el término posmoderno ha perdido sentido -por todos los usos que le han dado- y prefieren describir el mundo actual como de "modernidad líquida", mientras otros, como Giddens, hablan de una "modernidad tardía" (Giddens, Beck y Lash, 1994). 
Debido a esta confusión posmoderna, resulta difícil encontrar explicaciones sociológicas. Como la sociología pasa por un período de incertidumbre, también queda cada vez menos claro en qué consiste la sociología de la educación superior. Si agregamos a esto que hay cada vez menos investigadores con una formación sociológica en el campo educativo, lo sociológico parece perder aún más peso. Como resultado, las referencias a la teoría sociológica son escasas, y las que aparecen en los artículos suelen basarse en propuestas sociológicas de hace décadas. Dicho de otra forma, en los estudios actuales sobre la educación superior mexicana hay una notable ausencia de referencias o debates sobre la sociología actual, hay pocas referencias en inglés, y continúa el soslayo de lo cuantitativo.

\section{El campo de la educación superior}

Al mismo tiempo que la sociología pasó por cambios, el mundo de la educación superior sufrió modificaciones radicales. Cabe recordar que todavía en 1963, Kerr (2001) señalaba que algunos sectores de la sociedad, como las iglesias, el parlamento de la isla de Man y 70 universidades se resistieron al cambio y continúan básicamente inalterados; agregando que, estas últimas, todavía se encuentran en los mismos lugares con algunos de los mismos edificios, con profesores y estudiantes que hacen las mismas cosas, y con la gobernanza llevada a cabo de la misma manera.

Sin embargo, desde los años ochenta, los sistemas de educación superior pasaron por muchos cambios. Algunos establecimientos quizá todavía se asemejan a las universidades del pasado, pero la mayoría es radicalmente distinta. Así, el sociólogo de Sousa Santos (2005) describe los cambios que resultaron de diferentes exigencias externas:

La incapacidad de la universidad para desempeñar cabalmente estas funciones contradictorias provocó que el Estado y los agentes económicos buscaran fuera de ella medios alternativos para lograr esos objetivos, de esta forma la universidad dejó de ser la única institución en el campo de la educación superior y en la producción de la investigación. La crisis de legitimidad, provocada por el hecho de haber dejado de ser una institución consensual, frente a la contradicción entre la jerarquización de los saberes especializados, por una parte, a través de las restricciones del acceso y certificación de competencias y, por otra parte, por las exigencias sociales y políticas de la democratización de la universidad y la reivindicación de la igualdad de oportunidades para las clases populares. Finalmente, la crisis institucional, que es una consecuencia de la contradicción entre la reivindicación de autonomía en la 
definición de valores y objetivos de la universidad y la presión para someterla a criterios de eficiencia y productividad empresarial o de responsabilidad social. (p. 24)

Lo que destaca en la cita es que hay una cierta nostalgia hacia la universidad idealizada del pasado, algo bastante común entre sociólogos de la educación superior. Pero, también, resalta la ausencia de nuevas tipologías que logran describir y entender los cambios sociales dentro de los sistemas terciarios. Lo que se observa en la literatura son maromas crecientemente complicadas para poder captar las nuevas permutas en viejos conceptos.

En efecto, uno se puede preguntar si frente a las reformas todavía se puede analizar a los académicos bajo la bandera de conceptos como profesionalización y proletarización, o incluso como "capitalismo académico", cuando hay factores inusitados en juego (Finkelstein et al., 2009). Además, la investigación científica (o la generación del conocimiento) parece haber entrada en una nueva dinámica, tanto al interior de las universidades como afuera (Erickson y Webster, 2012).

Igualmente, cabe aclarar términos como la equidad (cuando las mujeres rebasaron a los hombres en cuanto a la matrícula) o revisar si la educación superior continúa siendo un filtro, un colador, un templo o más bien un eslabón (Stevens, Armstrong y Arum, 2008; Naidoo, 2004), cuando en países desarrollados más de la mitad de los jóvenes de 18 a 24 años cursa estudios superiores y personas mayores regresan a la educación superior. Al mismo tiempo, debe causar serias dudas cuando en el seguimiento de egresados se sigue manejando términos como empleabilidad, tasas de retorno o la coincidencia entre estudios y trabajo, cuando los mercados laborales han cambiado drásticamente (Brown, Lauder, Ashton, Yingje y Vincent-Lancrin, 2008).

Del mismo modo, queda por aclarar si la universidad moderna, emprendedora, todavía opera como anarquía organizada, flojamente acoplada, o si están surgiendo nuevos tipos de organización en el mundo posmoderno (Clegg, 2012). De la misma manera, cabe la duda si los gobiernos nacionales siguen reformando sus sistemas nacionales mediante procesos de "timoneo a distancia", usando la evaluación y el financiamiento. Quizá en algunos países (o en el ideario de algunos funcionarios) este modelo persiste, pero en otras partes del mundo, la dinámica ha cambiado significativamente (King, Marginson y Naidoo, 2011; Marginson y Rhoades, 2002).

\section{El investigador-académico}

Ahora bien, incorporar los temas emergentes mundiales de la sociología y de la educación superior en la agenda de investigación de la sociología de educación superior mexicana tiene sus bemoles. Desde el inicio de este campo, el problema principal radica en que los investigadores son a la vez 
académicos, sujetos a las reglas de juego que estudian. Así, una posible explicación para la menor dinámica en el campo durante la última década -comparado con la situación al inicio de los noventa- radica en el desarrollo de la profesión académica. Destaca que, en el caso mexicano, la "profesionalización" adquirió rasgos peculiares: desde los noventa, se enfatizó que los académicos en servicio tenían que obtener un posgrado y una plaza de tiempo completo, mientras que al mismo tiempo se frenó la contratación de académicos jóvenes. Ello implica que, en la práctica, los núcleos de investigación que se establecieron al inicio de los noventa siguen siendo los mismos, y que sus integrantes se preocupan más por la jubilación que por el cambio generacional.

Paralelamente, cabe señalar que la sociología, como disciplina, tuvo poco crecimiento desde los ochenta, mientras que el posgrado en ciencias de la educación -que agrupa una enorme variedad de enfoques disciplinarios- tuvo un crecimiento explosivo. De esta manera, surgieron múltiples formas de indagar los cambios en la educación superior, y el enfoque sociológico es solamente uno de tantos.

Influye también que el financiamiento para proyectos pasa por vaivenes y que está sujeto a la agenda de instancias educativas gubernamentales. Ello implica no sólo una escasez de recursos - ante todo para proyectos nacionales- sino una delimitación de temas susceptibles al apoyo: algunos temas pueden carecer de importancia, mientras otros se pueden repentinamente poner de moda. Así, a lo largo de tres décadas, distintos temas han pasado de la prioridad al olvido.

Por supuesto, juega también el siempre complicado encuentro entre investigadores y hacedores. Los tiempos de investigación son más largos que los de la toma de decisiones, amén de que existe una buena cantidad de publicaciones -en revistas arbitradas e indizadas- que no brindan ninguna información útil. Sin embargo, también existe una creciente producción de informes ejecutivos o estudios aplicados que no contribuyen al conocimiento.

En resumen, la sociología de la educación enfrenta una triple hélice: hay que conjugar la sociología con los cambios en la educación superior, considerando las condiciones locales de trabajo.

\section{Un esbozo de agenda}

Lo anterior, lleva a la pregunta acerca de lo que podrían hacer los sociólogos de la educación superior para fortalecer el campo. Como esbozo de agenda, dos puntos parecen importantes. El primero, consiste en conjugar o entrelazar los hallazgos sobre los distintos temas. El segundo, implica adentrarse a nuevos caminos de investigación.

Para el primer punto resulta cada vez más factible e interesante comparar los cambios en un área de investigación con otra. Así, una pregunta clave, después de décadas de reforma, consiste 
en indagar si los cambios en la profesión académica han llevado a mejoras en el aprendizaje de estudiantes o en la productividad científica. Ya existen estudios sobre esta relación (EstévezNenninger, 2009), pero valdría la pena ampliarlos. Igualmente, cabe preguntarse si las nuevas formas de gobierno o los nuevos sectores del sistema terciario, contribuyeron en algo. Otro tema es la introducción de las TIC y el paso hacia la educación virtual. En este aspecto, hay muchas posibilidades de proyectos de investigación.

El segundo punto es más complicado por tratarse de predecir el futuro antes de que acontezca. Se trata, en gran medida, de revisar los cambios en la educación superior y distinguir posibles tendencias. Ello implica revisar hacia dónde se está desarrollando el trabajo académico -y, a la par, la enseñanza y la investigación científica- en México y en otros países. Una pregunta clave para la sociedad del conocimiento es dónde se produce el conocimiento, quién lo hace, cómo y cuánto cuesta.

De manera semejante, podemos preguntarnos si el análisis de políticas debe adoptar nuevos enfoques y formas de análisis, ya que una creciente proporción de las políticas no proviene de gobiernos nacionales. Las formas de gobierno institucional o los métodos de regulación de sistemas nacionales estarán igualmente sujetos a presiones internacionales y merecen nuevas formas de análisis.

Cabe preguntarse, retomando a Clark (1991), si todavía existen modelos -norteamericanos, europeos, anglosajones, continentales- o si casi todos son iguales. Del mismo modo, queda la interrogante acerca de qué pasó con la adscripción del académico, quien en la obra de Clark se movía entre la disciplina y el establecimiento. ¿Sigue como tipo ideal el profesor de tiempo completo con doctorado, el gurú o somos ya todos vendedores ambulantes de conocimiento? ¿Son realmente distintos los estudiantes si provienen de estratos sociales anteriormente excluidos? ¿Se resuelve el problema de la equidad cuando casi todos acceden a la educación superior? ¿Existen hoy nuevas minorías sociales, como el hombre blanco sin título de educación superior, que aparece como el fiel seguidor del presidente Donald Trump o la mujer con estudios superiores sin empleo del suburbio que está dejando de votar por el mismo presidente? En cuanto a la juventud, ¿existen ya los ninis por elección, es decir, jóvenes que deciden que ni quieren estudiar ni trabajar? ¿Qué pasa con el tejido social y la estratificación, o con la división social del trabajo, si cada vez más personas acceden a la educación superior?

En fin, como los sistemas de educación superior son cada vez más complejos, hay que poner a trabajar la imaginación sociológica para explicar cómo y para qué sirven. Una vez que logremos eso, sin duda, serán remplazados por sistemas aún más complicados. Según algunos, eso ya sucedió. 


\section{Referencias}

Acosta-Silva, A. (2009). Príncipes, burócratas y gerentes. El gobierno de las universidades públicas en México. México: ANUIES.

Acosta-Silva, A., \& Planas-Coll, J. (2014). La arquitectura del poliedro: itinerarios universitarios, equidad y movilidad ocupacional en México. Guadalajara: Universidad de Guadalajara.

Aguilar-Villanueva, L. (1995). El estado actual de la investigación sociológica en México. En Estudios de teoría e historia de la sociología en México. México: UNAM/UAM-A.

Álvarez, G. (2004). Modelos académicos de ciencias sociales y legitimación científica en México. México: ANUIES.

Asociación Nacional de Universidades e Instituciones de Educación Superior (ANUIES). (2018). Anuario estadístico licenciatura 2016-2017. México: ANUIES. Recuperado de http://www. anuies.mx/informacion-y-servicios/informacion-estadistica-de-educacion-superior/ anuario-estadistico-de-educacion-superior

Bartolucci-Incico, J. (1994). Desigualdad social, educación superior y sociología en México. Ciudad de México: UNAM/Porrúa.

Bauman, Z. (1992). Intimations of Postmodernity. London: Routledge.

Bourdieu, P., \& Passeron, J.C. (1964). Les héritiers: les étudiants et la culture. Paris: Les Éditions de Minuit.

Bourdieu, P., \& Passeron, J.C. (1990). Reproduction in education, society and culture. London: Sage.

Brown, P., Lauder, H., Ashton, D., Yingje, W., \& Vincent-Lancrin, S. (2008). Education, Globalization and the Future of the Knowledge Economy. European Educational Research Journal, 7(2), 131-156. https://doi.org/10.2304/eerj.2008.7.2.131

Brunner, J.J. (2009). Apuntes sobre sociología de la educación superior en contexto internacional, regional y local. Estudios Pedagógicos, XXXV(2), 203-230.

Casillas, M., Chaín, R., \& Jácome, N. (2007). Origen social de los estudiantes y trayectorias estudiantiles en la Universidad Veracruzana. Revista de la Educación Superior, XXXVI(142), 7-29.

Castañeda, F. (2004). La crisis de la sociología en México. México: Porrúa.

Clark, B.R. (1973). Development of the Sociology of Higher Education. Sociology of Education, 46(1), 2-14. Recuperado de https://www.jstor.org/stable/2112203

Clark, B.R. (1983). The higher education system. Academic organization in cross-national perspective. Berkeley: University of California Press.

Clark, B.R. (1991). El sistema de educación superior: una visión comparativa de la organización académica. México: Nueva Imagen/Universidad Autónoma Metropolitana. 
Clark, B.R. (1998). Creating Entrepreneurial Universities. Organizational Pathways of Transformation. London: Pergamon Press.

Clegg, S.R. (2012). The Sociology of Organizations. En G. Ritzer, The Wiley-Blackwell companion to Sociology (pp. 164-181). Oxford: Blackwell Publishers.

Cohen, M.D., March, J.G., \& Olson, J.P. (1972). A Garbage Can Model of Organizational Choice. Administrative Science Quartly, 17(1), 1-25. Recuperado de https://www.jstor.org/ stable/2392088

de Garay, A. (2001). Los actores desconocidos. Ciudad de México: ANUIES.

de Garay, A. (2004). Integración de los jóvenes en el sistema universitario. Barcelona: Editorial Pomares.

de Garay, A. (2013). La expansión y diversificación de la educación superior privada en México en los primeros diez años del siglo XXI. Espacio Abierto. Cuaderno Venezolano de Sociología, 22(3), 413-436.

de Sousa Santos, B. (2005). La universidad en el siglo XXI. Para una reforma democrática y emancipatoria de la universidad. México: UNAM-CEIICH.

De Vries, W., \& Álvarez-Mendiola, G. (2005). Acerca de las políticas, la política y otras complicaciones en la educación superior mexicana. Revista de la Educación Superior, XXXIV(134), 81-105.

De Vries, W., \& Álvarez-Mendiola, G. (2015). Can reform policies be reformed? An analysis of the evaluation of academics in Mexico. En P. Zgaga, U. Teichler, H.G. Schuetze, \& A. Wolter, Higher Education Reform: Looking Back - Looking Forward. New York: Peter Lang Editors.

De Vries, W., \& Ibarra-Colado, E. (2004). Presentación. La gestión de la universidad. Interrogantes y problemas en busca de respuestas. Revista Mexicana de Investigación Educativa, 9(22), 575-584.

De Vries, W., León, P., Romero, F., \& Hernández, I. (2011). ¿Desertores o decepcionados? Distintas causas para abandonar los estudios universitarios. Revista de la Educación Superior, 15(4), 29-50. Recuperado de https://www.researchgate.net/publication/260777552_Desertores_o_ decepcionados_Distintas_causas_para_abandonar_los_estudios_universitarios

Durkheim, E. (1975 [1922]). Educación y sociología. Barcelona: Ediciones Península.

Erickson, M., \& Webster, F. (2012). Science and Technology: Now and in the Future. En G. Ritzer, The Wiley-Blackwell companion to Sociology (pp. 609-625). Oxford: Blackwell.

Estévez-Nenninger, E.H. (2009). El doctorado no quita lo tarado: Pensamiento de académicos y cultura institucional en la universidad de Sonora: significados de una política pública para mejorar la educación superior en México. México: ANUIES. 
Finkelstein, M.J., Galaz-Fontes, J., \& Scott Metcalfe, A. (2009). Changing Employment Relationships in North America: Academic Work in the United States, Canada and Mexico. En J. Enders, \& E. De Weert, The Changing Face of Academic Life. Analytical and Comparative Perspectives (pp. 218-247). New York: Palgrave.

Giddens, A., Beck, U., \& Lash, S. (1994). Modernización reflexiva. Política, tradición y estética en el orden social moderno. Madrid: Alianza.

Gil-Antón, M. (2000). Los académicos de los noventa: ¿actores, sujetos, espectadores o rehenes? Revista Electrónica de Investigación Educativa, 2(1), 100-116.

Gil-Antón, M. (2003). Big City Love. The Academic Workplace in Mexico. En P.G. Altbach, The Decline of the Guru. New York: Palgrave Macmillan.

Gouldner, A.W. (1970). The coming crisis of Western Sociology. London-New Delhi: Heinemann.

Gumport, P.J. (2007). Sociology of Higher Education. Contributions and their Context. Baltimore: The Johns Hopkins Press.

Guzmán-Gómez, C., \& Saucedo-Ramos, C. (2015). Experiencias, vivencias y sentidos en torno a la escuela y a los estudios: Abordajes desde las perspectivas de alumnos y estudiantes. Revista Mexicana de Investigación Educativa, 20(67), 1019-1054.

Kent, R., Álvarez, G., González, M., Ramírez, R., \& de Vries, W. (2002). Cambio organizacional y disciplinario en las ciencias sociales en México. México: DIE-CINVESTAV/Plaza y Valdez.

Kent-Serna, R. (2009). Las políticas de educación superior en México durante la modernización. Un análisis regional. México: ANUIES.

Kerr, C. (2001). The Uses of the University. Cambridge: Harvard University Press.

King, R., Marginson, S., \& Naidoo, R. (2011). Handbook on Globalization and Higher Education. Cheltenham: Edward Elgar Publishing.

Levy, D. (1986). Higher Education and the State in Latin America: Private Challenges to Public Dominance. Chicago: University of Chicago Press.

López-Zárate, R. (2014). La interacción gobierno-universidades: una relación compleja. Bordón. Revista de Pedagogía, 66(1), 75-87. http://dx.doi.org/10.13042/Bordon.2014.66105

Marginson, S., \& Rhoades, G. (2002). Beyond national states, markets, and systems of higher education: a glonacal agency heuristic. Higher Education, 43(3), 281-309.

Mendoza-Rojas, J. (2015). Ampliación de la oferta de educación superior en México y creación de instituciones públicas en el período 2001-2012. Revista Iberoamericana de Educación Superior, 6(16), 3-32. 
Mora, J.G., Carot, J.M., \& Conchada, A. (2010). Informe resumen del proyecto PROFLEX en América Latina. Comparativa con el proyecto REFLEX en Europa. Valencia: Universidad Politécnica de Valencia.

Moya-López, L.A., \& Olvera-Serrano, M. (2013). La historiografía de la sociología en México: balances y una propuesta de interpretación desde la historia conceptual. Sociológica, 28(80), 7-40. Recuperado de http://www.scielo.org.mx/scielo.php?script=sci_arttext\&pid=S018701732013000300001\&lng=es\&tlng=es

Naidoo, R. (2004). Fields and institutional strategy: Bourdieu on the relationship between higher education, inequality and society. British Journal of Sociology of Education, 25(4), 457-471. http://dx.doi.org/10.1080/0142569042000236952

Ordorika, I. (2013). La universidad constructora del Estado. En R. Rodríguez, El siglo de la UNAM: vertientes ideológicas y políticas del cambio institucional (pp. 105-130). México: Miguel Ángel Porrúa/UNAM.

Pascarella, E.T., \& Terenzini, P.T. (2005). How College Affects Students: A Third Decade of Research. San Francisco: Jossey-Bass.

Planas, J. (2013). Los itinerarios laborales de los universitarios y la calidad de su inserción profesional. Revista de la Educación Superior, XLII(165), 31-62.

Stevens, M.L., Armstrong, E.A., \& Arum, R. (2008). Sieve, Incubator, Temple, Hub: Empirical and Theoretical Advances in the Sociology of Higher Education. Annual Review of Sociology, (34), 127-151. http://dx.doi.org/10.1146/annurev.soc.34.040507.134737

Szelenyi, I. (2015). The triple crisis of Sociology. Contexts. Recuperado de https://contexts.org/blog/ the-triple-crisis-of-sociology/

Weber, M. (1992 [1917]). Wissenschaft als Beruf 1917/1919/Politik als Beruf 1919. En M. Weber, W. Mommsen, W. Schluchter, \& B. Morgenbrod (Edits.), Max Weber Gesamtausgabe (pp. 77-111). Tûbingen: Mohr/Siebeck. 


\section{Capítulo VII}

Una aproximación sociológica y ética

a la identidad de los ciudadanos

de Cuenca-Ecuador en su relación

con los procesos de creación

y aplicación del derecho

Juan Morales Ordóñez *

* Cátedra UNESCO Ética y Sociedad en la Educación Superior, Universidad Técnica Particular de Loja (UTPL). Contacto:jmorales@utpl.edu.ec 


\section{Introducción}

La hipótesis de este trabajo sostiene que la búsqueda de una identidad propia para los latinoamericanos ha sido y es uno de los aspectos que más se han desarrollado y debatido, lo que no es intrascendente, sino vital para la comprensión de nuestra realidad y su proyección a futuro.

Formando parte de la hipótesis, se afirma que pese a ser el derecho el más sofisticado sistema de organización y convivencia social, el debate acerca de su naturaleza, entre nosotros, no se ha dado; circunstancia que ha incidido de manera decisiva en la comprensión técnica y, también, ciudadana de lo que es, con consecuencias negativas. En este sentido, al no existir análisis sobre este concepto, se han adoptado determinados criterios a los que hemos accedido y adherido sin reflexión, adoptándolos "sin beneficio de inventario".

A través de una posición teórica crítica, se analiza la realidad del derecho en América Latina que esencialmente obedeció a la adopción de modelos foráneos y, que al ser elaborados por culturas diferentes a las nuestras, siempre evidenciaron dificultades en su aplicación en nuestras sociedades. Se plantea la necesidad de una mayor conexión con las esencias latinoamericanas y ecuatorianas para que, desde esa experiencia tanto teórica como vivencial, emerjan elementos jurídicos que incidan en la estructura del derecho que rige nuestra convivencia, participando así, de alguna manera, en la definición del sistema normativo que define nuestras vidas de forma forzosa y obligatoria.

Teniendo como referentes los grandes temas mencionados, se afirma que las manifestaciones éticas cuencanas (gentilicio de los habitantes de la ciudad de Cuenca-Ecuador) y su relación con el derecho se enmarcan en dicho escenario. Se defiende la tesis de que la cultura cuencana, en relación con lo jurídico, no está al margen de lo descrito, siendo necesario el desarrollo de una 
conciencia jurídica que incluya más y de manera sistémica a las manifestaciones culturales que, tradicionalmente, casi no influenciaron en el desarrollo del derecho en la ciudad.

Se cuestiona el mantenimiento de un statu quo relacionado directamente con fuentes foráneas y la no profundización -en lo jurídico- del análisis de lo local; situación que, de haberse dado, hubiese permitido aportar en los procesos de creación del derecho, tanto en los contenidos de las normas, como en la comprensión, y en la posible transformación y mejoramiento de la dogmática jurídica.

Al tratar la ética cuencana en su relación con los procesos de creación y aplicación del Derecho, se evidencia la existencia de una cultura de respeto a determinadas virtudes ciudadanas como la honorabilidad, la honradez, el esfuerzo, la búsqueda del bien común -en el marco del statu quo- y la integridad moral.

Se reconoce una cierta forma de cultura o manera de ser ciudadana, también común a otras ciudades ecuatorianas, que potenció el prestigio y el buen nombre alcanzado por el foro de abogados en Cuenca y en el Azuay (provincia ecuatoriana, cuya capital es la ciudad de Cuenca).

Para finalizar y a modo de exhortación, se propone que es preciso profundizar en el mejoramiento personal como ciudadanos, abogados y juristas y continuar en el proceso de construcción de un bien común que cada vez tenga menos centros exclusivos de claridad y pertinencia, fortaleciendo el aporte de todos los individuos y segmentos sociales. Se señala la necesidad de potenciar el respeto a las manifestaciones tradicionales que siempre fueron consideradas menores para el sistema jurídico. Es imperativo impulsar el fortalecimiento de un sistema jurídico que nos represente culturalmente de manera más fidedigna.

\section{La identidad en América Latina y en el Ecuador}

El pensamiento tradicional ciudadano y, también, de algunos intelectuales en América Latina se ha desarrollado desde la Conquista española, orientado al problema de la identidad cultural. ¿Quiénes somos? ¿indios, occidentales, mestizos? ¿nos debemos a lo aborigen? ¿nos definimos como foráneos? ¿tenemos algo propio que se forjó desde los inicios mismos de la relación y fusión de las culturas locales con las extranjeras? Son las interrogantes que siempre han sido el centro del debate de una problemática tan antigua y nueva a la vez.

La literatura de nuestros países permite mirar la realidad desde enfoques culturales amplios que incorporan elementos sociológicos, filosóficos e históricos; trata permanentemente sobre el tema de la identidad en sus diferentes manifestaciones. Los aportes de pensadores notables como Octavio Paz, Juan Rulfo, Carlos Fuentes, José Martí, Rubén Darío, Joaquín Gallegos, García 
Márquez, Vargas Llosa, Ciro Alegría, Pablo Neruda, Gabriela Mistral, José Hernández, Mario Benedetti, Jorge Amado y tantos otros, a lo largo y ancho de nuestro continente, tienen en común la constante preocupación sobre la realidad cultural y la esencia latinoamericana.

En Ecuador, el tema es tratado recurrentemente por muchos escritores como: Montalvo, Peralta, Icaza, Carrera Andrade, Carrión, Ortiz, Estupiñán, Benites Vinuesa, Dávila Andrade y otros. Quizá, es tan reiterado porque se trata de una búsqueda inconclusa de una realidad sentida y definida de distinta manera por todos y cada uno. Esto se debe al mestizaje, producto de la conquista y colonización española, que trazó un escenario social con características propias, entre las cuales puede destacarse como relevante, en el Ecuador, un cierto rechazo, por parte de un importante segmento social, de lo indígena y la complacencia y emulación de lo blanco y extranjero.

Dávila (1984), en Boletín y Elegía de las Mitas, describe con profundidad la vergüenza de la condición de ser hijos de indias y lo que eso representa en el estatus social y por ende en la construcción de lo jurídico.

Y vuestro Teniente y Justicia Mayor/ José de Uribe: "Te ordeno". Y yo, / con los otros indios, llevábamosle a todo pedir, / de casa en casa, para sus paseos, en hamaca. / Mientras mujeres nuestras, con hijas, mitayas, / a barrer, a carmenar, a texer, a escardar;/ a hilar, a lamer platos de barros - nuestra hechura-. Y a yacer con Viracochas, / nuestras flores de dos muslos, / para traer al mestizo y verdugo venidero. (p. 287)

Es probable que a muchos esta referencia les parezca lejana y relacionada solamente con "Ios hijos de las indias", porque consideran que no tienen esas raíces genéticas. Sin embargo, tal vez, es aplicable a muchos o a todos, no solamente por lo étnico, sino por lo cultural que engloba a todas las manifestaciones humanas.

El rechazo de lo indio no solamente es la negación de esa raíz racial, por considerarla menor y vergonzosa, sino de todo lo que ésta representa. En ese caso, se estaría rechazando algo que nos invade y define como cultura mestiza. Por un lado, lo indio, por otro, lo español y por fin un mestizaje cultural amplio con esos referentes y con otros, que se han ido sumando día a día, dando forma a este crisol social que es lo latinoamericano, lo ecuatoriano y lo cuencano.

También, es posible que la referencia al gran poema de Dávila a muchos les parezca no contemporánea. De hecho, muy pocos mencionan al gran escritor morlaco y sus ideas no son debatidas ni académica ni socialmente, pudiendo pensarse que no se lo hace porque esos conceptos fueron superados y la sociedad actual no se mira más en esas ideas. Sin embargo, me parece que 
cuando son planteadas en los diferentes foros académicos o espacios sociales, siguen teniendo vigencia e impactan tan fuertemente como impactaron cuando fueron publicadas.

En realidad, lo que se da es la absorción de la cultura local por la cultura global, condicionada en sus manifestaciones más generales por el mercado, que vende y posiciona, también, a una idea del mundo vinculada siempre con la compra de artefactos, tecnología y con una defensa mediática de la importancia superlativa de lo banal de la vida y de las sociedades. No es conveniente para el mercado o sociedad global que se hable del dolor, de la inequidad y de todas esas pequeñeces humanas, cuando bien puede realizarse la apología de un prototipo de ser humano que puede comprar y así ser feliz.

Probablemente, el rechazo de lo indígena -que en realidad se dio desde el inicio mismo del encuentro de las dos culturas- no tuvo problemas para imponerse y ser aceptado, por el imperio avasallador de la cultura española sobre la aborigen, siendo un asunto aún no resuelto -para algunos-. Para otros, el tema se elucidó desde el comienzo del encuentro-desencuentro entre españoles e indígenas, con la paladina afirmación: "somos occidentales", porque se consideran a sí mismos como productos de la cultura europea, continuadores, en estas tierras, de esas raíces y de esa cultura.

Soy de aquellos que piensan que, al reconocernos mestizos, es necesario trabajar sobre la vertiente indígena. Personalmente, -es probable que otros coincidan con este punto de vista- encuentro que la fuente cultural local es muy importante y que, por las razones expuestas anteriormente, no ha sido suficientemente analizada ni aprehendida. Desde la misma raíz de la vergüenza de ser indígena o mestizo -si es que lo es en realidad- se ha soslayado lo local en beneficio de lo foráneo. Sin embargo, para algunos es difícil renegar la vertiente local que identifica nuestra manera de ser. Si en un momento dado así se procedió, la vida nos lleva a vinculaciones, cada vez más estrechas, con esta parte de nuestra condición humana. Vivimos una cultura propia que es el resultado de los aportes de todas las que han incidido e inciden en la realidad latinoamericana.

Conectarse con las amplias manifestaciones culturales latinoamericanas: con su música, su gastronomía, su sentido del humor, su arte, sus formas de vida y su idiosincrasia es, desde todo punto de vista, conectarse con lo simple y lo esencial, que debe ser el fundamento de lo sofisticado y elaborado de otras expresiones culturales y, sobre todo, de la jurídica. Ser y vivir la latinoamericanidad es elemental y fácil para nosotros. Es un tema de piel y de corazón.

Es más complicado y, quizás, limitante conectarse exclusivamente con la "Madre Patria" y con el escenario al cual pertenece, Europa y toda su historia, pese a toda la seducción superficial e intelectual que pueda desprenderse de la fusión con culturas que han influido de manera de- 
terminante en el desarrollo del mundo global contemporáneo, por cualquiera de las razones que podrían explicar este fenómeno.

Como siempre, las dificultades son de cada individuo, de cada persona, no es un tema de debate el pensamiento propio que se expresa a modo de autointerrogación e incertidumbre permanente. Sí, lo es de análisis desde una tentativa de comprensión. Cuando alguien asegura de manera radical que su afirmación es una verdad personal, se puede debatir y buscar diferencias y consensos, claro, si es que hay la predisposición y conocimiento-humildad para ello.

En el plano de lo que se entiende actualmente como cultura, se podría afirmar que es lo mestizo aquello que nos identifica, por supuesto para quienes así pensamos y sentimos. Algunos podrían afirmar que no es necesario que nos devanemos la cabeza tratando de encontrar aquello que ya desapareció, en este caso, la organización social indígena, previa a la Conquista. Es posible que así sea. Se puede también defender la pertinencia de un punto de vista, un sentimiento, que se traduce en la afirmación de que somos una mezcla de razas y cultura y que partimos de ahí, sin que sea preciso abundar en indagaciones sobre un pasado que debe permanecer en ese estado, pues el presente es específico y éste debe merecer nuestra atención casi exclusiva.

Desde mi punto de vista, considero que es necesario que nos conozcamos más en la vertiente indígena, que no ha sido vislumbrada cabalmente. Es una especie de regresión emocional a lo que sentimos que, también, nos identifica. Es como una especie de autoconfesión de que una de las partes que nos conforman ha sido soslayada y dejada de lado. Es como si en el plano particular reconociéramos que somos determinados por la herencia que se ha ocultado expresamente por considerarla menor.

Occidente es tan poderoso y controlador que no es necesario que reivindiquemos su valor y la importancia mundial de su cultura. Grecia, Roma y el cristianismo son tan relevantes que hablar sobre su incidencia, podría ser una redundancia. Pero, lo que debe reconocer es que esas bases, junto con el aporte ibérico, llegaron a América con la Conquista y se impusieron como cultura dominante, casi eliminando la vertiente local o empobreciéndola tanto que hasta nos avergonzamos de ella. Todo o casi todo de la cultura anterior fue barrido por la nueva. ¿Culpa española solamente? ¿Debilidad intrínseca de esas culturas? Responsables son las dos. Por una parte, una cultura que quería imponerse con fines ligados siempre al poder en diferentes formas; y, por otra, civilizaciones locales débiles, listas para ser dominadas por otros.

Es probable que se trate, en mi caso, de rescatar esa parte no desarrollada convenientemente, para poder encontrarme en esta búsqueda y poder continuar en ejercicio de una lucidez que, también, quiere ser ejercida siempre. 
La búsqueda de la identidad, desde el reconocimiento de nuestra nacionalidad ecuatoriana, es fundamental, pese a que, como las otras nacionalidades, la nuestra, también, es el producto de procesos políticos de dominación, conquista y repartición de poder. Lo ecuatoriano ha sido, por siglos, el referente de unión de quienes hemos nacido y vivimos en este territorio. Debemos comprender esta raíz y conocerla profundamente en sus diferentes expresiones culturales y geográficas. Es necesario fomentar el espíritu de un sano nacionalismo; pues, encontrándolo y viviéndolo, podremos proyectarnos adecuadamente en la sociedad global que acepta lo auténtico y rechaza la imitación penosa de formas de vida ya desarrolladas en otros lugares.

La soterrada vergüenza de ser ecuatorianos, que se evidencia en muchas manifestaciones culturales que desconocen lo autóctono, contribuye al debilitamiento de nuestra nacionalidad. Debemos identificarnos con lo nuestro y, para hacerlo, es necesario conocer el País, vivirlo, apreciarlo y amarlo. Es preciso respetar en su especificidad las diversas formas culturales de los pueblos que conforman el Ecuador. No existen culturas mejores o peores que otras. Cada pueblo aporta al universo desde su propia especificidad y, ahí, precisamente, se encuentra su genuino valor.

Nuestra proyección como pueblo depende del sentido de identidad y del orgullo que desarrollemos de ser ecuatorianos, poseedores de un pasado y un porvenir comunes, que deben ser sistemáticamente fortalecidos en los diferentes momentos. (Morales, 2011, p. 164)

Nos hemos educado reconociendo la excelencia de las manifestaciones culturales occidentales. Desde niños, para muchos, los referentes culturales literarios fueron europeos, Julio Verne y su maravillosa producción, luego, Alejandro Dumas nos mostró la Francia del Rey Sol y a héroes como los mosqueteros, después, Cervantes, Shakespeare y los grandes nombres de Balzac, Voltaire, Víctor Hugo y Baudelaire. También, llegó Goethe, Nietzsche, más tarde, Sartre, Camus, de Beauvoir y tantos y tantos otros.

En música, nos educamos apreciando Strauss, Bach, Beethoven, Mozart, Debbusy, Satie y los del siglo XX: Mahler, Stravinsky, Messiaen, Boulez, Stockhausen, Schonberg y Xenakis.

Y, en pintura, aprendimos a amar las obras del Renacimiento con Boticelli, Miguel Ángel, Da Vinci, y las de Rembrant, Van Dick, y las de los impresionistas franceses: Manet, Monet, Degas, 
Pizarro, Sisley, Cezanne y otros, luego, el surrealismo con Dalí y Picasso, y los expresionistas alemanes.

Y, qué se puede decir de la ciencia occidental con sus producciones en todos los aspectos del conocimiento objetivo que define el mundo actual, en medicina, física, química, nanotecnología, informática, etc. Occidente nos abruma con su historia, su aporte y su poder.

Por todo aquello, es necesario que nos busquemos en la vertiente que nos falta, en la indígena y afro en primer lugar y, luego, en la mestiza que ya nos es propia a muchos, quizás, incluso le es propia a aquellos que reniegan de ella explícitamente, pues han nacido y se han desarrollado en un espacio histórico, también, definido por los indios. ¿Cómo es posible dejar de lado la historia local y validar la de los otros?

La búsqueda y construcción de nuestra identidad para que podamos entendernos colectivamente es necesaria en un país como el nuestro, diverso y complejo. El conocimiento de la realidad nacional, de su historia y de los factores actuales que interactúan definiendo un escenario social concreto es muy importante. Benites Vinueza en su obra "Ecuador: drama y paradoja" relaciona nuestra cultura con la geografía $y$, desde ese enfoque, describe con acierto a hombres y paisajes en un intento de mostrar la identidad de los ecuatorianos. Jorge Enrique Adoum en "Ecuador: señas particulares" pretende delinear el modo de ser nacional, desde la descripción crítica de sus diferentes formas culturales. Oswaldo Hurtado, en su última publicación, "Las costumbres de los ecuatorianos", atribuye a una cierta manera de ser negativa, propia de los ecuatorianos, la responsabilidad para que no hayamos podido alcanzar el tan buscado desarrollo nacional. (Morales, 2011, p. 193)

Desde un enfoque personal, pienso que como comunidad nos hace falta conocernos más para aceptarnos más en nuestra verdadera dimensión. Creo que los procesos de aculturación se dan con fuerza renovada en nuestros días y que nos equivocamos mucho cuando no valoramos el pensamiento y la realidad nacional. Los referentes de calidad con los cuales nos medimos están dados por formas culturales distintas a las nuestras y, por esa razón, permanentemente, pretendemos ser otros, parecernos a otros, desconociendo el valor intrínseco de nuestra cultura que en sí misma es rica y tan valiosa como cualquier otra.

El abandono de lo propio para adoptar lo ajeno trae consecuencias de diferente índole, todas relacionadas con la adopción de producciones de los otros y el rechazo más o menos explícito 
de lo local. Esta forma de pensar y de actuar no favorece el aporte, sino la reproducción. Precisamente, los autores franceses Bourdieu y Passeron (1970), en su obra La Reproduction, Éléments pour une théorie du systéme d'enseignement, citan un poema de Robert Desnos relacionado con los efectos de la reproducción:

El capitán Jonathan,

A la edad de diez y ocho años,

Un día captura un pelícano

En una isla del Extremo Oriente.

El pelícano de Jonathan,

Por la mañana, pone un huevo muy blanco

Del cual sale un pelícano

Que se le parece extraordinariamente.

$Y$ este segundo pelícano

Pone, a su vez, un huevo muy blanco

Del que sale, inevitablemente,

Otro que lo mismo hace.

Esto puede durar mucho tiempo

Si antes no se hace una tortilla.

Y, no nos favorece, sino que nos ubica en el plano de toda la vida. Esto es copiar, comprar, adquirir y venerar lo que viene de fuera. Si ya está hecho, ¿para qué perder el tiempo haciéndolo nosotros? Podría ser el agudo argumento que se esgrime. ¿Cómo y para qué gastar en el desarrollo de tecnología si ya existe? Es mejor comprar que invertir en el desarrollo local que al fin y al cabo será de menor calidad que lo extranjero. Pero, es todo lo contrario. Debemos permanecer en una constante búsqueda, pues este es un proceso sin fin, tratar de llegar a la concreción de nuestras mejores características. Si desde el encuentro con lo nuestro proyectamos nuestra acción, esta es más efectiva.

Ya en lo jurídico, sostengo que la relación con lo foráneo y su dependencia es todavía más evidente que con los otros elementos culturales. Pese a las referencias reiteradas que se hace del pensamiento de Montesquieu, cuando plantea que cada pueblo debe darse un Derecho que le sea propio. Se lo estudia y se lo repite con poca conciencia de su coherencia con la cultura local, como si el tema no fuera con nosotros. 


\section{El concepto del Derecho}

Abordar la identidad latinoamericana y ecuatoriana al inicio de este ensayo es pertinente en un trabajo sobre sociología, ética y derecho, pues este último, en muchas escuelas de pensamiento jurídico, no se encuentra desvinculado de los valores, sino que más bien son un mecanismo que permite el ejercicio de los mismos.

El derecho no es únicamente la norma escrita o la ley, como tradicionalmente y aún, hoy, se puede considerar por una parte importante de la ciudadanía. Estudiar Derecho significaba estudiar leyes, es decir, normas jurídicas ya elaboradas que debían aplicarse correctamente.

Si se revisan las mallas curriculares de hace algunas décadas y se las compara con las contemporáneas, se encuentra un fenómeno recurrente; esto es, la supremacía de la ley en su estudio, no para comprenderla en su estructura y funcionamiento, sino para conocerla textualmente y luego aplicarla, también, de manera lineal y sin interpretación, pues en la tradición del Código Civil francés de 1804, fue atributo exclusivo de los hacedores de la norma, es decir, de los legisladores.

Solamente a modo de ejemplo menciono la publicación de la Facultad de Jurisprudencia y Ciencias Sociales de la Universidad de Cuenca del año 1957, hace algo más de sesenta años, denominada Programas de Enseñanza, en la cual se puede observar el predominio de las asignaturas de derecho positivo. Si se analizan las mallas curriculares contemporáneas, se encuentra una concentración aún mayor de materias de códigos de leyes. Esto significa que hoy la situación es aún más legalista que lo que lo fue en esa época.

Estos dos términos están asociados y son considerados como sinónimos por un gran número de juristas y abogados, así como por la comunidad que sigue estos criterios, identificando a los dos conceptos como iguales.

La Ley y el Derecho se confunden. Esta situación se explica si se analiza históricamente los aportes jurídicos de la Revolución Francesa de 1789, entre los cuales tiene importancia mayor la creación de la figura conceptual de la Ley o manifestación de la voluntad del pueblo expresada a través del Legislador. Tan importante fue este nuevo paradigma que, Robespierre, el revolucionario, consideraba que ni siquiera era necesaria la interpretación de la norma, pues la Ley era una manifestación perfecta y no debía ser tocada por ninguna mano que la mancille, alterándola. 
Sin embargo, estos dos conceptos no son sinónimos, pues la Ley es solamente uno de los elementos que conforma al Derecho o conjunto de normas de carácter obligatorio que buscan la consecución de la justicia y el bien común. Además de la Ley, el Derecho está conformado por la Jurisprudencia o resoluciones de los tribunales de más alta instancia, por la Costumbre o formas reiteradas de actuar colectivo con contenido jurídico, por la Doctrina o pensamiento de los teóricos del Derecho y por los Principios Generales del Derecho o valores fundamentales que sostienen moralmente a la sociedad a la que sirve la creación jurídica. (Morales, 2011, p. 266)

Entre nosotros, no se ha debatido siquiera sobre el concepto de derecho. Se da por hecho que es algo, sobre lo que no hemos escrito ni profundizado. Sin embargo, el debate sobre este aspecto, origen de cualquier estructura posterior, no se ha dado.

En mi país, Ecuador, no tocamos el tema (...) como si no fuese necesario. Corremos el riesgo de adoptar, nuevamente, conceptos que nos vienen de la ilustración internacional, para desde una autocomplacencia mental, pensar que estamos en algo importante porque la "inteligentzia" académica así lo ha definido. Y eso es algo que, precisamente, no lo debemos hacer, porque esas prácticas generan dependencia del modelo y es imperativo que busquemos lo nuestro para aportar a la cultura mundial y para lograr lo que es necesario: instituciones sociales que respondan a nuestra realidad e independencia cognitiva que nos lleve a una adecuada, potente y orgullosa inserción en el ámbito mundial. (Morales, 2009)

Probablemente, se enseña a los estudiantes las teorías iuspositivistas o iusnaturalistas y se adopta una u otra, sin que nos pronunciemos con argumentos del porqué de la adopción de una corriente u otra. A veces, nos declaramos seguidores de un iusnaturalismo ortodoxo y otras, demasiado a menudo y sin análisis, nos declaramos iuspositivistas, porque estudiamos leyes y códigos. En realidad, luego de un superficial análisis, podemos percatarnos que el positivismo no es en esencia el conocimiento de las leyes, sino que es el estudio de la dogmática jurídica y de la estructura jurídica que permite que las normas o leyes puedan ser. Este es un tema relacionado con la epistemología jurídica. Un ejemplo puede ilustrar el punto de vista manifestado. Si se analiza el contenido de la obra clásica del positivismo jurídico, "La Teoría Pura del Derecho", no se encontrará el tratamiento del contenido de una sola ley. Se trata más bien del tratamiento de 
los elementos de la estructura lógica de la norma o del silogismo jurídico: derecho y naturaleza, derecho y moral, definición del derecho, obligación jurídica, hecho ilícito, responsabilidad jurídica, ciencia del derecho y sociología jurídica, y otros temas relacionados con la técnica y la dogmática jurídica. El positivismo jurídico no es el aprendizaje de las leyes, sino el estudio de su estructura dogmática de funcionamiento.

Este enfoque permite que se visualice la importancia del estudio de la Teoría del Derecho, situación que, entre nosotros, casi no se ha dado, con consecuencias como las de contar con un Derecho deslegitimado por la ciudadanía debido a la falta de coherencia de las afirmaciones teóricas con la práctica. Si se dice que el Derecho responde a valores y los tiene, también, como objetivos, esto debe aplicarse en la realidad y, para hacerlo, además de tener una clara conexión con el hecho social ecuatoriano que es el escenario básico del cual emergen los valores que posicionamos y potenciamos, se debe tener el conocimiento técnico necesario para que la estructura dogmática y técnica del Derecho sea la adecuada para que esos enfoques sociales y deontológicos puedan manifestarse correctamente. Si se cambian los contenidos de normas porque nos impresionan las foráneas o porque se considera que es una reivindicación nacional justa, pero no se cambia la estructura, casi no se cambia nada, pues el camino jurídico con la serie de dogmas y ficciones que lo caracterizan sigue intacto. (Morales, 2007, p. 1)

El estudio de la teoría del derecho debería permitir incidir de mejor manera en la construcción estructural de lo jurídico, para que desde ahí cambiemos.

Si se analiza el estudio del derecho en el Ecuador, desde la perspectiva diacrónica, este nos remite al nacimiento de la universidad ecuatoriana.

La formación en derecho ha sido considerada como una carrera de estudio en todas las universidades del mundo, desde su funcionamiento en el siglo XII en Europa, en virtud de la importancia y trascendencia de los sistemas jurídicos que permiten la organización social.

En el Ecuador, el estudio y la enseñanza del derecho se inician en el siglo XVII, con el funcionamiento de la primera universidad ecuatoriana en el año de 1603. La carrera 
de derecho en nuestro país, como en el resto del mundo, ha sido uno de los pilares académicos fundamentales en la conformación de las universidades o centros de educación superior.

En los orígenes de las Facultades de derecho, el estudio del Derecho Canónico fue el eje central del pensum académico, en virtud de la incidencia determinante del pensamiento religioso católico en las manifestaciones culturales de la época. También, en ese momento histórico, la Filosofía del derecho y el Derecho Natural se constituyeron en materias fundamentales de estudio.

Ya, en el siglo XIX, el novísimo Código Civil francés determina en gran medida el estudio del derecho en general, pues se lo consideraba como la esencia del pensamiento jurídico. De ahí, que materias relacionadas con las instituciones jurídicas del Código, constituían la base de la enseñanza del derecho. Entre nosotros, esta gran corriente internacional influye de manera determinante, pues distinguidos profesores de las Facultades de derecho producen obras trascendentales sobre instituciones del derecho civil, que hasta hace poco tiempo influenciaron notablemente en el desarrollo teórico, normativo y sobre todo en la práctica jurídica del país.

En esta época, se desarrolla una saludable motivación por el estudio del Derecho Internacional Público y existe motivación por un renovado interés por el derecho romano y sus instituciones.

Durante la segunda mitad del siglo XX, dentro de las Facultades de derecho se incorporan los estudios de la realidad política, económica y social del Ecuador y del mundo, a su pensum académico. Esta situación conduce a otorgar una titulación media vinculada, precisamente, con las Ciencias Políticas y Sociales.

Actualmente, las Facultades de derecho deben responder a realidades contemporáneas, definidas por elementos como los Derechos Humanos, la necesidad de proteger el medio ambiente, la propiedad intelectual, la internacionalización del derecho y otros enfoques conceptuales que deben ser recogidos por la normativa jurídica, tanto en el ámbito nacional como internacional. (Morales, 2007, pp. 2-3) 
La educación jurídica se encuentra aún conectada con referentes históricos muy fuertes. Situación que no podría ser de otra manera en virtud de la construcción permanente y nunca detenida de la estructura jurídica y de los contenidos de las normas. Sin embargo, los referentes tradicionales, estructurales, sobre todo, no son abordados académicamente en su comprensión, situación que imposibilita el avance y el cambio sistémico del derecho. Por otro lado, a nivel de contenidos, las realidades contemporáneas son tratadas, también, con distancia, en el sentido de que sigue primando el estudio de lo tradicional, como las materias relacionadas con lo civil, penal y otros, soslayando, de alguna manera, a lo nuevo: derechos humanos, medio ambiente, justicia indígena, medios alternativos de solución de conflictos y otros aspectos.

Ante la ausencia de debate respecto del concepto del derecho, se nos impone por la fuerza de la no reflexión, criterios no analizados y sí asumidos ligeramente. Situación grave, pues esa toma de posición y adopción de conceptos no son neutros, sino que definen toda la vida jurídica, desde su estudio en las aulas universitarias hasta su aplicación práctica por los profesionales del derecho en sus diferentes roles.

Se debe escribir y debatir. Esta es una exigencia moral tanto para los académicos como para los profesionales dentro de la cultura jurídica. Solamente, desde una sólida teoría, constantemente enriquecida y renovada, se podrán construir herramientas estructurales que determinen nuestra conducta y que estas sean las apropiadas para que permitan alcanzar los objetivos axiológicos del derecho.

\section{Sociología y ética cuencana frente a lo jurídico}

Occidente, con todo su desarrollo y presencia mundial ha influenciado grandemente en la cultura cuencana. La forma de ver el mundo y los valores que se reivindican entre nosotros, en gran medida, responden al modelo europeo y sus derivaciones en todos los campos.

Es evidente que la construcción del acervo cultural local, representado por grandes figuras de ciudadanos notables, ha recibido una influencia definitiva de los paradigmas occidentales, a los cuales, siempre nos hemos acogido para asumirlos como referentes de nuestro propio pensamiento y accionar. Por supuesto, que no es la única fuente, pues, además de los aportes personales inherentes a la obra de cada individuo, existen otras fuentes que provienen del entorno local en su dinámica de convivencia cotidiana.

Esta conexión casi inexorable con el centro del paradigma cultural imperante y emulado a ultranza por la intelectualidad local, llevó a considerar como expresiones menores e intrascendentes las generadas por los otros, por aquellos que, no encontrándose dentro de la órbita de una 
intelectualidad sofisticada, fueron considerados de menor importancia. Esto es un error, pues la verdad no se encuentra solamente en la sofisticación de la teoría y en los constructos culturales foráneos.

si se preparase a los sudamericanos, no para vivir en Francia, cuando no son franceses; ni en los Estados Unidos, que es la más fecunda de estas modas malas, cuando no son norteamericanos, ni en los tiempos coloniales, cuando están viviendo ya fuera de la Colonia, en competencia con pueblos activos, creadores, vivos, libres; sino para vivir en la América del Sur (...) Mata a su hijo en la América del Sur el que le da mera educación universitaria. (Martí, citado en Morales, 2010)

El pensamiento del gran José Martí nos ubica en la realidad local y latinoamericana, diferente a la europea, ni menor ni mayor, pero sí específica. Tratar de comprender la cultura local con parámetros generados en otros lares, resulta inapropiado y sin sentido, pues solo compartir con los otros desde el deslumbramiento de su especificidad permite la construcción de una visión adecuada de la realidad. La ilustración aislada de la validación del otro en sus diferentes expresiones es inútil, pretenciosa, arrogante y hace daño por su consustancial miopía conceptual.

Esta afirmación se fundamenta en el pensamiento cristiano que rechaza al escriba y al sabio para validar las manifestaciones simples de la gente poseedora de una sabiduría diferente, pero más vital, sostenible y humana. De hecho, Jesús debatió permanentemente con aquellos y los llamó fariseos. Prefirió la sencillez de los ignaros y también la mansedumbre de espíritu.

La apropiación del paradigma foráneo, por un segmento de la intelectualidad local, puede entenderse desde la lógica del poder y de la importancia de conocer para mantener las estructuras sociales. América Latina, el Ecuador y Cuenca, por supuesto, fueron definidas a partir de la Conquista, por los criterios establecidos por una Ilustración generada en Europa y aplicada en nosotros. De ahí, puede explicarse el fenómeno de la adhesión al poder omnímodo de la estructura imperante y su preservación.

Es más delicado analizar la situación de los dominados que hacen suyo un modelo de vida foráneo y lo defienden como si fuera propio. Tal vez, esta acción se debe a que la identidad nacional estaba y está definida por el apego a lo extranjero. No existen cuestionamientos en verdad, pues la autoafirmación de la gente es la de ser continuadores de los que ejercieron el poder y nos conquistaron. Si esto es así, quienes así piensan, se conectan con lo europeo y desconocen lo local y hasta lo rechazan. 
Ecuador, en diferentes momentos históricos, pudo concretar jurídicamente lo valioso de la identidad nacional. El texto constitucional vigente, aprobado en el año 2008, recoge reivindicaciones tradicionales relacionadas con el respeto a formas culturales locales. Desafortunadamente, este hito no provino de quienes se relacionan con el Derecho. Por el contrario, fueron otros quienes llevaron a la norma jurídica estos criterios, precisamente porque no estaban comprometidos con el modelo jurídico imperante, en el que la repetición beata del mismo era sinónimo de conocimiento y erudición, situación que favoreció la evidente e histórica inequidad social que nos ha caracterizado y caracteriza como pueblo.

La ética cuencana en el proceso de búsqueda de identidad y su reconocimiento jurídico, se ha quedado en instancias que reivindican conductas correctas y ejemplares en el pasado, frente al respeto de la norma. Virtudes como honradez, honorabilidad, cordialidad, decencia e integridad moral han sido características de una "cuencanidad" jurídica de la cual todos nos enorgullecemos y con la cual nos conectamos para preservarla y potenciarla en las generaciones actuales y venideras. Sin embargo, desde esas virtudes estamos obligados moralmente a ir más allá, comprometiéndonos con el cambio en un país en el cual, como el nuestro, coexisten formas culturales diversas que tradicionalmente han sido excluidas de los procesos de desarrollo y bienestar.

Si queremos una institucionalidad que nos represente como pueblo, debemos construirla; esa tarea exige compromiso total y búsqueda de la excelencia moral, sobre todo en la parte personal, que permita la comprensión de la interdependencia y la necesidad de contribuir al mejoramiento moral de la condición humana. Pues, como decía Martí: "Sobre cada hombre debe pesar la carga de todo el universo..." "Un hombre es un instrumento del deber: solo así se es hombre" (citado en Morales, 2010).

El comportamiento ético cuencano en el marco de la cultura jurídica ecuatoriana ha sido conservador frente a las posibilidades de innovación de la estructura del derecho. Se podría hablar de una suerte de connivencia con el statu quo.

Las posibilidades que se tienen, si se entra en la dimensión de la exigencia moral del aporte al afinamiento del derecho desde nuestra cultura ecuatoriana, son muy grandes, pues se superaría la posición ideológica de repetir el modelo y pasaríamos a ser parte de la generación de propuestas que permiten incorporar a la dogmática jurídica, tan imponente y sólidamente constituida, criterios culturales que nos representen como pueblo con una identidad y un destino propios. Así se superaría el nivel de meros conocedores y aprendices de estructuras y leyes, validándolas beatíficamente, a una aproximación sociológica jurídica que mire la realidad local con respeto y pertinencia; y, de ahí a una cabal ética del derecho. 


\section{Conclusiones}

Los pueblos deben contar con un sistema jurídico que sea el producto de sus propias realidades sociales y culturales. Por las condiciones de conquista y ejercicio del poder mundial, América Latina y el Ecuador, como otras regiones del planeta, han definido sus estructuras institucionales contando con sistemas generados por otras civilizaciones, sin que las realidades locales hayan incidido en ellos.

Es necesario aportar desde lo local al imponente edificio conceptual que significa el sistema jurídico, que es el fundamento de nuestra organización social. Hacerlo es el gran desafío y, para lograrlo, es preciso desarrollar una profunda identificación con todas las manifestaciones culturales ecuatorianas, esencialmente con aquellas comunes a los grandes grupos sociales de nuestro país.

Solamente desde la incorporación anímica y conceptual de la diversidad cultural del Ecuador y de los niveles de inequidad e injusticia social, se puede abordar el tratamiento del derecho para mejorarlo y hacerlo, cada vez más propio. La inveterada emulación de lo foráneo nos perjudica y detiene en la construcción de una estructura jurídica acorde con nuestra cultura e idiosincrasia.

La ética cuencana frente a lo jurídico ha sido de respeto a principios y valores, pero también, de réplica de lo extranjero con las evidentes consecuencias de preservación de una realidad social alejada del concepto del bien común y la justicia distributiva. La honorabilidad, decencia e integridad que caracteriza a la cultura de la urbe, constituyen el fundamento sólido para dar un paso más y trascender hacia una vinculación potente con el más débil, llegando a incorporar a este objetivo como el más alto nivel moral de una ética aplicada. 


\section{Referencias}

Bourdieu, J-C., \& Passeron, J-C. (1970). La Reproduction - Elements pour une théorie du systeme d'enseignement. Paris: Editions de Minuit.

Dávila, C. (1984). Obras Completas. Poesía. Quito: Pontificia Universidad del Ecuador.

Morales, J. (2007). Proyecto de Caracterización y Características y Estándares de calidad para la evaluación y acreditación de la Carrera de Derecho de las Universidades del Ecuador. Quito: CONEA.

Morales, J. (2009). El momento constitucional ecuatoriano: Una aproximación desde la Filosofía del Derecho. Conferencia Magistral. Congreso Internacional "Décimo Aniversario de la Constitución de la República Bolivariana de Venezuela", Caracas, Venezuela.

Morales, J. (2010). Conferencia Magistral Inaugural. Congreso Mundial: "Derecho y Justicia". La Habana, Cuba.

Morales, J. (2011). Ética y Sociedad. Cuenca, Ecuador: Universidad del Azuay. 


\section{Capítulo VIII}

Oportunidades educativas, ocupacionales y movilidad social en México. El peso de la familia $y$ el lugar de nacimiento

María Rocío Grediaga Kuri * 


\section{Introducción}

Como parte de los festejos del 40 Aniversario de la Licenciatura en Sociología de la Universidad de Sonora, quisiera reflexionar con quienes han elegido a la sociología como vocación, sobre uno de los temas clásicos de la disciplina y que representa una de las grandes tensiones en las sociedades contemporáneas: herencia versus movilidad social.

Es mayor peso de la herencia sobre las oportunidades cuando la sociedad tiene altas tasas de inequidad. A pesar del aumento en indicadores como acceso a infraestructura, ampliación de las expectativas de vida y la escolaridad promedio de la población, la desigualdad sigue siendo un grave problema en México y no se ha logrado reducir la brecha en el acceso a las oportunidades, ni en las condiciones de vida de la población.

La desigualdad social es multifactorial: la posición socioeconómica de la familia de origen afecta las oportunidades educativas, que tienen una relación importante con el acceso al mercado ocupacional y que se traduce, a su vez, en condiciones de ingreso, vida y bienestar desiguales. Afectan las oportunidades educativas y ocupacionales tanto los factores adscriptivos (Blau 1970; Jencks, 1980): la situación socioeconómica de la familia de origen, el sexo, la etnia o la raza; como cuestiones circunstanciales (Blau y Duncan, 1967; Boudon, 1974; Roemer y Trannoy, 2013): el país, lugar de residencia o las condiciones de socialización durante los primeros años de vida (Solís, 2018).

El presente ejercicio de análisis sobre la evolución de las oportunidades educativas, ocupacionales y el grado de movilidad intergeneracional en México utilizará como referente empírico el Módulo de Movilidad Social Intergeneracional (MMSI) de la encuesta aplicada por el Instituto Nacional de Estadística y Geografía (INEGI, 2016a) a una muestra representativa a nivel nacional 
de la población entre 24 y 65 años. Dicha encuesta proporciona información sobre la situación educativa y ocupacional de los progenitores o proveedor principal, así como del acceso a bienes y servicios en el hogar de los encuestados cuando tenían 14 años (condiciones familiares cuando realizaban sus estudios) y de su situación en estas mismas dimensiones en el momento de aplicación de la encuesta.

\section{Antecedentes de investigación sobre el tema en México}

Hay diversos estudios y bases de información disponibles sobre trayectorias, oportunidades y movilidad (horizontal y vertical) en México. El proyecto de la Encuesta Demográfica Reconstructiva (EDER), aplicada por INEGI por primera vez en 1998 y replicada en 2010, bajo la dirección de Coubés, Zavala y Zenteno (2005). Dicha encuesta diseñó una metodología denominada historias cuantitativas de vida, en la que se reconstruye año por año de vida la situación del encuestado en seis dimensiones: datos generales y condición de la familia, migración, educación, entrada en unión, fertilidad y ocupación. La muestra tiene representatividad nacional para tres grupos generacionales, los nacidos en los siguientes periodos: 1936-1938, 1951-1953 y 1966-1968.

A partir de los datos de la Encuesta sobre Trayectorias Educativas y Laborales de los Jóvenes de la Zona Metropolitana de la Ciudad de México (ETEL) aplicada a fines de 2010, a una muestra aleatoria de 2,920 jóvenes entre 18 y 29 años de edad, Blanco, Solís y Robles (2014) contrastaron dos hipótesis: a) la "hipótesis de selección" (Mare, 1980; Shavit, Yaish y Bar-Heim, 2007), que sostiene que la desigualdad disminuye en la medida en que se progresa en los niveles educativos debido a la creciente selectividad de los niños y jóvenes de bajos recursos socioeconómicos que continúan estudiando; y b) la denominada "desigualdad vinculada a la cobertura", que sostiene que es mayor la desigualdad en los niveles o localidades con menor cobertura, pues en el tránsito a estos niveles operan más intensamente los procesos de selección social. En este sentido, son importantes las disparidades en la calidad de la oferta educativa, según el tipo de institución educativa a que asisten los jóvenes en los distintos niveles. No solo las desigualdades de origen, sino la calidad institucional heterogénea del Sistema Educativo Nacional (SEN) tiene efectos acumulativos sobre la desigualdad de las trayectorias escolares, principalmente después de los niveles definidos como obligatorios, "determinando no solo las probabilidades de continuidad escolar al nivel siguiente, sino también el tipo de escuela al que se logra tener acceso" (Blanco et al., 2014, p. 20).

1 En general, el cuestionario capta información sobre: educación, ocupación, nivel socioeconómico (riqueza) y percepción de la movilidad social. También cuenta con un tema referente a las características sociodemográficas sobre el informante, su padre, su madre y/o proveedor principal. 
La Encuesta de Movilidad Intergeneracional (EMOVI, 2017), aplicada en 2011 y 2015 por el Centro Espinoza Yglesias, plantea dimensiones analíticas que son recuperadas en la construcción de la información más reciente disponible en el MMSI 2016. En un reporte publicado por la Comisión Económica para América Latina y el Caribe (CEPAL), Solís (2018) analizó esta información.

La base del MMSI será reanalizada aquí en función de los cambios estructurales en el SEN, la composición del mercado ocupacional y el acceso a bienes y servicios en el país.

Los resultados reportados por Solís (2018) revelan:

la persistencia de altas tasas absolutas de movilidad intergeneracional ascendente educativa y ocupacional, pero una baja movilidad económica. También muestran que en las tres dimensiones existe una alta asociación neta entre los orígenes y destinos sociales de las personas, lo que es indicativo de la alta desigualdad de oportunidades que prevalece en el país. Finalmente, existe una muy baja asociación entre la movilidad educativa y ocupacional y la movilidad económica, lo que sugiere una devaluación de la movilidad ascendente en la escolaridad y el mercado de trabajo. (p. 5)

\section{El contexto cambiante de la movilidad social en México}

Dado el amplio espectro de tiempo y la diversidad de las oportunidades educativas y laborales de las distintas entidades y localidades del país, así como sus transformaciones a partir de la segunda mitad del siglo pasado, resulta fundamental definir una periodización que considere los aspectos estructurales que Zenteno y Solís (2006) denominan movilidad absoluta, vinculados con los cambios:

- En la estructura social, de edad y distribución regional de la población.

- La dotación de servicios o infraestructura básica en el territorio nacional

- Las oportunidades en función del desarrollo del SEN.

- En la estructura económico-productiva y el mercado laboral del país.

Conocer dichas transformaciones permite valorar el peso de las condiciones de escolaridad y ocupación de los padres en las de los hijos. Con la información del MMSI 2016, es posible explorar factores estructurales e institucionales, así como la diferencia en las oportunidades según el grupo social de origen los encuestados. Esto es relevante, en tanto el origen social es una dimensión que atraviesa directamente las oportunidades educativas y laborales y el acceso a la información, 
fundamenta las decisiones escolares e indirectamente, vía las oportunidades educativas y el capital social, el destino social de los encuestados. Como señalaron Crozier y Friedberg (1990) ningún actor puede funcionar fuera del sistema, pero no existen sistemas sociales completamente regulados y controlados, por lo que la actuación, aunque no determinada, sí está acotada por reglas estructurales más o menos flexibles.

\section{La distribución poblacional, desigualdad social y del ingreso en México}

En México los procesos de industrialización en la segunda mitad del siglo XX se asocian no solo a cambios en el mercado laboral, sino en la distribución territorial y composición por edad de la población (Zenteno y Solís, 2006). Los cambios en la estructura poblacional pueden clasificarse en dos ejes: su distribución territorial y la pirámide de edad. A principios del siglo XX (1908-1910), $71 \%$ de la población era rural y 29\% urbana, situación que cambia drásticamente al final del siglo XX; $25.4 \%$ vivía en comunidades rurales y 74.6\% en zonas urbanas. En 2015, 20.75\% de la población habita en comunidades rurales y el resto se localizan en zonas urbanas.

La pirámide poblacional está modificándose paulatinamente, con tendencia hacia el envejecimiento. Sin embargo, a diferencia de lo que ocurre en los países de Europa, 27.81\% de la población mexicana se ubica entre 0 y 14 años, dos tercios (66.93\%) forman parte del grupo de edad correspondiente a la población económicamente activa (PEA) y sólo poco más de una vigésima parte (6.47\%) son mayores de 64 años (Statista, 2017). Por la disminución de la tasa de natalidad en el país, la matrícula de educación primaria ha decrecido en las últimas dos décadas, por lo que la oferta y uso de la infraestructura escolar han requerido ajustes importantes, principalmente en las ciudades.

Durante el proceso de industrialización por sustitución de importaciones (1940 a 1976), nombrado El Milagro Mexicano, la agricultura y la industria de la transformación, así como el crecimiento del aparato gubernamental fueron los ejes del desarrollo económico y del mercado laboral. Esto aumentó la demanda de personal calificado para apoyar el desarrollo de distintas áreas del gobierno y nuevas ramas del sector productivo, que se atendió a través de la ampliación de las oportunidades de educación superior (ES).

A pesar del periodo de auge relativo y cierta recuperación del crecimiento económico posterior a la crisis, no se ha logrado disminuir la pobreza, ni reducido la brecha en la distribución del ingreso en el país. Si observamos la evolución del coeficiente de Gini, 0.496 en 2012 y 0.491 en 2016, constatamos que no se aprecia una disminución significativa del nivel de desigualdad, ni de la proporción de la población del país en condición de pobreza (INEGI, 2016b). En la tabla 1 se observa la distribución del ingreso de 2008 a 2014. 
Tabla 1. Distribución del ingreso 2008 a 2014, sin transferencias

\begin{tabular}{|c|c|c|c|c|}
\hline Deciles & 2008 & 2010 & 2012 & 2014 \\
\hline I & 2531.7 & 2478.58 & 2633.07 & 2658.23 \\
\hline II & 7482.11 & 7004.12 & 6748.36 & 7055.01 \\
\hline III & 12469.44 & 11468.61 & 10779.8 & 11418.79 \\
\hline IV & 17183.93 & 15624.87 & 14908.1 & 15306.27 \\
\hline V & 22007.06 & 20145.51 & 19551.96 & 19608.38 \\
\hline VI & 27935.64 & 25515.87 & 24578.37 & 24363.94 \\
\hline VII & 35808.21 & 31972.79 & 31049.76 & 30203.79 \\
\hline VIII & 46523.8 & 41331.42 & 40473.09 & 38532.86 \\
\hline IX & 65065.3 & 56932.68 & 55249.01 & 53211.01 \\
\hline$x$ & 149596.76 & 122301.81 & 124522.65 & 124745.87 \\
\hline
\end{tabular}

Fuente: INEGI (2017).

Según el Consejo Nacional de Evaluación de la Política Social (CONAPO, 2009) millones de mexicanos viven en condición de pobreza, 18.2\% en pobreza extrema. México ocupa el lugar 52, de un total de 177 países, por su índice de desarrollo humano (Programa de Naciones Unidas para el Desarrollo [PNUD], 2007). Pero la ausencia de cambio o el incremento en la desigualdad de la distribución del ingreso no es privativa de nuestro país.

El último informe de la Organización para la Cooperación y el Desarrollo Económicos (OECD, 2018a) señala que el ingreso mundial promedio del 10\% más rico es nueve y media veces más alto que el promedio de ingreso del 10\% más pobre, distancia mayor que la brecha de siete veces que se daba hace 25 años. El 10\% más rico concentra casi mitad de la riqueza total, mientras que el $40 \%$ más pobre solo participa del $3 \%$ de la misma.

Pero en términos de movilidad absoluta o estructural no solo es importante dar cuenta del nivel de desigualdad social, sino que se necesita contextualizar, aunque sea someramente, las condiciones de estudio y ocupacionales de distintas generaciones. Es decir, describir los cambios en la dimensión espacial (cobertura territorial de la oferta educativa y el mercado ocupacional) y temporal (modificaciones principales y puntos de inflexión relevantes) del aparato productivo y el SEN. 
La evolución de la estructura económico-productiva 1940-2015

En cuanto a los cambios en la estructura económica, la economía mexicana creció a ritmo acelerado hasta mediados de la década de 1970. Este período, como se señaló antes, se caracterizó por la intervención gubernamental directa y la protección del mercado interno. Durante el proceso de industrialización, la agricultura y la industria de la transformación eran los ejes del desarrollo económico y aumenta la demanda de personal calificado para apoyar el desarrollo de distintas áreas del gobierno, ramas del sector productivo y atender la ampliación de oportunidades de ES. Por esta razón, especialmente los que iniciaron su trayectoria académica durante la expansión acelerada del sistema (1960 a 1980), tuvieron oportunidad de colocarse en el mercado laboral, en ocasiones incluso antes de terminar la licenciatura, en lugar de buscar continuar su formación ingresando inmediatamente a un posgrado.

A partir de la crisis de la década de 1980, el estancamiento económico y la transformación del modelo de desarrollo, producen una disminución del tamaño del sector gubernamental, que deja sin empleo formal a una amplia masa de trabajadores. A pesar de la relativa recuperación del crecimiento económico durante el presente siglo (aunque a tasas muy por debajo de las que presentaba la economía antes de las crisis de 1980, 1995 y 2009), no se aprecia una disminución significativa en la tasa de desigualdad y la proporción de la población del país en condición de pobreza (INEGI, 2016b).

En lo que va del siglo XXI, la tasa de crecimiento en el país fluctúa alrededor de 2 y $3 \%$ del Producto Interno Bruto (PIB). EI PIB per cápita en México en 2015 era de 9,009.96 US dólares anuales, y la tasa de desempleo de 3.53\%, de acuerdo con información del Banco Mundial (2016). La baja tasa de desempleo se debe a la forma en que se construye este indicador, que parece claro que no refleja el crecimiento acelerado del sector informal en el país.

A partir de la crisis de la década de los años 80 ocurre un desmantelamiento de algunos sectores de la economía mixta (cierre de pequeñas o medianas empresas del sector privado, así como de las paraestatales o empresas productivas y de distribución administradas por el gobierno).

las características y procesos de transformación más recientes del mundo laboral en el país: segmentación de mercados, precarización y flexibilización de condiciones de empleo, desajuste entre credenciales educativas y requisitos. (Blanco et al., 2014, p. 17)

Desde fines del siglo pasado y lo que va de éste, la actividad económica principal en México es el sector terciario. La rama de comercio representa la principal fuente de ocupación, el sector 
de servicios personales ocupa la cuarta posición y otras actividades como el turismo, los servicios profesionales y el sector gubernamental (que ocupan de la $7^{\mathrm{a}}$ a la $9^{\mathrm{a}}$ posición, respectivamente) han contribuido a la tercerización de la economía nacional (63.7\% del PIB proviene de este sector) (Statista, 2017). En cambio, pierden importancia el sector agropecuario, la industria de la transformación y la extractiva, que habían constituido los pilares del desarrollo hasta 1976, primer signo de agotamiento y crisis del modelo sustitutivo de importaciones.

Tabla 2. Distribución de la población económicamente activa por sector de ocupación 2016, sexo y nivel educativo de los contratados

\begin{tabular}{lcccccc}
\multicolumn{1}{c}{$\begin{array}{c}\text { Sector } \\
\text { ocupacional }\end{array}$} & $\begin{array}{c}\text { Millones } \\
\text { ocupados }\end{array}$ & $\begin{array}{c}\text { Ingreso } \\
\text { promedio }\end{array}$ & $\begin{array}{c}\text { Asalariados } \\
\%\end{array}$ & $\begin{array}{c}\text { Educación } \\
\text { primaria } \\
\text { menos } \%\end{array}$ & $\begin{array}{c}\text { Educación } \\
\text { superior } \\
\%\end{array}$ & $\begin{array}{c}\text { Mujeres } \\
\text { ocupadas } \\
\%\end{array}$ \\
\hline Sector comercio & 7.8 & $\$ 4,244.00$ & $54.60 \%$ & $30.00 \%$ & $12.90 \%$ & $48.20 \%$ \\
\hline $\begin{array}{l}\text { Industria } \\
\text { de la transformación }\end{array}$ & 6.4 & $\$ 4,556.00$ & $80.00 \%$ & $53.20 \%$ & $3.90 \%$ & $35.00 \%$ \\
\hline Sector servicios personales & 4.9 & $\$ 3,630.00$ & $74.80 \%$ & $41.60 \%$ & $6.70 \%$ & $53.70 \%$ \\
\hline Sector agropecuario & 4.7 & $\$ 2,665.00$ & $46.30 \%$ & $70.00 \%$ & $2.00 \%$ & $6.40 \%$ \\
\hline Sector educación y salud & 3.7 & $\$ 7,364.00$ & $92.00 \%$ & $3.80 \%$ & $55.30 \%$ & $63.60 \%$ \\
\hline Sector de la construcción & 3.4 & $\$ 5,166.00$ & $74.60 \%$ & $46.20 \%$ & $17.20 \%$ & $3.00 \%$ \\
\hline Sector turismo & 2.6 & $\$ 4,036.00$ & $62.90 \%$ & $34.80 \%$ & $9.70 \%$ & $56.30 \%$ \\
\hline $\begin{array}{l}\text { Sector servicios } \\
\text { profesionales }\end{array}$ & 2.5 & $\$ 6,936.00$ & $76.20 \%$ & $9.30 \%$ & $47.80 \%$ & $38.00 \%$ \\
\hline Sector gubernamental & 2.2 & $\$ 7,355.00$ & $85.00 \%$ & $13.30 \%$ & $37.50 \%$ & $35.60 \%$ \\
\hline Sector industria transporte & 2.2 & $\$ 6,083.00$ & $80.00 \%$ & $22.50 \%$ & $16.60 \%$ & $12.00 \%$ \\
\hline Sector industria extractiva & 0.35 & $\$ 9,489.00$ & $98.00 \%$ & $19.20 \%$ & $29.30 \%$ & $12.80 \%$ \\
\hline
\end{tabular}

Fuente: Observatorio Laboral (2017). 
El ingreso promedio en los distintos sectores económicos en 2016 (tabla 2) fluctúa entre poco menos de $150^{2}$ y casi $500^{3}$ dólares mensuales; según las encuestas de ocupación del INEGI (2016b), el ingreso promedio de los profesionistas es sólo un poco superior (585.00 dólares mensuales) y en la profesión mejor remunerada, arquitectura, diseño y urbanismo, supera ligeramente los 700 dólares mensuales ${ }^{4}$ ). Si se considera, además, el amplio crecimiento del sector informal se explicaría al menos parcialmente la aparentemente baja tasa de desempleo (menos del 5\% en 2017), por lo que habría que tomar con cautela la información oficial de que se dispone.

Si como primera aproximación a la relación entre ocupación y escolaridad retomamos la proporción de empleados con ES en cada sector (tabla 2), destacan en primer lugar el sector de educación y salud (55.3\%) y el de servicios profesionales (47.8\%), en el cual alrededor de la mitad o más de los contratados han realizado estudios de nivel superior. Los sectores en que se presenta una mayor participación femenina son los sectores de educación y salud (63.6\%), turismo (56.3\%) y el de servicios personales (53.7\%). En los dos últimos hay una proporción menor a una décima parte de los contratados en contacto con ES y, con excepción del sector de educación, se caracterizan por ingresos inferiores (servicios personales es segundo nivel promedio de ingresos más bajo y el de turismo ocuparía el tercero). Lo que al menos, como hipótesis, sugiere desigualdad de género en las condiciones laborales.

No obstante, los datos sobre ocupación e ingreso que brinda el INEGI, aunque no dejan de ser un referente para contrastar los ingresos reportados por la población en estudio, no bastan para caracterizar el origen social de la población. Hay otras dimensiones, como el capital cultural o las expectativas, que están vinculadas con las oportunidades educativas y también con la ampliación de oportunidades de acceso a la información, que se ha incrementado aceleradamente con el desarrollo de las nuevas tecnologías de información y comunicación (Castells, 1999).

Aunque se profundizará posteriormente, paulatinamente se han ido equiparando las oportunidades educativas entre los hombres y las mujeres, pero todavía hay diferencias importantes en la participación femenina en el mercado ocupacional (figura 1). En el conjunto de la población, mientras que casi la totalidad (91.3\%) de los hombres declararon ser activos laboralmente, solo menos de tres quintas partes (58.6\%) de las mujeres estaban trabajando. Pero, observando el comportamiento laboral por género, según el nivel de educación alcanzado, adquiere relevancia la ampliación de oportunidades educativas para las mujeres. Sobre todo, las oportunidades

$2 \quad$ USD 139.00, precios del 5 de noviembre de 2017.

3 USD 495.00, precios del 5 de noviembre de 2017.

$4 \quad$ USD 718.21, precios del 5 de noviembre de 2017. 
educativas adquieren otro sentido si consideramos que la brecha entre géneros se acentúa en la medida en que es menor el nivel educativo alcanzado (89.1\% de los hombres y $49.1 \%$ de las mujeres con estudios incompletos de primaria formaban parte de la PEA en 2016). La distancia en la proporción de hombres y mujeres activos laboralmente es significativamente menor entre quienes tienen estudios de licenciatura o más (91.1\% de los hombres y $75.1 \%$ de las mujeres).

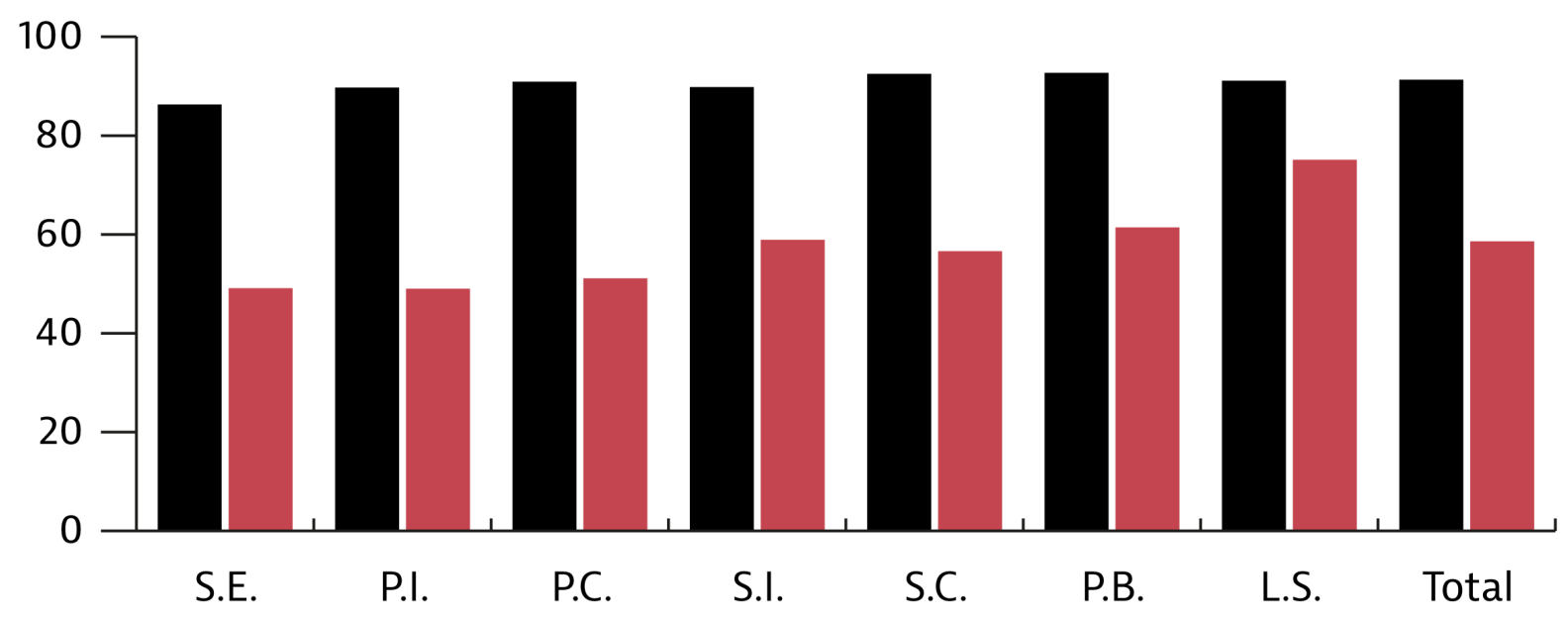

Figura 1. Diferencia en la proporción de activos laboralmente según género y nivel educativo de los encuestados MMSI-2016. Fuente: Elaboración propia con la información de INEGI (2016a). Nota: ROJO: Mujeres, NEGRO: Hombres. S.E. = Sin educación, P.I. = Primaria incompleta, P.C. = Primaria completa, S.I. = Secundaria Incompleta, S.C. = Secundaria completa, P.B. = Preparatoria o Bachillerato, L.S. $=$ Licencuatura o Superior.

\section{Evolución del Sistema Educativo Nacional (SEN)}

\section{y ampliación de las oportunidades educativas}

México es el tercer país más grande en la región latinoamericana, con más de 119 millones de habitantes en 2015, distribuidos en dos millones de kilómetros cuadrados de territorio. La ampliación de los ciclos incluidos en la educación obligatoria y la condición de rezago educativo en el país son elementos que se requieren para aquilatar la distancia entre la normatividad y los resultados efectivamente logrados:

- La educación primaria en México es laica, obligatoria y gratuita desde el 2 de diciembre de 1867, cuando Benito Juárez expidió la Ley Orgánica de la Instrucción Pública.

- José Vasconcelos, a partir de su gestión en la recién fundada Secretaría de Educación Pública (SEP) en 1921, emprendió un programa para abatir el analfabetismo. 
- En el sexenio de Adolfo López Mateos (1958-1964), con el plan de once años se establece como objetivo la universalización del nivel primaria y se inicia la producción de los libros gratuitos para los distintos cursos y niveles de este nivel.

- En 1993, se publica la Ley General de Educación, que establece que "Todo individuo tiene derecho a recibir educación de calidad en condiciones de equidad, por lo tanto, todos los habitantes del país tienen las mismas oportunidades de acceso, tránsito y permanencia en el sistema educativo nacional [...]" (art. $2^{\circ}$ ). Después del Tratado de Libre Comercio con América del Norte (1988) y poco antes del ingreso de México a la OECD (1994), la educación obligatoria en el país incluía educación prescolar y 9 años de educación básica (primaria y secundaria).

- En 2009, se inicia la reforma de la educación media superior (bachillerato o preparatoria) y en 2012, aparece en el Diario Oficial de la Federación el decreto que reforma el párrafo primero; el inciso c) de la fracción II y la fracción V del artículo 3o., y la fracción I del artículo 31 de la Constitución Política de los Estados Unidos Mexicanos, volviendo obligatoria la educación media superior. La intención es que de manera gradual se logre universalizar la cobertura de este nivel hacia el ciclo 2021-2022 (Secretaría de Gobernación, 2012).

Según datos del VI Informe de Gobierno del presidente Felipe Calderón, en el ciclo 2011-2012, el SEN contaba con 34.8 millones de estudiantes en modalidad escolarizada, distribuidos en los distintos tipos, niveles y servicios educativos. En educación básica, se atendió a 25.8 millones de alumnos, que corresponden a 74\% del SEN. En preescolar se atendió a 83\% de la población entre tres y cinco años. En primaria, la cobertura de niños entre seis y doce años se considera prácticamente universal, y el ingreso a secundaria casi había alcanzado 96.8\% del grupo de edad.

Se mantienen diferencias importantes en el logro educativo alcanzado en las distintas entidades federativas. El promedio de años de escolaridad es de 10.5 y 9.8 años de escolaridad en el Distrito Federal y Nuevo León, respectivamente, frente a 7.3, 6.9 y 6.7 en Guerrero, Oaxaca y Chiapas, respectivamente. La tasa de analfabetismo es de $2.1 \%$ y $2.2 \%$ en las primeras entidades, frente a 16.7\%, 16.3\% y 17.8\% en los estados con mayor grado de marginalidad (INEGI, 2010; Consejo Nacional de Población [CONAPO] 2009; 2015).

En México, casi una quinta parte (21.2\%) en el grupo de edad entre 60 y 74 años son analfabetos, pero esta proporción difiere entre los sexos, pues una de cada cuatro (25.1\%) mujeres de ese mismo grupo de edad comparten esa situación educativa. En cambio, solo se registra menos de una vigésima (4.2\%) parte de analfabetos entre quienes tienen entre 30 y 44 años, aunque 
nuevamente es ligeramente mayor (4.7\%) entre las mujeres, ha disminuido la brecha entre ambos géneros (INEGI, 2010). Otra dimensión de la desigualdad de oportunidades se presenta en función de las condiciones étnicas y lingüísticas de la población. Según la UNICEF (2010), 40\% de la población indígena de 15 años y más no ha terminado la escuela primaria, y menos de una décima parte de los hijos de jornaleros migrantes asiste regularmente a la escuela.

La atención en el nivel medio superior (ciclo escolar 2011-2012) ascendió a 4.3 millones de estudiantes en la modalidad escolarizada. El 60.4\% de esa matrícula cursó estudios de bachillerato general, 30.7\% el bachillerato tecnológico y $8.9 \%$ lo hizo en escuelas de profesionales técnicos. Los estudiantes de este nivel representaron 12.4\% del total de la matrícula del SEN (Calderón, 2012, p. 481). La conclusión del nivel medio superior es un requisito de ingreso a la (ES), por lo que no es trivial que menos de la mitad del grupo de edad correspondiente a este nivel concluya el bachillerato.

En 2012 apenas la mitad de la población de 20 a 24 años completó la educación media superior. Aunque se aprecia una ligera ventaja de las mujeres (51.7\%) sobre los varones (48\%) en alcanzar esta escolaridad, la desigualdad se amplía entre las distintas subpoblaciones de nuestros jóvenes de este grupo de edad. Por ejemplo, completan este nivel educativo apenas un tercio de los que residen en áreas rurales en contraste con $57 \%$ de los que residen en áreas urbanas, o la alcanzan sólo 23 de cada 100 de quienes se encuentran en condiciones de pobreza alimentaria a diferencia de $62 \%$ de quienes residen en hogares no pobres. (Blanco et al., 2014, p. 13)

A partir de la inclusión de la formación de profesores de educación básica como parte de la ES, el 2.6\% de la matrícula está inscrita en el subsistema de educación normal. Paralelamente, se inician un conjunto de programas orientados al mejoramiento de la formación de los profesores de educación básica, y se amplía la participación en la formación de maestros a través de campus y programas de la Universidad Pedagógica Nacional (UPN). También se impulsa la mejora de la formación del personal académico nacional, primero a través del Programa Nacional de Superación del Personal Académico (SUPERA), coordinado por la ANUIES con recursos proporcionados por la presidencia de la república, y luego con el Programa de Mejoramiento del Profesorado (PROMEP) en 1996, bajo la supervisión de la entonces Subsecretaría de Educación Superior e Investigación Científica de la Secretaría de Educación Pública (SEP). Hoy sigue operando, aunque cambió su denominación por Programa de Desarrollo del Profesorado (PRODEP). 
Tabla 3. Evolución del Sistema de Educación Superior (SES) 1960-2016

\begin{tabular}{lrrrrr} 
& 1960 & 1984 & 1990 & 2003 & 2016 \\
\hline Matrícula de licenciatura & 78753 & 939513 & 1078191 & 1865475 & 3655134 \\
\hline \% crecimiento matrícula de licenciatura & & $1092.99 \%$ & $14.76 \%$ & $73.05 \%$ & $95.99 \%$ \\
\hline $\begin{array}{l}\text { Promedio anual de crecimiento } \\
\text { por periodo }\end{array}$ & & $78.07 \%$ & $2.46 \%$ & $5.61 \%$ & $7.38 \%$ \\
\hline \% de feminización & $12 \%$ & $30 \%$ & $40 \%$ & $48.70 \%$ & $49.80 \%$ \\
\hline Matrícula de posgrado & & 32169 & 43965 & 139669 & 313997 \\
\hline Tasa de crecimiento en el periodo & $440.38 \%$ & $36.67 \%$ & $214.54 \%$ & $124.82 \%$ \\
\hline Crecimiento promedio anual & $1.00 \%$ & $5.30 \%$ & $8.40 \%$ & $10.00 \%$ & $12.00 \%$ \\
\hline Mayores de 15 años en contacto con ES & 10749 & 77209 & 104207 & 192593 & 363695 \\
\hline Plazas académicas en licenciatura & $2.70 \%$ & $13.60 \%$ & $15.00 \%$ & $20.00 \%$ & $29.30 \%$ \\
\hline Tasa bruta de cobertura (TBES) & 34.9 & 66.8 & 81.3 & 99.5 & 119.1 \\
\hline Total de población (censo más próximo) & & & $6.11 \%$ & $16.50 \%$ & $9.02 \%$ \\
\hline
\end{tabular}

Fuente: Elaboración propia con información de ANUIES (s.f.) y datos poblacionales (INEGI).

En términos de la movilidad absoluta o estructural, los esfuerzos del sector público por ampliar y descentralizar territorialmente la oferta de ES para incrementar la cobertura (hasta la crisis de los años 80), cuando los cambios en el modelo de desarrollo y la inclusión de México en los organismos internacionales, se acompaña de una modificación de la orientación de la política pública, cambios en la regulación del Sistema de Educación Superior (SES) e incremento de la participación del sector privado.

Si consideramos, como otro indicador, las oportunidades de acceso a la ES en los distintos momentos, habría que destacar que menos del 1\% de la población mayor de 15 años contaba con ES en el país en 1960. Resulta interesante que entre ese momento y el ciclo 2016-2017 (último ciclo con el que se cuenta con información en ANUIES) se multiplica por más de diez veces la presencia de mayores de 15 años con algún nivel de ES en el país. La tasa bruta de cobertura de la ES en el ciclo escolar 2016-2017 es poco menos de 30\% de jóvenes entre 20 y 24 años los que están matriculados en este nivel.

Aunque, como puede observarse en la tabla 3 sobre la evolución de los indicadores básicos del desarrollo del SES, son indudables los avances logrados a partir de la segunda mitad del siglo 
$\mathrm{XX}$, aunque no es menos cierto que se mantienen las desigualdades regionales y hay una gran heterogeneidad en la composición institucional y calidad de la oferta educativa.

\section{Algunos programas o políticas públicas para enfrentar la desigualdad de oportunidades}

México destina una proporción superior de recursos del PIB a la educación que otros países de la OECD. De acuerdo con el informe de gobierno 2012, el gasto en educación fue de 975,723.3 millones de pesos, 62.3\% de los cuales fueron aportados por la federación, 16\% por los gobiernos estatales y municipales y $21.7 \%$ por el sector privado, lo que todavía no representa el $8 \%$ del PIB señalado como objetivo en la Ley General de Educación (Mendoza, 2018). Sin embargo, no solo importa la cantidad de recursos públicos y/o privados destinados, sino que se requiere establecer políticas con poblaciones objetivo que pongan especial atención a la promoción de equidad y calidad (OECD, 2018b, p. 17).

La noción de derechos y obligaciones que corresponden al gobierno y la ciudadanía definen la medida en que las políticas educativas promueven la igualdad de oportunidades o al menos disminuyen las desventajas en el acceso a la educación que se desprenden de la desigualdad social. Si se privilegia la libertad individual por encima de la justicia o equidad, el mecanismo de acceso a la educación sería la libre competencia. En este supuesto, tanto la riqueza, como el talento son criterios de selección para el ingreso a la escuela, favoreciéndose la reproducción de los privilegios. Un sistema meritocrático supone que los procesos de selección deben valorar el esfuerzo, el talento y el desempeño. Es decir, cualidades innatas o desarrolladas por los individuos a lo largo de su trayectoria, con supuesta independencia de su cuna. En este segundo supuesto, el problema radica en que se obvia que la ubicación social o el capital cultural de la familia de origen representan puntos de partida distintos, por lo que la competencia dista de ser justa. Finalmente, la lógica compensatoria implica reconocer como punto de partida que la sociedad es desigual, por lo que, si los procesos de selección se basaran únicamente en el mérito, los puntos de partida diferenciales constituyen ventajas o desventajas que debieran considerarse. Para que la competencia fuera justa debe privilegiarse a quienes se encuentran en condiciones desfavorables, compensando desventajas y promoviendo un acceso justo a la educación.

Por tanto, en sociedades desiguales tienden a impulsarse programas compensatorios para generar igualdad de oportunidades para los grupos menos favorecidos o en riesgo. En este tipo de políticas pueden identificarse dos tipos: los destinados a mejorar las condiciones materiales de escuelas, sobre todo rurales e indígenas, y los que buscan incidir en la pobreza extrema considerando un componente educativo. Son ejemplos del primer tipo de programas el mejoramiento de la formación docente, la modificación del modelo educativo y el mejoramiento de infraestructura 
en las escuelas de las zonas más desfavorecidas. Desde 1988, en México, el Programa Nacional de Solidaridad (Pronasol) -convertido después en Progresa, luego en Oportunidades y más tarde en Prospera- ha sido un ejemplo de la política social compensatoria del segundo tipo. Uno de sus componentes centrales se refiere al factor educativo -los otros son salud y alimentación-. Las evaluaciones realizadas sobre su influencia no son concluyentes: las académicas lo definen como un programa de alivio a la pobreza, más que de lucha contra ella, de efectos más bien modestos. Las oficiales, en cambio, tienden a sobreestimar sus efectos positivos. La valoración del componente educativo tampoco es concluyente, ya que no contempla aspectos significativos para el rendimiento escolar, como las condiciones socioculturales o las expectativas de las familias y docentes hacia el logro de sus estudiantes (Cortés y Escobar, 2005).

La política educativa desde inicios del siglo XXI ha estado centrada en la evaluación como principal instrumento. Sin embargo, una evaluación acotada por los intereses gremiales y electorales en manos del Sindicato Nacional de Trabajadores de la Educación (SNTE). Al alinearse a estrategias y lineamientos de los organismos internacionales, desconocen la heterogeneidad del panorama nacional, soslayan el contexto local y no regulan adecuadamente el funcionamiento de las instituciones privadas o los proveedores extranjeros de servicios educativos.

\section{Rezago educativo en los distintos grupos de edad en México}

Como en muchos temas, una es la cuestión normativa y otra las condiciones de desarrollo efectivamente alcanzados. Entre 1993 y 2012, el Sistema de Educación Básica obligatoria implicaba 9 niveles, en que se atendía a 25 millones de estudiantes en 227,000 planteles escolares (Instituto Nacional para la Evaluación de la Educación [INEE], 2012).

Hace diez años, antes de la definición del bachillerato como nivel obligatorio en el país,1.8 millones de niños entre 3 y 5 años, 387 mil niños entre 6 y 11 años, 635 mil adolescentes entre 12 y 15 años, en total 2.8 niños y jóvenes no habían tenido la oportunidad de cumplir con el nivel de educación obligatorio.

En 2011, mientras que el 99\% de los niños entre 6 y 12 años asistían a la primaria, sólo el 69.7\% de los niños en edad de 4 a 6 años cursaban preescolar, el 78.8\% de los jóvenes de 12 a 15 años asistían a la secundaria y el 50.8\% de los jóvenes entre 15 y 18 cursaban media superior (INEE, 2018).

EI INEE (2018) indica que 31.3 millones de personas de 15 años y más (39.3\% de la población de ese grupo de edad) no ha concluido la educación básica.

La desigualdad social y educativa en los grupos indígenas es 11 veces más profunda que cualquier otro grupo social; tienen ingresos 17 veces menores al promedio de los capitalinos y casi 50\% de los niños indígenas padece desnutrición y no completa la primaria (PNUD, 2009). 


\section{Cobertura, calidad e infraestructura heterogéneas en la oferta educativa}

\section{de los distintos niveles del SEN}

A pesar de los esfuerzos de planeación, expansión y descentralización territorial de la oferta educativa, que sin duda han rendido frutos y cuyos avances se reflejan en la inversión de las proporciones de la matrícula que inicialmente se concentraba en la ciudad de México, Guadalajara y Nuevo León, y que hoy se distribuye mejor a lo largo del territorio nacional, no se ha superado la mirada centralista del Poder Ejecutivo Federal y de la SEP, que muestra poca sensibilidad con las circunstancias nacionales y los rasgos de diversidad geopolítica, socioeconómica, cultural e ideológica que caracterizan al país y al SEN.

Si tomamos en cuenta los trabajos que presentan evidencia del efecto que tienen en los logros educativos las condiciones formativas del profesorado, organizacionales de los planteles, la infraestructura educativa y el acceso a los servicios básicos (electricidad, agua, alcantarillado y teléfono) en las escuelas, es de suponer que la desigualdad de las condiciones de la oferta institucional tendrán consecuencias importantes en las posibilidades de permanencia y éxito escolar de los estudiantes (Blau, 1970; Tinto, 1989; Pascarella y Terenzini, 1991; Programa para la Evaluación Internacional de Alumnos [PISA], 2003). ${ }^{5}$

Otra dimensión del análisis de la movilidad de tipo estructural en el país es la heterogeneidad institucional de la evolución de la cobertura en las oportunidades educativas y laborales. Los datos del INEGI (2004) respecto a la distribución del rezago educativo en las distintas entidades federativas, antes de la reforma en 2012, son los siguientes:

En el año 2000 en Chiapas, Oaxaca, Zacatecas, Michoacán, Guanajuato, Guerrero, Veracruz y Puebla la población de 15 años y más que está en rezago educativo corresponde, en una clasificación de estratos a los mayores valores, al representar la población sin secundaria terminada entre $71.5 \%$ y $60.6 \%$ de dicho grupo de edad; por su parte en el Distrito Federal, Nuevo León y Baja California la población sin educación básica completa adquiere las menores proporciones, entre 33.7\% y 44.9\%. (INEGI, 2004, p. 8)

5 En 2007, la SEP identificó que más del 20\% de las escuelas se encontraba en malas, muy malas o pésimas condiciones físicas. 
Tabla 4. Tasa de cobertura de la ES según los niveles de marginalidad de las distintas entidades federativas del país

\begin{tabular}{|c|c|c|c|c|c|c|}
\hline & \multirow{2}{*}{$\begin{array}{l}\text { Entidades federativas } \\
\text { Índice de margnialidad } \\
2005\end{array}$} & \multicolumn{2}{|c|}{$\begin{array}{c}\text { Rango de } \\
\text { cobertura } 2010\end{array}$} & \multirow[t]{2}{*}{$\begin{array}{l}\text { Reacomodo cobertura } \\
\text { ES 2016-2017* }\end{array}$} & \multicolumn{2}{|c|}{$\begin{array}{l}\text { Rango de } \\
\text { cobertura } \\
2016-2017\end{array}$} \\
\hline & & Inicial & Final & & Inicial & Final \\
\hline \multirow{4}{*}{$\begin{array}{c}\text { Debajo } \\
\text { de la media }\end{array}$} & Chiapas, Guerrero, Oaxaca & \multirow{4}{*}{$14.5 \%$} & \multirow{4}{*}{$23.6 \%$} & $\begin{array}{l}\text { Oaxaca, Chiapas, } \\
\text { Guerrero }\end{array}$ & \multirow{4}{*}{$21.4 \%$} & \multirow{4}{*}{$32.28 \%$} \\
\hline & $\begin{array}{l}\text { Guanajuato, Michoacán, } \\
\text { Veracruz }\end{array}$ & & & Michoacán & & \\
\hline & México, Tlaxcala & & & $\begin{array}{l}\text { Quintana Roo, } \\
\text { Guanajuato, Tlaxcala, } \\
\text { Durango }\end{array}$ & & \\
\hline & Quintana Roo & & & México & & \\
\hline \multirow{4}{*}{$\begin{array}{l}\text { Alrededor } \\
\text { de la media }\end{array}$} & $\begin{array}{l}\text { SLP, Yucatán, Hidalgo, } \\
\text { Campeche, Puebla }\end{array}$ & \multirow{4}{*}{$24.6 \%$} & \multirow{4}{*}{$31.1 \%$} & $\begin{array}{l}\text { Veracruz, SLP, Yucatán, } \\
\text { Querétaro, Hidalgo }\end{array}$ & \multirow{4}{*}{$33.48 \%$} & \multirow{4}{*}{$39.53 \%$} \\
\hline & $\begin{array}{l}\text { Durango, Morelos, } \\
\text { Querétaro, Zacatecas }\end{array}$ & & & $\begin{array}{l}\text { Morelos, Zacatecas, } \\
\text { Tabasco }\end{array}$ & & \\
\hline & Jalisco, BCS, Chihuahua & & & $\begin{array}{l}\text { Campeche, Jalisco, BCS, } \\
\text { Tamaulipas }\end{array}$ & & \\
\hline & Baja California & & & Coahuila, Baja California & & \\
\hline \multirow{5}{*}{$\begin{array}{l}\text { Por encima } \\
\text { de la media }\end{array}$} & Tabasco, Nayarit & \multirow{4}{*}{$32 \%$} & \multirow{4}{*}{$44.8 \%$} & Puebla & \multirow{4}{*}{$41.01 \%$} & \multirow{4}{*}{$91.42 \%$ ** } \\
\hline & Sinaloa & & & Colima, Nayarit, Sinaloa & & \\
\hline & $\begin{array}{l}\text { Aguascalientes, } \\
\text { Tamaulipas, Colima, } \\
\text { Sonora }\end{array}$ & & & $\begin{array}{l}\text { Chihuaha, Aguascalien- } \\
\text { tes, Sonora }\end{array}$ & & \\
\hline & Coahuiila, Nuevo León, DF & & & Nuevo León, CDMX & & \\
\hline & Total nacional & & $27.8 \%$ & & & $38.4 \%$ \\
\hline
\end{tabular}

Nota : Rojo $=$ Muy alto. Amarillo $=$ Alto. Gris $=$ Medio. Azul $=$ Bajo. Verde $=$ Muy bajo. La tasa bruta de cobertura es la relación entre el grupo poblacional de 20 a 24 años y la matrícula correspondiente a este rango de edad. *Según índice de marginalidad CONAPO de las entidades federativas y estimación población 20-24 en 2015 por INEGI. ** Resulta tan alta porque incluye a las tres IES federales, que absorben jóvenes de la ZMVM y otras entidades del país. Elaboración propia con el Índice de Marginalidad CONAPO (2009; 2015). 
Pero estas desigualdades no solo se mantienen, sino incluso se vuelven más agudas conforme se avanza hacia los niveles más altos del SEN. Si se establece la relación entre la matrícula con la población entre 20 y 24 años (TBES), pueden observarse diferencias importantes entre las distintas regiones y entidades federativas. Al vincular la tasa bruta de cobertura con la clasificación de niveles de marginalidad de las entidades resultantes del análisis de CONAPO (2009 y 2015), no se encuentra una asociación perfecta, aunque sí cierto grado de relación (CONAPO, 2009).

Como se observa en la tabla 4, entre 2005 y 2015, algunos estados mejoraron su condición de marginalidad: Guanajuato, Nayarit y Tabasco cambiaron de Alto nivel de marginalidad a Medio. Pero, también, hubo retrocesos: Morelos y Quintana Roo pasaron de nivel Bajo a nivel Medio de marginalidad. Las tres entidades con mayores niveles de marginalidad, Oaxaca, Chiapas y Guerrero son las que presentan las TBES más bajas. Mientras que, en 2010, uno de cada diez jóvenes entre 20 y 24 años tenía la oportunidad de cursar una licenciatura universitaria o tecnológica en esas entidades, la oportunidad era entre 1 de cada 3 y de la mitad de los jóvenes de dicho grupo de edad en las entidades con menores índices de marginalidad (Baja California, Coahuila, Nuevo León o la $(D M X)$.

Con el surgimiento de nuevos tipos de IES y la ampliación de la oferta del sector privado, aunque se extiende en todas las entidades, subsisten las desigualdades entre los Estados del país.

\section{Las distintas dimensiones de la movilidad intergeneracional}

La movilidad social es multifactorial. Para articular las dimensiones: estructural, institucional y familiar, se reorganizó a la población en estudio en tres generaciones, recodificando en tres grupos de edad a los encuestados en MMSI 2016, según los cambios en las políticas y la evolución de los subsistemas mencionados. La influencia del origen social en la movilidad educativa, ocupacional y social de los encuestados requiere incluir en el análisis las condiciones del contexto en el que tanto los padres como los hijos realizaron sus estudios o iniciaron sus trayectorias laborales.

Ubicar a los actores en el cambio estructural de las oportunidades educativas, ocupacionales o de condiciones generales de acceso a infraestructura y servicios, permite explorar la relación entre dichas transformaciones generales y el peso específico del origen social en cada uno de estos aspectos. Considerando las políticas públicas, mecanismos de operación, cambios en la estructura económica y la evolución del SES se definieron tres periodos:

- Primer período (1960-1983). Durante el Estado de Bienestar, la economía y el SES tuvieron un moderado y después acelerado crecimiento en la formación de recursos humanos de alto nivel. 
- Segundo período (1984-2001). Evolución de los distintos mecanismos de evaluación periódica de la productividad, inicialmente para los investigadores y posteriormente su generalización. Así como, la institucionalización del financiamiento de la investigación e inicio de la expansión del posgrado.

- Tercer período (2002 a la fecha). Generalización de la evaluación hacia instituciones, programas e individuos y mayor articulación de los programas e instancias a cargo de regular este nivel educativo. Cambio en la Ley de Ciencia y Tecnología.

Quienes pertenecen a la primera generación (entre 50 y 64 años en 2016), nacieron entre 1953 y 1967, si estudiaron primaria en la edad típica, lo hicieron entre 1960 y 1973, cuando ya estaba en curso el plan de once años. Habrían estudiado secundaria entre 1966 y 1979; el bachillerato entre 1969 y 1982; y el nivel superior en plena expansión acelerada o al inicio de la crisis de los ochenta. Los padres de los integrantes de este grupo nacieron entre la década de 1930 y 1940, antes o en el arranque del modelo de industrialización a través de la sustitución de importaciones, pero antes de la expansión de la universalización de la educación primaria en el país.

El segundo grupo (entre 35 y 50 años en 2016) nacieron entre 1968 y 1983. Habrían estudiado primaria entre 1974 y 1989; secundaria entre 1980 y 1992; bachillerato entre 1983 y 1995; e ingresado a ES entre 1986 y 1998. Es decir, estudian la secundaria, el bachillerato y la ES durante el peor tiempo de crisis económica del país en los últimos años. Los padres de esta generación nacieron entre las décadas 1950 y 1960, por lo que el SEN ya buscaba generalizar este nivel como requisito obligatorio en el país (Plan de once años en operación). Los padres de esta segunda generación vivieron la expansión acelerada de la matrícula de ES, por lo que tuvieron mayor posibilidad de estudiar en la universidad que los padres de la generación previa.

La tercera generación (entre 24 y 34 años en 2016) nacieron en el período de 1980 a 1994. Realizaron sus estudios de primaria y secundaria en los años noventa y los principios del siglo XXI. Sus estudios universitarios se desarrollan en el marco de la expansión del posgrado y la ampliación de la oferta de nivel superior del sector privado. Los padres de esta generación realizaron sus estudios de nivel básico en los años setenta u ochenta, durante la crisis económica cuando cursan estudios de nivel superior y al inicio de la expansión y diversificación de la oferta institucional privada y de los tipos de instituciones públicas de nivel superior. ${ }^{6}$

6 La primera Universidad Intercultural surgió en 2004 en la zona mazahua, San Felipe del Progreso, Estado de México. Actualmente existen 11 de carácter público y dos privadas (gratuitas). 
Tabla 5. Evolución del Sistema de Educación Superior (SES) 1960-2016

\begin{tabular}{lcccc} 
& $\begin{array}{c}\text { Padres } \\
\text { analfabetos }\end{array}$ & $\begin{array}{c}\text { Madres } \\
\text { analfabetas }\end{array}$ & $\begin{array}{c}\text { Padres o proveedor } \\
\text { principal analfabetos, } \\
\text { más el grupo sin } \\
\text { escolaridad básica } \\
\text { completa }\end{array}$ & $\begin{array}{c}\text { Al menos uno } \\
\text { de los padres } \\
\text { o proveedor } \\
\text { principal con } \\
\text { contacto con ES }\end{array}$ \\
\hline Padres de los mayores de 55 años & $60.20 \%$ & $55.10 \%$ & $71.60 \%$ & $2.90 \%$ \\
\hline Padres de 35 a 55 años & $71.80 \%$ & $70.20 \%$ & $53.50 \%$ & $5.20 \%$ \\
\hline Padres de 24 a 34 años & $79.30 \%$ & $81.70 \%$ & $29.70 \%$ & $13.60 \%$ \\
\hline Total & $72.30 \%$ & $71.4 \%$ & $49.20 \%$ & $7.90 \%$ \\
\hline
\end{tabular}

Fuente: Elaboración propia con información del MMSI 2016 (INEGI, 2016a).

Más de tres quintas partes (60.2\%) de los padres y ligeramente más que la mitad de las madres (55.1\%) de los encuestados mayores de 50 años (primera generación) sabían leer y escribir (tabla 5). En concordancia con la evolución de la cobertura del SEN en los distintos momentos, esta proporción, aumenta a más de dos terceras parte de los padres de la segunda generación (71.8\% de los padres y $70.2 \%$ de las madres) y alrededor de cuatro quintas partes de los padres (79.3\%) y las madres (81.7\%) de los encuestados menores de 35 años. Como puede observarse en la figura 2, dicha tendencia se mantiene entre los encuestados de las distintas generaciones.

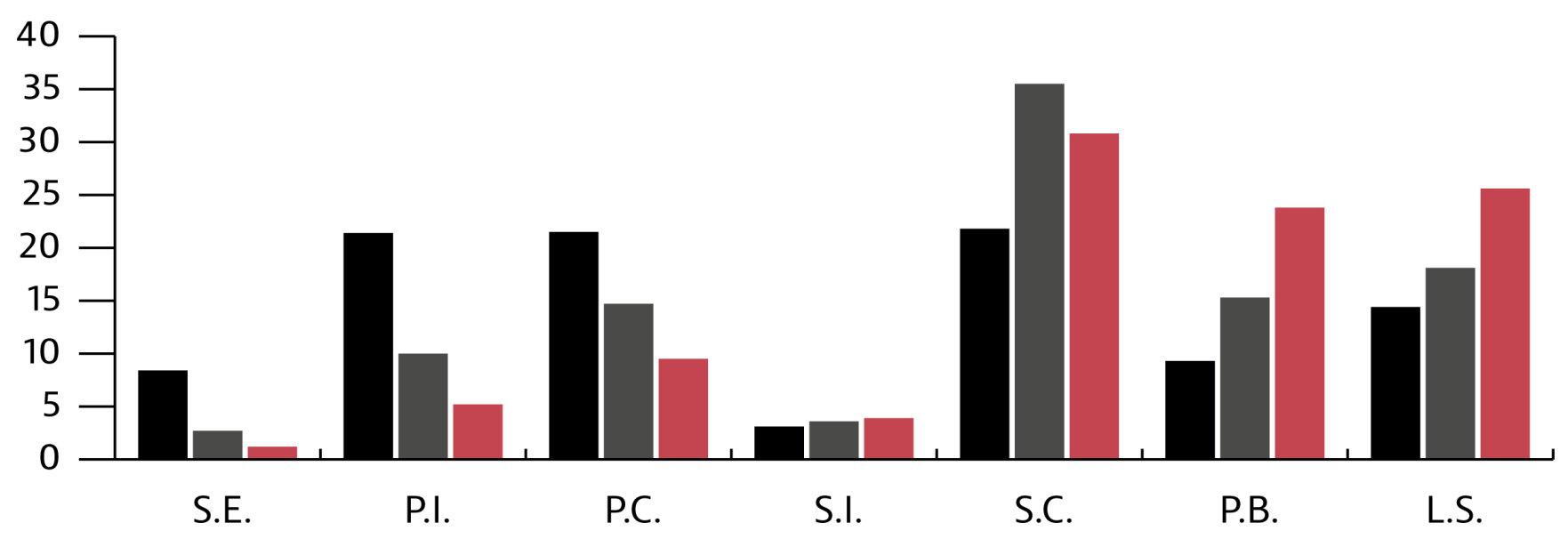

Figura 2. Niveles máximos de escolaridad de los encuestados según las generaciones definidas en función de los periodos de evolución del SEN. Fuente: Elaboración propia con la información deL MMSI (INEGI, 2016). Nota: NEGRO = Mayores de 50 años, GRIS = Entre 35 y 50 años, ROJO = Menores de 35 años. P.I. = Primaria incompleta, P.C. = Primaria completa, S.I. = Secundaria Incompleta, S.C. = Secundaria completa, P.B. = Preparatoria o Bachillerato, L.S. = Licenciatura o Superior. 
Si retomamos la escolaridad reportada por los informantes del MMSI 2016, puede observarse este avance en los niveles educativos de la población a través de las generaciones que corresponden a los periodos planteados. El valor modal entre los mayores de 50 años se distribuye entre secundaria completa (21.8\%), primaria completa (21.5\%) y primaria incompleta (21.4\%). Estos niveles pierden importancia en la segunda generación (el grupo de entre 35 y 50 años) donde más de la tercera parte (35.5\%) reportó estudios completos de nivel secundaria, una sexta parte (15.0\%) había culminado el bachillerato y casi una quinta parte más (18.1\%) contaba con ES. En la tercera generación, casi cuatro quintas partes tienen estudios de secundaria o más. Poco menos de un tercio solo culminó los estudios secundarios (30.0\%), una cuarta parte más había concluido sus estudios de bachillerato (23.8\%) y otra (25.6\%) contaba con ES.

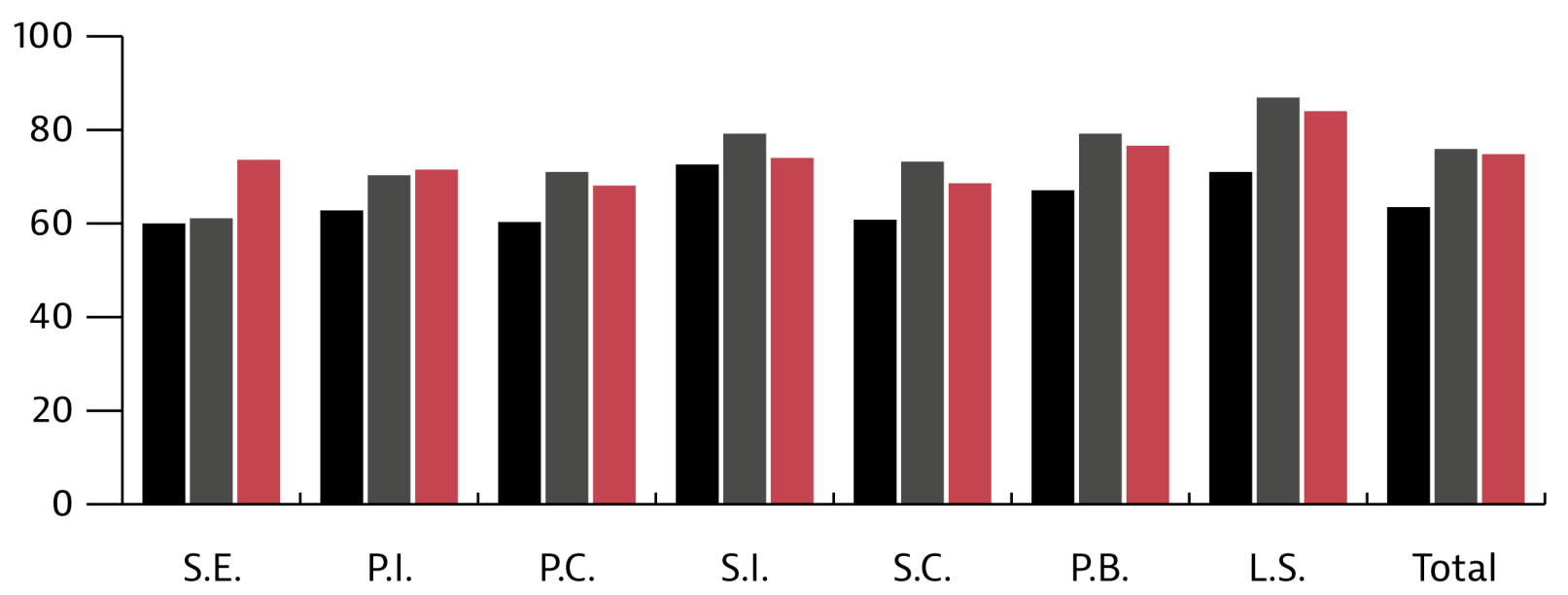

Figura 3. Informantes laboralmente activos por generación según grado máximo de estudios logrado. Fuente: Elaboración propia con la información deL MMSI (INEGI, 2016a). Nota: NEGRO = Mayores de 50 años, GRIS = Entre 35 y 50 años, ROJO = Menores de 35 años. P.I. = Primaria incompleta, P.C. = Primaria completa, S.I. = Secundaria Incompleta, S.C. = Secundaria completa, P.B. = Preparatoria o Bachillerato, L.S. = Licenciatura o Superior.

Tres cuartas partes de la segunda (75.9\%) y tercera generación (74.8\%) se encuentran activos laboralmente (figura 3), en cambio en la primera generación, probablemente porque una parte ya se ha retirado, la proporción disminuye a poco menos de dos tercios (63.5\%). Pero se presentan diferencias importantes entre generaciones y según el nivel máximo de escolaridad. Más de cuatro quintas partes entre quienes contaban con ES en la segunda (86.9\%) y tercera generación (84.0\%) y una proporción equivalente de los de la segunda (79.2\%) con bachillerato o estudios completos de secundaria reportaron estar activos laboralmente. La menor proporción de miembros activos, 
solo tres quintas partes (60\%) se presenta entre los integrantes de la primera y segunda generación pertenecientes al grupo de sin escolaridad o entre quienes en la primera generación cuentan únicamente con primaria o secundaria completa.

\section{Comparación intergeneracional de la movilidad educativa}

Para analizar la movilidad educativa u ocupacional intergeneracional, el primer paso fue construir índices que sintetizaran el nivel de escolaridad o el tipo de ocupación del núcleo familiar de cada informante. Dichos índices se cruzaron con el grado máximo de escolaridad alcanzado o el tipo de ocupación que realizaba el encuestado. Como puede verse en la figura 4, en correspondencia con lo señalado respecto a la evolución del SEN, se incrementan los niveles educativos tanto entre las distintas generaciones de encuestados, como entre ellos y sus padres.
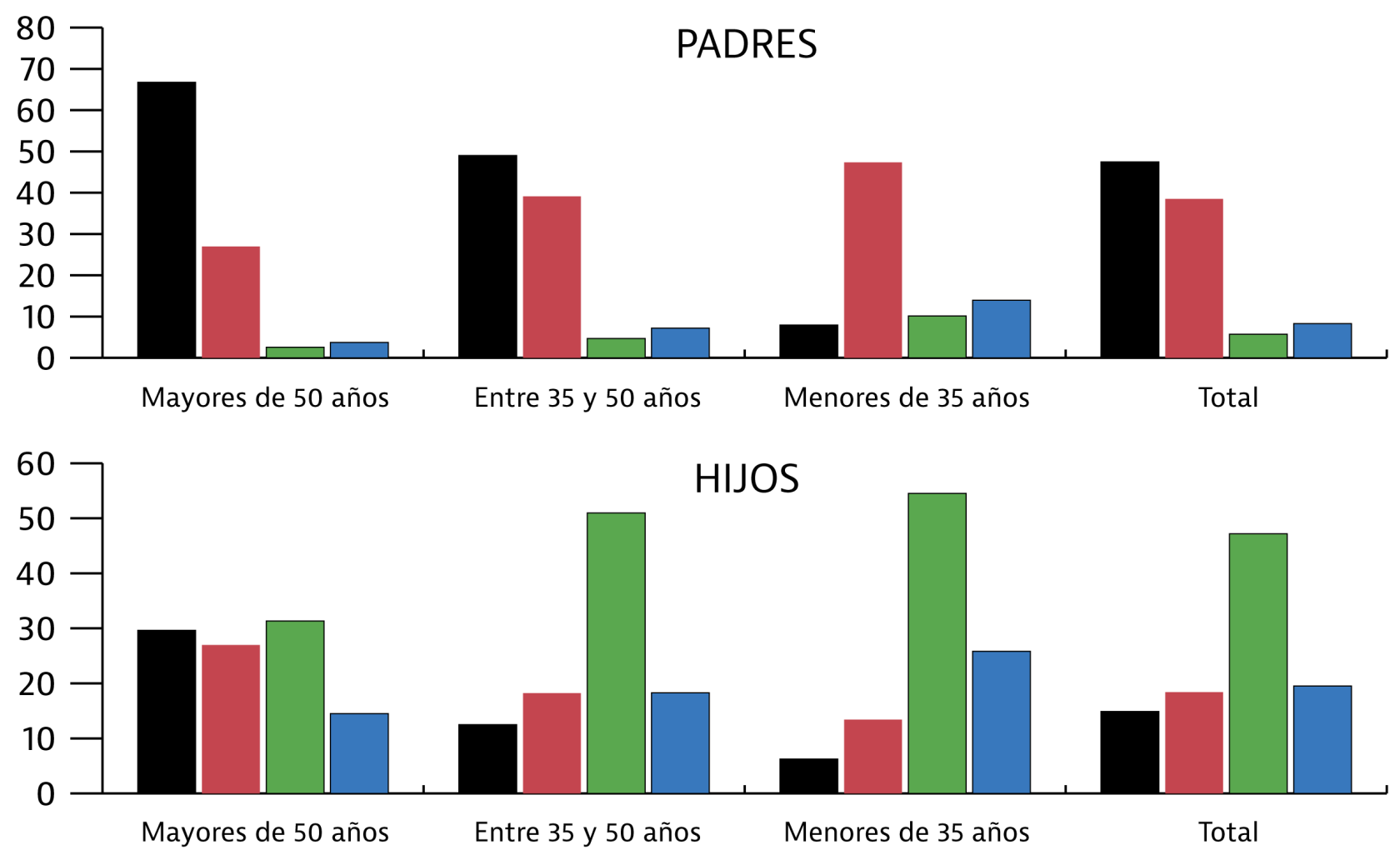

Figura 4. Distribución de nivel de escolaridad de padres e hijos según generación de los encuestados. Fuente: Elaboración propia con la información deL MMSI (INEGI, 2016). Nota: NEGRO = Analfabetos o sin escolaridad básica completa, ROJO = Uno o ambos con escolaridad básica completa, VERDE = Uno o ambos con escolaridad media, AZUL = Uno o ambas con escolaridad superior 
Para valorar el grado de movilidad educativa respecto a los progenitores, se toma el nivel más alto obtenido por los padres, o en su caso proveedor principal. La diagonal del cruce de ambas variables representa la tasa de reproducción del nivel educativo alcanzado, debajo de la misma se ubican las categorías correspondientes a la movilidad descendente y por arriba las que corresponden a una movilidad escolar ascendente. Los resultados del primer análisis, con independencia del nivel de escolaridad alcanzado en ambas generaciones, muestran el grado de reproducción y movilidad presente en las distintas generaciones. En una segunda etapa, se analiza más detalladamente, trabajando la tasa de reproducción según el máximo nivel de escolaridad del núcleo familiar.

Tabla 6. Situación del encuestado respecto a sus padres por generación

Mayores de 50 años Entre 35 y 50 años Menores de 35 años

\begin{tabular}{lrrr} 
Escolaridad superior a la de sus padres & $64.2 \%$ & $70.7 \%$ & $63.9 \%$ \\
\hline Escolaridad equivalente a sus padres & $29.1 \%$ & $24.0 \%$ & $29.9 \%$ \\
\hline Escolaridad inferior a la de sus padres & $6.7 \%$ & $5.3 \%$ & $6.3 \%$ \\
\hline Total & $100.0 \%$ & $100.0 \%$ & $100.0 \%$ \\
\hline
\end{tabular}

Fuente: Elaboración propia con los datos proporcionados por MMSI 2016 (INEGI, 2016a).

Si analizamos el nivel de escolaridad de los hijos respecto al que tenían sus padres (tabla 6), encontramos que la mayoría de los integrantes de todas las generaciones (alrededor de dos tercios en la primera y tercera generación y 70.7\% de los de la segunda generación) tienen una escolaridad superior a la que tenían sus progenitores. La mayor tasa de movilidad ascendente y menor de reproducción o movilidad descendente ocurre entre los integrantes de la segunda generación, que realizan sus estudios antes del cambio de modelo de desarrollo en México.

\section{Relación entre escolaridad y empleo en distintas generaciones}

En las sociedades contemporáneas, la educación es un mecanismo para distribuir a la población en la estructura ocupacional. Aunque no es el único criterio, pues en ningún sistema social el empleo y las recompensas obedecen únicamente al mérito, en principio una mayor educación permite el acceso a posiciones de mayor prestigio, poder o recompensas económicas.

Se consideró necesario realizar el análisis comparativo de las condiciones de origen social según el género del encuestado, pues entre las hipótesis explicativas sobre la expansión acelerada 
de la matrícula de ES señalan que no necesariamente representó una democratización del acceso, sino que en parte obedeció a la inclusión de las mujeres del grupo social que ya tenía acceso a este nivel de estudio. La figura 5 muestra la similitud de la composición por escolaridad y ocupación del núcleo familiar (incluido proveedor principal) entre los padres de hombres y mujeres encuestados.
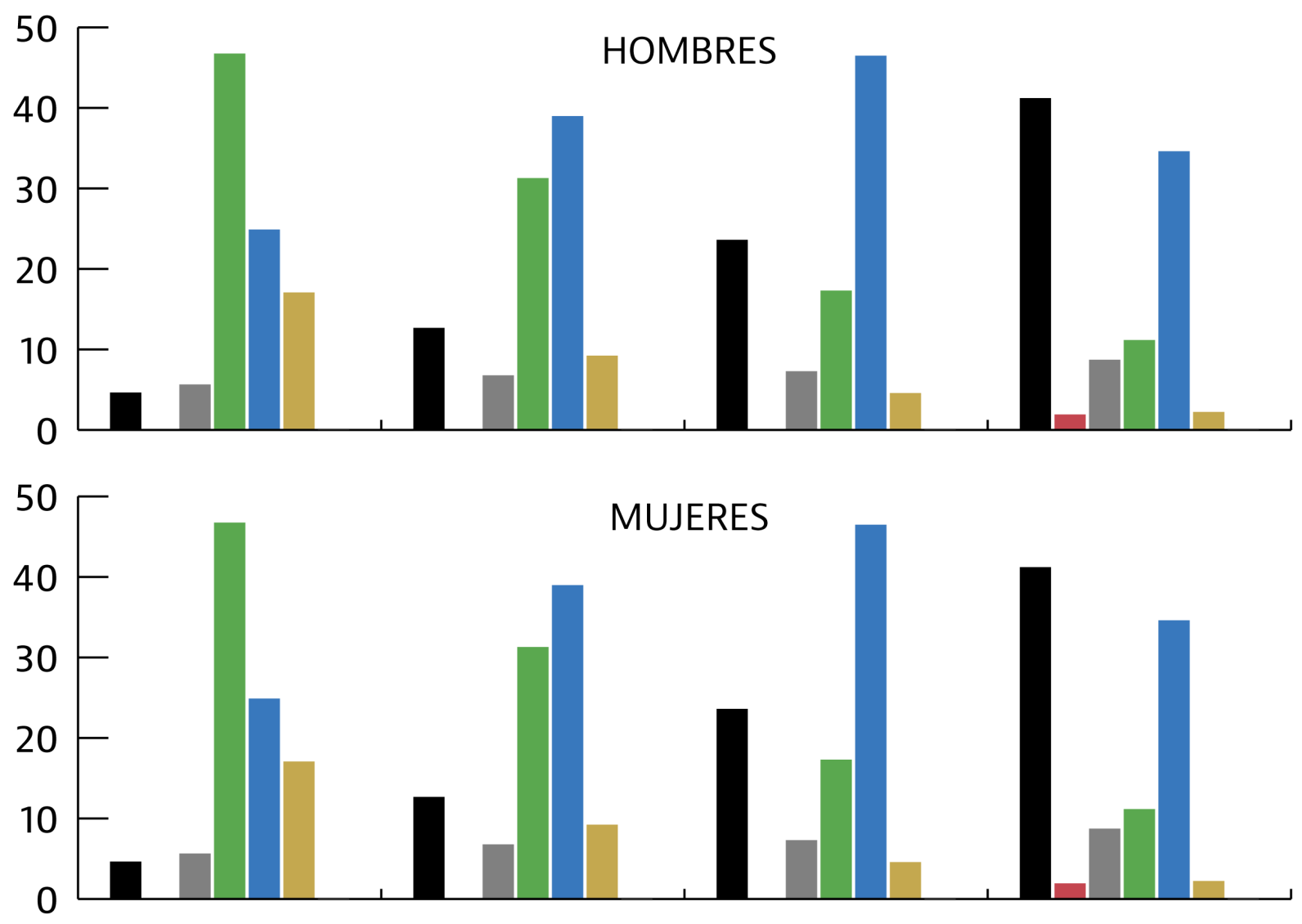

Figura 5. Relación entre escolaridad y ocupación del núcleo familiar de origen de los encuestados (cuando tenían 14 años). Fuente: Elaboración propia con la información deL MMSI 2016 (INEGI, 2016). Nota: NEGRO = Puestos directivos en el gobierno o el sector privado, ROJO = Propietarios empresas medianas o grandes, GRIS = Propietarios empresas pequeñas (menos de 14 empleados), VERDE = Propietarios de empresas sin empleados, AZUL = Empleados sin personal a su cargo, AMARILLO = Jornaleros, Morado = Dedicados al hogar

Menos de una vigésima parte de quienes no contaban con escolaridad básica completa ocupaban posiciones directivas o tenían puestos estables con responsabilidad sobre otros (figura 5), mientras que alrededor de dos quintas partes (41.1\% entre los padres de los hombres y $39.29 \%$ en las familias de origen de las mujeres encuestadas) con núcleos familiares en que uno o ambos padres contaban con ES tenían posiciones de este tipo. 
171 - Capítulo VIII

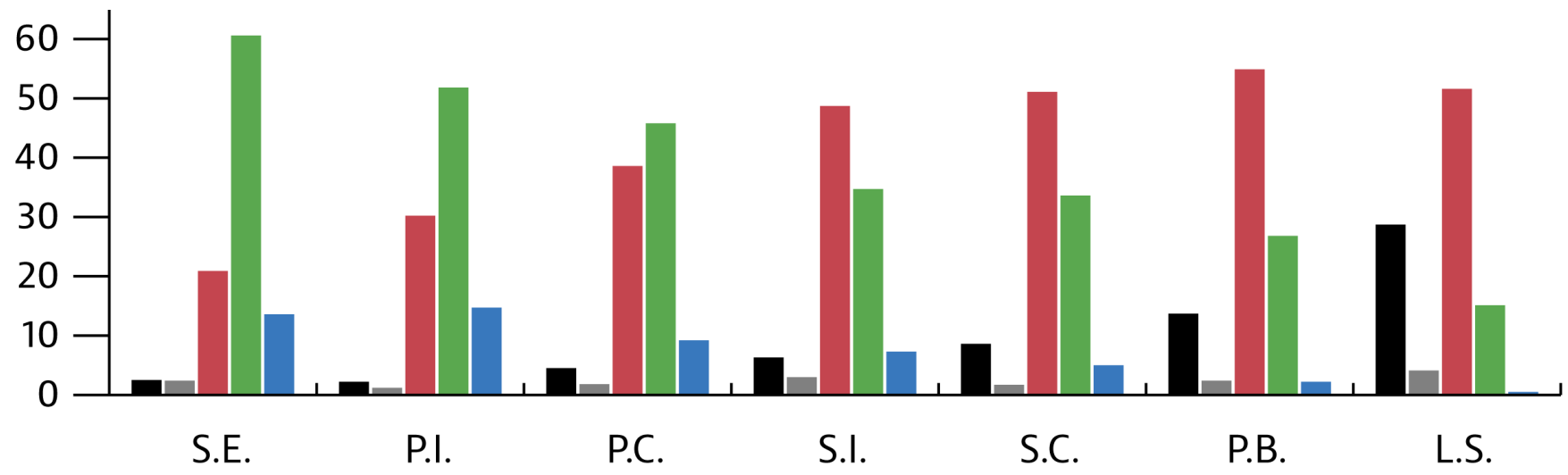

Figura 6. Relación entre escolaridad y ocupación de los encuestados al momento de aplicar la encuesta. Fuente: Elaboración propia con la información deL MMSI (INEGI, 2016a). Nota: NEGRO = Altos funcionarios o directivos en el sector público o privado, GRIS = Propietarios de empresas (con empleados), ROJO = Empleados sin personal a su cargo (sector público o privado), VERDE = Propietarios de negocios individuales o familiares sin empleados, AZUL = Jornaleros o peones (trabajo manual). S.E. Sin escolaridad, P.I. = Primaria incompleta, P.C. = Primaria completa, S.I. = Secundaria Incompleta, S.C. = Secundaria completa, P.B. = Preparatoria o Bachillerato, L.S. = Licenciatura o Superior.

No es muy distinta la asociación entre escolaridad y empleo entre los encuestados (figura 6) y la observada entre sus padres. Los propietarios de empresas individuales o familiares sin empleados decrecen en la medida que aumenta el nivel de escolaridad y la tendencia inversa se presente entre quienes ocupan posiciones directivas o tienen posiciones laborales como empleados (con mayor estabilidad y las prestaciones correspondientes).

\section{Movilidad ocupacional del encuestado según la ocupación del proveedor principal cuando tenían 14 años}

La tendencia general de reproducción intergeneracional de la condición ocupacional de la familia se matiza en parte por el aumento estructural en las oportunidades de escolarización entre las generaciones, pero sobre todo por el cambio en la composición del mercado ocupacional. La migración del campo a la ciudad, el avance en la industrialización y el desarrollo del sector servicios están detrás del grado de movilidad ocupacional entre padres e hijos y entre las distintas generaciones de encuestados. Sin embargo, la tasa de reproducción se presenta en alrededor de dos quintas partes de los casos en todas las generaciones (41.46\% en la primera, $40.02 \%$ en la segunda y $40.90 \%$ en la tercera). Sin embargo, contra lo que se supondría por los cambios estructurales reseñados en las secciones anteriores, la tendencia a la movilidad ascendente decrece y aumenta la de movilidad ocupacional descendente entre la primera y la tercera generación. 


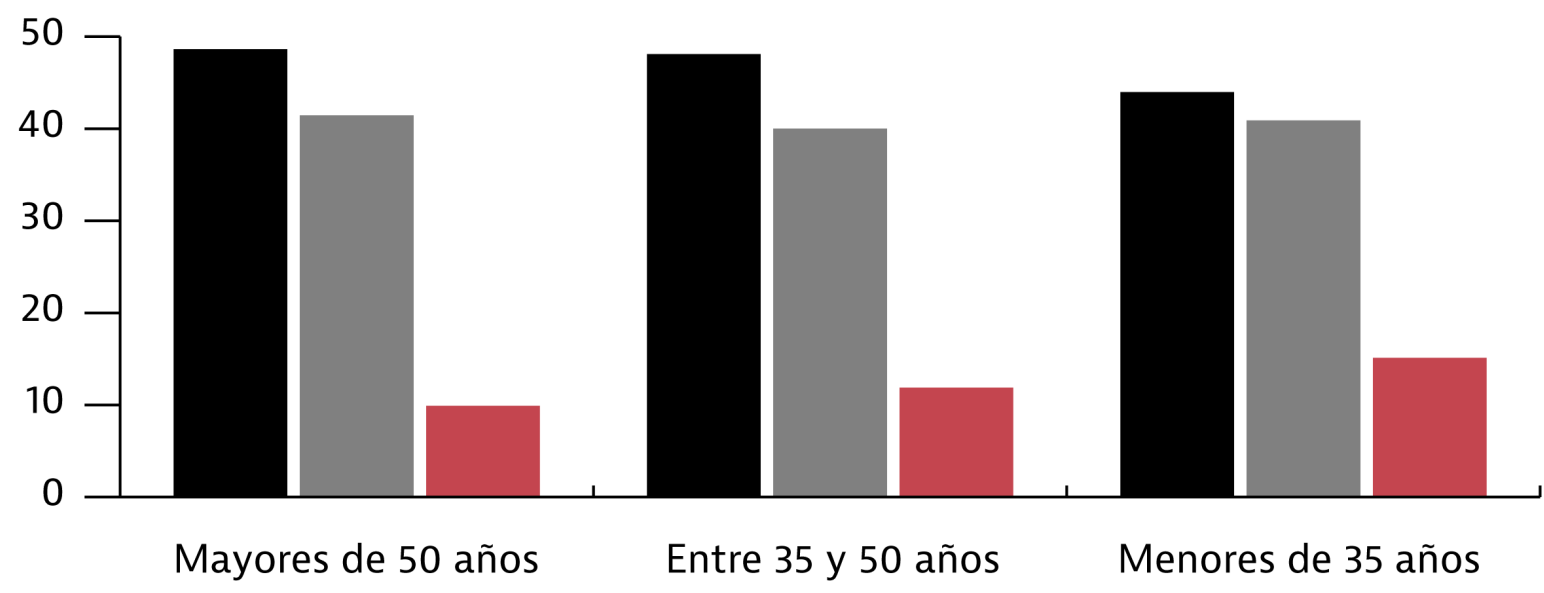

Figura 7. Grados de movilidad y reproducción tipo de ocupación por generación. Fuente: Elaboración propia con la información deL MMSI (INEGI, 2016). Nota: NEGRO = Movilidad ascendente, GRIS = Reproducción, ROJO = Movilidad descendente.

A pesar del cambio estructural del mercado laboral, el grado de reproducción de la ocupación de los hijos respecto a la de sus padres no ha variado significativamente entre las distintas generaciones (figura 7), presentándose sólo una ligera disminución de 0.028 del coeficiente de asociación direccional (ETA) entre la primera y la tercera generaciones de encuestados.

Tabla 7. Medidas direccionales: Asociación ocupación familiar y ocupación actual del encuestado (dependiente)

\begin{tabular}{ll} 
& ETA* $^{*}$ \\
Mayores de 50 años & 0.262 \\
\hline Entre 35 y 50 años & 0.247 \\
\hline Menores de 35 años & 0.234 \\
\hline Total & 0.251 \\
\hline
\end{tabular}

Nota: *Coeficiente de asociación direccional. Fuente: Elaboración propia con la información proporcionada en el MMSI 2016 (INEGI, 2016a).

Al analizar la posición laboral de los encuestados según el tipo de ocupación de sus padres (tabla 7) se observa un ligero incremento de la proporción de casos con movilidad descendente y una relativa estabilidad de la tasa de reproducción a través del tiempo. 
173 - Capítulo VIII

Tabla 8. Movilidad ocupacional según generación

\begin{tabular}{|c|c|c|c|c|c|}
\hline & $\begin{array}{c}\text { Altos } \\
\text { Funcionarios }\end{array}$ & Propietarios & Empleados & $\begin{array}{l}\text { Negocios } \\
\text { individuales }\end{array}$ & Jornaleros \\
\hline & \multicolumn{5}{|c|}{ Primera generación: mayores de 50 años } \\
\hline Altos Funcionarios & $21.50 \%$ & $5.40 \%$ & $43.90 \%$ & $27.80 \%$ & $1.40 \%$ \\
\hline Propietarios & $14.80 \%$ & $9.00 \%$ & $34.20 \%$ & $38.60 \%$ & $3.40 \%$ \\
\hline Empleados & $11.60 \%$ & $2.40 \%$ & $48.70 \%$ & $34.70 \%$ & $2.70 \%$ \\
\hline Negocios indivuduales & $6.60 \%$ & $2.60 \%$ & $32.30 \%$ & $53.40 \%$ & $5.20 \%$ \\
\hline \multirow[t]{2}{*}{ Jornaleros } & $2.90 \%$ & $1.50 \%$ & $31.80 \%$ & $46.60 \%$ & $17.20 \%$ \\
\hline & \multicolumn{5}{|c|}{ Segunda generación: entre 35 y 50 años } \\
\hline Altos Funcionarios & $24.20 \%$ & $2.90 \%$ & $50.50 \%$ & $21.10 \%$ & $1.30 \%$ \\
\hline Propietarios & $19.10 \%$ & $8.40 \%$ & $39.40 \%$ & $29.80 \%$ & $3.40 \%$ \\
\hline Empleados & $12.00 \%$ & $1.80 \%$ & $55.50 \%$ & $28.70 \%$ & $2.00 \%$ \\
\hline Negocios indivuduales & $9.10 \%$ & $2.00 \%$ & $39.80 \%$ & $43.90 \%$ & $5.20 \%$ \\
\hline \multirow[t]{2}{*}{ Jornaleros } & $6.10 \%$ & $1.40 \%$ & $39.60 \%$ & $34.20 \%$ & $18.70 \%$ \\
\hline & \multicolumn{5}{|c|}{ Tercera generación: menores de 35 años } \\
\hline Altos Funcionarios & $23.30 \%$ & $2.50 \%$ & $58.10 \%$ & $14.40 \%$ & $1.70 \%$ \\
\hline Propietarios & $17.60 \%$ & $7.40 \%$ & $49.40 \%$ & $22.60 \%$ & $3.10 \%$ \\
\hline Empleados & $13.60 \%$ & $1.10 \%$ & $63.10 \%$ & $18.80 \%$ & $3.50 \%$ \\
\hline Negocios indivuduales & $11.20 \%$ & $1.20 \%$ & $45.40 \%$ & $34.80 \%$ & $7.40 \%$ \\
\hline Jornaleros & $8.00 \%$ & $0.90 \%$ & $46.60 \%$ & $22.10 \%$ & $22.50 \%$ \\
\hline
\end{tabular}

Fuente: Elaboración propia con la información deL MMSI (INEGI, 2016a).

Si se desglosa dicha relación según el tipo de ocupación (tabla 8), es mayor la reproducción entre quienes ocupan altos cargos directivos (24.2\% en la segunda y $23.3 \%$ en la tercera generación) que entre quienes eran propietarios de empresas con trabajadores contratados. Alrededor de una quinta parte de los hijos de propietarios de empresas con personal contratado ocuparon posiciones como altos funcionarios en el sector público o privado (19.1\% en la segunda y 17.6\% en la tercera). Dicha proporción ligeramente menor (14.8\%) en la primera generación, donde una vigésima parte de los hijos de altos funcionarios reportan ser dueños de empresas con personal contratado (5.4\%). 
La actividad como propietario de negocios individuales o familiares, disminuye más de diez puntos porcentuales entre la primera (53.4\%) y segunda (43.9\%) y entre la segunda y la tercera generaciones (34.8\%), incrementándose el grupo de empleados sin personal a su cargo (asalariados y empleados en el sector servicios), lo que indicaría una mayor movilidad en los sectores medios o medio bajos entre ocupaciones formales (empleados) y propietarios de empresas individuales o familiares sin personal contratado, en que una parte de las mismas puede corresponder al sector informal. Una quinta parte de los que provenían de núcleos familiares cuya principal ocupación fuera jornaleros o peones continúan en este tipo de ocupación. Casi la mitad de ellos hijos de jornaleros (46.6\%) en la primera generación, poco más de una tercera parte de los de la segunda (34.2\%) y una quinta parte $(22.1 \%)$ de los de la tercera declararon ser propietarios de empresas pequeñas, sin empleados contratados.

Pero al igual que en las oportunidades educativas, también existe una desigualdad importante en la composición ocupacional entre las entidades federativas o según el tamaño de las localidades en el país. Es distinto el grado de movilidad ocupacional entre padres e hijos al comparar la influencia de la ocupación de los padres en el destino laboral de los hijos entre las zonas urbanas y los poblados de menos de 2,500 habitantes. Las posiciones directivas son más de 3 veces superiores en las zonas urbanas que en las poblaciones rurales (16.7\% vs. 4.5\%, respectivamente). Lo contrario ocurre con las ocupaciones manuales (jornaleros o peones) que representan una sexta parte de las ocupaciones en las localidades menores de 2,500 habitantes y menos de un puesto sobre cien en las zonas urbanas. Las posiciones como empleados sin subordinados son más frecuentes en las ciudades grandes (54.5\%), que en los poblados de menos de 2,500 habitantes (31.7\%). Los propietarios de pequeños negocios sin trabajadores contratados representan casi la mitad (47.0\%) de las posiciones de los que habitan en poblados de menos de 2,500 habitantes, pero solo una cuarta parte (25.2\%) de las posiciones en las zonas urbanas.

Si bien, el origen social no determina el destino educativo u ocupacional, parece tener influencia en tanto atraviesa las decisiones, experiencias, recursos y condiciones disponibles para estudiar; los contactos, relaciones e información de la familia parecerían constituir un recurso adicional al mérito y éxito escolar para ingresar al mercado ocupacional. Tienen mayor probabilidad de ubicarse en posiciones prestigiosas y bien remuneradas quienes provienen de familias propietarias de empresas o negocios con personal contratado u ocupan posiciones directivas en el sector público o privado, que aquellos cuyos padres eran jornaleros, peones, empleados sin personal a su cargo o propietarios de microempresas sin personal contratado. 
Relación entre condiciones de vida a los 14 años, estrato social de los encuestados y percepción de movilidad respecto a la familia de origen

En esta última sección, se busca profundizar en la relación entre las condiciones de la vivienda y acceso a los servicios básicos a los 14 años y la posición social de origen y actual de la población en estudio. Como punto de partida se supone que el cambio en los niveles de educación y la movilidad ocupacional se reflejarán en las condiciones de vida y posición social al momento de responder la encuesta.
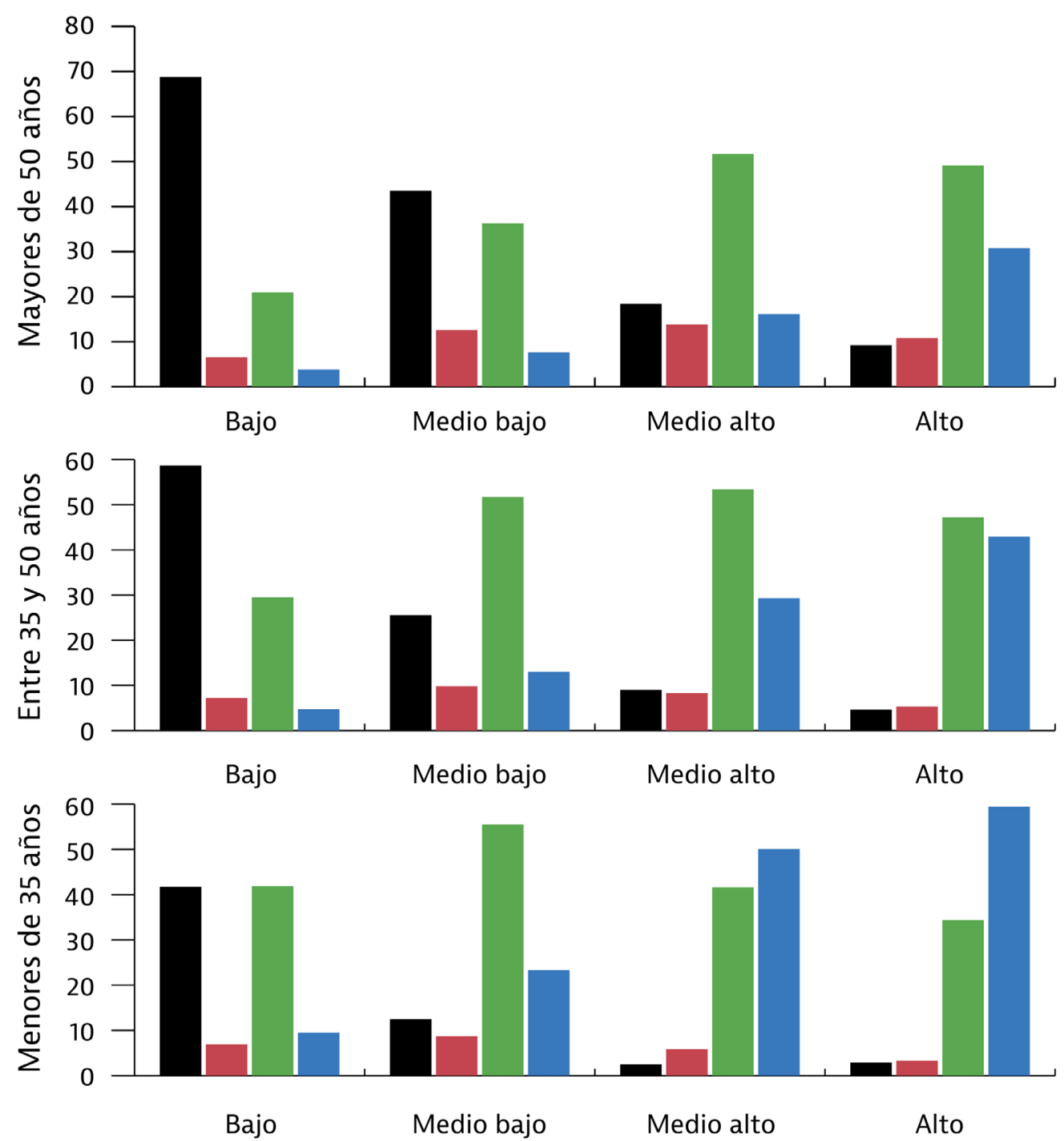

Figura 8. Índice de condiciones de la vivienda familiar (14 años) y la clasificación de estrato social en el MMSI 2016 por generación Fuente: Elaboración propia con la información deL MMSI 2016 (INEGI, 2016a). Nota: NEGRO = Alta densidad, carencia de infraestructura básica, ROJO = Media densidad, acceso heterogéneo a algunos servicios de infraestructura básica, $\mathrm{VERDE}$ = Baja densidad, acceso a los servicios de infraestructura básica, AZUL = Menos de una persona por cuarto y acceso general a los servicios, vivienda en propiedad, menos de un quinto rentada. 
EI MMSI 2016 proporciona información sobre condiciones de la vivienda cuando los encuestados tenían 14 años (es decir, con alta probabilidad de habitar con sus padres o proveedor principal durante sus estudios) y clasifica el estrato social de pertenencia del encuestado en 2016. Se propone, como aproximación al cambio en las condiciones de vida, comparar la clasificación de estratos social en 2016 propuesta en la base de datos del MMSI, el índice que se construyó sobre las condiciones de consumo y acceso a los servicios básicos en la vivienda cuando los encuestados tenían 14 años, que incluyó también una medida de la densidad de ocupación (número de habitantes entre número de cuartos en la vivienda) y el tipo de propiedad.

Mientras más de dos tercios de los encuestados mayores de 50 años (68.8\%) que están clasificados en el estrato social bajo y más de dos quintas partes (43.5\%) de los encuestados de esta generación clasificados como estrato medio bajo vivían en viviendas con alto grado de hacinamiento y carencia de servicios (figura 8), dicha proporción ha disminuido en ambos estratos entre los integrantes de la tercera generación (41.7\% de los clasificados como nivel bajo y solo 12.5\% de los que forman parte del estrato medio bajo en esta generación tenían dichas condiciones en la vivienda familiar cuando tenían 14 años).

El cambio también se observa entre quienes forman parte de los estratos medio alto y alto en todas las generaciones. Poco menos de un tercio (30.8\%) de los encuestados de la primera generación clasificados como estrato alto, habitaban en casas con menos de 1 habitante por cuarto y disponían de todos los servicios en la vivienda familiar, mientras que en la tercera se duplica la proporción de quienes contaban con dichas condiciones en la casa de sus padres.

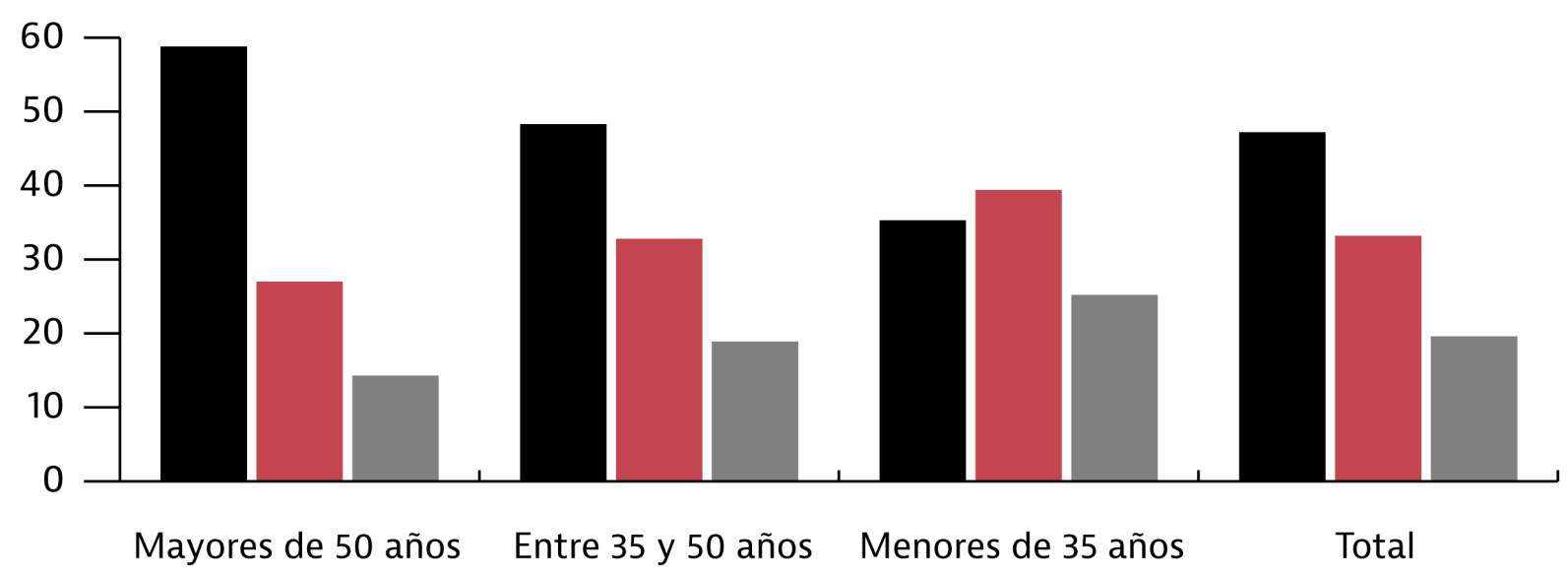

Figura 9. Percepción de los encuestados de su situación social frente a la de su familia de origen. Fuente: Elaboración propia con la información deL MMSI 2016 (INEGI, 2016a). Nota: NEGRO = Inferior a la de sus padres, ROJO = Equivalente a la de sus padres, GRIS = Superior a la de sus padres. 
Como en las otras dimensiones de cambio estructural mencionadas antes el acceso a infraestructura y las condiciones de vida de las distintas generaciones han mejorado, aunque todavía subsisten importantes diferencias según región, entidades o tamaño de las localidades de residencia de los encuestados. Se han ido generalizando el acceso a la electricidad, el servicio de agua potable y drenaje y ampliado las posibilidades de acceso a la telefonía celular y las nuevas tecnologías (OECD, 2017).

Sólo una quinta parte (19.6\%) del total de los encuestados reportaron una situación social superior a la de su núcleo familiar de origen (figura 9), aunque dicha apreciación de movilidad ascendente se incrementa ligeramente entre generaciones. Casi la mitad del total de encuestados (47.2\%) consideraron que tenían una situación social inferior y otra tercera parte (33.3\%) que su posición era equivalente a la de sus padres. Si lo analizamos según el estrato social en que INEGI clasificó a los encuestados, más de dos terceras partes (70.1\%) de quienes están clasificados en el estrato socioeconómico bajo y casi la mitad (49.0\%) del grupo ubicado en el medio bajo consideran que su situación social es inferior a la de sus padres. Mientras que sólo una vigésima parte (23.8\%) de quienes están clasificados en el estrato social alto y poco menos de un tercio (31.7\%) de los clasificados en el medio alto consideraron que tenían una situación inferior a sus progenitores. Lo que vuelve a poner sobre la mesa la influencia del punto de partida en las oportunidades y trayectorias de los encuestados.

\section{Reflexiones finales}

En todas las sociedades contemporáneas existen grados de diferenciación y desigualdad, pero el grado de estas varía de manera significativa entre los países. Por la desigualdad en las sociedades de clase, como señalaba Giddens (1995), de la ubicación de la familia en que se nace dependerán muchas de las oportunidades u obstáculos que se enfrentan en las trayectorias formativas y oportunidades laborales de sus integrantes. La propiedad, el poder y el prestigio asociados a las distintas ocupaciones de la familia son la base de la diferenciación y la desigualdad social y de oportunidades de los hijos. La movilidad absoluta en términos de escolaridad o la transformación de la estructura ocupacional no necesariamente se traducen en una disminución de las desigualdades, en la medida en que la pobreza es relativa.

Pero, aunque el incremento en la escolaridad no se traduzca necesariamente en disminución de las desigualdades sociales, otros aspectos de la vida social se afectan positivamente por el cambio en los niveles educativos. Mientras mayor es el nivel de escolaridad menor es la brecha de género entre informantes en cuanto a su participación laboral, lo que favorece la productividad y la riqueza producida. 
Las sociedades capitalistas no solo han encontrado límites en sus posibilidades de crecimiento y rentabilidad del capital, sino que parece haberse fracturado el elevador social, o por lo menos no funciona como se suponía la relación entre crecimiento económico-desarrollo y disminución de la pobreza. La persistencia de la ley de la herencia y reproducción de las desventajas asociadas a las condiciones de origen, parecen contravenir las expectativas de que el incremento en los niveles educativos de la población llevaría a una mejora de las condiciones de vida y desarrollo del país. Más bien, reparar el elevador social descompuesto para resolver la injusticia que implica la reproducción de la condición de origen, requeriría poner mayor atención a la igualdad de oportunidades de acceso a la educación y la salud, buscar que las políticas hacia la familia, los espacios rurales y urbanos, los impuestos y las transferencias contribuyan efectivamente a promover la igualdad de oportunidades para todos (OECD, 2018b).

Aunque se trata apenas de una primera exploración, es posible desprender algunas hipótesis y ratificar algunas reflexiones ya planteadas por Solís (2018) en el primer análisis de dicha información. Sin duda, en el país se han incrementado los niveles de cobertura y los promedios de educación de la población. También, aunque no con el mismo ritmo que el observado entre la primera y la segunda generaciones (ubicadas en el contexto del crecimiento económico), se ha modificado la estructura ocupacional, ampliando la demanda de un mayor nivel de instrucción de la población para capacitarla en el manejo de nuevas tecnologías del aparato productivo y los servicios.

A pesar del avance en el desarrollo, cobertura y descentralización del SEN, las transformaciones del aparato productivo y el mercado laboral y la ampliación de infraestructura y acceso a los servicios en el país, persisten desigualdades importantes entre entidades, localidades, grupos étnicos y lingüísticos en el acceso tanto a la educación y el empleo, como en el acceso a las condiciones de infraestructura y servicios. Por un lado, no parecen estar fuertemente asociados los distintos factores o dimensiones de la movilidad intergeneracional, por lo que requieren medidas que orienten los cambios estructurales no solo para crear, sino para redistribuir más equitativamente las oportunidades (Solís, 2018, pp. 27-29). 


\section{Referencias}

Asociación Nacional de Universidades e Instituciones de Educación Superior (ANUIES). (s.f.). Anuarios Estadísticos de Educación Superior. Recuperado de http://www.anuies.mx/informaciony-servicios/informacion-estadistica-de-educacion-superior/anuario-estadistico-deeducacion-superior

Banco Mundial (2016). Informe Anual 2016. Washington: Banco Internacional de Reconstrucción y Fomento/Banco Mundial. Recuperado de http://documentos.bancomundial.org/curated/ es/715721475494725180/pdf/108682-WBAR-v1-PUBLIC-SPANISH-PUBDATE-9-28-2016.pdf

Blanco, E., Solís, P., \& Robles, H. (Coords.). (2014). Caminos desiguales. Trayectorias educativas y laborales de los jóvenes en la Ciudad de México. México: COLMEX, INEE.

Blau, P.M. (1970). A Formal Theory of Differentiation in Organizations. American Sociological Review, 35(2).

Blau, P., \& Duncan, O.D. (1967). The American Occupational Structure. New York: Wiley.

Boudon, R. (1974). La desigualdad de oportunidades educativas. Barcelona: Laia.

Calderón, F. (2012). 3.3 Transformación educativa. VI Informe de Gobierno. Recuperado de http:// calderon.presidencia.gob.mx/informe/sexto/sexto_informe.html

Castells, M. (1999). La sociedad red. La era de la información. Economía Sociedad y Cultura. Madrid: Siglo XXI.

Consejo Nacional de Población (CONAPO). (2009). Índice de marginación por localidad 2005. México: CONAPO.

Consejo Nacional de Población (CONAPO). (2015). Índices absolutos de marginación 2000-2010. México: CONAPO.

Cortés, F., \& Escobar, A. (2005). Movilidad social intergeneracional en el México urbano. Revista de Ia CEPAL, (85), 149-167.

Coubès, M-L., Zavala, M.E., \& Zenteno, R. (Coords.). (2005). Cambio demográfico y social en el México del siglo XX. Una perspectiva de historias de vida. Tijuana: El Colegio de la Frontera Norte. Recuperado de http://biblioteca.diputados.gob.mx/janium/bv/ce/scpd/LIX/cam_dem_soc_ mex.pdf

Crozier, M., \& Friedberg, E. (1990). El Actor y el sistema. México: Fondo de Cultura Económica.

Encuesta Movilidad Social (EMOVI). (2017). Levantamiento de la Encuesta ESRU de movilidad social en México 2017. México: Centro de Estudios Espinosa Yglesias.

Fondo de las Naciones Unidas para la Infancia (UNICEF). (2010). Informe Anual 2010. Recuperado de https://www.unicef.org/spanish/publications/ 
Giddens, A. (1995). Sociología. Madrid: Alianza.

Instituto Nacional de Estadística y Geografía (INEGI). (2004). El rezago educativo en la población mexicana. México: INEGI.

Instituto Nacional de Estadística y Geografía (INEGI). (2010). Censo de Población y Vivienda 2010. México: INEGI. Recuperado de https://www.inegi.org.mx/programas/ccpv/2010/

Instituto Nacional de Estadística y Geografía (INEGI). (2016a). Módulo de Movilidad Social Intergeneracional 2016. México: INEGI.

Instituto Nacional de Estadística y Geografía (INEGI). (2016b). Encuesta Nacional de Ingresos y Gastos de los Hogares 2016 (ENIGH Nueva serie). México: INEGI.

Instituto Nacional de Estadística y Geografía (INEGI). (2017). Encuesta Nacional de Empleo Urbano y Encuesta Nacional de Ocupación y Empleo, primer trimestre 2017. México: INEGI.

Instituto Nacional para la Evaluación de la Educación (INEE). (2012). Panorama educativo de México. Educación básica y media superior. México: INEE.

Instituto Nacional para la Evaluación de la Educación (INEE). (2018). La educación obligatoria en México. Informe 2018. México: INEE.

Jencks, C. (1980). La escuela no es responsable de las desigualdades sociales y no las cambia. En A. Gras (Comp.), Sociología de la Educación (pp. 278-288). Madrid: Narcea.

Ley General de Educación (1993). Nueva Ley Publicada. Diario Oficial de la Federación, DOF 19-012018. Recuperado de http://www.diputados.gob.mx/LeyesBiblio/pdf/137190118.pdf

Mare, R. (1980). Social Background and School Continuation Decisions. Journal of the American Statistical Association, 75(370), 295-305.

Mendoza, J. (2018). Conferencia. Seminario ES, IISUE-UNAM.

Observatorio Laboral (OLA). (2017). Ocupación por sectores económicos. Recuperado de https:// www.observatoriolaboral.gob.mx/static/estudios-publicaciones/Ocupacion_sectores.html

Organisation for Economic Co-operation and Development (OECD). (2017). Education at glance. Paris: OECD.

Organisation for Economic Co-operation and Development (OECD). (2018a). A broken social elevator. How to promote social mobility? Paris: OECD. http://dx.doi.org/10.1787/9789264301085-en

Organisation for Economic Co-operation and Development (OECD). (2018b). Panorama de la educación. Indicadores de la OCDE 2018. Ministerio de Educación y Formación Profesional. Informe Español. Recuperado de http://www.educacionyfp.gob.es/inee/dam/jcr:2cba4aaa4892-40d7-ac8b-00efbc95b8a2/Panorama\%20de\%20la\%20Educacion\%202018_final.pdf 
Pascarella, E.T., \& Terenzini, P. (1991). How College Affects Students: Findings and Insights from Twenty Years of Research, Volume I. USA: Jossey-Bass

Programa de Naciones Unidas para el Desarrollo (PNUD). (2007). Informe sobre Desarrollo Humano 2007-2008. La lucha contra el cambio climático: Solidaridad frente a un mundo dividido. México: PNUD. Recuperado de http://www.economia.unam.mx/cegademex/DOCS/ HDR_20072008_SP_Complete.pdf

Programa de las Naciones Unidas para el Desarrollo (PNUD). (2009). Informe sobre Desarrollo Humano 2009. Superando barreras: Movilidad y desarrollo humanos. New York: PNUD. http://hdr.undp.org/sites/default/files/hdr_2009_es_complete.pdf

Programa para la Evaluación Internacional de Alumnos (PISA). (2003). Informe PISA 2003. Aprender para el mundo del mañana. España: OECD. Recuperado de https://www.oecd.org/ pisa/39732493.pdf

Roemer, J.E., \& Trannoy, A. (2013). Equality of opportunity. Cowles Foundation Discussion Paper, (1921).

Secretaría de Gobernación (2012). DECRETO por el que se declara reformado el párrafo primero; el inciso c) de la fracción II y la fracción $\mathrm{V}$ del artículo 30., y la fracción I del artículo 31 de la Constitución Política de los Estados Unidos Mexicanos. Diario Oficial de la Federación, DOF 11-01-2012. Recuperado de http://www.dof.gob.mx/avisos/2126/SG_090212/SG_090212.htm

Shavit, Y., Yaish, M., \& Bar-Heim, E. (2007). The persistence of persistent inequality. En S. Scherer, R. Pollak, G. Otte \& M. Gangl (eds.), From Origin to Destination. Trends and Mechanisms in Social Stratification Research. Chicago: The University of Chicago Press.

Statista. (2017). Dossier México. Recuperado de https://www.statista.com/study/10703/mexicostatista-dossier/

Solís, P. (2018). Barreras estructurales a la movilidad social intergeneracional en México. En CEPAL - Serie Estudios y Perspectivas - México - N 176. México: Naciones Unidas.

Tinto, V. (1989). Definir la deserción: una cuestión de perspectiva. Revista de la Educación Superior, 18(71). Recuperado de http://publicaciones.anuies.mx/revista/71

Zenteno, R., \& Solís, P. (2006). Continuidades y discontinuidades en la movilidad ocupacional en México. Estudios Demográficos y Urbanos, 21-3(63), 515-546. 


\section{Capítulo IX}

La investigación científica

en el desarrollo humano y social.

A propósito de la visión

de Óscar Varsavsky

Hebe Vessuri *

* Investigadora independiente. Profesora visitante del Centro de Investigaciones en Geografía Ambiental, Universidad Nacional Autónoma de México (CIGA-UNAM). Investigadora emérita del Instituto Venezolano de Investigaciones Cientificas. Contacto: hvessuri@gmail.com 


\section{Introducción}

Aprovecho la gentil invitación que me hicieron los colegas de la Universidad de Sonora a publicar un trabajo en este libro, para retomar una reflexión que se me quedó a medio camino hace diez años. En aquella ocasión, se trataba de un foro en Caracas que llevó a una publicación. Sin embargo, por alguna razón que desconozco, mi presentación quedó totalmente desconfigurada, al punto de no entenderse si estaba en español, en esperanto o alguna lengua extraterrestre.' En ese tiempo yo me sentía muy mal, mi hija estaba con un cáncer muy grave en México, mi esposo había fallecido unos meses atrás y yo misma había sido sometida a una cirugía muy exigente. Así que decidí olvidarme del disgusto que me provocó aquella publicación de mi trabajo y todo lo que tuviera que ver con el asunto y lo borré de mi memoria.

Hace unas semanas, sin embargo, un colega tucumano me preguntó si sabía de una publicación en Caracas de homenaje a Oscar Varsavsky hace unos años. Amablemente esta persona omitía mencionar mi incomprensible trabajo que, seguramente, había intentado leer en la publicación que acabo de mencionar. Esa misma semana, por una de esas casualidades que ocurren, mientras buscaba otras cosas, encontré la carpeta de archivo del Foro Varsavsky del 2007 en la computadora, y allí estaba mi vieja presentación. Se la mandé al colega curioso junto con unos pocos comentarios sobre aspectos que recordaba del evento. Como este intercambio coincidió con la invitación a participar en este volumen, se me ocurrió releer la presentación para ver si tenía aún alguna relevancia volver sobre ella. Me dieron ganas de revisar el pensamiento de Varsavsky y pensé que tal vez algunos lectores pudieran compartir conmigo el interés en el ejercicio.

1 Insisto, nunca entendí por qué lo publicaron pues seguramente era una transcripción desgrabada verdaderamente incomprensible. Creo recordar que yo había avisado a los organizadores que no disponía de tiempo para transformar mis láminas de power point en un paper. 
En particular me intrigaban las coincidencias entre el redescubrimiento azaroso de mi trabajito, cuando me lo recordaron desde la Universidad Nacional de Tucumán en Argentina, el posible interés de resituarlo en el momento en que lo escribí en Venezuela en 2007 haciendo referencia a un autor que había fallecido 30 años antes, y su eventual resignificación en la circunstancia política que se vive en México en el 2018. La triangulación de momentos de cambio en la región, vinculados por la lectura de uno de los autores más destacados del siglo XX en el ámbito de la política científica y cultural, resultaba tentadora. La relectura de Oscar Varsavsky, un polifacético y polémico químico y matemático argentino, que murió prematuramente en 1976, más allá de los argumentos que han quedado superados por el tiempo, los cambios en el escenario político y las transformaciones en los estilos expositivos, resulta una experiencia poderosa y desafiante sobre la ciencia y la sociedad en nuestra región, que nos invita una y otra vez a preguntarnos qué se hizo, qué no, y qué se puede hacer en los tiempos que corren.

Sus análisis sobre ciencia, política, estilos de desarrollo y proyectos nacionales están escritos en un lenguaje político que suena en buena medida anacrónico, no obstante, sus planteamientos a menudo conservan una frescura especial, producidos en un "estilo epistemológico"2 que pone el acento en un ejercicio directo -alejado de los cánones tecnocráticos- lo que acerca y facilita la comprensión del argumento. Muy significativa de su forma de aproximarse a los lectores, es su insistencia en señalar que se trata de obtener descripciones y propuestas abiertas, provisorias, sujetas a modificaciones y enriquecimiento permanente, como resultado de la activa participación democrática y consensuada de expertos y otros actores. El saber experto ya no debía entenderse, según Varsavsky, como un saber jerárquico ni una expresión de poder, sino como un componente esencial de la experiencia compartida y del crecimiento de todos los actores del sistema que analizaba.

Su planteamiento acerca de los efectos perversos del uso del conocimiento, aún en formas no deliberadas, como instrumento de poder y desigualdad, desperdiciando la posibilidad de transformarlo en una herramienta para el desarrollo colectivo y el mejoramiento de la condición humana, retoma relevancia en el México actual, donde comienzan a vivirse momentos de cambio que se relacionan con ideas y proyectos que tienen más de un punto de contacto con las pro-

2 Este fue el término con el que el grupo de autores de un seminario sobre Varsavsky realizado en Buenos Aires en 1996, a veinte años de la muerte de éste, y publicado en Caracas en 2007, se refirieron a su forma de trabajo, como "el manejo deliberado e 'inteligente' de elementos aparentemente sencillos, transparentes, que van construyendo un marco metodológico incisivo: propósito cuidadosamente explicitado haciendo uso de un lenguaje claro, directo, en el que se revaloriza la descripción cualitativa, sin dejar de ser exhaustivo, del campo de análisis". 
puestas de Varsavsky, al mismo tiempo que sirve de advertencia sobre los cambios profundos ocurridos en el orden internacional, y lo fútil y negativo que puede ser embarcarse en aventuras ciegamente encerradas en clichés del pasado.

Dado lo anterior, me parece que el ejemplo de Venezuela resulta instructivo. En el año 2007, cuando se celebró el Foro "Ciencia y Universidad" con la participación del ministro de Ciencia y Tecnología, Ing. Héctor Navarro, hombre de universidad que había acompañado al presidente Chávez desde antes de que éste asumiera el gobierno en 1999, Venezuela vivía un tiempo de extensa movilización política y de profundas controversias incluso en el ámbito del conocimiento. En aquella ocasión, como parte de mi participación en dicho Foro, para mi presentación tomé como incitación inicial las ideas de Varsavsky, en referencia a que en una región como la nuestra, la ciencia debe ser ciencia politizada, lo que para él significaba buscar un objetivo social en la actividad científica; valorar la autonomía científica; valorar la autonomía científica, independencia de criterio y actitud crítica, pero de ninguna manera rechazo indiscriminado a lo que provenga del extranjero (Varsavsky, 1981), algo que en Venezuela a menudo se perdió de vista cayéndose en algunos de los errores más lamentables de la ignorancia, que es el de no reconocer el valor del conocimiento útil cuando más se lo necesita; y promover el estudio interdisciplinario para fortalecer y enriquecer los estudios y los modos de pensar.

En particular, me propuse comentar dos de sus ideas fuertes, la primera era: "en [nuestra región] $]^{3}$ es tanto o más importante formar las nuevas generaciones de científicos que hacer investigación ya, y que la investigación que se haga debe servir al país a corto o mediano plazo" (Varsavsky, 1968, s.p.).

La segunda sostenía que: "Si un país [latinoamericano] quiere ser realmente libre, y no un estado libre asociado, tiene que tener su propia política educativa, dirigida mal o bien por sus ciudadanos" (Varsavsky, 1968, s.p.).

Ambas ideas han sido fuertemente inspiradoras y a la vez criticadas. Varsavsky observa con agudeza que nuestra dependencia cultural frente al Norte es mayor en el terreno científico y a la vez es menos percibida (Varsavsky, 1969). En varios trabajos (Vessuri, 1997; 2008; 2009; 2015; Vessuri y Teichler; 2008) he coincidido con la intuición de Varsavsky en referencia a que el peligro para la ciencia no está tanto en la supervivencia de lo que él solía adjetivar como los científicos

3 En esta y en la cita siguiente, Varsavsky se refiere a Sudamérica, pero entiendo que su argumento es válido para Latinoamérica en su conjunto. 
"fósiles", 4 sino en la formación acrítica de los científicos "modernizadores". No cualquier modernización ni modernidad vale la pena y hay que saber qué se busca obtener.

\section{La necesidad de formar científicos de nuevo cuño}

Los años en que Varsavsky estuvo más activo en su escritura y en su hacer como científico e intelectual, fueron las décadas de 1960 y 1970, período de modernización de las sociedades latinoamericanas, en particular, modernización de la investigación científica. Se adoptaron nuevos patrones de actividad, se instaló una nueva institucionalidad, surgieron fuentes de financiamiento desde el ámbito internacional para la ciencia en nuestros países, mientras crecía y se radicalizaba un movimiento estudiantil a medida que empezaban a percibirse los límites de la modernización buscada. En ese período efervescente, donde había surgido una nueva intelectualidad sintonizada con distintas fuentes del ámbito internacional que a su vez se habían renovado profundamente desde el final de la Guerra, Varsavsky publica en 1969 su primer y más reconocido libro, el breve opúsculo Ciencia, política y cientificismo, del cual se hicieron siete ediciones en los primeros cinco años, con enorme impacto relativo en el medio universitario, enfrentando polémicas y sumando seguidores.

Para la formación del nuevo investigador, Varsavsky no niega el conocimiento existente ni todo lo que venga del exterior, de hecho, sostiene que el entrenamiento "se hace un poco en el trabajo y otro poco también en el extranjero" (Varsavsky, 1968, s.p.). Sin embargo, está convencido de la necesidad de su redefinición para lograr la autonomía cultural, que era lo que buscaba. No eran solo elementos externos a la actividad científica los que la afectaban con efectos nefastos. Varsavsky argumenta que la negativa de parte de miembros de la propia comunidad científica a asumir su responsabilidad social conducía a una ciencia sin conciencia, conformista y demasiado subordinada a los intereses económicos dominantes.

Observaba las dificultades de muchos científicos para comunicarse más allá de su ámbito de experticia, condicionados por una formación hiperespecializada y bastante dogmática que los hacía sentirse incómodos manejando las variables sociales y los compromisos de valor, mientras reducían la evaluación del conocimiento científico a la revisión de pares (sus colegas) de cuestiones estrechamente técnicas. De esta forma, y este es uno de los problemas que le preocupan porque lo vio en la Facultad de Ciencias Exactas de Buenos Aires en el período 1955-1968, el crecimiento de un estrato de educación superior "nuevo" en la sociedad formado en los mejores cánones de la ciencia internacional en instituciones de los países avanzados no aseguraba necesariamente

$4 \quad$ Científicos "fósiles" era una forma de referirse a investigadores y profesores atrasados, con ideas obsoletas, en la Argentina y otros países latinoamericanos de los años sesenta. 
que países individuales en el mundo globalizado redujeran la desigualdad social y económica. A menudo contribuían a incrementarla.

Su propuesta incluía que los jóvenes se formaran como investigadores sobre la marcha dentro de los pocos grupos de investigación activos en el medio local, los cuales, sin embargo, ayudarían a definir su tema de trabajo en relación con problemas definidos estratégicamente en función de los intereses locales. Sólo después de madurar como persona y habiendo trabajado localmente en la docencia y formación de otros jóvenes, el futuro becario estaría más preparado a incorporar con criterio independiente lo que deseara del ámbito internacional. Era muy crítico de la salida de jóvenes inmaduros como becarios al exterior, donde asimilaban acríticamente pautas culturales y orientaciones científicas que nada tenían que ver con las necesidades e intereses de su sociedad de origen.

\section{¿Por qué una política educativa propia con grados relativos de autonomía?}

Tener una política educativa propia, dirigida bien o mal por sus ciudadanos, le parecía indispensable a Varsavsky. Ya hace tiempo que dejó de tomarse como válida la descripción convencional de los científicos y los tecnólogos formados en los países avanzados como agentes positivos de la modernización y el cambio en los países en vías de desarrollo. Su papel resultó ser mucho más complicado que eso, con implicaciones positivas y negativas. El crecimiento específico de sectores medios en los países en desarrollo a menudo creó situaciones de modernización parcial que actuaron como frenos y resultaron en fuentes de distorsión, desviación e inclusive frustración de la modernización, particularmente en conexión con la posibilidad de fortalecer una modernidad democrática.

Viendo las cosas varias décadas después, si bien sigo coincidiendo en la necesidad de tener una política educativa con grados relativos, aunque irrenunciables de autonomía, ahora cuestiono la adjetivación que acompañaba en ese momento a la formulación de Varsavsky. Pienso que hoy sabemos que una política educativa no debe hacerse mal bajo ninguna excusa. La educación y la investigación desprolijas, improvisadas o mediocres, que han sido uno de los problemas frecuentes en la educación superior bajo las presiones de la masificación en nuestros países son inaceptables. La experiencia venezolana llevó a la destrucción del sistema de ciencia que se había logrado construir durante décadas de esfuerzo, aun cuando hasta entonces se habían dado allí también problemas de dependencia intelectual y subordinación cognitiva. Pero no se lo sustituyó por un sistema de conocimiento mejor, sino que se cayó en un proceso que hundió al país en la pobreza y el caos. 
Varsavsky, en esos años tempranos de la modernización científica de la región, identificó uno de los problemas claves ligados a la formación y práctica de la investigación científica cuando enfatizó con fuerza la cuestión de la evaluación de la investigación y de la educación. La región no siguió su propuesta, que reclamaba posturas de mayor independencia intelectual y moral. Y, hoy, nos encontramos atrapados en un sistema de vías que no parecen llevarnos a buen puerto. La noción misma de calidad tiene que ser redefinida en términos de formas de evaluación más ricas, diversificadas y relevantes, que permitan incluir más actores, temas, problemas y propósitos. ${ }^{5}$

La visión canónica de una actividad de investigación científica única, ideológicamente neutra y aristocrática ${ }^{6}$ hace tiempo que dejó de ser la más apropiada a seguir. Para Varsavsky (1981), la alternativa puede ser la gran diversidad de estilos científicos, ya que los tipos de problemas y los desafíos que los países enfrentan varían considerablemente de acuerdo con su especificidad, estado de desarrollo económico, social, científico y tecnológico.

Su planteamiento acerca de los efectos perversos que se derivaban de la adopción acrítica de ideas establecidas en otros contextos, y la denuncia del uso del conocimiento, aun en forma no deliberada, como instrumento de poder y desigualdad, desperdiciando la posibilidad de transformarlo en una herramienta para el desarrollo colectivo y mejoramiento de la condición humana, siguen siendo profundamente vigentes. Con esto, no quiero implicar que esos países hubieran estado mejor sin educación superior y sin ciencia y tecnología -sólo que esas capacidades por sí solas, sin una hoja de ruta clara y aisladas de otros componentes esenciales de la responsabilidad social, política y moral, no alcanzan a realizar su pleno potencial para mejorar la vida de las personas en cualquier colectivo-.

\section{La ciencia por sí sola no basta}

En algunos lugares comienza a repensarse la investigación realmente en términos de una sociedad global. La reducción de la pobreza requiere que los países pobres logren una actualización tecnológica, que dominen y produzcan conocimiento y que inviertan en innovación. Eso supone retomar la cuestión de los cambios en la comprensión de las relaciones entre investigación, innovación y desarrollo socioeconómico. Varsavsky opinaba fuertemente con relación a esto y sus libros todavía tienen muchas ideas para explorar. Entre otros conceptos proponía los de estilos de desarrollo y proyectos nacionales.

5 Para una discusión reciente sobre este tema puede consultarse Vessuri, Guédon y Cetto (2014).

$6 \quad$ Ligada a la idea de una meritocracia 
El concepto de estilo de desarrollo era para Varsavsky el principio organizador, que le permitía confrontar la sociedad vigente con la sociedad deseada. "Se trata del funcionamiento del sistema, su lógica subyacente, sus principios organizativos. Un estilo de desarrollo implicaría un estilo de consumo, de trabajo, de acción política, un estilo científico-tecnológico y artístico." (Roca, 2007, p. 35). Esta noción Ilamó la atención de la Comisión Económica para América Latina y el Caribe (CEPAL) a comienzos de los años setenta, y sirvió de base para numerosas discusiones entre sus expertos. Más que como modelos, éstos funcionaban como una suerte de epistemología de la economía, explicitando el pensamiento, analizando lo que había detrás de cada razonamiento.

Una vez definido un estilo de desarrollo, se podrían empezar a construir las estrategias para lograr una sociedad cuyo objetivo fundamental sería la satisfacción de las necesidades sociales. Los Proyectos Nacionales que visualizaba Varsavsky (1971) eran marcos de referencia de largo plazo para los planes comunes y en especial para la estrategia política. Eran una manera de calcular la viabilidad de la sociedad deseada y del proceso que llevaría a ella desde la realidad inicial. Los planteaba como proyectos porque había una intencionalidad de llevarlos a cabo, y eran nacionales en el sentido de que se aplicaban a todo un país o grupo de países. Creía en la posibilidad de viabilizar un proyecto de liberación en el cual se hicieran explícitas la ideología y el modelo propuesto y sus posibilidades de realización.

En la era actual, se dificulta la viabilidad de los proyectos nacionales visualizados por Varsavsky. El suyo era un tiempo en que, tal vez, aún podía pensarse en la recuperación de un cierto grado de autonomía nacional. Pero, además, a esta altura, me arriesgo a sostener que, a pesar de escribir sobre proyectos nacionales, Varsavsky no aparece como nacionalista o patriotero, no lo veo como pensando en una ciencia estrechamente "nacional". Lejos de ello, sostiene con claridad que la ciencia moderna es cosmopolita, y sus resultados son generalizables. En todo caso, se identifica con esquemas que prefiere llamar pueblo-céntricos, orientados a la satisfacción de las necesidades de todos los sectores, incluyendo los más desprotegidos de una sociedad.

Como bien señalaba Ribeiro (2007), en sus palabras de homenaje póstumo a Varsavsky, los dos buscaron "durante varios años tener condiciones para elaborar concretamente, para un país cualquiera de los nuestros, un proyecto nacional global de auto-reconstrucción intencional" (p. 152), una "metodología disponible [para ser] utilizada para estructurar sociedades que liberen al hombre de viejas y nuevas servidumbres" (p. 152), sin etiquetas partidistas ni concesiones elitistas. Es más, revisando su actuación pública universitaria, en Venezuela, cuando Varsavsky se refiere a los profesores o expertos extranjeros, no se incluye a sí mismo como tal, sino que parece visualizarse como un venezolano más, o más bien, como un latinoamericano más. Para los jóvenes 
esta manera de identificarse y diferenciarse puede parecer extraña hoy en día. Pero, por lo menos, creo que tenía críticas fuertes al nacionalismo y al populismo.

\section{Un mundo más allá de la OCDE}

Durante la segunda mitad del siglo XX, el mundo experimentó un enorme progreso económico. En los últimos sesenta años, el Producto Interno Bruto (PIB) mundial se multiplicó más de doce veces, mientras que el ingreso per cápita se triplicó. El crecimiento fue impresionante, incluso en los Ilamados países en vías de desarrollo. La globalización del mercado pareció abrir la puerta a muchos beneficios: la innovación, la creación de riqueza y el emprendimiento, mejores comunicaciones, una mayor conciencia de derechos e identidades.

Cuando se observa el crecimiento de la educación superior en el mundo, se comprueba que el tamaño de la empresa académica creció tremendamente en el siglo pasado. Comparadas con las de 1900, las cifras para el 2000 simplemente estallaron, con una velocidad creciente en las últimas décadas del siglo XX. La cantidad de instituciones de educación superior se multiplicó 20 veces, el número de revistas científicas, sin hablar de los científicos y personal académico mostró un ritmo similar. El aumento fue vertiginoso en las universidades y en otras organizaciones de investigación.

No obstante, esta afirmación no se puede aceptar sin calificarla. La expansión tuvo lugar en una porción bastante limitada del mundo. De los recursos gastados en ciencia y universidades a finales del siglo XX, más del 80\% todavía correspondían al área de la Organización para la Cooperación y el Desarrollo Económicos (OCDE). Dentro de la OCDE, la mayoría absoluta de las actividades ocurrían en Norteamérica y Europa. Si expandimos esta región para incluir en la Unión Europea a sus estados miembros de Europa Central y del Este, el predominio se volvía todavía más abrumador. Hace treinta años, Norteamérica y Europa juntas tenían el 95\% mundial de los grados de doctor y continuaban superando al resto del mundo totalmente en la producción de nuevos doctores a una tasa de 10 a 1. De los artículos científicos mundiales ellos eran responsables del 75\%. Esa región albergaba a la gran mayoría de los profesores universitarios y virtualmente todas las instituciones de más alta calidad estaban ubicadas dentro de esa región (Sörlin y Vessuri, 2008).

Sin embargo, en este siglo es probable que la situación cambie dramáticamente, no sólo porque el mundo no OCDE es mucho más grande, con un $85 \%$ de la población mundial, sino porque la mayoría de las proyecciones sostienen que el crecimiento económico en esas regiones hará posible que muchos países hagan inversiones sustanciales en educación superior y tecnociencia. Cómo van a ocurrir las cosas en detalle es difícil de prever. Son posibles diferentes escenarios, algunos de los cuales le hubieran gustado a Varsavsky. 
Si nos atenemos a las tendencias actuales parece muy probable que el crecimiento será enorme. El incremento de las matrículas y las instituciones de educación superior (IES) en el mundo en desarrollo ya es exponencial, a pesar de que todavía es demasiado bajo para enfrentar las necesidades. Tanto China como India crecen rápidamente y están en vías de convertirse en súper poderes científicos. Además, otros países en el Sur global han mejorado su posición científica significativamente en las últimas décadas: Corea del Sur, Hong Kong, Indonesia, Malasia, Singapur y Tailandia, en Asia; Argentina, Brasil, Chile y México, en América Latina, si bien los dos primeros están en problemas recientemente; Sudáfrica en África, por mencionar algunos. África sub-sahariana, en el otro extremo de la escala, no alcanza al 1\% de la producción total de artículos, aunque algunas universidades individuales han mejorado su record de docencia e investigación (Dakar, Makerere/Kampala, Dar-es-Salaam y algunas otras).

Estos países difieren en tamaño e historia. El proceso de actualización no ha sido uniforme entre ellos, ni en sus comienzos ni en sus velocidades, y básicamente siguen siendo casi los mismos que en otro momento se llamaron "de industrialización tardía". El crecimiento económico en ellos estuvo asociado con un cambio estructural en la composición del output y el empleo que también llevó a una mejora en las condiciones de vida de la mayoría de las personas en esos países. Esta hipótesis, desarrollada por Ocampo, Rada y Taylor (2009), intenta explicar las divergencias en el crecimiento y desarrollo durante los últimos cincuenta años entre países que llegaron tarde a la industrialización. El foco está en los vínculos entre la estructura económica, la política y el crecimiento, que en algunos países ampliaron la libertad de elección mientras que en otro la restringieron.

\section{Políticas gubernamentales y la nueva agenda internacional}

Una prudente macro-orientación y gestión de la investigación científica en el nivel nacional se han visto necesarias y deseables. En los países desarrollados, hay un amplio consenso que las políticas públicas son para apoyar las actividades de Investigación y Desarrollo (I+D) en los sectores público y privado. Las políticas públicas son incluso más necesarias en los países en desarrollo, aunque las reglas globales existentes usurpan un espacio de política esencial en ellos. El sistema actual de derechos de protección de la propiedad intelectual, entre otros factores, sofoca el desarrollo de las capacidades tecnológicas en los países en vías de desarrollo. Combinadas, las reglas y condiciones de la actual dinámica internacional contribuyen a limitar el uso de la política industrial, la política comercial y la política financiera, que fueron las formas estratégicas de intervención para estimular la industrialización en países como los nuestros. Las políticas públicas de ciencia, tecnología e 
innovación, subsidiarias de las anteriores y que pudieran estimular las actividades locales de I+D necesarias para construir capacidades comprehensivas en nuestros países para estimular el aprendizaje tecnológico y la innovación, sufren en forma proporcional.

Se siguen haciendo declaraciones retóricas que la investigación y el sistema científico sirven para promover la "independencia de la sociedad", pero continúan teniendo un papel más fuerte el mercado y la competición internacional. Mientras que a nivel del discurso se sostiene universalmente la deseabilidad de usar la investigación científico-técnica para atacar la pobreza, las políticas concretas para lograrlo están severamente restringidas por el contexto del mercado. De hecho, durante la segunda mitad del siglo XX, la brecha de ingresos entre países ricos y pobres aumentó. La exclusión de personas del proceso de desarrollo es parte de la misma historia. La incidencia de la pobreza en el mundo en desarrollo en 1950 era elevada. Desde entonces hasta la década de 1980 hubo una reducción de la población por debajo de la línea de pobreza en la mayoría de los países en desarrollo, pero en ninguna parte cercanamente a lo que se requería disminuir. Desde los años ochenta, el cambio fue para mal en muchas partes del mundo en cuestión de desarrollo. La incidencia de la pobreza aumentó en la mayoría de los países latinoamericanos.

El conocimiento científico es hoy más crucial que nunca en la democracia, pero también es cierto que ha surgido el "problema del conocimiento" como uno de los principales desafíos de la gobernabilidad, en términos de la dificultad de entender y evaluar correctamente cuestiones sociales complejas al igual que los vínculos causales entre recursos y objetivos. Varsavsky se adelanta en su análisis, de una manera más bien intuitiva, reconociendo lo que estará presente en los años siguientes: argumenta que, por un lado, los científicos tienden a adoptar las agendas de problemas que están ligadas a las fuentes de financiamiento de la ciencia en el ámbito internacional y que son los temas naturalizados en esa comunidad de investigación, postergando así indefinidamente la atención a los problemas de su región; y por el otro, que la confianza excesiva en las opiniones de los expertos contribuye a la despolitización de la sociedad e induce una mayor distancia respecto de la participación ciudadana, llevando a la indiferencia y la subordinación.

Hoy predomina una nueva política del conocimiento en el mundo, en un campo de juego en el cual los objetivos políticos y los intereses económicos tienen que reconciliarse con normas y valores universales. Es obvio que hay restricciones específicas en diferentes países, que difieren además en el espacio o que emergen a través del tiempo. Pero, también, hay restricciones exógenas a los países que se vuelven prácticamente imposibles de manejar.

La generalización de la educación en la sociedad es una condición ineludible pues sienta las bases del desarrollo en los países post-industriales. También, resulta esencial el desarrollo de una 
infraestructura física y social como parte de las condiciones iniciales e intermedias de desarrollo. Pero, tal vez, más importante que éstas es un papel crítico del estado en términos de políticas, instituciones y gobernabilidad, en esta fase en la que el grueso de las políticas públicas proviene del ámbito internacional, a través de la importación de políticas desarrolladas en otra parte por las élites nacionales y la imposición de políticas por agencias multilaterales y/o procesos de convergencia estructural. La multiplicación de organizaciones supranacionales y corporaciones multinacionales en el financiamiento de la investigación ha contribuido a redefinir el espacio de la investigación científico-técnica, sacándola del paradigma anteriormente dominante de la ciencia nacional. La expansión y aceleración de la interconectividad global tiene implicaciones socioeconómicas e ideacionales significativas que reconfiguran el sistema internacional, estimulando en parte la emergencia de nuevos espacios económicos incongruentes con las fronteras políticas existentes.

\section{A modo de conclusión}

Para cerrar, otra idea de Varsavsky nos devuelve al viejo problema de la relación entre disidencia y conocimiento: "El cientificismo [hoy lo llamaríamos "academicismo", esa práctica universitaria in vitro] es la actitud del que, por progresar en la carrera científica, olvida sus deberes sociales hacía su país y hacia los que saben menos que él" (Varsavsky, 1968, s.p.). En el intento de parafrasear algunas de sus preocupaciones en un lenguaje más actual, tal vez pueda decirse que un actor social que debe ser movilizado son las clases medias. Él ya estaba preocupado en su momento por la orientación del segmento de clase media constituido por universitarios y científicos. Pero ese segmento, como vimos, no ha dejado de crecer en las últimas décadas, haciendo que su orientación, así como la de las clases medias en general, adquiera más relevancia que nunca. Pareciera, entonces, que será la orientación que adopten las clases medias lo que posibilitará o no que haya menos desigualdades en el futuro y más justicia social.

Se puede observar que el sonambulismo consumista de la clase media del Tercer Mundo, que claramente es el blanco de las consultoras empresariales, las corporaciones trasnacionales y sus agentes intelectuales, ya es un problema fundamental. El mito de la historia capitalista moderna vista a través del prisma de la clase media tanto liberal como populista de la región latinoamericana, comparte diferentes versiones de una tergiversación deliberada de la historia de sus propios países durante los siglos XIX y XX. Esta distorsión suele borrar las luchas y los movimientos de obreros, campesinos, minorías étnicas y mujeres, así como las conductas ignorantes y discriminadoras de amplios sectores de las clases medias urbanas en ascenso. Otras 
veces, se engancha en las promesas de las viejas izquierdas y sectores progresistas de variado cuño relacionadas con la igualación social y étnica, sin que el discurso se apoye en estrategias y realizaciones concretas significativas.

Con todo, la primera década del siglo XXI fue testigo de un significativo aumento de la igualdad en la historia latinoamericana. En el proceso de democratización posmilitar, los pueblos indígenas irrumpieron en las agendas de democracia y desarrollo. Los aspectos raciales y étnicos de la desigualdad existencial constituyeron un problema central en la primera década del nuevo siglo en América Latina. Sin embargo, los gobiernos latinoamericanos que promovieron la igualdad en el período se mostraron bastante frágiles, vulnerables y limitados y duraron lo que el ciclo económico favorable a la exportación de materias primas. Entre 2002 y 2008, los precios de los commodities se multiplicaron más de cuatro veces. Pero, a pesar de la importante reducción de la pobreza en la región -que bajó del 44\% de la población en 2002 al 28\% en 2012, según la CEPAL (2012)-, persistió una profunda desigualdad.

Una experiencia como la de Venezuela en esos años de "revolución bolivariana", acabó no siendo una revolución social por la igualdad sino:

un proceso de desindustrialización severo en favor de una casta importadorafinanciera que, con un discurso enardecido y un clientelismo popular vigoroso, ha acelerado de manera drástica la fase depresiva del ciclo económico capitalista de un proceso nacional de acumulación de capital basado en la apropiación de la renta hidrocarburífera. (Sutherland, 2018, p. 143)

Un observador externo simpatizante de la igualdad, comenta que:

la "Revolución Bolivariana" de Venezuela resultó un caso más de populismo regional encabezado por un líder carismático; sólo sucedió después de que el sistema político existente se había declarado en bancarrota y nunca logró establecer una autoorganización colectiva o un proceso de institucionalización. (Therborn, 2016, p. 190)

Argentina es un país que impulsa desde hace años un Estado proveedor, tanto desde el empleo público, que cuenta con un poco menos de cuatro millones de trabajadores, como por parte de quienes siguen exigiendo políticas relacionadas con lo "libre y gratuito". Un comentarista político escribía recientemente que tiene un partido hegemónico aunque dividido, el peronismo, 
que domesticó incluso a sus antagonistas, y así es como hay progresistas, radicales, neoliberales, conservadores, intelectuales, empresarios, banqueros y funcionarios que por simple acostumbramiento anhelan seguir en las mismas viejas coordenadas, para luego criticar desde lejos la corrupción, pero a salvo de cualquier compromiso, en el dulce confort de lo meramente declarativo y testimonial. Sembrado de sindicatos mafiosos, narcos y organizaciones sociales agresivas, el país tiene un 30\% de pobreza, media población laboral en negro, carece de soberanía energética, tiene una cultura populista asentada y una hipoteca financiera colosal (Fernández, 2018).

La situación brasileña, donde un Lula encarcelado por delitos contra el Estado encabeza todas las encuestas para la elección presidencial mientras el establishment empresarial apoya sin fisuras su detención, al tiempo que aumentan los episodios de violencia contra las organizaciones sociales, ofrece apenas un esbozo del oscuro escenario posible para el futuro cercano.

¿Qué esperar ahora de México? No hay un solo populismo. Es un estilo de gobierno que consigue acomodarse tanto a la derecha como a la izquierda. Sin embargo, la relación con la idea de nación que tienen el populismo de izquierda y el de derecha es diferente. La alternativa planteada por el neocardenismo y el Partido de la Revolución Democrática (PRD) en 1988, quebró la hegemonía del Partido Revolucionario Institucional (PRI), formado por una élite tecnocrática autoritaria aliada a corporaciones sindicales y redes clientelares urbanas y rurales, con el soporte de la oposición "leal" del Partido de Acción Nacional (PAN), que representaba el conservadurismo provinciano de derechas, que le permitió gobernar al país la mitad del período. Pero, el neocardenismo propugnaba el retorno al desarrollismo, con un acento más pronunciado en la justicia social. El horizonte de la revolución democrática implicaba un proyecto de transición no solo formal sino sustancial: el igualamiento de las disparidades socioeconómicas como condición para el ejercicio de la democracia tanto representativa como directa.

La situación actual es distinta. A diferencia de esa izquierda, ahora Andrés Manuel López Obrador (AMLO) y su partido, Movimiento Regeneración Nacional (Morena), coloca a la corrupción como el factor sistémico, como causa y no como consecuencia de las relaciones y los desequilibrios de poder y de las desigualdades sociales. En esta victoria de AMLO han participado grupos muy variados con creencias y prácticas diversas. Entre otros, ha contado con el apoyo de:

vastas franjas de clases medias conservadoras, así como de sectores empresariales a los cuales AMLO dedicó especial atención durante la campaña en el afán de desactivar su animadversión y contar con su colaboración a la hora de tomar posesión del cargo, en diciembre de 2018. Cada uno de ellos exigirá lo propio y será valorado 
en relación con su específico peso social, político y económico, en aras de mantener el equilibrio interclasista y la gobernabilidad. (Modonesi, 2018, p. 7)

En esta segunda década del siglo XXI han aparecido nuevas formas de desigualdad. Fallan, simultáneamente, las instituciones que hacen funcionar el vínculo social y la solidaridad (crisis del Estado proveedor), las formas de la relación entre economía y sociedad (crisis del trabajo), y las identidades individuales y colectivas (crisis del sujeto). Por no haber apreciado la importancia de esas conmociones, las fuerzas políticas tradicionales se encuentran cada vez más apartadas de la sociedad. De allí, el riesgo de un aumento de la aceptación social de un populismo perverso o de posiciones francamente autoritarias.

No puedo menos que tener un sentimiento de profundo escepticismo frente a una ideología de modernidad reducida a la clase media a pesar de que me gusta el elogio de Borges a la clase media:

a la que dice haber pertenecido por "ganar un modesto sueldo, quedarme sin dinero antes de fin de mes...". La Argentina siempre se definió como un país de clase media, pero el escritor dijo: "Nadie quiere pertenecer a la clase media, que es la mejor. Le falta el prestigio y sin embargo es la mejor clase, yo diría que es la única". Citó también la Epístola moral a Fabio, del sevillano Andrés Fernández de Andrada (15751648), que hace un elogio a una vida sencilla, sin estridencias: "una mediana vida yo posea, un estilo común y moderado, que no lo note nadie que le vea". (Urien, 2018)

Sin embargo, citas como las de Varma (1998) contra "la clase media india", a la que describe como "moralmente desorientada, obsesivamente materialista y socialmente insensible" (p. 174), y de Fernandes (2006), quien observa "el surgimiento de un nuevo modelo de clase media basado en el ciudadano consumidor que ha procurado reformular las exclusiones sociales como una nueva forma de vida cívica que se inspira en discursos de consumo y privatización" (p. 214) que se pudieran aplicar como generalidades al caso latinoamericano, nos muestran la profundidad de la manipulación ideológica a la que están sometidas esas capas sociales.

Si esto fuera así, ¿quiénes serían los actores que liderarían los cambios hacia sociedades realmente sostenibles? El tema de hasta dónde las ideas de Varsavsky guardan algo de su fertilidad originaria, dependerá de si nuevos sujetos sociales concretizan "contratos sociales" renovados y más equitativos. La atmósfera actual refleja los cambios de época. El resurgimiento de un 
debate social amplio en la región sólo parece estarse dando hoy en México. Sin embargo, es claro el modo en el que AMLO ha moderado su lenguaje, siguiendo el camino de otros líderes socialdemócratas o reformistas en la región.

En su discurso, hubo cada vez menos críticas al modelo económico como causante de la pobreza, la desigualdad y el bajo crecimiento económico. Para AMLO y Morena, la raíz de estos y otros males está en la corrupción política y el derroche gubernamental. Sería interesante que la corrupción pudiera verse como un indicio del malestar ante la ilegitimidad de la riqueza desmedida. Tal vez, sirviera también para una eventual toma de conciencia del costo social que la pobreza de los pobres implica para el conjunto de la sociedad, afectando también a las individualidades de la clase media. Pero, para ello, pareciera necesario un giro de opinión profundo que no sé cómo pudiera producirse. 


\section{Referencias}

Comisión Económica para América Latina y el Caribe (CEPAL). (2012). Panorama Social de América Latina. Chile: Santiago de Chile. Recuperado de https://repositorio.cepal.org/bitstream/ handle/11362/1247/1/S2012959_es.pdf

Fernandes, L. (2006). India's New Middle Class. Minneapolis: University of Minnesota Press.

Fernández, J. (2018). Los que atizan sin querer las Ilamas del populismo. La Nación. Recuperado de https://www.lanacion.com.ar/2151263-los-que-atizan-sin-querer-las-Ilamas-del-populismo

Modonesi, M. (2018). México: el gobierno progresista tardío. "Alcances y límites de la victoria de AMLO». Nueva Sociedad, (276), 4-12. Recuperado de http://library.fes.de/pdf-files/nuso/ nuso-276.pdf

Ocampo, J.A., Rada, C., \& Taylor, L. (2009). Economic Structure, Policy and Growth in Developing Countries. New York: Columbia University Press.

Ribeiro, D. (2007). Respuesta de Darcy...Segunda Parte: La Carpeta. Los amigos. En S. Rietti (Comp.), Oscar Varsavsky: Una lectura postergada. Caracas: Ediciones Ministerio del Poder Popular para Ciencia y Tecnología/Monte Avila Editores Latinoamericana.

Roca, A. (2007). Oscar Varsavsky, calculador de sueños. En S. Rietti (Comp.), Oscar Varsavsky: Una lectura postergada. Caracas: Ediciones Ministerio del Poder Popular para Ciencia y Tecnología/Monte Avila Editores Latinoamericana.

Sörlin, S., \& Vessuri, H. (2007). Introduction: The Democratic Deficit of Knowledge Economies. En S. Sörlin \& H. Vessuri (eds.), Knowledge Society versus Knowledge Economy. Issues in Higher Education. New York: Palgrave Macmillan.

Sutherland, M. (2018). La ruina de Venezuela no se debe al «socialismo» ni a la «revolución». Nueva Sociedad, (274), 142-151.

Therborn, G. (2016). Los campos de exterminio de la desigualdad. México: Fondo de Cultura Económica.

Urien, P. (2018). El pensamiento de Borges sobre las discusiones, la clase media y el éxito. La Nación. Recuperado de https://www.lanacion.com.ar/2151159-el-pensamiento-de-borgessobre-las-discusiones-la-clase-media-y-el-exito

Varma, P. (1998). The Great Indian Middle Class. Londres: Viking.

Varsavsky, O. (1968). Facultad de Ciencias en un país sudamericano. Charla en la Universidad Central de Venezuela. OEI - Programación -CTS+I - Sala de Lectura. Recuperado de https:// www.oei.es/historico/salactsi/varsavsky.htm

Varsavsky, O. (1969). Ciencia, política y cientificismo. Buenos Aires: Centro Editor de América Latina. 
Varsavsky, O. (1971). Proyectos Nacionales. Planteo y estudios de viabilidad. Buenos Aires: Ediciones Periferia.

Varsavsky, O. (1981). Oscar Varsavsky. Obras Escogidas. Buenos Aires. Centro Editor de América Latina.

Vessuri, H. (1997). Science for the South in the South. Exploring the role of local leadership as a catalyst of scientific development. In T. Shinn et al. (eds.), Science and Technology in a Developing World. The Sociology of the Sciences Yearbook 1997. Dordrecht: Kluwer Academic Publishers.

Vessuri, H. (2008). La formación de investigadores en América Latina. En J. Sebastián (ed.), Claves del desarrollo científico y tecnológico de América Latina (pp. 1-36. España: Siglo XXI /Fundación Carolina.

Vessuri, H. (2009). Cambios recientes en la internacionalización de las ciencias sociales: la socialidad de redes impacta América Latina. En S.D. Aupetit, \& E. Gérard (Eds.), Fuga de cerebros, movilidad académica y redes científicas. México: IRD-UNESCO/IESALC-CINVESTAV.

Vessuri, H. (2015). Global Social Science Discourse: a southern perspective on the world. Current Sociology, 63(2), 297-313.

Vessuri H., Guédon, J.C., \& Cetto, A.M. (2014). Excellence or quality? Impact of the current competition regime on science and scientific publishing in Latin America and its implications for development. Current Sociology, 62(5). http://dx.doi.org/10.1177/0011392113512839

Vessuri, H., \& Teichler, U. (2008). Research in the University: Contextual Sub-Optimisation or Epistemic Subordination? Some Introductory Considerations. In H. Vessuri \& U. Teichler (Eds.), Universities as Centres of Research and Knowledge Creation: An Endangered Species? Rotterdam: Sense Publishers. 
Cuatro décadas de Sociología en la Universidad de Sonora

ISBN 978-607-518-312-1

ISBN 978-607-98270-8-3

DOI 10.29410/QTP.19.04

Esta obra se terminó de producir en marzo de 2019.

Su edición y diseño estuvieron a cargo de:

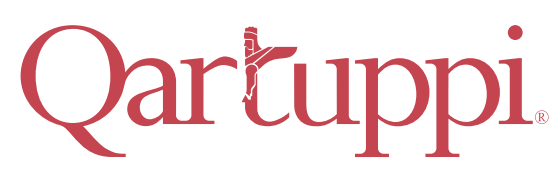

Qartuppi, S. de R.L. de C.V. http://www.qartuppi.com 
Desde su propia creación y hasta la actualidad, la sociología realiza periódicamente escrupulosos exámenes sobre sus cuerpos teóricos, recursos metodológicos y capacidades analíticas para acercarse al conocimiento de los procesos sociales. Más allá de los debates y conflictos entre los principales representantes de las escuelas de sociología, estos ejercicios muestran una ciencia que trata de actualizar permanentemente sus saberes frente a los siempre nuevos y complejos escenarios sociales.

Este libro se inscribe en esta perspectiva de revaloración crítica de la propia disciplina y bajo el pretexto de la celebración del XL Aniversario de la Licenciatura en Sociología de la Universidad de Sonora, el volumen reúne nueve trabajos inéditos, en los cuales está presente la intención de mostrar los alcances y límites de la sociología contemporánea.

ISBN 978-607-518-312-1

ISBN 978-607-98270-8-3

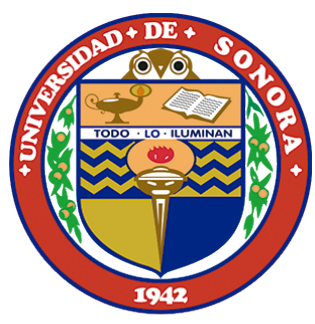

"El saber de mis hijos Qartuppi. hará mi grandeza" 